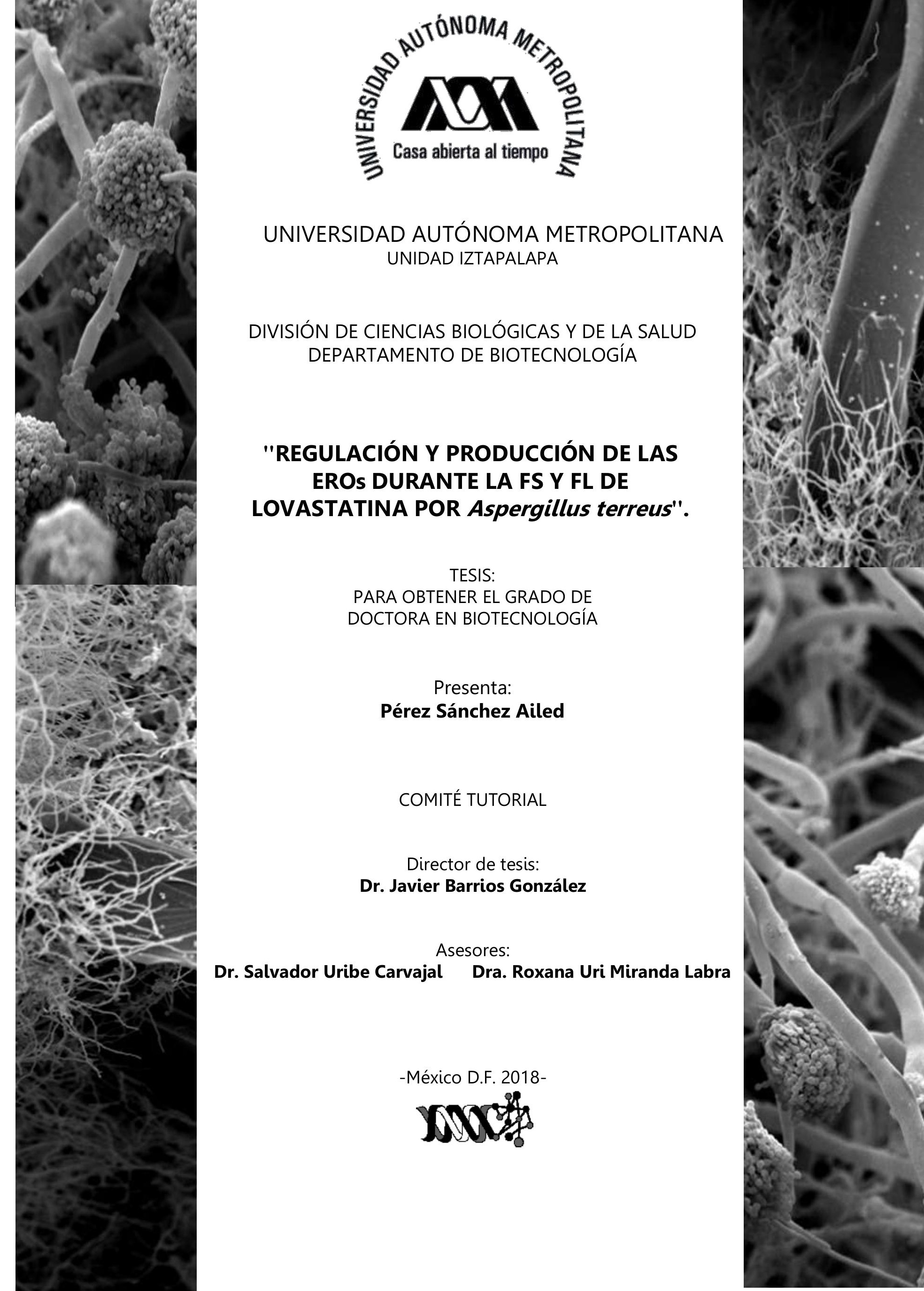


El presente proyecto se realizó en el Laboratorio de Ingeniería Genética y Metabolitos Secundarios del Departamento de Biotecnología de la División de Ciencias Básicas y de la Salud, Universidad Autónoma Metropolitana, Unidad Iztapalapa.

El Doctorado en Biotecnología de la Universidad Autónoma Metropolitana está incluido en el Programa Nacional de Posgrados de Calidad (PNPC) del CONACYT.

Así mismo, se contó con el Apoyo de CONACyT, con el otorgamiento de la Beca para Estudios de posgrado No. 486197.
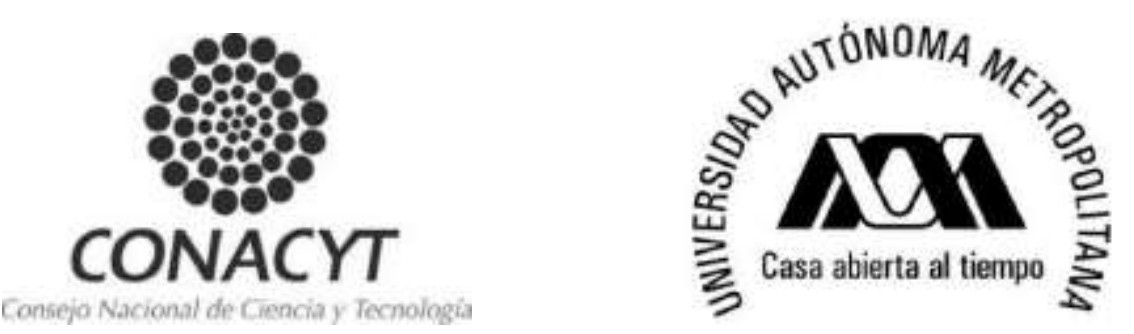

México, 2018. 
El jurado designado por la División de Ciencias Biológicas de la Salud de la Unidad Iztapalapa aprobó la tesis:

\section{"REGULACIÓN Y PRODUCCIÓN DE LAS EROS DURANTE LA FS Y FL DE LOVASTATINA POR Aspergillus terreus".}

Que presentó:

Ailed Pérez Sánchez

Director: Dr. Javier Barrios González

Asesores: Dr. Salvador Uribe Carvajal

Dra. Roxana Uri Miranda Labra

Jurado:

Presidente Dr. Luis Enrique Gómez Quiroz

Secretario Dr. Armando Mejía Álvare

Vocal Dra. Gabriela Rodríguez Serrano

Vocal Dra. Roxana Uri Miranda Labra

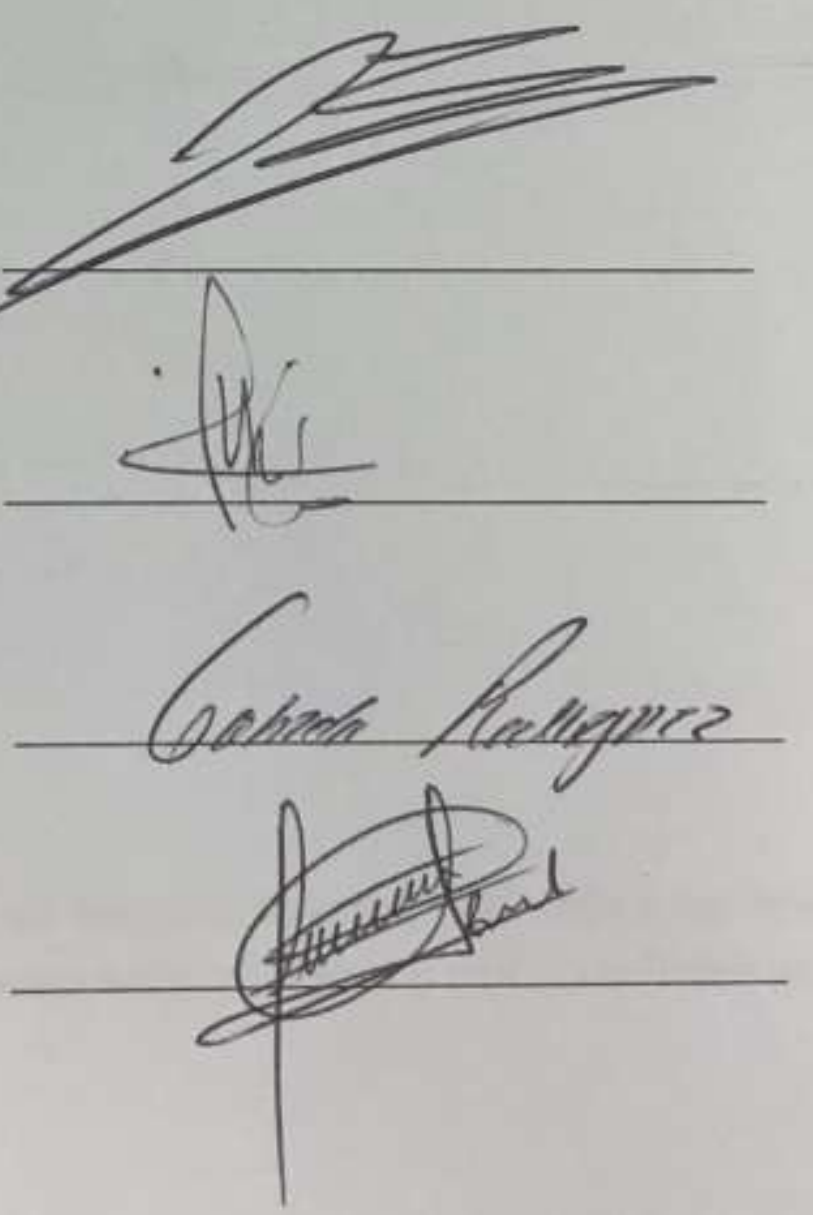


Dedico esta tesis a mi madre por creer siempre en mí y motivarme cada día a ser mejor. Por su apoyo incondicional y por su infinito amor. 


\section{AGRADECIMIENTOS}

Gracias a Dios.

A mi madre Alma Delia por darme tanto amor, apoyo, sabiduría y esfuerzo que ha sido siempre el pilar de mi vida. Gracias a mi hermana Deli Pérez por siempre ser una inspiración y mi mayor motivación.

Quiero agradecer en especial al Dr. Javier Barrios González, por ser más que un maestro, ser una guía y un mentor no solo en la investigación si no en la vida, por brindarme la oportunidad de realizar este proyecto bajo su dirección. Gracias por la constante motivación y el apoyo que siempre me alentaron a no darme por vencida y a ser mejor.

A mi asesora la Dra. Roxana Uri Miranda Labra gracias por toda la paciencia y por trasmitirme tanto conocimiento, por enseñarme con tanta dedicación y paciencia.

A mi asesor el Dr. Salvador Uribe Carvajal, así como a su equipo de trabajo Cristina Uribe Álvarez y Alfredo Cabrera Orefice, gracias por sus consejos y apoyo para poder realizar mejor mi trabajo.

Un agradecimiento especial a CONACYT por la beca otorgada para poder cumplir con este objetivo, y sobre todo a la UAM-I por darme la oportunidad para lograrlo.

Y a todos aquellos que de alguna manera estuvieron siempre conmigo y que creyeron en mí. 



\section{ÍNDICE}

Índice de figuras y tablas.................................................................................................... $\quad 3$

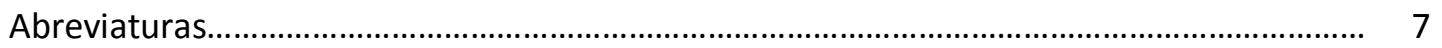

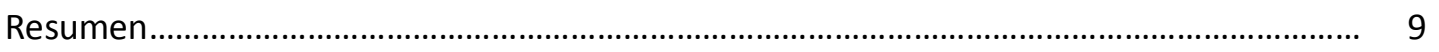

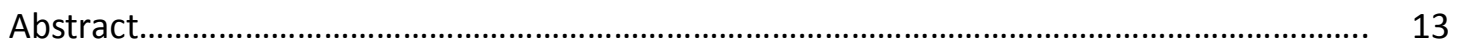

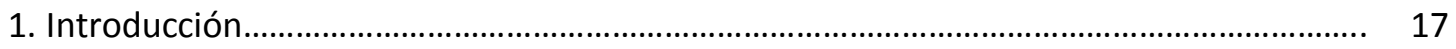

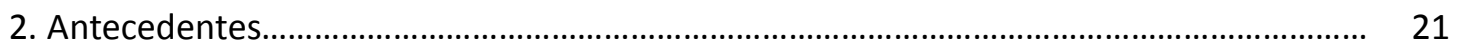

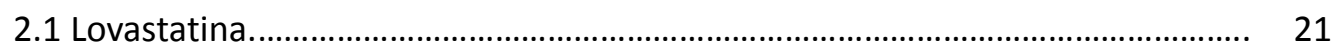

2.2 Fisiología de la fermentación sólida.................................................................. 26

2.3 Especies reactivas de oxígeno EROs............................................................... 30

2.3.1 Enzimas antioxidantes reguladoras de EROs..................................... 32

2.3.2 Origen de las especies reactivas de oxígeno....................................... 32

2.4 Factores transcripcionales de respuesta a EOX. ................................................ 36

2.5 Regulación de AMPc Y PKA.............................................................................. 37

2.6 EOX en la aireación.......................................................................................... 39

2.7 Principios de la respiración alternativa................................................................. 42

2.7.1 Respiración alternativa vs EOX. ....................................................... 48

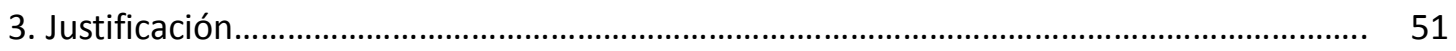

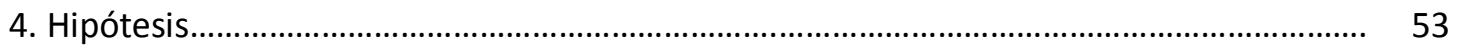

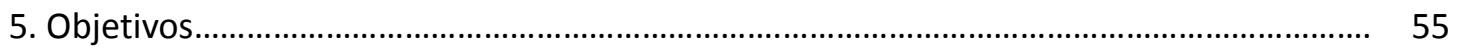

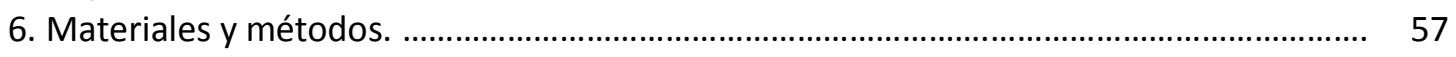

6.1 Equipos empleados. ............................................................................... 57

6.2 Microorganismos. ........................................................................................... 57

6.2.1 Aspergillus terreus TUB-F514. ...................................................... 57

6.2.2 Atyap1 cepa silenciada de yap1. .................................................. 57

6.3 Medios de cultivo. .......................................................................................... 59

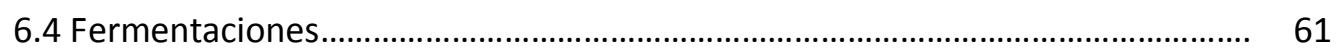

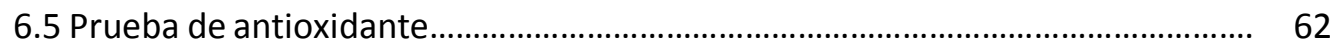

6.6 Adición de NAC en diferentes tiempos. ............................................................ 63

6.7 Origen de las EROs en la célula........................................................................ 64

6.8 Peróxido de hidrogeno y Anión súper oxido...................................................... 64

6.9 Actividad enzimática de la catalasa y súper oxido dismutasa............................ 65

6.10 Medición de la respiración.............................................................................. 66

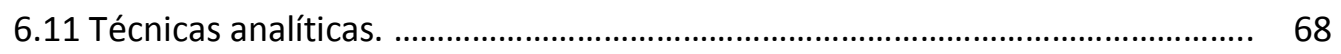

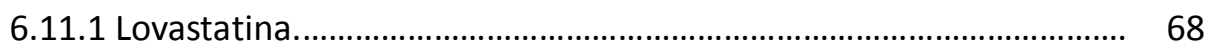

6.11.2 Determinación de biomasa y humedad.......................................... 68

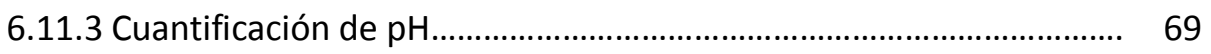

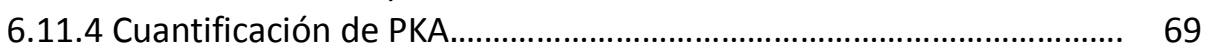

6.11.5 Cuantificación de AMPc.................................................................. 70

6.11.6 Cuantificación de azúcares............................................................ 71

6.11.7 Cuantificación de EROs. ............................................................... 71 
6.11.8 Muestreo para expresión de genes................................................... 72

6.12 Técnicas moleculares. .................................................................................. $\quad 73$

6.12.1 Extracción de ADN genómico de Aspergillus terreus......................... 73

6.12.2 Electroforesis y cuantificación de ADN. ........................................... 73

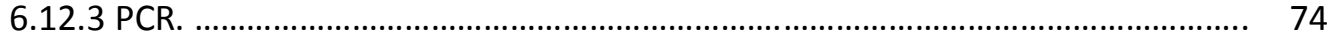

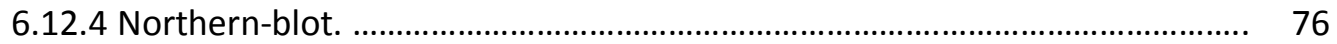

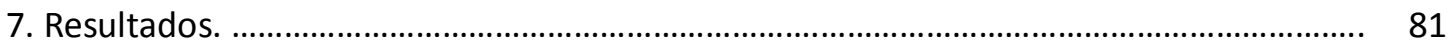

7.1 Prueba antioxidante para lovastatina.................................................................. 81

7.2 Importancia en la acumulación de EROs durante toda la idiofase.................... 82

7.3 Origen de las EROs en la célula........................................................................ 85

7.4 Composición de EROs: peróxido de hidrógeno y anión superóxido................... 86

7.5 Enzimas antioxidantes: superóxido dismutasa (SOD) y catalasa (CAT).............. 87

7.6 Respiración alternativa: regulación de las EROs................................................ 88

7.6.1 Respiración alternativa en FS con diferentes grados de aireación.... 88

7.6.2 Respiración alternativa en FS y FL..................................................... 91

7.6.3 Efecto de la adición de EROs en la respiración alternativa................. 93

7.6.4 Efecto de la adición de inhibidores en la respiración alternativa....... 95

7.6.5 Estudio de las principales enzimas de la respiración alternativa:

AOX y NADH alternativa. ......................................................................... 97

7.7 Vía de transducción de señales de las EROs en el metabolismo secundario.... 98

7.7.1 Adición de NAC a la fermentación en $\triangle$ siyap1.................................... 98

7.7.2 AMPc - PKA .................................................................................... 101

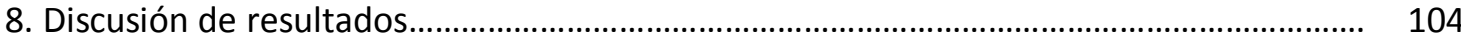

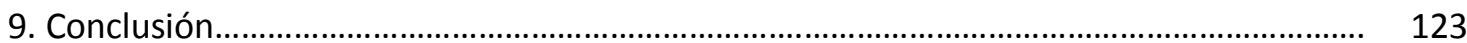

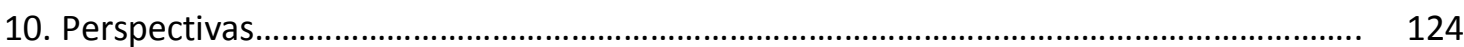

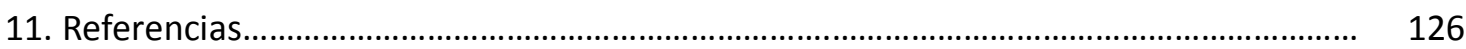

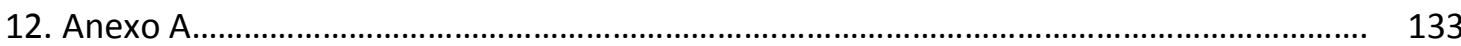

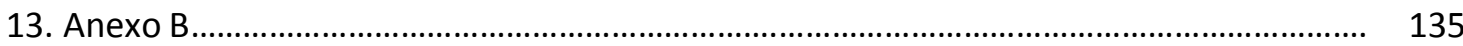

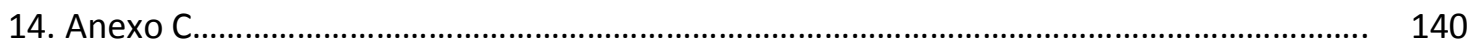




\section{ÍNDICE DE FIGURAS Y TABLAS}

Figura 2.1 Modelo que explica la gran variedad de efectos biológicos de las estatinas; y por tanto, los usos actuales y potenciales. La inhibición de la HGM-CoA reductasa, no solamente reduce los niveles de colesterol, sino también los intermediarios isoprenoides, afectando la prenilación de las proteínas $G$ (i.e., Ras). Esto puede resultar en la modulación de la transducción de señales de los receptores hacia la expresión de los genes, que directa o indirectamente afectan el balance proliferación/apoptosis, quimiosinas inflamatorias, y mensajeros citogenéticos, todos mediados por proteínas G (Barrios- González y Miranda 2010)...

Figura 2.2 Estructura base de las estatinas (izquierda). Cadenas ligadas al C8 (R1) y al C6 (R2) de la estructura base (derecha) (Manzoni y Rollini 2002).

Pág.

Figura 2.3 Estructura química de la lovastatina (Rollini 2002)

Figura 2.4. Ruta biosintética del colesterol en humanos (Fernández et al. 2003)............

Figura 2.5. Ruta biocinética de la lovastatina (Manzoni et al., 2002).

Figura 2.6. Clúster biosintético de la lovastatina: lov $B$ y lov $F$ biosíntesis de policétidos; lov $C$ enoil reductasa; lov $D$ transesterasa; lov $E$ y lovH genes reguladores; ORF2 y ORF17 genes del citocromo P-450; ORF1 y ORF10 genes potenciales de resistencia; ORF12 y ORF16 genes de transporte; lovG, ORF12, ORF15 y ORF18 función desconocida) (Rollini et al. 2002).

Figura 2.7 Especies Reactivas derivadas del oxígeno (Folch-Mallol et al. 2004).

Figura 2.8 Modelo para la activación transcripcional de genes de biosíntesis de antioxidantes y de aflatoxina por factores de transcripción relacionados con el estrés oxidante (Sung-Ypng et al. 2013).

Figura 2.9 Esquema de la ruta de transducción de señales de la PKA en S. cerevisiae. Los cuadros representan a componentes de la vía que actúan de manera más íntima permitiendo apreciar claramente las interacciones entre los distintos módulos que la componen. La ubicación espacial intracelular y la dinámica temporal de las interacciones implican niveles de regulación no representados en este esquema. Las líneas discontinuas indican las relaciones que se han demostrado entre los módulos cuando se añade glucosa a un cultivo que se encuentra creciendo en fuentes de carbono no fermentables. Las líneas continuas indican las relaciones que se han demostrado entre los módulos durante GPCR un minuto después de que la célula en ayuno percibe por primera vez a la glucosa en el medio extracelular, mientras que el sistema de proteínas $G$ pequeñas (Ras) activa y mantiene de manera sostenida la actividad de la adenilato ciclasa en respuesta ciclasa en respuesta al aumento en los niveles de glucosa fosforilada y a la disminución del $\mathrm{pH}$ intracelulares.

Figura 2.10 Sistema de fosforilación oxidativa (Chaudhuri, Ott et al. 2006)..................... Figura 2.11 Un diagrama de componentes alternativos y estándar redox presentes en el sitio de la acción de SHAM, antimicina A (AA), rotenona (ROT) y KCN están marcados. El complejo I NADH deshidrogenasa-rotenona sensible; Complejo III oxidasa terminal SHAM sensible (Nian-Qing et al., 2002).

Figura 6.1 Vector pGdpPki-RNAi empleado para silenciar yap1 de A. terreus (Marcial et al. 2011). 
Figura 6.2 Mecanismo de interferencia por RNA (Monika Dominska et al. 2010)..........

Figura 6.3 Reacciones catalíticas de las enzimas antioxidantes Sod y Cat con sus respectivos reactivos y productos.

Figura 6.4 Fundamento de la cuantificación de la actividad de SOD (Kit Biovision SOD)..

Figura 6.5 Ejemplificación de cómo se percibe el cambio de consumo de oxígeno al usar los inhibidores.

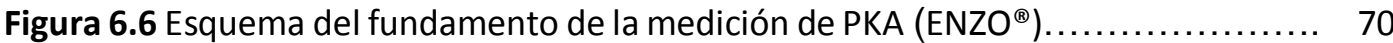

Figura 6.7 Esquema del fundamento de la medición de $\mathrm{AMPc}\left(\mathrm{ENZO}^{\circledR}\right) \ldots \ldots \ldots \ldots \ldots \ldots . \ldots 1$

Figura 6.8 Mecanismo de reacción de la DCF (Sigma-Aldrich)......................................... 72

Figura 6.9 Sondas de los genes: nadh1, aox, ras1 y ras2 ................................................. 75

Figura 7.1 Comparación química de diversos tratamientos con DCF (10mM): en peróxido de hidrógeno $(50 \mathrm{mM})(\mathrm{H} 2 \mathrm{O} 2)$, peróxido de hidrógeno más antioxidante NAC $(10 \mathrm{mM})(\mathrm{N}$ acetil cisteína) $(\mathrm{H} 2 \mathrm{O} 2+\mathrm{NAC})$ y peróxido de hidrógeno con lovastatina $(10 \mathrm{mM})(\mathrm{H} 202+\mathrm{Lov})$ en una reacción de 10 minutos. Se lee la fluorescencia de la DCF a excitación en $485 \mathrm{~nm}$ y emisión en $530 \mathrm{~nm}$.

Figura 7.2 Prueba in vivo de diversos tratamientos con DCF $(10 \mathrm{mM})$ y micelio de $A$. terreus de la $\mathrm{FL}$ a las $48 \mathrm{~h}$ con la adición de los reactivos a las $0 \mathrm{~h}$ : peróxido de hidrógeno $(50 \mu \mathrm{M})\left(\mathrm{H}_{2} \mathrm{O}_{2}\right)$, antioxidante NAC (10mM) (N acetil cisteína) (H2O2 + NAC), lovastatina (Lov) $(10 \mathrm{mM}$ ) y la combinación de estos. Se lee la fluorescencia de la DCF a excitación en $485 \mathrm{~nm}$ y emisión en 530nm

Figura 7.3 Efecto en el pH y la biomasa de la adición de NAC ( $n$-acetil cisteína $15 \mathrm{mM}$ ) a la FL a diferentes tiempos: A0 adición a las 0 h, A23 adición a las 23 horas, A44 adición a las 44 horas, a lo largo del tiempo de las 24 a las $68 \mathrm{~h}$

Figura 7.4 Efecto en las EROs de la adición de NAC (n-acetil cisteína $15 \mathrm{mM}$ ) a la FL a diferentes tiempos: $\mathrm{A} 0$ adición a las $\mathrm{Oh}, \mathrm{A} 23$ adición a las 23 horas, A44 adición a las 44 horas, a lo largo del tiempo de las 24 a las $68 \mathrm{~h}$.

Figura 7.5 Efecto en la producción de lovastatina de la adición de NAC (n-acetil cisteína $15 \mathrm{mM}$ ) a la $\mathrm{FL}$ a diferentes tiempos: A0 adición a las $0 \mathrm{~h}, \mathrm{~A} 23$ adición a las 23 horas, A44 adición a las 44 horas, a lo largo del tiempo de las 24 a las $92 \mathrm{~h}$.

Figura 7.6 Origen de las EROs en A) FL y B) FS: \% de la producción de EROs en mitocondria, NOX, xantina oxidasa y otros.

Figura 7.7 Producción de anión superóxido (rombos) y peróxido de hidrógeno (barras) en A) FL y B) FS a lo largo del tiempo.

Figura 7.8 Actividad enzimática de superóxido dismutasa (SOD) y catalasa (CAT) a lo largo del tiempo (horas) en fermentación líquida ( $\mathrm{FL}$ ), fermentación sólida (FS) y columnas de aireación (C).

Figura 7.9 Comparación de la capacidad respiratoria a lo largo del tiempo (h) en S (Matraz Cerrado) $\square$ y C (Columna aireada) $\square$; compuesta por respiración citocrómica, panel A); respiración alternativa, panel $B$ ); y respiración residual, panel C) en $\mathrm{mmol}_{2}$ /h mg de biomasa

Figura 7.10 Capacidad respiratoria a lo largo del tiempo (h) en diferentes sistemas de

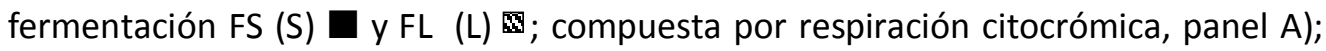
respiración alternativa, panel B); y respiración residual, panel C) en mmol $\mathrm{O} 2 / \mathrm{h} \mathrm{mg}$ de biomasa 
Figura 7.11 Efecto de la adición de peróxido de hidrógeno; $\mathrm{FS}$ control $\mathbf{\square}$, FS con $\mathrm{H}_{2} \mathrm{O}_{2}$ $\square$, FL control $\square$ y FL con H2O2⿴囗大 ; evaluando los parámetros de: respiración citocrómica y alternativa, acumulación de EROs y biosíntesis de lovastatina a las 48h.

Figura 7.12 Efecto de los inhibidores de la respiración: En FS $\square$, FS con CN⿴囗大 , FS con PG

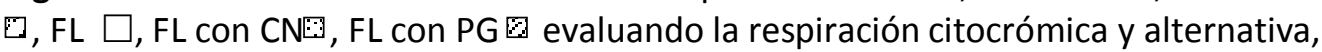
acumulación de EROs y la producción de lovastatina alas $48 \mathrm{~h}$.

Figura 7.13 Actividad de la NADHa y AOX durante la idiofase (h) en diferentes sistemas de fermentación A) FS y B) FL

Figura 7.14 Expresión genética de aox y nadh1 enzimas de la respiración alternativa y residual, a lo largo (horas) de la fermentación en FS y FL obtenida por Northen Blot...

Figura 7.15 EROs en FL y FS a lo largo del tiempo. Para la cepa parental (P), para la transformante del silenciamiento de yap1 $(T)$, y la transformante con silenciamiento y tratamiento de antioxidantes (T3mM $+1 \mathrm{mM}$ y T20mM) se adicionó en FL a las Oh una concentración de $3 \mathrm{mM}$ para después a las $25 \mathrm{~h}$ adicionar NAC y llegar a una concentración final de $1 \mathrm{mM}$. En el caso de la FS, se adicionó NAC a las Oh para llegar a una concentración final de $20 \mathrm{mM}$.

Figura 7.16 Producción de lovastatina en FL y FS a lo largo del tiempo. Para la cepa parental $(\mathrm{P})$, para la transformante del silenciamiento de yap1 $(\mathrm{T})$, y la transformante del silenciamiento yap1 con tratamiento de antioxidantes (T3mM+1mM y T20mM) se adicionó en $\mathrm{FL}$ alas $0 \mathrm{~h}$ una concentración de $3 \mathrm{mM}$ para después a las $25 \mathrm{~h}$ adicionar NAC y llegar a una concentración final de $1 \mathrm{mM}$. En el caso de la FS se adicionó NAC a las Oh para llegar a una concentración final de $20 \mathrm{mM}$.

Figura 7.17 Cinética de AMPc, PKA, EROs, lovastatina, glucosa y lactosa en FL panel A) y en la FS panel B), de la cepa parental $\square$ (WT) y la transformante con el silenciamiento de yap1 $\mathbf{\square}$ (siyap1)

Figura 7.18 Expresión genética de Ras 1 y 2, a lo largo (horas) de la fermentación en FS y FL obtenida por Northen Blot

Tabla 2.1. Especies Reactivas de Oxigeno (The Molecular Probes ${ }^{\circledR}$ Handbook)...

Tabla 2.2 Sistemas de Fosforilación Oxidativa (Mitchell and Moyle 1967)...

Tabla 6.1 Diseño de los primers de los genes analizados por Northen Blot

Tabla 7.1 \% de disminución de la producción de lovastatina con la adición de NAC a diferentes tiempos a lo largo de la fermentación. 


\section{ABREVIATURAS}

A0 Adición a las $0 \mathrm{~h}$

A23 Adición a las 23 horas

A44 Adición a las 44 horas

AA Antimicina A

ABTS Ácido 2,2'-azino-bis (3-etilbenzotiazolin -6-sulfónico)

ADN Acido desoxirribonucleico

ADP Adenosín difosfato

ALO Alopurinol

AMPc Adenosín monofosfato cíclico

AOX Enzima mitocondrial oxidasa alternativa

ATP Trifosfato de adenosina

C Columna

CAT Catalasa

$\mathrm{CO}_{2}$ Dióxido de carbono

DFC Di acetato de 2', 7'-diclorofluoresceina

DPI Difeniliodonio

EOX Estrés Oxidante

EROs Especies Reactivas de Oxigeno

FL Fermentación sumergida tradicional o Fermentación liquida

FS Fermentación en estado sólido

GTP Guanosín trifosfato

H2O2 Peróxido de Hidrogeno

KCN Cianuro de potasio

MC Matraz Cerrado

MS Masa seca (de la FS: biomasa, soporte y restos del medio).

NAC N-acetil cisteína

NOX NADPH oxidasa

O2 Oxigeno diatomico

O2*_ Anión súper oxido

PKA Proteína quinasa $\mathrm{A}$

PUF Poliuretano

RA Respiracion alternativa

RAS Proteína G monomérica, GTPasa, actividad reguladora GTP-hidrolasa

RNA Ácido ribonucleico

RNAi RNA de interferencia

ROT Rotenona

$\mathrm{RR} \quad$ Respiracion residual

RT Respiracion total

SHAM Ácido salicilhidroxámico

SOD Súper oxido dismutasa 


\section{RESUMEN}

En el estudio de la FS se han encontrado atributos muy interesantes y de gran impacto como por ejemplo que se pueden utilizar sustratos económicos, se requiere poco procesamiento y se utiliza menos potencia. El factor más importante es que presentan altas productividades y rendimientos generalmente más altos que en FL. Además, existen metabolitos secundarios que sólo pueden producirse en FS, a pesar de que el hongo productor también crece en FL.

Otras ventajas que presenta la FS es la baja actividad del agua, que ayuda a evitar las contaminaciones además de que genera menos efluentes. La FS se caracteriza también por poder utilizar altas concentraciones de sustrato que permite utilizar reactores más pequeños en comparación con los utilizados en otro tipo de fermentación.

Debido a todas estas ventajas la FS es un método de cultivo alternativo que se ha vuelto cada vez más atractivo para la investigación y para la industria. Se sabe que estas ventajas de la FS provienen de una fisiología especial que presentan los microorganismos en FS no está bien caracterizada, aunque ya se ha acuñado el término de fisiología del medio sólido.

En estudios realizados por Miranda et al. 2013, se estudió la generación de EROs y el estado oxidante de la célula, se encontró sorprendentemente que la acumulación de EROs coincide con el inicio de la producción de lovastatina es decir las EROs contribuyen en la señalización para iniciar la idiofase de FS y FL, en estudios posteriores se demostró que las EROS regulaban la biosíntesis de lovastatina (Miranda et al. 2014).

Es evidente que las EROs juegan un papel muy importante como moléculas señalizadoras y que interactúan con las vías de transducción de señales, para dar una respuesta a ciertas condiciones ambientales. Los resultados obtenidos en este proyecto han aclarado la función de las EROs en la biosíntesis de lovastatina y cómo se ha avanzado paso a paso, para entender el mecanismo del papel de estas moléculas en el metabolismo secundario.

Debido a que se ha planteado que varios metabolitos secundarios tienen actividad antioxidante, debido a que son producidos en respuesta al estrés oxidante, en el caso de la lovastatina, se estudió si tiene esta función y se determinó que la lovastatina no juega ningún papel en el control de las EROs dentro de la célula. Se analizó la acumulación de EROs a lo largo del tiempo y se observó que las EROs están señalizando durante toda la idiofase y que las primeras horas son las más importantes para que las EROs señalicen la biosíntesis de lovastatina. 
Usando diferentes inhibidores se determinó el aporte de las fuentes de EROs durante la idiofase para ambas fermentaciones: de la respiración originada en la mitocondria con un 75-80\%, NOX 13-17\% y la Xantina oxidasa 2-6\%; esto para ambas fermentaciones (FS y FL).

Se estudió la acumulación de anión súper oxido y peróxido de hidrógeno, principales EROs en la célula, para el anión superóxido se encontró que al inicio de la idiofase a las $24 \mathrm{~h}$ hay una acumulación, esto indica que podría estar participando en el arranque del inicio de la idiofase y la biosíntesis del metabolismo secundario. En el caso del peróxido de hidrógeno se encontró que está acumulándose durante toda la idiofase.

Se estudiaron las actividades enzimáticas de las principales defensas antioxidantes de la célula: la superóxido dismutasa (SOD) y la catalasa (CAT), lo que se observó fue que en la trofofase la actividad de estas enzimas, tanto de SOD como de CAT, está fuertemente activa y va decreciendo conforme inicia la idiofase. Este comportamiento aparece en ambos sistemas de fermentación. Pero no se encontraron diferencias en la actividad de estas enzimas en la idiofase.

Los principales estudios se centraron en la respiración de los cultivos sólido y líquido, así se estableció que en la FS de lovastatina, la respiración alternativa (RA) se activa precisamente al comienzo de idiofase manteniendo una actividad bastante constante durante toda la fase de producción. Mientas que no se encontró actividad de la enzima mitocondrial oxidasa alternativa (AOX) en la FL. Por otro lado, se identificó el gen aox y nadh alternativa en el genoma de $A$. terreus. Se demostró que el gen aox en FS se induce durante la idiofase, mientras que en FL las NADH alternativas son las que se están expresando fuertemente en idiofase.

Se propone que en FS, el contacto directo con el aire representa una gran disponibilidad de $\mathrm{O}_{2}$, esto puede generar concentraciones de EROs peligrosas, entonces, la RA se activa para disminuir la producción de EROs en idiofase. Dado que no se encontró actividad de AOX en $\mathrm{FL}$, pero sí de las $\mathrm{NADH}$ alternativas es posible que estas oxidasas no mitocondriales alternativas sean el mecanismo de reducción de las EROs en este sistema de cultivo.

La cepa silenciada de yap1 se caracterizó, las principales diferencias fueron el adelanto e incremento en la acumulación de EROs, así como también el adelanto e incremento en la biosíntesis de lovastatina. Se igualaron las EROs de la cepa parental con la transformante siyap1, a través del uso de un antioxidante exógeno, y la biosíntesis de lovastatina también se redujo al mismo rango de la cepa silvestre, mientras que siyap1 sin antioxidantes muestra mayores niveles característicos del silenciamiento y con un adelanto. Por lo tanto el silenciamiento de yap1 cambió las EROs y éstas fueron las responsables del aumento y adelanto de la biosíntesis de lovastatina; lo que demuestra que el gen yap1 no es un regulador negativo de la biosíntesis de lovastatina. 
Se determinaron en los sistemas de FS y FL los niveles intracelulares de AMPc, la actividad enzimática de las PKA; y las concentraciones de glucosa y los niveles de EROs. Se encontró que los niveles de AMPc-PKA son mayores en trofofase y van decreciendo conforme inicia la idiofase. Se encontró que en hay un adelanto en la disminución de los niveles de AMPc en la cepa silenciada de yap1 a las 21 h en FL y 19 h FS; esto coincidió con un adelanto en la acumulación de EROs y un adelanto de la baja de la actividad de PKA, lo que provocó un adelanto de la biosíntesis de lovastatina. Esto propone que la regulación de las EROs está cascada arriba de la represión catabólica y que es a través de la modificación de AMPc-PKA en la biosíntesis de lovastatina por Aspergillus terreus.

Las proteínas Ras son miembros de una familia de pequeñas GTPasas monoméricas que se conserva notablemente en eucariotas. Ras sirve como un transductor de señal entre los estímulos extracelulares y las cascadas de señalización intracelular. Se realizó un análisis de expresión de estas enzimas, lo que se encontró fue muy interesante, ya que para el caso de ras1 como se muestra que la expresión es estable en trofofase y se intensifica en la idiofase. En el caso de ras2, sorprendentemente sólo se encontró expresión en la FS. Esto podría ser la clave para la diferente fisiología que se observa en este tipo de fermentación.

Este trabajo ayudó a entender como las EROs están presenten en el metabolismo secundario de Aspergillus terreus para poder aplicar y desarrollar sistemas de fermentación que aprovechen las particularidades de la FS, y aunque aún falta para poder comprender qué estímulos son los que propician las altas producciones, además de las diferencias fisiológicas que surgen durante el crecimiento de células microbianas en los dos tipos de sistemas de cultivo, se ha logrado un importante avance para entender la fisiología del medio sólido. 


\section{ABSTRACT}

In the study of FS, very interesting and high-impact attributes have been found, for example, that economic substrates can be used, little processing is required, and less power is used. The most important factor is that they have high productivities and yields that are generally higher than in FL. In addition, there are secondary metabolites that can only be produced in FS, even though the producing fungus also grows in FL.

Other advantages that FS presents are the low water activity, which helps to avoid contamination and generates less effluents. The FS is also characterized by being able to use high concentrations of substrate that allows to use smaller reactors compared to those used in another type of fermentation.

Because of all these advantages FS is an alternative growing method that has become increasingly attractive to research and industry. These advantages of FS are known to come from a special physiology presented by microorganisms in FS is not well characterized, although the term physiology of the solid medium has already been coined.

In studies conducted by Miranda et al. 2013 was studied the generation of EROs and the oxidative state of the cell, it was surprisingly found that the accumulation of EROs coincides with the start of the production of lovastatin i.e. the EROs contribute in the signaling to initiate the idiofase of FS and FL, subsequent studies showed that ROS regulated the biosynthesis of lovastatin (Miranda et al., 2013).

It is evident that the EROs play a very important role as signaling molecules and that they interact with the signal transduction pathways, in order to respond to certain environmental conditions. The results obtained in this project have clarified the role of EROs in the biosynthesis of lovastatin and how it has been advanced step by step, to understand the mechanism of the role of these molecules in secondary metabolism.

Lovastatin was studied as a possible antioxidant and it was determined that lovastatin plays no role in the control of ROS in the cell. The accumulation of EROs was analyzed over time and it was observed that the EROs are signaling throughout the idiofase and that the first hours are the most important for the EROs to signal the biosynthesis of lovastatin.

Using different inhibitors, the contribution of the sources of EROs during the idiofase was determined for both fermentations: from respiration originated in the mitochondria with 75-80 \%, NOX 13-17\% and xanthine oxidase 2-6\%; this for both fermentations (FS and FL). 
We studied the accumulation of anion super oxide and hydrogen peroxide, main EROs in the cell, for the superoxide anion it was found that at the beginning of the idiofase at $24 \mathrm{~h}$ there is an accumulation, this indicates that it could be participating in the start of the start of the idiofase and the biosynthesis of secondary metabolism. In the case of hydrogen peroxide it was found that it is accumulating throughout the idiofase.

The enzyme activities of the main antioxidant defenses of the cell were studied: superoxide dismutase (SOD) and catalase (CAT), what was observed was that in the trophophase the activity of these enzymes, both SOD and CAT, is strongly active and decreasing as the idiofase starts. This behavior appears in both fermentation systems. But no differences were found in the activity of these enzymes in the idiofase.

The main studies focused on the respiration of the solid and liquid cultures, thus establishing that, in the FS of lovastatin, RA is activated precisely at the beginning of idiofase, maintaining a fairly constant activity throughout the production phase. While there was no AOX activity in the FL. On the other hand, the aox and nadh alternative gene were identified in the A. terreus genome. It was shown that the aox gene in FS is induced during idiophase, whereas in FL alternative NADH are those that are being strongly expressed in idiofase.

It is proposed that in FS, the direct contact with air represents a high availability of $\mathrm{O} 2$, this can generate dangerous concentrations of EROs, then, the RA is activated to decrease the production of EROs in idiofase. Since no AOX activity was found in FL, but it is possible for alternative NADHs, it is possible that these alternative non-mitochondrial oxidases are the mechanism for reducing the EROs in this culture system.

The silenced strain of yap1 was characterized, the main differences were the advancement and increase in the accumulation of EROs, as well as the progress and increase in the biosynthesis of lovastatin. The EROs of the parental strain were equalized with the transformant siyap1, through the use of an exogenous antioxidant, and the biosynthesis of lovastatin was also reduced to the same range of the wild strain, while siyap1 without antioxidants shows higher levels characteristic of the silencing and with an advance. Therefore, the silencing of yap1 changed the EROs and these were responsible for the increase and advancement of lovastatin biosynthesis; demonstrating that the yap 1 gene is not a negative regulator of lovastatin biosynthesis.

The intracellular levels of CAMP, the enzymatic activity of PKA were determined in the FS and FL systems; and glucose concentrations and ERO levels. It was found that the levels of AMPc-PKA are higher in trophophase and decrease as the idiofase starts. It was found that there is an advance in the decrease of cAMP levels in the silenced of yap1 at $21 \mathrm{~h}$ in $\mathrm{FL}$ and 
19h FS; this coincided with an advance in the accumulation of EROs and an advance in the decline of PKA activity, which led to an advancement of lovastatin biosynthesis. This proposes that the regulation of EROs is cascaded upstream of catabolic repression and that it is through the modification of CAMP-PKA in the biosynthesis of lovastatin by Aspergillus terreus.

Ras proteins are members of a family of small monomeric GTPases that are conserved remarkably in eukaryotes. Ras serves as a signal transducer between extracellular stimuli and intracellular signaling cascades. An expression analysis of these enzymes was carried out, which was found to be very interesting, since in the case of ras1, it is shown that the expression is constitutive, although it is intensified in the idiofase. In the case of ras2, surprisingly only expression was found in the FS. This could be the key to the different physiology observed in this type of fermentation.

This work helped to understand how the EROs are present in the secondary metabolism of Aspergillus terreus to be able to apply and develop fermentation systems that take advantage of the particularities of the FS, and although it is still lacking to be able to understand which stimuli are those that propitiate the high productions besides From the physiological differences that arise during the growth of microbial cells in the two types of culture systems, an important advance has been made to understand the physiology of the solid medium. 


\section{INTRODUCCIÓN}

La fermentación en estado sólido ha construido credibilidad en los últimos años en las industrias de biotecnología, debido a sus potenciales aplicaciones en la producción de metabolitos secundarios biológicamente activos en alimentación, combustibles, productos químicos industriales, productos farmacéuticos, etc., se ha convertido en una atractiva alternativa a la fermentación sumergida tradicional. La innovación es la clave del éxito y es imprescindible para estar al día con las cambiantes demandas de la industria y satisfacer sus necesidades para un mejor producto y servicios.

Una mejor comprensión de los aspectos de ingeniería bioquímica, ha hecho posible la ampliación de los procesos de FS y algunos diseños se han desarrollado para su comercialización, con el fin de poder desarrollar una tecnología económicamente viable. En el futuro, la tecnología de la FS estará bien desarrollada, a la par con FL, si la racionalización y estandarización continúa en la tendencia actual.

La fermentación en estado sólido se entiende como un método de cultivo alternativo para la producción de metabolitos primarios, secundarios, enzimas entre otros; que ha despertado el interés de la ciencia, así como de la industria, debido a que esta presenta importantes ventajas en comparación con la FL.

Quizás la ventajas principal es la mayor producción de metabolitos secundario (y enzimas) que generalmente se observa., en algunos casos los metabolitos o enzimas sólo se pueden producir en FS. Otras ventajas que presenta la FS es la baja actividad del agua requerida, esto es de gran ayuda para evitar las contaminaciones, especialmente de bacterias y levaduras; las altas concentraciones de sustrato permiten utilizar reactores más pequeños en comparación con los utilizados en otro tipo de fermentación. Es posible un ahorro de agua debido a los bajos requerimientos de esta, además de que hay una menor generación de aguas residuales.

Muchas de estas ventajas están relacionadas con la fisiología especial mostrada por hongos en el FS; referido como "fisiología de medio sólido", Sin embargo, pocos trabajos han estudiado las diferencias fisiológicas que surgen durante el crecimiento de células microbianas, por lo que las razones moleculares y fisiológicas que subyacen a este comportamiento no están bien caracterizadas en la actualidad, aunque hay varios informes recientes que están contribuyendo a su comprensión.

Para conocer los eventos que causan estas diferencias, nuestro grupo de trabajo ha realizado estudios bioquímicos y moleculares que muestran que existen ciertos estímulos ambientales que sólo se encuentra en medio sólido, estos son detectados y traducidos para así generan una respuesta fisiológica y molecular. 
En esos estudios se demostró que el contacto directo con el aire es un estímulo muy importante para inducir la fisiología del medio sólido (Ávila et al., 2016). Pensando que este estímulo podría estar mediado por EROs, se comenzó una serie de estudios tendientes a ver la relación entre las EROs y la producción de lovastatina.

Las EROs son generadas como subproductos del metabolismo aeróbico. Un exceso de EROs conduce al EOX y como consecuencia, puede dañar directa o indirectamente moléculas como el ADN, proteínas y lípidos, sin embargo, existe evidencia que esta acumulación de EROs también provee señales vitales para funciones de diversos procesos celulares. Se conoce que las EROs producidas en ciertos puntos de tiempo durante el ciclo celular y a concentraciones fisiológicas adecuadas, pueden participar de manera significativa en la homeostasis del organismo y sus funciones celulares.

En Aspergillus terreus, nuestro grupo demostró que las EROs regulan a nivel transcripcional la biosíntesis de lovastatina durante la idiofase, en FS y FL (Miranda et al. 2014). Otros estudios recientes apoyan una interacción funcional entre el EOX y el metabolismo secundario, en particular la producción de aflatoxinas (Roze et al. 2011). Aunque actualmente, el mecanismo molecular que conecta el metabolismo secundario, con el EOX y el desarrollo no está claro (Roze et al. 2011). Cabe aclarar, que el modelo de estudio que hasta ahora ha sido empleado para estudiar esta relación es la biosíntesis de aflatoxinas por dos especies de Aspergillus (Narasaiah et al. 2006; Jayashree \& Subramanyam 2000; Reverberi et al. 2008; Roze et al. 2011), no encontrándose hasta el momento, ningún estudio que relacione al EOX con otro tipo de metabolitos.

En trabajo previo se desarrolló el silenciamiento del gen atyap1 en Aspergillus terreus y se encontró que este provocó a disminución de la expresión de atyap1 pero también de sod1, el inicio precoz e incremento en la acumulación de EROs, una sensibilidad a estrés oxidante, así como también un adelanto e incremento de la expresión de lovE y el inicio precoz y fuerte incremento en la producción final de lovastatina, además de inducir un adelanto e incremento de la expresión de brlA y como consecuencia un inicio precoz y fuerte aumento de la esporulación (Ailed Pérez, Manuscrito en preparación).

Estudios realizados en FS han demostrado que una baja aireación es más compatible con la producción de lovastatina, debido a que conserva mejor la humedad en el sistema de producción (Baños et al., 2009). Estos resultados contrastan con el efecto de la aireación en otros sistemas de cultivo, tales como FS de salvado de trigo e incluso $\mathrm{FL}$, en el que la aireación elevada favorece la producción de metabolitos (Valera et al. 2005). 
El estrés oxidanteen general ejerce un impacto negativo en el crecimiento de hongos. Una posible explicación para muchas de estas observaciones es la actuación de la respiración alternativa. Una de cuyas funciones putativas, o hipotéticas en este estudio, es la de disminuir la producción de EROs, pero a expensas de la generación de ATP (Li Q. et al. 2011).

Sung-Ypng et al. 2013, propone un modelo de regulación por factores de transcripción de respuesta al estrés oxidante, donde se plantea que los niveles intracelulares de EROs, activan a los factores de transcripción de estrés oxidante lo cuales a su vez regularan la biosistesis de aflatoxinas. La regulación se piensa que es por dos vías, la vía de señalización de AMPc-PKA y la otra regulación seria activando las cascadas de señalización a través del sistema de etapas múltiples de fosforilación (MAPK) (Sung-Ypng et al. 2013).

Nosotros proponemos una mecanismo alterno que ayuda a la regulación de EROs, y es por este que la fisiología del medio sólido impide el exceso de EROs en un ambiente aun con aireación que representa una alta concentración de $\mathrm{O}_{2}$ y $\mathrm{CO}_{2}$, este mecanismo estaría regulado por la Respiración alternativa, que activa diferentes NADH alternativas y Oxidasas alternativas que favorecen la producción de lovastatina al dirigir la fisiología al metabolismo secundario, metabolismo que está diseñado para adaptarse a condiciones no optimas o comunes como lo es la falta de oxígeno.

Es importante entender los estímulos que caracterizan el medio solido a nivel molecular, bioquímico y fisiológico, pues además de su interés científico, esto permitirá en un futuro, diseñar mejores sistemas de producción de enzimas, metabolitos secundarios y sistemas racionales para construir cepas mejoradas genéticamente. Esto no sólo es necesario para un mejor control y/o dirección de la formación de productos en FS, pero esta información también será de vital importancia para el diseño de producciones eficaces e incluso para crear nuevas tecnologías. 


\section{ANTECEDENTES}

\subsection{LOVASTATINA.}

De acuerdo con la Organización Mundial de la Salud (OMS), las enfermedades cardiovasculares son la principal causa de muerte en todo el mundo, tan sólo en el 2005, cerca de 17.5 millones de personas murieron por esta causa, representando aproximadamente el $30 \%$ de la mortalidad global. Esto se relaciona con altos niveles de colesterol en sangre, siendo la hipercolesterolemia el factor de riesgo primario para la aterosclerosis y enfermedades coronarias (Kannel et al. 1961).

Del colesterol total del cuerpo, solamente una tercera parte proviene de la dieta, las otras dos terceras partes son sintetizadas por el hígado (Furberg et al. 1999; Alberts et al. 1980). Debido a esto, la inhibición de la biosíntesis del colesterol es una estrategia importante para reducir los niveles de colesterol en sangre (Manzoni y Rollini 2002; Barrios-González y Miranda 2010).

Las estatinas son un grupo de medicamentos que inhiben a la HMG-CoA reductasa, enzima clave en la regulación de la biosíntesis de colesterol. Es en esta forma, que estas moléculas disminuyen los niveles de colesterol en sangre. Además, mediante ensayos clínicos, las estatinas han demostrado prevenir enfermedades cardiovasculares, y se han descubierto nuevas actividades farmacológicas potenciales, por ejemplo, en el tratamiento en enfermedades como cáncer, Alzheimer, esclerosis múltiple, etc. (Barrios-González y Miranda, 2010).

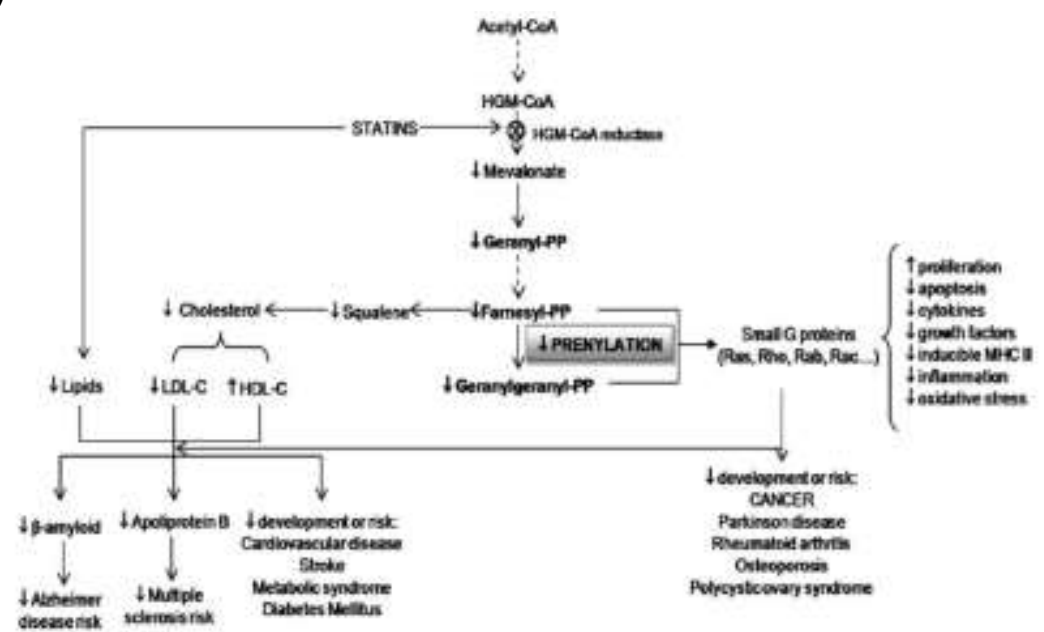

Figura 2.1 Modelo que explica la gran variedad de efectos biológicos de las estatinas; y, por tanto, los usos actuales y potenciales. La inhibición de la HGM-CoA reductasa, no solamente reduce los niveles de colesterol, sino también los intermediarios isoprenoides, afectando la prenilación de las proteínas G (i.e., Ras). Esto puede resultar en la modulación de la transducción de señales de los receptores hacia la expresión de los genes, que directa o indirectamente afectan el balance proliferación/apoptosis, quimiosinas inflamatorias, y mensajeros citogenéticos, todos mediados por proteínas G (Barrios- González y Miranda 2010). 
Esto explica el gran éxito de las estatinas en el mercado farmacéutico. Tan sólo en el 2006, encabezaron la lista de los medicamentos más vendidos en Estados Unidos, con ventas de hasta 8.4 billones de dólares anuales (Barrios-González y Miranda, 2010).

Actualmente son 5 estatinas las utilizadas en el ámbito clínico: dentro de este grupo se pueden encontrar estatinas naturales (lovastatina y pravastatina), semisintéticas (simvastatina) y sintéticas (atorvastatina y fluvastatina) (Barrios-González y Miranda 2010).

Estos compuestos disminuyen los niveles de colesterol; particularmente las lipoproteínas de baja densidad o colesterol de baja densidad (conocido popularmente como el colesterol malo); con un ligero aumento de las lipoproteínas de alta densidad (colesterol bueno), por consiguiente, previenen la acumulación de la placa de colesterol dentro de las arterias (Alberts et al. 1980; Manzoni et al. 1998).

Las estatinas naturales son muy similares en estructura química, ya que poseen en común un policétido principal, un sistema de anillos de hidróxido-hexahidro-naftaleno, el cual es diferente en los lados de la cadena, en la posición del C8 (R1) y del C6 (R2), (Figura 2) (Manzoni y Rollini 2002).

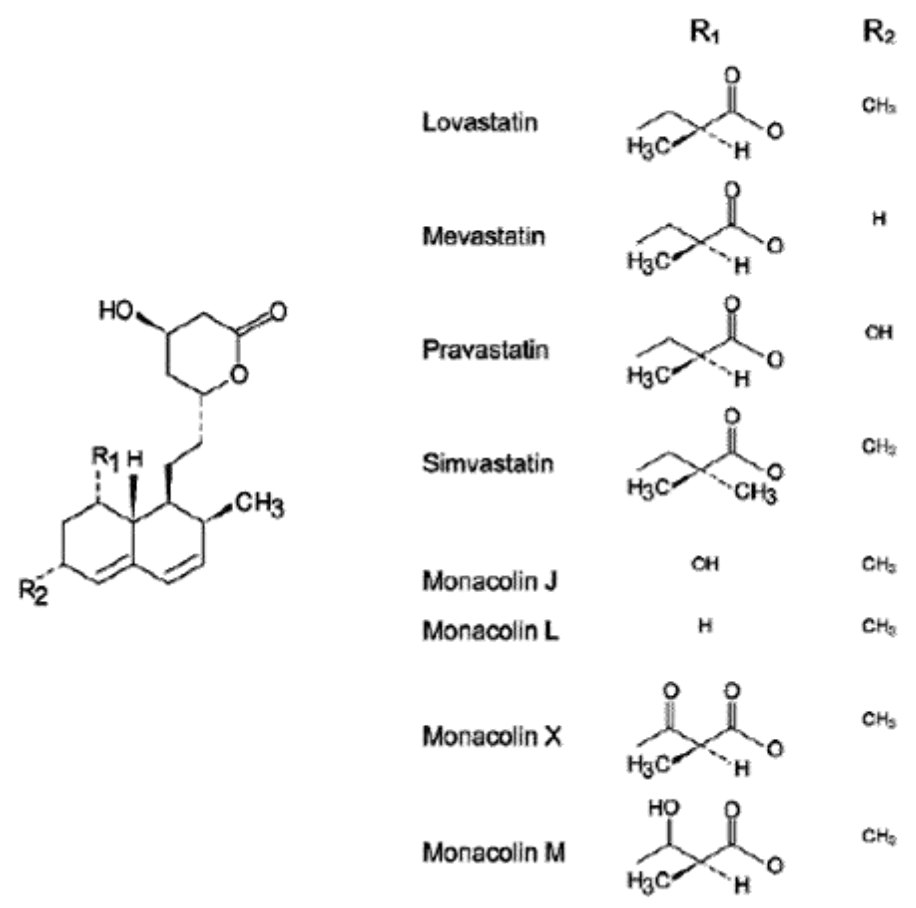

Figura 2.2 Estructura base de las estatinas (izquierda). Cadenas ligadas al C8 (R1) y al C6 (R2) de la estructura base (derecha) (Manzoni y Rollini 2002). 
De todas las estatinas, la lovastatina fue el primer medicamento hipocolesterolémico en ser aprobado por la FDA de EU y en años recientes, se le ha encontrado uso como agente potencial terapéutico para el tratamiento de varios tipos de tumores (Valera et al. 2005). Actualmente no se ha demostrado que la lovastatina tenga propiedades antioxidantes (Barrios-González y Miranda, 2010).

La lovastatina actúa como un inhibidor de la enzima hidroximetilglutaril-coenzima A (HMGCoA) reductasa (Figura 3), la cual cataliza la reducción de HMG-CoA a mevalonato durante la síntesis del colesterol (Hajjaj et al., 2001). Se ha encontrado que un número de organismos tales como Aspergillus terreus, Monascus ruber y ciertas especies de Penicillium y Trichoderma, producen lovastatina como metabolito secundario (Valera et al., 2005).

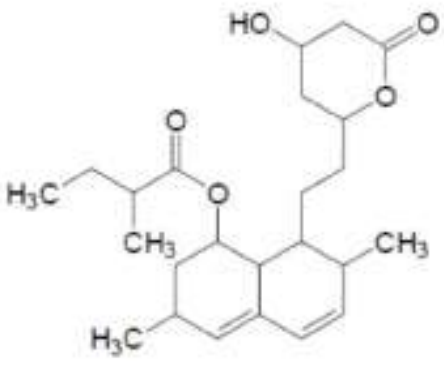

Figura 2.3 Estructura química de la lovastatina (Rollini 2002).

La lovastatina es un metabolito secundario derivado de la Acetil-CoA; los metabolitos secundarios son compuestos producidos principalmente por hongos y actinomicetos, usualmente en la fase tardía de crecimiento llamada idiofase, son compuestos con una variedad en estructuras químicas sofisticadas (Pandey et al. 2001; Barrios-González et al. 2005).

\section{BIOSÍNTESIS.}

La producción de metabolitos secundarios inicia cuando el crecimiento es limitado por el agotamiento de un nutriente clave: carbono, nitrógeno o fosfato (Barrios-González et al., 1988). La ruta biosintética de la lovastatina se ha investigado por resonancia magnética nuclear y espectroscopia de masas (Yoshizawa et al. 1994; Hendrickson et al. 1999). Estos estudios concluyeron que la lovastatina está compuesta de dos cadenas de policétidos unidas a través de un enlace éster, las cuales son ensambladas por la Policétido Sintasa, resultados que provienen de la clonación y la parcial caracterización del clúster de genes biosintéticos de lovastatina de $A$. terreus (Hajjaj et al. 2001). El clúster de genes biosintéticos de la lovastatina consiste en 18 probables marcos de lectura abiertos (open reading frames u ORFs), 2 de los cuales codifican para proteínas reguladoras, lovE y lovH (Rollini 2002). 


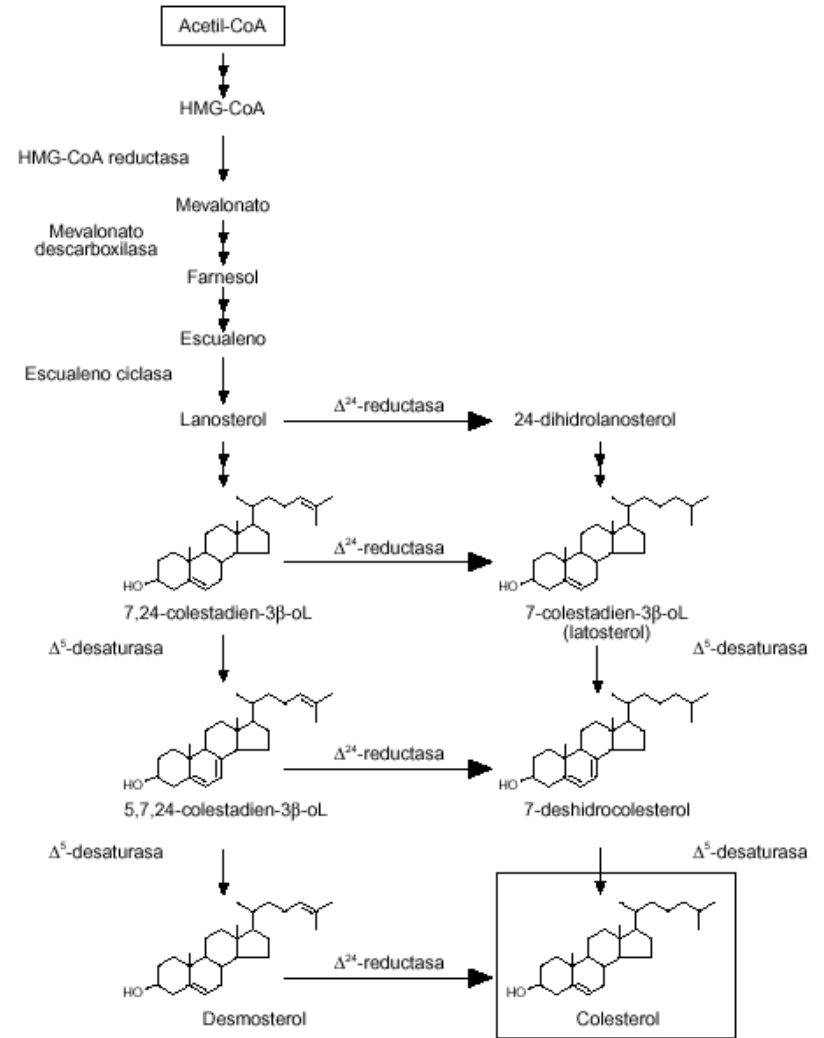

Figura 2.4. Ruta biosintética del colesterol en humanos (Fernández et al. 2003).

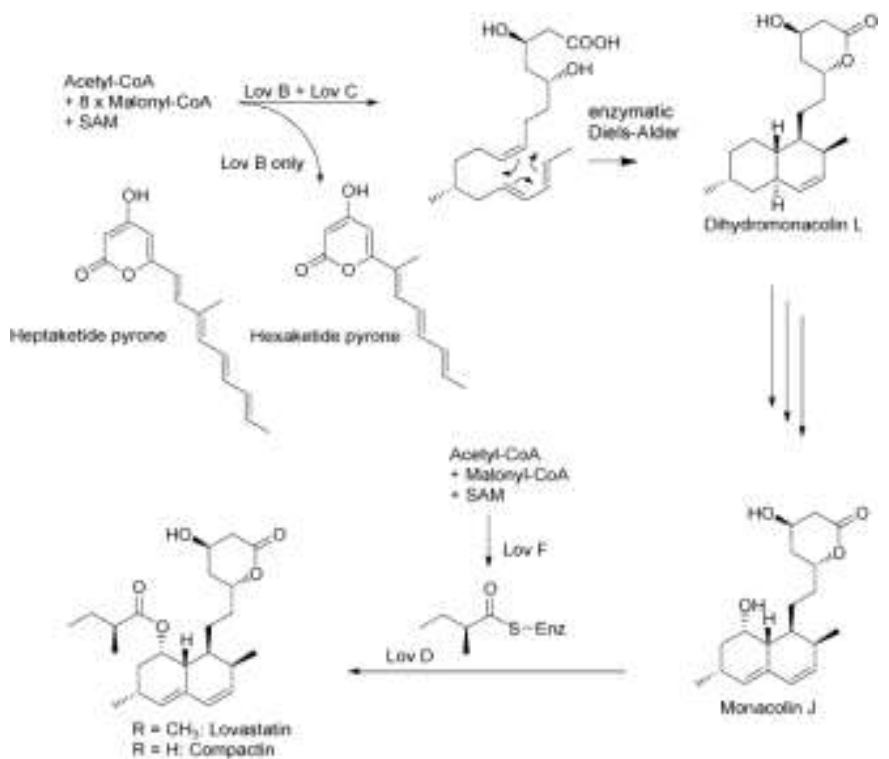

Figura 2.5. Ruta biocinética de la lovastatina (Manzoni et al., 2002). 


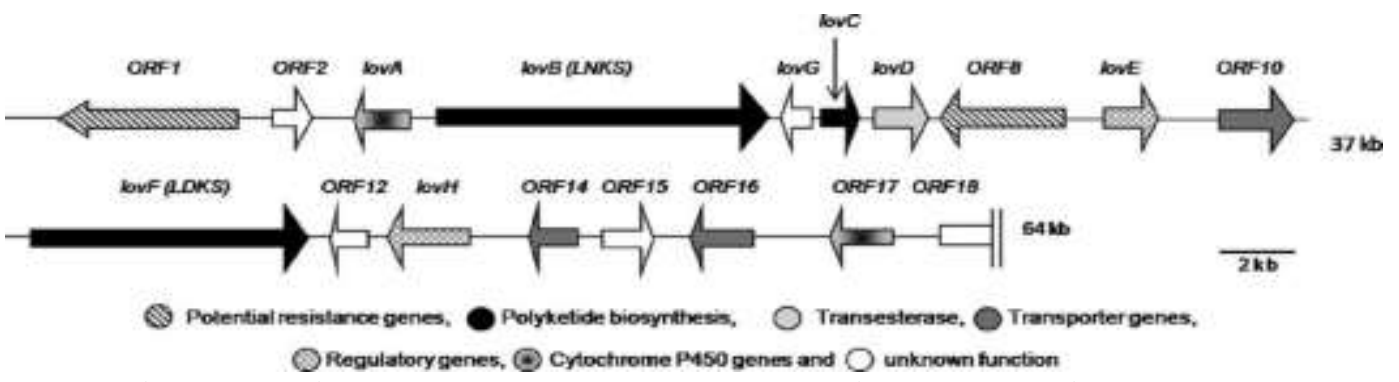

Figura 2.6. Clúster biosintético de la lovastatina: $\operatorname{lov} B$ y lov $F$ biosíntesis de policétidos; lov $C$ enoil reductasa; lovD transesterasa; lovE y lovH genes reguladores; ORF2 y ORF17 genes del citocromo P-450; ORF1 y ORF10 genes potenciales de resistencia; ORF12 y ORF16 genes de transporte; lovG, ORF12, ORF15 y ORF18 función desconocida) (Rollini et al. 2002).

\section{PRODUCCIÓN INDUSTRIAL}

Las investigaciones llevadas a cabo desde 1970 han indicado la posibilidad de obtener un amplio rango de estatinas, tanto como los productos finales e intermediarios del metabolismo microbiano secundario. Se han desarrollado procesos a gran escala solamente para pocas de las estatinas descritas en la literatura. Para otras moléculas, la investigación todavía está en curso y por lo tanto son susceptibles de desarrollo. Estos estudios han resultado en un profundo entendimiento de los diferentes aspectos relativos a los mecanismos involucrados en la producción de las estatinas, lo que ha generado el conocimiento necesario para el desarrollo de proceso a gran escala (Barrios-González y Miranda 2010).

La lovastatina (llamada mevinolina) fue la primera estatina en ser aprobada por la FDA de EU en 1987 y puesta a disposición para el mercado farmacéutico como un medicamento anticolesterolémico. Esta estatina fue obtenida de una cepa aislada del suelo y clasificada como Aspergillus terreus en los Laboratorios CIBE en Madrid (España) y de Monascus ruber (llamada monacolina K) por Endo (2008). Pocos años después la lovastatina también fue obtenida de 17 cepas de diferentes especies de 124 cepas probadas de Monascus, en particular, M. ruber, M. purpureus, M. pilosus, M. vitreus, y M. pubigerus (Hajjaj et al. 2001; Rollini 2002).

La producción convencional de lovastatina se ha llevado a cabo mediante FL. Sin embargo, en años recientes, los investigadores han mostrado un creciente interés por la FS, como una alternativa potencial a la $\mathrm{FL}$, dado que se pueden utilizar sustratos económicos (como residuos agrícolas), se requiere poco procesamiento y las etapas de transmisión continua, utiliza menos potencia y genera menos efluentes. Además, la FS tiene una alta productividad y ofrece mejor estabilidad de producto (Rollini 2002). 
Por otro lado, se ha producido lovastatina empleando Aspergillus flavipes mediante FS usando diferentes sustratos sólidos, tales como salvado de trigo, harina de soya, salvado de grano, desechos frutales y sus combinaciones. Se encontró que empleando salvado de trigo se llegaba a producir hasta $13.49 \mathrm{mg} / \mathrm{g}$ de lovastatina en camas estancadas y $16.65 \mathrm{mg} / \mathrm{g}$ de lovastatina en camas agitadas aireadas, después de 6 días de fermentación (Valera et al. 2005).

Biocon (Biocon, Bangalore, India) es una de las compañías que ha obtenido la aprobación para la producción de lovastatina por el FDA de EU (enero 2001). Fue la primera compañía hindú en obtener esta aprobación para moléculas derivadas de fermentación para uso farmacéutico. El proceso de producción de lovastatina está basado en una tecnología propia de fermentación, el Plafractor, un biorreactor a gran escala de matriz sólida (Mazumdar y Suryanaraya, 2003; Barrios-González et. al, 2003).

\subsection{FISIOLOGÍA DE LA FERMENTACIÓN SÓLIDA.}

La fermentación en estado sólido (FS) se define como un cultivo microbiano que se desarrolla en la superficie y en el interior de una matriz sólida en la ausencia de agua libre. La FS ha sido ampliamente utilizado desde la antigüedad, para la producción de alimentos fermentados como el miso y la salsa de soja en el Lejano Oriente (Barrios- González 2012).

Se distinguen principalmente dos tipos de sistemas de FS dependiendo de la naturaleza de la fase sólida utilizada: el más comúnmente utilizado involucra un sistema de cultivo sobre material natural y el menos frecuentemente utilizado, un cultivo que involucra un soporte inerte impregnado de medio de cultivo (Aidoo et al., 1982).

La FS sobre soportes sólidos naturales es el sistema más comúnmente usado para el cultivo de microorganismos sobre productos agrícolas tales como el arroz, salvado de trigo, etc. El cultivo sobre este tipo de materiales sirve tanto como soporte, como fuente de nutrientes (Barrios Gonzáles, 2010).

La FS sobre soporte inerte impregnado involucra el cultivo de microorganismos sobre un soporte inerte impregnado con medio líquido. En esta fermentación, el soporte sirve exclusivamente como un reservorio de nutrientes de la fase liquida, pero también como un punto de anclaje para los microorganismos (Ojivas et al. 2000; Baños 2010).

La FL es el sistema de producción más usado y más estudiado actualmente, para la mayoría de los productos biotecnológicos debido a su disponibilidad de tecnología y compresión de esta; sin embargo, en los últimos años ha habido un creciente interés en la FS ya que las producciones de enzimas y metabolitos secundarios en este sistema son grandes y muy frecuentemente superan a las secretada en FL. Las ventajas más importantes de la FS son 
una consecuencia de la fisiología mostrado por hongos y otros microorganismos sobre un sustrato sólido, en relación con la presentada en la FL; curiosamente, todos estos sistemas de FS muestran una fisiología especial que se denomina "fisiología de medio sólido".

La fisiología es la ciencia que estudia las funciones orgánicas por las cuales la vida se manifiesta y se mantiene en su forma individual. Para los hongos filamentosos la vida se manifiesta bajo diferentes formas importantes:

- Morfológicas: multiplicación del micelio, conidiogénesis, liberación de las esporas, etc.

- Bioquímicas: producción de metabolitos primarios y secundarios.

- Respirométricas: producción de $\mathrm{CO}_{2}$ y el consumo de $\mathrm{O}_{2}$ durante el crecimiento (Barrios Gonzales, 2010).

Entre las principales diferencias que se han encontrado entre FL y FS son las mayores productividades y menor tendencia a problemas con la inhibición de sustrato en FS. Además, hay muchos casos en que las enzimas producidas en FS difieren de los producidos en FL: enzimas con diferentes características como una mayor temperatura óptima o mayor estabilidad del $\mathrm{pH}$, diferentes parámetros cinéticos o incluso las enzimas que no se secretan al medio en FL se secretaron en FS (Barrios-González, 2012).

Existen reportes donde se manifiesta con claridad esta fisiología especial del medio sólido, ya que en algunos casos se ha encontrado que enzimas que se producen en forma intracelular en FL, son de tipo extracelular en FS, y que ambas muestran peso molecular y características cinéticas diferentes. También se ha encontrado que los hongos contienen distintos genes que codifican para una misma clase de enzima, y que estos genes equivalentes son regulados diferencialmente dependiendo del medio donde se encuentren. Estos hechos sugieren que, el hongo recibe señales que indican que está en uno u otro sistema de cultivo y que esto hace generar una expresión diferencial de genes que dan como resultado una fisiología diferencial (Hisada et al. 2005, Bigelis R et al. 2006).

Esta diferente fisiología se cree que se debe a que la evolución de los hongos superiores y actinomicetos se llevó a cabo sobre sustratos de crecimiento sólidos; en otras palabras, estos organismos pasaron su historia evolutiva como terrestre, han desarrollado un metabolismo más específico y tal vez hasta más completo para el uso en sustratos sólidos húmedos, pero no en los sistemas líquidos (Barrios-González, 2012).

Con relación a los metabolitos secundarios de producción por la FS, una clara diferencia con la FL es el mayor rendimiento, a menudo en períodos más cortos. Además, a veces el metabolito se produce sólo en FS, a pesar de que el organismo también muestra un buen crecimiento en FL (Barrios-González, 2012). 
Por ejemplo, en FS en salvado de trigo producida de Aspergillus oryzae se han obtenido rendimientos 500 veces mayores de proteína heteróloga (quimosina) que en FL, además que se observó que este sistema tiene ventajas que permite la reducción de problemas debidos a procesos posteriores durante la extracción del producto (Barrios-González 2012).

El caso de la alta productividad de glucoamilasa por A.oryzae en FS es un caso especial de un mecanismo bien estudiado a nivel molecular. Los estudios de Hata et al. 1997 revelaron que la enzima glucoamilasa era producida en mucha mayor cantidad por FS. Después, los autores descubrieron que la glucoamilasa producida en FS era distinta a la producida en FL, por lo que determinaron la secuencia de aminoácidos de ambas, pudiendo así clonar los genes. Mediante un análisis de expresión encontraron que el gen glaB se expresaba exclusivamente en medio sólido.

Baños et al. (2010), diseñaron un proceso de producción de lovastatina por FS sobre un soporte inerte artificial. Estos estudios fueron desarrollados con $A$. terreus TUB F-514, una cepa silvestre aislada de muestras de suelo de Irak (Szakacs et al. 1998). La producción de esta cepa, en FL con exactamente el mismo medio de cultivo, fue solamente de $0.62 \mathrm{mg} / \mathrm{mL}$.

Esta cepa también fue probada en FS sobre bagazo de caña impregnado con el mismo medio líquido, y la producción final fue de $8.61 \mathrm{mg} / \mathrm{g}$. Estos estudios muestran que la producción de lovastatina obtenida en el sistema en FS fue más alta que en cualquier sistema de FS o FL reportado (Baños et al. 2010).

La "fisiología especial" del medio sólido se manifiesta con claridad aquí ya que se ha encontrado que al producir lovastatina por Aspergillus terreus en FS, empleando poliuretano como soporte inerte usando un medio más concentrado $2.5 \mathrm{X}$, se alcanzó una producción 30 veces mayor que en FL. El emplear este tipo de soporte, permitió conocer la producción específica, obteniendo un parámetro comparable con respecto a lo obtenido en $\mathrm{FL}$, y se encontró que esta era 13 veces mayor en FS con respecto a FL (Baños et al. 2010).

Estudios desarrollados en nuestro grupo de trabajo al producir lovastatina utilizando $A$. terreus, revelaron que en FS los genes de la vía (relacionados con la biosíntesis de lovastatina) se expresan más intensamente en este sistema sólido en comparación con la FL. Esto sugiere que en FS, el hongo recibe señales que le indican que está en un medio sólido y que generan una expresión diferencial de genes que dan como resultado una fisiología diferente (de medio sólido); y que una de sus características es la alta capacidad de producción de lovastatina (Barrios-González et al. 2008). 
Actualmente, la fisiología de la FS no está bien caracterizada, aunque se han realizado importantes avances en los últimos años. Estos avances demuestran mayores productividades y menos predisposición a problemas con la inhibición de sustrato. Además, hay muchos casos en que las enzimas producidas en FS difieren de los producidos en FL, y que las cepas silvestres o mutantes seleccionadas para los procesos de FS son diferentes a las seleccionadas para los procesos de FL.

Es decir, muy rara vez son cepas eficientes en ambos sistemas. Sin embargo, pocos trabajos han estudiado las diferencias fisiológicas que surgen durante el crecimiento de células microbianas en los dos tipos de sistemas de cultivo (Barrios-González 2012).

Se ha desarrollado estudios que indicaron que existen ciertos estímulos ambientales que hacen notar al hongo que se encuentra en medio sólido. Estos estímulos deben ser detectados y entonces traducidos, disparando un número de eventos a nivel molecular, que a su vez generan una respuesta y con esto se desencadena la fisiología del medio sólido (Barrios-González 2012).

Ávila-Cisneros (2009), desarrolló estudios fisiológicos diseñados para evaluar la contribución de diferentes estímulos a la fisiología del medio sólido. Se identificaron al contacto con el aire como un estímulo muy importante, seguido por el estímulo del soporte, y un menor efecto de la baja actividad de agua y alta concentración de nutrientes. Estos hechos sugieren que, el hongo recibe señales que indican que está en uno u otro sistema de cultivo y que esto hace generar una expresión diferencial de genes que dan como resultado una fisiología diferencial.

El contacto directo con el aire fue uno de los estímulos de la fisiología del medio sólido encontrados por Ávila-Cisneros (2009); realizó experimentos en donde varió el tiempo de contacto con el aire. Los resultados obtenidos muestran que entre más tiempo se expone el micelio al aire la producción aumenta lo que indicar que el contacto aire es un importante estímulo al que responde el micelio para ajustar su fisiología.

Una vez que se determinó la importancia e influencia del contacto con el aire como estímulo de la fisiología del medio sólido, emergía la duda de cómo es que se lleva a cabo la señalización para el desarrollo de esta fisiología. Aportaciones importantes surgen a partir de la investigación realizada por Baños et al. (2007), en donde A. terreus (TUB F-514) fue mutada y una cepa resistente a estrés oxidante (EOX), fue elegida por métodos de selección racional, la nueva mutante presentó resistencia a estrés oxidante y un aumento en la producción de lovastatina (Baños et al. 2010). 
Estos resultados indican que la alta producción de lovastatina de $A$. terreus está relacionada con su capacidad de responder a el EOX. Esto indicó que este estrés tiene mayor intensidad en FS, en relación con $\mathrm{FL}$, y que los mecanismos de adaptación al EOX no solo son valiosos para el hongo creciendo en medio sólido, sino que probablemente inducen una mayor producción de lovastatina y otras características de la fisiología del medio sólido (Baños et al. 2010).

Hay cierta evidencia que sugiere que el EOX impone efectos significativos sobre cultivos de hongos en los sistemas de bioproducción, en términos de morfología, velocidad de crecimiento, el metabolismo, y la secreción de proteína (Li Q. et al. 2011).

El panorama comenzó a surgir que tanto el contacto con el aire, así como el estrés oxidante son factores importantes en fermentaciones sólidas, sin embargo, no es aún muy clara esta relación. Lo que se propuso entonces fue, que un estímulo que potencialmente puede ser detectado por el micelio en FS, es el contacto directo con el aire, y es posible que este contacto pueda estimular la biosíntesis a través del EOX, por la formación de Especies Reactivas de oxigeno (EROs).

\subsection{ESPECIES REACTIVAS DE OXÍGENO EROs}

Las EROs se generan endógenamente en las células, no sólo como consecuencia de la reducción incompleta del oxígeno a agua durante la respiración, sino también en otros procesos metabólicos como la $\beta$-oxidación de ácidos grasos, o al exponer las células a fuentes de radiación ionizante, a químicos de reciclaje redox o a metales pesados. A pesar de las condiciones oxidantes de la vida aeróbica y de los distintos ataques ambientales, los organismos son capaces de mantener un ambiente redox intracelular reducido. Sin embargo, si la concentración de las EROs sobrepasa la capacidad celular para eliminarlos, se produce un estado de estrés oxidante (EOX) (Barrios-González et al. 2008).

Los EROs están siendo generados constantemente en todas las células que crecen aeróbicamente junto con un conjunto bioquímico de antioxidantes y enzimas que facilitan la descomposición de estos y así mantener la célula en un estado de equilibrio redox, cuando este equilibrio se altera por el aumento de EROs se produce entonces un estado de EOX (Barrios-González et al. 2008).

En las células eucariontes el estrés oxidante, se debe a la generación de EROs por la reducción química del oxígeno realizada a través de oxidasas celulares, como peroxidasas, monooxigenasas, dioxigenasas, por la exposición a los rayos UV u otros agentes ambientales y por la reducción incompleta del oxígeno a agua en la cadena respiratoria mitocondrial (Barrios-González et al. 2008). 
Existe mucha información sobre el daño a lípidos, carbohidratos, proteínas y ácidos nucleicos mediado por los intermediarios reactivos del $\mathrm{O}_{2}$, daños que eventualmente pueden conducir a la muerte celular (Storz et al. 1987). Dado que el EOX puede ocurrir rápidamente, la ruta de respuesta de los hongos debe ser similarmente rápida. La célula debe ser capaz de detectar el balance redox alterado, modular la actividad de reguladores transcripcionales apropiados, y entonces inducir la expresión de los genes requeridos (Bai Z et. al, 2003a).

Los hongos usan diferentes estrategias para controlar la expresión de los genes activados por el redox, y una característica común es la necesidad de una respuesta transcripcional a los cambios oxidante (Moye-Rowley et al. 2003).

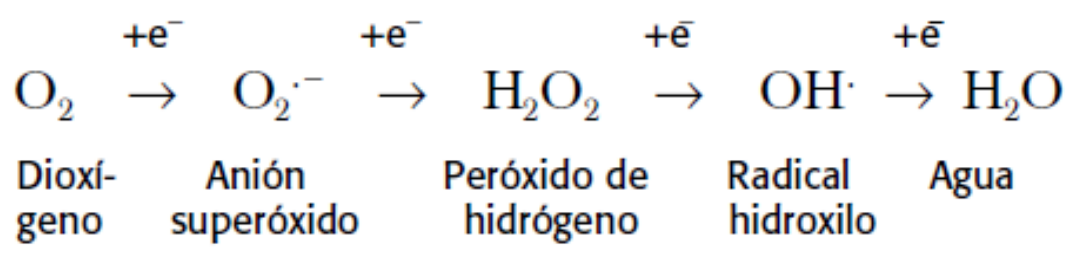

Figura 2.7 Especies Reactivas derivadas del oxígeno (Folch-Mallol et al. 2004).

Las EROs son moléculas muy reactivas entre las que se encuentran los iones de oxígeno, los radicales libres y los peróxidos. Su gran reactividad se debe a que poseen electrones desapareados que les hace reaccionar con otras moléculas orgánicas en procesos de óxidoreducción. Las distintas especies reactivas de oxígeno pueden participar en distintos tipos de reacciones en las que pueden sufrir procesos de oxidación o reducción. De menor a mayor grado de reducción son especies reactivas de oxígeno:

- El anión superóxido $\mathrm{O}_{2}^{-}$que es un potente agente oxidante muy reactivo con el agua La formación del radical superóxido ocurre por la reducción univalente del oxígeno; es decir, cuando el oxígeno acepta un electrón, reacción que se puede llevar a cabo después de varios eventos. Esta especie es relativamente inestable y se encuentra en equilibrio con su ácido conjugado, el radical hidroperoxilo (Folch-Mallol et al. 2004). El anión superóxido tiene una función importante in vivo, ya que participa en la descarga respiratoria (aumento súbito del consumo de oxígeno) de las células fagocíticas activadas por contacto con partículas extrañas en los eventos inmunológicos. Cuando estas células se activan, el complejo enzimático NADPH (forma reducida de nicotinamida adenín dinucleótido fosfato) oxidasa, localizado en la membrana citoplasmática, reduce parcialmente el oxígeno (Bedard y Krause, 2007).

- El peróxido de hidrógeno $\mathrm{H}_{2} \mathrm{O}_{2}$ es un oxidante débil; sin embargo, difunde y cruza las membranas fácilmente $y$, al reaccionar con algunos metales de transición como el fierro o el cobre reducidos $\left(\mathrm{Fe}^{2+} \mathrm{o} \mathrm{Cu}^{+}\right.$respectivamente) forma al radical hidroxilo 
(HO•) uno de los radicales conocidos con mayor reactividad (Folch-Mallol et al. 2004). El $\mathrm{H}_{2} \mathrm{O}_{2}$ es formado por la enzima superóxido dismutasa SOD, aunque no es un radical libre, tiene una gran lipofilicidad que le permite atravesar las membranas celulares y reaccionar con el anión superóxido en presencia de metales de transición, para generar el radical hidroxilo. Por esta razón se le considera un oxidante importante en las células de los organismos aerobios (Bedard y Krause, 2007).

- El radical hidroxilo * $\mathrm{OH}$ que es el más reactivo. Aceptando un electrón más, el radical hidroxilo da lugar a una molécula de agua (Bedard y Krause, 2007).

Tabla 2.1. Especies Reactivas de Oxigeno (The Molecular Probes ${ }^{\circledR}$ Handbook)

\begin{tabular}{|c|c|c|c|}
\hline \multirow{2}{*}{$\begin{array}{l}\text { Reactive Oxygen Species } \\
\text { Hydrogen peroxide }\end{array}$} & \multirow{2}{*}{$\begin{array}{l}\text { Structure } \\
\mathrm{H}_{2} \mathrm{O}_{2}\end{array}$} & \multicolumn{2}{|c|}{ Detection Reagents } \\
\hline & & 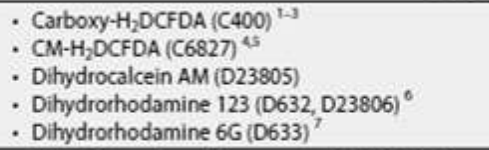 & $\begin{array}{l}\text { - } \mathrm{H}_{2} \text { DCFDA }(\mathrm{D} 399)^{\mathrm{s-11}} \\
\text { - Lucigenin }(\mathrm{L} 6868)^{12,13} \\
\text { - Luminol (L8455) } \\
\text { - RedoxSensor }{ }^{14}\end{array}$ \\
\hline Hydroxyl radical * & HO. & $\begin{array}{l}\text { - } 3 \text {-(p-Aminophenyl) fluorescein (APF, A36003) } \\
\text { - } 3 \text {-(p-Hydroxyphenyl) fluorescein (HPF, H36004) } \\
\text { - } \mathrm{CM}-\mathrm{H}_{2} \mathrm{DCFDA}(\mathrm{C} 6827)^{16}\end{array}$ & $\begin{array}{l}\text { - Proxyl fluorescamine }(C 7924)^{17} \\
\text { - TEMPO-9-AC (A7923) }\end{array}$ \\
\hline Hypochlorous acid & $\mathrm{HOCl}$ & $\begin{array}{l}\text { - Aminophenyl fluorescein (APF, A36003) } \\
\text { - Dihydrorhodamine } 123(\mathrm{D} 632, \mathrm{D} 23806)^{18}\end{array}$ & - Luminol (L8455) ${ }^{19-21}$ \\
\hline Nitric oxide & NO & $\begin{array}{l}\text { - DAF-FM (D23841) } 22,23 \\
\text { - DAF-FM diacetate (D23842, D23844) } \\
\text { - DAA (D23840) }\end{array}$ & $\begin{array}{l}\text { 2,3-Diaminonaphthalene (D7918) } \\
\text { - Luminol (L8455) }\end{array}$ \\
\hline $\begin{array}{l}\text { Peroxyl radical, including both alkylperoxyl } \\
\text { and hydroperoxyl }{ }^{26} \text { radicals (wherein } \mathrm{R}=\mathrm{H} \text { ) }\end{array}$ & ROO. & 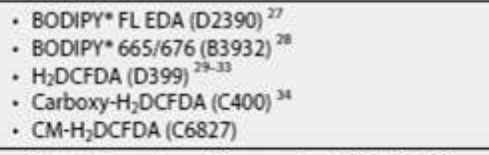 & $\begin{array}{l}\text { - DPPP }(\mathrm{D} 7894)^{35-37} \\
\text { - Luminol (L8455) } \\
\text { - cis-Parinaric acid (P36005) } \\
\text { - RedoxSensor"- Red CC-1 (R14060) }\end{array}$ \\
\hline Peroxynitrite anion $t$ & ONOO & $\begin{array}{l}\text { 3-(p-Aminophenyl) fluorescein (APF, A36003) } \\
\text { - } 3 \text {-(p-Hydroxyphenyl) fluorescein (HPF, H36004) } \\
\text { - } \mathrm{H}_{2} \mathrm{DCFDA}(\mathrm{D} 399) \\
\text { - Carboxy- } \mathrm{H}_{2} \mathrm{DCF} \text { (CFA (C400) } \\
\text { - } \mathrm{CM}-\mathrm{H}_{2} \mathrm{DCFDA}(\mathrm{C} 6827)\end{array}$ & $\begin{array}{l}\text { - Coelenterazine (C2944) } \\
\text { - Dihydrorhodamine } 123 \text { (D632, D23806) } \\
\text { - Dihydrores } \\
\text { - Luminol (L8455) }\end{array}$ \\
\hline Singlet oxygen $\neq$ & $\mathrm{O}_{2}$ & - Singlet Oxygen Sensor Green reagent (S36002) & - trans-1-(2'-methoxyvinyl)pyrene $(M 7913)^{51,5}$ \\
\hline Superoxide anion & $\cdot \mathrm{O}_{2}$ & 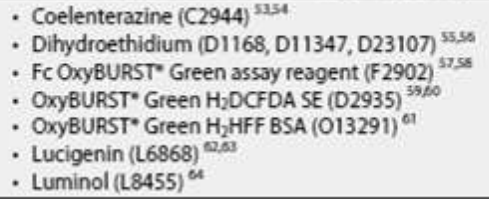 & 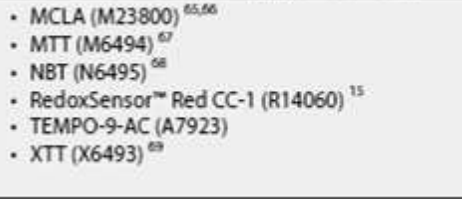 \\
\hline
\end{tabular}

\subsubsection{ENZIMAS ANTIOXIDANTES REGULADORAS DE EROs}

Para contender con el EOX y proteger los componentes celulares al mantener un adecuado ambiente redox dada la inherente exposición a las EROs, los organismos constantemente detectan y se adaptan a cualquier perturbación mediante una batería de defensa antioxidante conformada por sistemas enzimáticos y no enzimáticos (Belozerskaya et al. 2007). 
Los sistemas de defensa no enzimáticos consisten típicamente en moléculas pequeñas que son solubles en agua o, en algunos casos, en un ambiente lipídico. Estos en general actúan atrapando algunas de las EROs y son: glutatión, poliaminas, ácido eritroascórbico, metalotioneinas, flavohemoglobinas, glutarredoxinas y tiorredoxinas (Miranda et al. 2008).

Los sistemas de defensa enzimáticos incluyen a varias enzimas las cuales son capaces de eliminar EROs, entre ellas están:

- Superóxido dismutasas (SOD): son enzimas abundantes presentes en muchos de los organismos aeróbicos y anaeróbicos, constituyen la primera línea de defensa antioxidante. Es una enzima que se encuentra en el citoplasma (Cu-Zn SOD), mitocondria (Mn-SOD) y en el fluido extracelular (Cu-Zn SOD). Su actividad conocida es la dismutación del radical superóxido, $\mathrm{O}_{2}$, para dar dioxígeno y peróxido de hidrógeno, las enzimas de la ruta de las pentosas, la glutatión reductasa, la glutatión peroxidasa, la tiorredoxina peroxidasa y las peroxirredoxinas (Garrido y Grant, 2002).

- Catalasa (CAT): Esta enzima se encuentra en las mitocondrias y los peroxisomas, y cataliza la reducción del peróxido de hidrógeno a agua, transforma el $\mathrm{H}_{2} \mathrm{O}_{2}$ en $\mathrm{O}_{2}$ y $\mathrm{H}_{2} \mathrm{O}$. Cabe mencionar que esta enzima también tiene actividad de peroxidasa. Es una enzima tetramérica y cada subunidad contiene un grupo hemo-Fe(III) es su centro catalítico. Esta enzima tiene baja afinidad por el sustrato, pero una eficiencia catalítica muy elevada. Cuando los niveles de Peróxido de hidrogeno son bajos entra Cat (Delaunay et al. 2002).

- Glutatión Peroxidasa (Gxp): cataliza la reducción de peróxido, hidroperóxidos orgánicos y peróxidos lipídicos, utilizando como sustrato el glutatión reducido GSH o tiorredoxina. Las glutatión peroxidasa con selenio dependientes y son consideradas como las peroxidasas más importantes porque tienen una alta especificidad por el sustrato y una mayor afinidad por el peróxido que la catalasa. El centro activo de las GPXs contiene cuatro átomos de selenio unido covalentemente a cisteína formando selenocisteinas con actividad durante la catálisis (Miranda et al. 2008).

Las células fúngicas también deben tratar con una amplia variedad de cambios ambientales potencialmente tóxicos durante el curso de su proliferación. Un ejemplo importante de un desafío ambiental al que los hongos se enfrentan es precisamente a estos altos niveles de EROs. Una característica crítica en esta respuesta al EOX es la necesidad para señalar rápidamente al nuevo ambiente estresante, lo cual a su vez conduce a la reprogramación de la expresión de genes y a sus productos requeridos para contrarrestar la elevación letal de las EROs (Miranda et al. 2008). 
Existen varios estudios respecto a la respuesta provocada por el EOX, pero se ha encontrado que ésta ocurre a nivel transcripcional, y que existe superposición entre las respuestas provocadas ante una condición de EROs y aquellas observadas a otros tipos de estrés. Las diversas condiciones de estrés (térmico, osmótico, salino, etc.) generan conjuntamente una condición hiperoxidante (Miranda et al. 2008).

Es evidente la selección de diferentes moléculas reguladoras que le dan cierta especificidad a las vías de transducción de señales. Esto nos dice que existe una íntima interacción entre cada una de las diferentes vías. Mientras que combatir a las EROs es una necesidad común para el hongo, en diferentes organismos se hace uso de diferentes mecanismos para detoxificarse de las EROs y asegurar la supervivencia (Folch-Mallol et al., 2004).

En estudios realizados por Miranda et al. 2013, en donde se estudió la generación de EROs y el estado oxidante de la célula, se encontró sorprendentemente que las concentraciones de EROs en idiofase eran 10 veces mayores en ambos sistemas de fermentación: en otras palabras, la acumulación de EROs coincide con el inicio de la producción de lovastatina es decir las EROs contribuyen en la señalización para iniciar la idiofase de FS y FL (Miranda et al. 2013).

Otra aportación importante de este trabajo fue que los niveles bajos y controlados de EROs parecen ser importantes para un buen nivel de producción como los encontrados en FS: a diferencia de la FL, en FS era menor la acumulación de EROs, aunque mucho más estable a lo largo de la idiofase. Estas diferencias fisiológicas podrían estar asociadas a la alta producción de lovastatina en FS (Miranda et al. 2013).

Como segundos mensajeros, las EROs están involucrados en procesos de desarrollo en plantas y en mecanismos de defensa contra patógenos y estrés abiótico (Apel y Hirt 2004; Jones 1994). Efectos similares se han observado en mamíferos, donde niveles apropiados de EROs estimulan las reacciones antioxidantes, la modulación del sistema inmune y la regulación de la proliferación celular (Bokoch y Knaus 2003). Asimismo, estudios recientes han revelado que las rutas de señalización son reguladas por el estado intracelular redox (Kamata y Hirata 1999).

Existe evidencia que sugiere que las especies reactivas de oxigeno (EROs), tales como los aniones superóxido y el peróxido de hidrogeno, funcionan como segundos mensajeros intracelulares (Finkel, 1998). Otro trabajo que muestra evidencia de esto es el de Halliwell y Gutteridge, 1999, en donde se propone que las EROs regulan varios procesos celulares, aunque también resultan nocivas para los organismos.

Esto se ve reflejado en los estudios realizados con el hongo Neurospora crassa que indican que hay un breve periodo transitorio de incremento de EROs al comienzo de cada etapa morfogénica (Toledo et al. 1995). Kreiner et al. 2000, estudiaron el efecto de la tensión de oxígeno disuelto y la concentración de oxígeno en la tasa de crecimiento del hongo $A$. niger 
B1-D y en la producción de una enzima recombinante en FL; encontraron que existía una mayor actividad de las enzimas SOD y CAT al final de la fase estacionaria y el inicio de la fase de decaimiento de una FL (Bai Z et. al, 2003b).

Es interesante notar que estudios sobre la producción de aflatoxinas en Aspergillus parasiticus indicaron que hay un estado oxidante que coincide con la transición entre trofofase e idiofase; y que las cepas más aflatoxigénicas muestran un EROs en ese punto mucho más intenso que las cepas no toxigénicas. Indicando que la intensidad del EROs puede estar relacionada con el nivel de producción de la cepa (Jayashree et al. 2000).

Se ha propuesto que la diferenciación celular es una respuesta al EOX. De acuerdo con esto, el crecimiento y los estados diferenciados, son condiciones estables en las cuales los niveles de EROs son mantenidos por un balance en la generación de EROs (i.e. por mitocondria y NOX) y la eliminación (por enzimas antioxidantes) (Cano-Domínguez et al. 2008). Un cambio entre estos dos estados ocurre cuando un incremento transciende en los niveles de EROs, además de su capacidad celular de neutralizarlas (Aguirre et al. 2006).

El carácter transitorio de esta respuesta es debido en parte al hecho de que niveles elevados de EROs resultan en una alta expresión de enzimas que las descomponen. Además, varios reportes en diferentes microorganismos eucarióticos han mostrado una correlación entre los procesos de desarrollo y la regulación de enzimas antioxidantes específicas, tales como las superóxido dismutasas, catalasas, peroxidasas y peroxirredoxinas (Aguirre et al. 2006).

La importancia de relación entre la acumulación de EROs y la producción de lovastatina se determinó empleando el antioxidante $\mathrm{N}$-acetilcisteína (NAC) que redujo los niveles de EROs, resultando así la diminución de la biosíntesis de lovastatina, esto en consecuencia de una disminución en el nivel de transcritos de los genes de la vía por efecto del antioxidante. Además, se demostró que se pueden disminuir los niveles de EROs con el uso de este antioxidante NAC (10mM FL y 50mM FS) observándose un efecto, sin afectar otros parámetros como el crecimiento como ya lo demostraron en Miranda et al., 2014.

En el trabajo sucesivo a este se encontró que con la adición de peróxido de hidrógeno a la FL se logró adelantar la acumulación de EROs y en consecuencia adelantar la biosíntesis de lovastatina. Esto confirma que los EROs regulan la biosíntesis de lovastatina (Miranda et al., 2014). 


\subsubsection{ORIGEN DE LAS ESPECIES REACTIVAS DE OXIGENO}

Existen varios orígenes de los radicales libres en la célula, pero los principales cuatro son: Mitocondria, NOX, Citocromo P450 y Xantina Oxidasa (Chance B. et al. 1979).

\section{MITOCONDRIA.}

Este organelo genera el $90 \%$ de anión súper oxido en la célula, tiene dos orígenes de EROs. Complejo I: puede producir $\mathrm{O}_{2}$ - cuando los e- del $\mathrm{NADH}_{2}$ son trasferidos del flavin mononucleótido (FMN) a la Ubiquinona a través de los centros de Fe-S antes de llegar al complejo III. Complejo III: Los e- son trasferidos del Ubiquinol al citocromo $\mathrm{C}$ a través del ciclo de la Quinona. Aquí cuatro protones son translocados al espacio intermembranal, mientras dos e- son aceptados por el citocromo $C$ (Turrens, J.F. 2003). La producción de superóxido ocurre en el centro de la coenzima $Q$ donde un segundo ees necesario para reducir el citocromo $\mathrm{B}$, pero algunos de los e- son dirigidos al $\mathrm{O} 2$ formando anión súper oxido, que es liberando al espacio intermembranal o a la matriz. El citocromo $B$ es el único en estado reducido por el cual puede donar a quinona. El anión súper oxido se genera como subproducto (Luis E Gómez-Quiroz, 2017).

\section{NADPH OXIDASA (NOX).}

A diferencia de la mitocondria, esta enzima si fue diseñada para formar el anión súper oxido. La NOX está formada por varias proteínas que se encuentras distribuidas entre el citoplasma y la membrana plasmática cuando la célula está inactiva. En su mayoría los cinco componentes tienen que ser traslocados desde el citosol a la membrana plasmática donde ocurre el ensamblaje del complejo funcional. La enzima es activada por fosforilación se encuentra en la membrana plasmática y nuclear (Angélica Coyoy et al. 2012).

\section{CITOCROMO P450.}

Participa en el metabolismo de sustancias exógenas como drogas, pesticidas y endógenos. El citocromo cataliza una amplia variedad de reacciones incluyendo epoxidaciones, oxidaciones, hidroxilaciones, etc. La mayoría de las reacciones catalizadas requieren de la inserción de un grupo hidroxilo en el sustrato para formar un intermediario hidroxilado, molécula más polar. La formación de peróxido de hidrogeno y anión súper oxido es espontánea y ocurren como una reacción secundaria de la verdadera función del citocromo que es el metabolismo de toxinas. Todos los citocromos generan en su actividad EROs (Zorov, D. B et al. 2014).

\section{XANTINA OXIDASA.}

Participa en la vía metabólica de la degradación de las purinas. Lo que hace esta vía es pegar tres grupos cetos para polarizar, de esta forma es soluble en agua y se elimina. La formación de anión superóxido es como subproducto (Camile P. Semighini et al. 2008). 


\subsection{FACTORES TRANSCRIPCIONALES DE RESPUESTA A EOX.}

Se han logrado identificar varios factores transcripcionales que regulan la expresión génica en respuesta al EOX, que, en algunos casos, se modula por las vías de señalización de las diferentes condiciones de estrés:

- Factores transcripcionales tipo bZip: Yap1p, Yap2p, Gcn4p.

- Factores transcripcionales que unen a cobre: Ace1p, Mac1p.

- Factores transcripcionales con dedos de zinc: Hap1p, Hap2p, Hap3p y Hap4p.

El análisis in silico del promotor del gen lovE (factor transcripcional del tipo dedos de zinc (Zn2Cys6) de la vía biosintética de lovastatina (Kennedy 1999; Bok \& Keller 2004), reveló que el promotor es rico en posibles sitios de unión que en su mayoría responde a EOX como Skn7, Ap-1 (homólogo de atyap1), Msn2/4, Nrf2 y NF-K-B (Factores transcripcionales de respuesta a EOX en mamíferos), lo cual sugiere que este tipo de estrés puede regular a través de lovE la biosíntesis de lovastatina (Miranda et al. 2013).

Yap1p es un factor de respuesta antioxidante del tipo bZip, que parece ser regulado a nivel de localización nuclear y fosforilación. Una cremallera de leucina o factores de transcripción bZip es un motivo estructural supersecundario de proteínas que crea fuerzas de adhesión a través de hélices alfa en paralelo. Es un dominio de dimerización común en proteínas involucradas en la expresión génica. La familia de factores de transcripción bZip consiste en una región básica que interacciona con el surco mayor de la molécula de ADN a través de enlaces de hidrógeno, y una región hidrofóbica de cierre, que es la responsable de la dimerización (Moye-Rowley 2003).

El trabajo de Sung-Ypng et al. 2013, propone un modelo para la activación transcripcional de genes de biosíntesis de aflatoxina por factores de transcripción relacionados con el estrés oxidante. Donde se propone que el aumento de los niveles intracelulares de EROs en las células fúngicas regula por disminución la vía de señalización de AMPc-PKA (Figura 2.8). Esto promueve la unión a sitios STRE en promotores de genes antioxidantes por su proteína quinasa activada (SAPK / MAPK) cascadas de señalización a través del sistema de etapas múltiples de fosforilación (Sung-Ypng et al. 2013). 


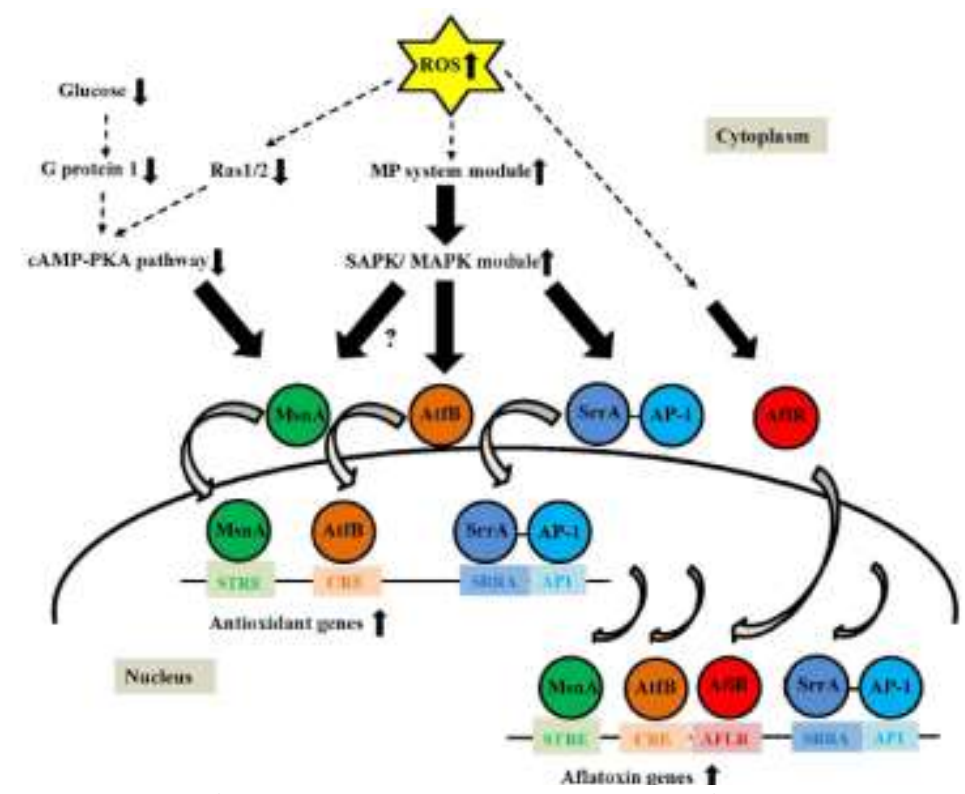

Figura 2.8 Modelo para la activación transcripcional de genes de biosíntesis de antioxidantes y de aflatoxina por factores de transcripción relacionados con el estrés oxidante (Sung-Ypng et al. 2013).

En trabajo previo se desarrolló el silenciamiento del gen atyap1 en Aspergillus terreus y se encontró que este provocó la disminución de la expresión de atyap1, pero también de sod1, el inicio precoz e incremento en la acumulación de EROs, una sensibilidad a estrés oxidante, así como también un adelanto e incremento de la expresión de lovE y el inicio precoz y fuerte incremento en la producción final de lovastatina, además de inducir un adelanto e incremento de la expresión de $b r l A$ y como consecuencia un inicio precoz y fuerte aumento de la esporulación (Ailed Pérez, manuscrito en preparación).

Por lo que se descartó entonces a Yap1 como regulador positivo y se siguiere que Yap1 podría estar actuando como un regulador negativo de lovE y los genes de biosíntesis, así como a brlA (y así a los genes relacionados con la esporulación) en $A$. terreus. Además de apuntar a que atyap1 regula positivamente a los genes que combaten la acumulación de EROs como sod1. Así, el factor transcripcional Yap1p podría ser el nexo entre los EROs y lovastatina. Sin embargo, también es posible que esto sea un efecto indirecto debido a la acumulación prematura de EROs, induciendo la lovastatina por medio de otro factor transcripcional de respuesta a estrés oxidante (Ailed Pérez, manuscrito en preparación). 


\subsection{REGULACION DE AMPC Y PKA.}

La fosforilación reversible de las proteínas regula una infinidad de procesos celulares. La cinasa de proteínas dependiente del AMP cíclico (PKA) está presente en todos los eucariontes (protozoarios, animales, algas y hongos) a excepción de las plantas terrestres y su estudio ha revelado mecanismos importantes para la señalización celular. Aquí se describen los componentes de la cascada de señalización de la PKA, la compartimentalización de las subunidades regulatorias, así como los mecanismos de regulación de la respuesta al estrés, la estimulación del crecimiento filamentoso y la retroregulación de la actividad de la PKA (Hu Y. et al. 2010).

La remodelación de la estructura celular está determinada por interacciones complejas y delicadas entre sus componentes, así como por las condiciones del ambiente extracelular. En vertebrados, la PKA juega un papel muy importante en actividades tan dispares como la regulación del metabolismo, los procesos secretorios, la memoria y el aprendizaje (Milenkovic L \& Scott MP, 2010). La PKA también regula el desarrollo, puesto que mutaciones en el gen DCO de Drosophila, que codifica a la subunidad catalítica de la PKA, ocasionan defectos en la oncogénesis y en la formación de patrones embrionarios (Sergio Pérez-Landero, 2013).

En S. cerevisiae, una de las rutas principales de señalización que regulan el metabolismo y el crecimiento en respuesta a la presencia de nutrientes y a las condiciones de estrés involucra a la PKA, la cual estimula tanto a las enzimas de la glucólisis y la fermentación como a aquellas involucradas en el desarrollo y en la proliferación celular. Al contrario, inhibe a las proteínas involucradas en la resistencia al estrés, en la gluconeogénesis y en la síntesis de la trealosa y del glucógeno (Thevelein JM et al., 1999).

Las células proliferan cuando disponen de nutrientes y, por el contrario, crecen lentamente cuando éstos escasean o cuando las condiciones fisicoquímicas del medio les son adversas. Para modular su crecimiento la célula monitorea el ambiente circundante mediante estrategias diversas, integrando los estímulos o señales generadas y restructurando, incluso, el estado transcripcional del genoma (Folch-Mallol JL, 2004).

La ruta de señalización de la PKA está altamente conservada en los hongos y, debido a su relevancia en la adaptación a las condiciones nutricionales y ambientales, se le considera como un blanco clave para el desarrollo de fármacos antifúngicos que permitan controlar enfermedades humanas y vegetales (Folch-Mallol JL, 2004).

La activación de la PKA requiere de dos vías principales. Una, la vía Gpa1-Gpr2, el equivalente funcional de las proteínas $G$ heterotriméricas de la adenilato ciclasa de los mamíferos, detecta la presencia extracelular de la glucosa o la sacarosa y estimula de manera rápida a la PKA. La segunda, la vía Cdc25-Ras, permite mantener elevada la actividad 
de la PKA cuando los niveles de glucosa fosforilada aumentan y el pH disminuye dentro de la célula como resultado de la actividad glucolítica. Para monitorear el ambiente circundante, la célula utiliza a los GPCR (Milenkovic L \& Scott MP, 2010).

Los azúcares extracelulares son inicialmente percibidos por la proteína receptora transmembranal Gpr1. El receptor, al censar a la glucosa, estimula el intercambio del GDP por el GTP de la proteína Gpa2 (proteína tipo Ga). Unido el GTP a Gpa2, la adenilato ciclasa (AC), Cyr1, es estimulada con el consecuente aumento en la actividad de la PKA en respuesta a la rápida elevación de los niveles del AMPc. Por el contrario, la subunidad Rgs2 (subunidad reguladora RGS -Regulator of G-protein Signaling-) promueve la retro/inhibición de la cascada, promoviendo la actividad GTPasa de la proteína Gpa2. Un segundo punto de control negativo de la actividad de Gpa2 lo constituye la proteína Asc1 que, al unirse al complejo Gpa2-GDP, inhibe el intercambio de GDP por GTP (Rubio-Texeira M et al., 2010).

En la Vía Cdc25-Ras, los sacáridos intracelulares son fosforilados antes de ser metabolizados y se postula que, cuando la glucosa se encuentra fosforilada, la unión del GTP a las proteínas G monoméricas Ras (Ras1 y Ras2) aumenta de dos a tres veces. Esto es relevante, ya que la isoforma Ras-GTP también estimula a la AC ayudando a mantener elevada su actividad. La estimulación de la AC por Ras-GTP requiere de elementos adicionales, como la proteína asociada a la AC, Srv2, o la proteína Sgt1, que puede actuar como chaperona (Fortwendel JR et al. 2004).

El intercambio del GDP por el GTP de Ras requiere de los factores de intercambio Cdc25 y Sdc25. Por el contrario, las proteínas Ira, Ira1 e Ira2, inhiben a Ras acelerando su actividad intrínseca de GTPasa. Ras y los intercambiadores de nucleótidos de guanina tipo Cdc25 están presentes en los mamíferos, pero no activan a la AC (Thevelein JM et al., 1999).

La PKA en $S$. cerevisiae consta de tres subunidades catalíticas codificadas por los genes TPK1, TPK2 y TPK3. Estas cinasas son reguladas negativamente por Bcy1 (R), mediante la formación de un complejo tetramérico inactivo compuesto por dos subunidades $R$ unidas a dos subunidades $C$. En otras especies, el número de isoformas que componen la PKA es mayor. En humanos, por ejemplo, cuatro genes codifican a las subunidades regulatorias y tres a las catalíticas, por lo que $S$. cerevisae representa un modelo de menor complejidad para el estudio de la dinámica y de las interacciones entre las subunidades de la PKA (Skroblin P et al., 2010).

A concentraciones elevadas del AMPc se activan las Tpk's, ya que dos moléculas de este nucleótido cíclico (AMPc) se unen a cada una de las subunidades $R$, promoviendo cambios estructurales que desencadenan en la disociación del complejo R-C y, en consecuencia, la liberación/activación de las subunidades catalíticas -Tpk1, Tpk2 o Tpk3- (Cannon J F \& Tatchell, 1987). 


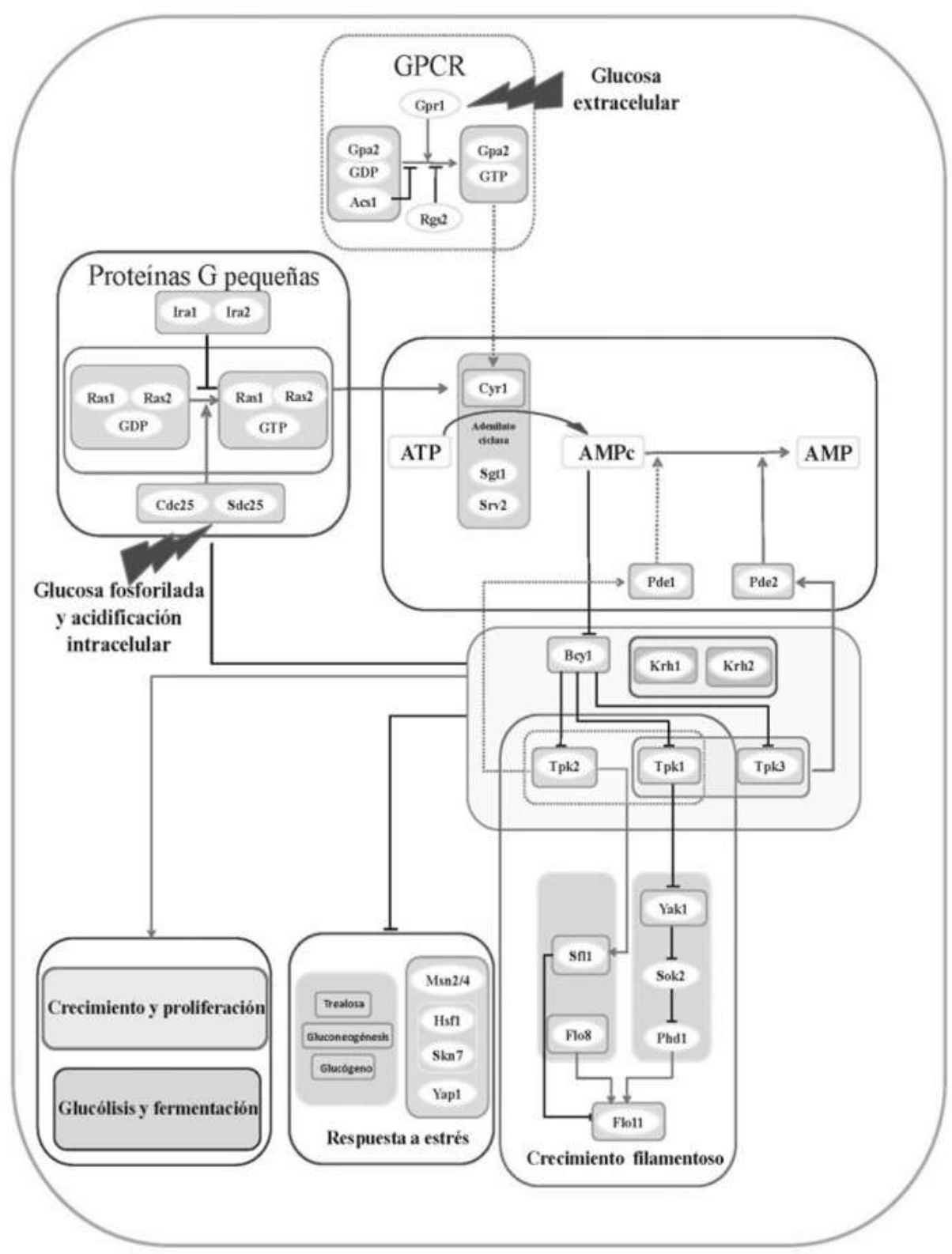

Figura 2.9 Esquema de la ruta de transducción de señales de la PKA en S. cerevisiae. Los cuadros representan a componentes de la vía que actúan de manera más íntima permitiendo apreciar claramente las interacciones entre los distintos módulos que la componen. La ubicación espacial intracelular y la dinámica temporal de las interacciones implican niveles de regulación no representados en este esquema. Las líneas discontinuas indican las relaciones que se han demostrado entre los módulos cuando se añade glucosa a un cultivo que se encuentra creciendo en fuentes de carbono no fermentables. Las líneas continuas indican las relaciones que se han demostrado entre los módulos durante GPCR un minuto después de que la célula en ayuno percibe por primera vez a la glucosa en el medio extracelular, mientras que el sistema de proteínas G pequeñas (Ras) activa y mantiene de manera sostenida la actividad de la adenilato ciclasa en respuesta al aumento en los niveles de glucosa fosforilada y a la disminución del pH intracelulares (Hahn JS et al. 2004). 


\subsection{EOX EN LA AIREACIÓN.}

Una de las variables de mayor significación en la FS es el contacto directo con el aire a través de la aireación, la que se utiliza para mantener la concentración de oxígeno imprescindible para el crecimiento del microorganismo; además, permite regular la temperatura y la humedad del sustrato dentro del reactor (Ruíz-Leza et al. 2007).

Estudios realizados en FS han demostrado que una baja aireación es más compatible con la producción de lovastatina, debido a que conserva mejor la humedad en el sistema de producción (Baños et al., 2009). Los cultivos con aireación limitada o sin aireación tuvieron los mayores rendimientos de lovastatina, a pesar de que estos cultivos presentaron menor concentración de biomasa (Baños et al., 2009). Estos niveles de lovastatina eran superiores debido a la mayor producción específica (mg de lovastatina/mg de micelio seco), quizás alentados por la mejor conservación de la humedad en cultivos con aireación limitada o nula.

Estos resultados contrastan con el efecto de la aireación en otros sistemas de cultivo, tales como FS de salvado de trigo e incluso FL, en el que la aireación elevada favorece la producción de metabolitos (Valera et al. 2005). El soporte de poliuretano (PUF) de la FS difiere de los otros sistemas FS ya que la fase líquida es más vulnerable al secado porque que el medio líquido en la estructura polimérica está en contacto directo con el flujo de aire.

En el trabajo de Baños et al., 2009, se muestra que la producción con medio con medio 2.5X, es decir medio más concentrado, resultó ser más eficiente en cuanto a la producción de lovastatina y biomasa, sin embargo este medio no se ha probado con diferente nivel de aireación, por lo que queda la incógnita si se hubiera comportado de la misma manera que los anteriores modelos o se produjera más biomasa lo que generaría más humedad y evitara que la aireación fuera desfavorable en la producción de lovastatina usando soporte de poliuretano.

Desde entonces en el grupo de trabajo la FS de lovastatina en PUF se realiza tapada para evitar la pérdida de humedad que es muy rápida en este sistema. Por lo tanto, se realiza con bajas concentraciones de $\mathrm{O}_{2}$. Entonces, es ahora importante confirmar que este perfil de acumulación de EROs en idiofase no es producto de la baja aireación, sino que es típico de este $u$ otros sistemas de FS. Aunque la parte metodológica de esto ha sido complicada por la dificultad de mantener \% de humedad comparables.

Esto implica que hay un mecanismo fisiológico para contener las EROs, es decir que asegura que los EROs se mantendrán bajos en $\mathrm{FS}$, sistema con muy alto contacto con el $\mathrm{O}_{2}$. Este mecanismo no sería a través de enzimas antioxidantes pues ya demostramos que éstas bajan en idiofase (Miranda et al. 2013). El estrés oxidante en general ejerce un impacto 
negativo en el crecimiento de hongos. Una posible explicación para muchas de estas observaciones es el compromiso de la respiración alternativa, uno de cuyas funciones putativas es disminuir la producción de EROs, pero a expensas de la generación de ATP ha debido su falta de bombeo de protones naturaleza (Li Q. et al. 2011).

Otra explicación posible es la inhibición específica de enzimas metabólicas clave por EROs. La sobreexpresión de gen sod1 de Kluyveromyces lactis (klsod1) aumentó la producción de dos diferentes proteínas heterólogas de $K$. lactis, albúmina de suero humano (HSA) y la glucoamilasa de Arxula adeninivorans (Raimondi et al. 2008). Esto se cree que es debido a la reducción del estrés oxidante causado por el daño al retículo endoplásmico durante la producción de proteína recombinante (Li Q. et al. 2011).

A la inversa, el estrés oxidante puede contribuir al aumento de producción de la enzima en determinadas circunstancias, por ejemplo, una mayor actividad lacasa extracelular se encuentra como parte de la respuesta del sistema de hongos de pudrición blanca, Trametes versicolor y Biennis abortiporus (Jaszek et al. 2006).

En el trabajo de previo de maestría realizado se determinó que la forma del perfil de acumulación de EROs en la FS de lovastatina en $A$. terreus es independiente del grado de aireación. Se encontró que en diferentes soportes cualquier tipo de fermentación sólida (en soporte inerte o en sustrato sólido), a mayor nivel de aireación hay una menor acumulación de EROs, con lo que se obtiene una menor producción de lovastatina, pero una mayor generación de biomasa (Ailed Pérez, Manuscrito en preparación).

Por eso se piensa que el mecanismo por el que la fisiología del medio sólido impide el exceso de EROs en un ambiente aun con aireación que representa una alta concentración de $\mathrm{O}_{2}$ y $\mathrm{CO}_{2}$, está regulada por la respiración alternativa, que activa diferentes $\mathrm{NADH}$ alternativas y Oxidasas alternativas que favorecen la producción de lovastatina al dirigir la fisiología al metabolismo secundario, metabolismo que está diseñado para adaptarse a condiciones no optimas o comunes como lo es la falta de oxígeno.

\subsection{PRINCIPIOS DE LA RESPIRACION ALTERNATIVA.}

El sistema de fosforilación oxidativa está formado conjuntamente por complejos I-IV y la síntesis de ATP complejo $\mathrm{V}$. Los electrones procedentes del $\mathrm{NADH}^{+} \mathrm{H}^{+}$van pasando ordenadamente a través del complejo I, la ubiquinona, el complejo III y el citocromo c para finalmente llegar al complejo IV, el cual los cede al oxígeno molecular para formar $\mathrm{H}_{2} \mathrm{O}$. De forma alternativa, los electrones del $\mathrm{FADH}_{2}$, producto final del complejo II, pasan a la ubiquinona y son canalizados sucesivamente por el complejo III, el citocromo c y el complejo IV para finalmente reducir al oxígeno molecular (Chaudhuri, Ott et al. 2006). 
Tabla 2.2 Sistemas de fosforilación oxidativa (Mitchell and Moyle 1967).

\begin{tabular}{|c|c|c|}
\hline COMPLEJO & COMPONENTES & DESCRIPCIÓN \\
\hline Complejo I & NADH Deshidrogenasa & $\begin{array}{l}\text { Esta es una enzima compleja, que contiene un } \\
\text { grupo FMN, cuya estructura es similar al FAD; Esta } \\
\text { porción de la enzima es la responsable de recibir los } \\
\text { electrones del NADH. también posee un centro } \\
\text { constituido por Hierro (Fe) y Azufre (S), que } \\
\text { participa en la transferencia de electrones hacia el } \\
\text { próximo intermediario de la cadena, la coenzima Q. }\end{array}$ \\
\hline Complejo II & $\begin{array}{l}\text { Succinato deshidrogenasa o } \\
\text { Succinato-coenzima Q reductasa }\end{array}$ & $\begin{array}{l}\text { Este complejo es responsable de la oxidación del } \\
\text { succinato en el ciclo de Krebs por medio del FAD, } \\
\text { dentro el mismo complejo la coenzima FAD } \\
\text { reducida (FADH }{ }_{2} \text { ) entrega el par de electrones al } \\
\text { centro activo Ferro-sulfurado similar al del } \\
\text { complejo I, el cual también entrega los electrones a } \\
\text { la coenzima Q. }\end{array}$ \\
\hline CoQ & Coenzima Q-10, Ubiquinona & $\begin{array}{l}\text { Es una coenzima Liposoluble, que contiene un anillo } \\
\text { cíclico de seis miembros }\end{array}$ \\
\hline Complejo III & $\begin{array}{c}\text { Citocromo } \mathrm{C}- \\
\text { coenzima } \mathrm{Q} \text { oxidorreductasa }\end{array}$ & $\begin{array}{l}\text { Este es un sistema multienzimático cuyos centros } \\
\text { activos se conocen como: Citocromo b, citocromo } \\
\text { c1 y la proteína de Rieske que contiene un grupo Fe- } \\
\text { S. La función de este complejo es la de catalizar el } \\
\text { paso de dos electrones desde el ubiquinol (forma } \\
\text { reducida de la ubiquinona) hasta el citocromo c. El } \\
\text { complejo III Ileva acoplado el bombeo de cuatro } \\
\text { protones al espacio intermembrana mediante un } \\
\text { proceso cíclico denominado ciclo Q, donde el } \\
\text { citocromo b tiene un papel fundamental. }\end{array}$ \\
\hline Complejo IV & Citocromo Oxidasa & $\begin{array}{l}\text { El complejo IV o citocromo } \mathrm{C} \text { oxidasa es el último de } \\
\text { los complejos de la mtCTE y su función es la de } \\
\text { catalizar la oxidación del citocromo c con la } \\
\text { consiguiente reducción del } \mathrm{O}_{2} \text { a } \mathrm{H}_{2} \mathrm{O} \text {. El complejo es } \\
\text { sólo funcional cuando está en forma de dímero. } \\
\text { Este proceso lleva acoplado el bombeo de dos } \\
\text { protones desde la matriz mitocondrial al espacio } \\
\text { intermembrana por cada molécula de } \mathrm{H}_{2} \mathrm{O} \text { formada. }\end{array}$ \\
\hline Complejo V & ATPsintasa & $\begin{array}{l}\text { Esta enzima es la responsable de la síntesis directa } \\
\text { del ATP. La membrana interna de la mitocondria } \\
\text { posee millones de estas enzimas que se pueden } \\
\text { apreciar como pequeñas esferas que sobresalen } \\
\text { desde su pared interna. }\end{array}$ \\
\hline
\end{tabular}




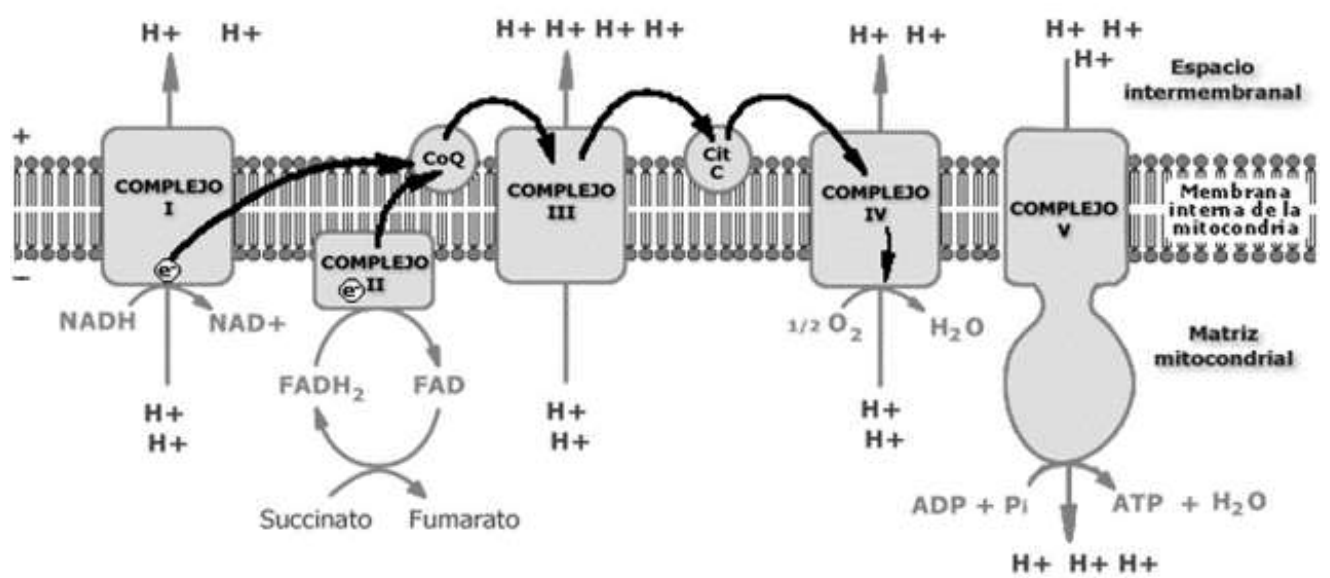

Figura 2.10 Sistema de fosforilación oxidativa (Chaudhuri, Ott et al. 2006).

Los complejos I, III y IV, son los puntos de la cadena respiratoria en los que se produce un bombeo de protones desde la matriz mitocondrial hasta el espacio intermembrana. Dicho bombeo de protones genera un potencial de membrana o gradiente electroquímico (de pH o electrogénico) que es aprovechado por el complejo $\mathrm{V}$ para la síntesis de ATP a partir de ADP y Pi, y así completar el proceso de la fosforilación oxidativa. El ATP que se obtiene a través de este proceso, es utilizado en los distintos tejidos para mantener las necesidades energéticas celulares (Chaudhuri, Ott et al. 2006)

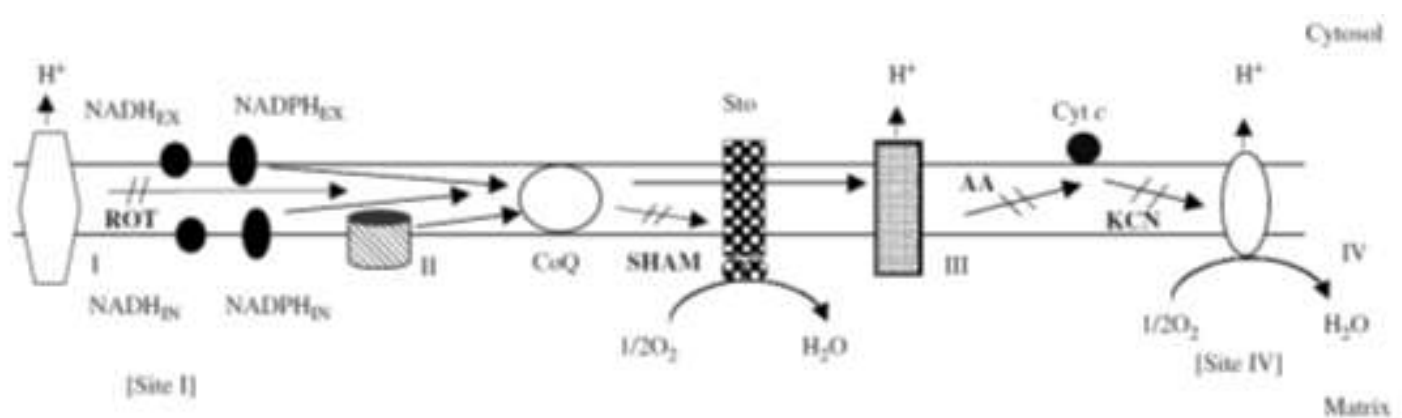

Figura 2.11 Un diagrama de componentes alternativos y estándar redox presentes en el sitio de la acción de SHAM, antimicina A (AA), rotenona (ROT) y KCN están marcados. El complejo I NADH deshidrogenasarotenona sensible; Complejo III oxidasa terminal SHAM sensible (Nian-Qing et al., 2002)

Al contrario que los mamíferos, las plantas y algunos eucariotas inferiores como protozoos y hongos contienen otras enzimas redox mitocondriales que proporcionan vías alternativas al flujo de electrones. Estas incluyen, por ejemplo, las NADH deshidrogenasas alternativas (NADH-DH), capaces de catalizar la oxidación del NADH de la matriz mitocondrial o del NADH citosólico directamente, y las oxidasas alternativas (AOX) capaces de aceptar los electrones desde el ubiquinol y cedérselos al oxígeno. Estas enzimas alternativas no bombean protones al espacio intermembrana mitocondrial, pero su organización dentro de la cadena hace posible la transferencia de los electrones desde el $\mathrm{NADH}$ hasta el $\mathrm{O}_{2}$ acoplada a la transferencia de protones, al menos por un complejo (Cristina Blan, 2012). 


\section{AOX: Oxidasa Alternativa}

El cianuro es capaz de inhibir la respiración de mamíferos, ya que actúa bloqueando el transporte de electrones desde el citocromo $\mathrm{C}$ hasta el $\mathrm{O}_{2}$, actuando a nivel del complejo IV. Muchos microorganismos y plantas sintetizan gran variedad de compuestos cianogénicos para su defensa, de igual forma que muchos depredadores han evolucionado para resistir a este mecanismo de defensa. Muchos parásitos también son capaces de sobrevivir en sus huéspedes pese a la producción de otros inhibidores del complejo IV por parte de estos, como por ejemplo el óxido nítrico (NO) (Chaudhuri, Ott et al. 2006).

Dicha resistencia al cianuro se basa en la existencia de una "oxidasa alternativa" (AOX), proteína que siempre se localiza anclada a la membrana interna mitocondrial y posee un doble núcleo de Fe que actúa como centro catalítico de la enzima (Juárez O et al. 2006). La función de AOX es transportar los electrones desde el ubiquinol hasta el $\mathrm{O}_{2}$, permitiendo saltar desde el complejo I hasta el aceptor final de electrones sin pasar por la parte de la mtCTE dependiente de citocromos (complejos III y IV) (Joseph-Horne et al., 2000).

En plantas AOX es un homodímero, mientras que en hongos y animales parece ser un monómero. En las plantas, AOX parece tener un papel protector frente al estrés oxidante, ya que reduce la acumulación de ubiquinol que favorece la formación de radicales libres. La proteína AOX también es capaz de orientar la respiración hacia una menor generación de energía, pues al sortear los dos pasos dependientes de citocromo también se evitan dos translocaciones de protones que contribuyen a la generación del gradiente electroquímico (McDonald 2009a).

Debido a la incapacidad de AOX de bombear protones al espacio intermembrana, la energía que se produce en la transferencia de electrones se disipa en forma de calor y esta característica le permite realizar una de sus funciones principales en plantas, la regulación de la termogénesis (McDonald 2009b).

\section{NADH deshidrogenasas}

En la mayoría de los animales Complejo I proporciona el único mecanismo para la entrada de los electrones de NADH en la cadena respiratoria. Como consecuencia, la oxidación de NADH está totalmente inhibida por rotenona y piericidin. En plantas, hongos y bacterias están las enzimas NADH deshidrogenasas, también llamadas NADH-quinona oxidorreductasas, tienen como función catalizar la transferencia de electrones desde el $\mathrm{NADH}$ a la quinona, y en algunos casos, llevan acoplado el bombeo de protones y/o $\mathrm{Na}^{+}$a través de las membranas (Joseph-Horne et al., 2000). 
Se pueden clasificar en tres grupos diferentes: las NADH deshidrogenasas capaces de translocar $\mathrm{H}^{+}$(complejo I mitocondrial o la enzima bacteriana $\mathrm{NDH}_{1}$ ); las $\mathrm{NADH}$ deshidrogenasas que no pueden translocar iones ( $\mathrm{NDH} 2$ ) en hongos y plantas y las $\mathrm{NDH}_{3}$ deshidrogenasas capaces de translocar $\mathrm{Na}^{+}$en bacterias. Las $\mathrm{NDH}_{2}$ se han identificado en el genoma de arqueas, bacterias, hongos y mitocondrias de plantas, pero no en las de mamíferos (Mitchell and Moyle 1967).

Los hongos y las plantas superiores se diferencian de otros eucariotas, ya que poseen en las cadenas de transporte de electrones (ETC) componentes alternativos en adición al sistema respiratorio estándar (Joseph-Horne et al., 2001). Existe una oxidasa alternativa terminal que es sensible al ácido salicilhidroxámico (SHAM) está presente además de la citocromo c oxidasa estándar (Cox). Esta oxidasa terminal sensible al SHAM (Sto) se ha encontrado en levaduras, Hongos y plantas mayores. Aunque el sistema de la respiración-SHAM sensible (STO) fue descubierto por primera vez hace 70 años, sus componentes funcionales y las funciones fisiológicas en levaduras y hongos siguen sin estar claros (McDonald, 2009a).

Desde este punto, los electrones son directamente donados a Sto, que a su vez reduce el oxígeno molecular a agua. Sto no está acoplado a la síntesis de ATP, por lo que esta ruta alternativa no pasa por al menos dos de los tres sitios generadoras de ATP (Joseph-Horne et al., 2001).

Las proteínas Sto de hongos muestran diferencias significativas en la estructura y la regulación de sus homólogos de la planta. Sto proteínas vegetales tienen centros de dihierro en sus sitios activos. Esto les separa completamente de las oxidasas terminales alternativos bacterianos, que utilizan un grupo hemo en sus sitios activos (Joseph-Horne et al., 2001).

A nivel transcripcional, a diferencia de la presencia constante de bajo nivel de transcritos de STO en las plantas, transcripciones Sto en hongos sólo se acumulan cuando se suprime el sistema de la vía del citocromo CYT. Por lo tanto, las proteínas Sto hongos están presentes normalmente en un estado reducida (activo) mientras que las proteínas vegetales Sto necesitan ser activados desde un estado oxidado (menos activos) a su estado reducido (activo) (Umbach y Siedow, 1996).

Además, las proteínas fúngicas Sto carecen de ciertos aminoácidos conservados que están implicados en la mediación del proceso de activación. Estas observaciones implican que las proteínas Sto fúngicas pueden desempeñar otras funciones fisiológicas importantes. (Umbach y Siedow, 1996). 
Expresión de genes AOX es constitutiva en Magnaporthe grisea, Neurospora crassa y A. niger, los genes AOX se transcribe constitutivamente a un bajo nivel basal incluso aunque la actividad de la proteína y la enzima no eran detectables. La observación de que no es inducida en cultivos de tipo salvaje en ocasiones contenía cantidades similares de aod-1 mRNA para cultivos inducidos, pero no reveló AOX detectable en las mitocondrias de $N$. crassa sugerido control de la traducción es también es indispensable para la regulación de la expresión génica (Tanton et al. 2003).

En contraste con las plantas, el AOX por hongos no es estimulado por el piruvato, pero por nucleótido de purina monofosfato y difosfato como AMP, ADP, húmedo y GMP. La evidencia de esto ha sido encontrado en una amplia gama de levaduras y hongos, tales como P. stipitis, N. crassa, U. ayclis, U. maydis, Tapesia acuformis y en las levaduras Hansenula anomala y Yarrowia lipolytica (Medentsev et al. 2004).

AOX se activa en presencia de inhibidores de la respiración del citocromo Numerosos estudios han demostrado que la AOX se activa cuando antimicina (un inhibidor de Complejo III de la cadena respiratoria principal), se añade a cultivos de hongos. Esta propiedad indica que se desborda de AOX cuando los electrones de la cadena respiratoria citocromo se inhibe o saturados.

En el patógeno hongo, U. maydis, AOX se cree que aumenta la flexibilidad metabólica de la célula, una función que podría ser valiosa para un organismo expuesto a las variaciones de la temperatura, fuente de nutrientes y factores de disponibilidad, y bióticos o abióticos que limitan la actividad de la vía del citocromo (Medentsev et al. 2004).

\subsubsection{RESPIRACIÓN ALTERNATIVA vs EOX.}

Los procesos que utilizan hongos son altamente aeróbicos en la naturaleza es decir el estrés oxidante es la consecuencia inevitable de un estilo de vida aeróbica, y por lo tanto se requiere un suficiente suministro de $\mathrm{O}_{2}$, así como el mantenimiento y velocidad de transferencia de $\mathrm{O}_{2}$ en el reactor es siempre un reto durante los procesos de producción, y especialmente en los procesos que implican una alta densidad celular.

Como solución, el uso de aire enriquecido de $\mathrm{O}_{2}$ se aplica con frecuencia en muchos procesos industriales de hongos (Bai et al. 2003a). Sin embargo, $\mathrm{O}_{2}$ puede ser una espada de doble filo para células microbianas dentro de reactores, debida principalmente a la generación de EROs, que es de particular importancia para el cultivo de hongos industriales.

El estrés oxidante puede ser provocado por la adición de factores de estrés químicas exógenas (simulada) o por condiciones altamente aeróbicas dentro de un sistema fermentador, por ejemplo, por un enriquecimiento de oxígeno de la en fase gaseosa. 
El estrés oxidante en general ejerce un impacto negativo en el crecimiento de hongos. Una posible explicación para muchas de estas observaciones es el compromiso de la respiración alternativa, uno de cuyas funciones putativas es disminuir la producción de EROs, pero a expensas de la generación de ATP, debido a su falta de bombeo de protones (Wongwicharn et al, 1999).

El estrés oxidante, provocado por un exceso de oxigenación para biorreactores, afecta negativamente a la producción de la proteína recombinante de A. niger (Bai et al 2004). Por lo tanto, la mitigación de daño oxidante en última instancia podría aumentar la producción de proteína por hongos. El estrés oxidante puede contribuir a la producción de enzimas como fue el caso donde se encontró que, en determinadas circunstancias, se producía una mayor actividad lacasa extracelular que se encuentra como parte de la respuesta del sistema de hongos de pudrición blanca, Trametes versicolor y Abortiporus biennis, usando paraquac para inducir condiciones de estrés oxidante (Jaszek et al. 2006).

En general se acepta que las mitocondrias son el sitio para la generación de EROs en los hongos debido a elección de fuga durante el proceso de respiración aeróbica (Li et al. 2009). Uno de los putativo funciones de las vías respiratorias por hongos alternativos puede ser para disminuir la generación de EROs debido a la naturaleza no bombeo de protones de muchos de los componentes de esta vía.

En M. grisea, por ejemplo, las EROs se cree que son mediadores de señal para activar la transcripción del gen AOX (Yukioka et al. 1998), y el anión superóxido está implicado en la inducción de cianuro resistente-respiración (CRR) en la levadura $H$. anomala (Minagawa et al. 1992). Los efectos de dos generadores de EROs agentes, el paraquat y el $\mathrm{H}_{2} \mathrm{O}_{2}$ se investigado en 12 especies de hongos, los resultados de lo que indica la exposición de las esporas de hongos o micelios a ambos agentes estimulado CRR (Angelova et al. 2005).

En A. fumigatus, la actividad AOX y la expresión de ARNm fueron tanto inducida con menadiona o paraquat, lo que sugiere un importante papel de AOX bajo condiciones de estrés oxidante (Magnani et al. 2007). Se ha mostrado que el estrés oxidante en cultivos discontinuos de $A$. niger causado por la sobre-oxigenación dio lugar a una disminución general del contenido de ATP en las células (Li et al. 2008b) lo que corrobora el compromiso de respiración alternativa en tales condiciones propuestas por Bai et al. (2003b).

Además de la oxidasa alternativa (AOX), muchos hongos filamentosos contienen una NADH alternativa: enzimas ubiquinona oxidorreductasa (NADH deshidrogenasa). Estas enzimas NADH alternativa deshidrogenasas no contienen sitios característicos Fe-S racimos y son insensibles a rotenona o amital. Del mismo modo, las alternativas NADH deshidrogenasas no contiene FMN, si no tienen incorporando flavina adenina dinucleótido (FAD) como su única prótesis grupo (Videira \& Duarte 2002). 
Como resultado de la naturaleza del no bombeo de protones de estas enzimas alternativas, los hongos deben evitar el emparejamiento de NADH deshidrogenasas alternativas con la oxidasa alternativa, ya que esto haría resultado en la disolución completa del gradiente de protones necesaria para la síntesis de ATP (Joseph-Horne et al. 2001).

Por lo tanto, NADH alternativas deshidrogenasas debe estar utilizado sinérgicamente con Complejo III y IV, mientras que AOX sólo debe estar utilizado junto con el Complejo I, para que la célula pueda mantener la síntesis de ATP suficiente para impulsar todos los procesos celulares (Joseph-Horne et al. 2001).

Experimentando en condiciones de estrés por oxidación, por ejemplo, de enriquecimiento de $\mathrm{O}_{2}$, sería de esperar que los niveles de EROs aumentaran debido a un aumento de la frecuencia de la respiración. Sin embargo, describieron una disminución de EROs en cultivos de $A$. niger y se propuso que esto puede ser debido a una mayor actividad de una enzima deshidrogenasa NADH alternativa, lo que podría actuar en lugar del Complejo I (Bai et al. 2003b).

Bajo condiciones oxidativamente desafiantes, los hongos filamentosos pueden manipular el transporte de electrones para favorecer el flujo a través de la vía respiratoria alternativa, reduciendo así la generación de EROs, una teoría que, asimismo, se ha propuesto para otros organismos (Li \& Trush 1998; Guerrero-Castillo et al 2009).

Seo et al. (2006) demostraron que la transducción de células de neuroblastoma humano con el gen que codifica la deshidrogenasa de $\mathrm{NADH}$ alternativa interna de $S$. cerevisiae redujo significativamente la generación de radicales superóxido dentro de la célula. A pesar de las propiedades protectoras de $\mathrm{NADH}$ deshidrogenasas alternativas contra el estrés oxidante, investigación más a fondo en $A$. niger ha demostrado que cuando estas enzimas se han mejorado en sus actividades, las concentraciones intracelulares de ATP y la viabilidad celular se redujo (O'Donnell et al. 2007).

Otros investigadores han afirmado también estas alternativas Enzimas NADH deshidrogenasa en realidad aumentar la producción de EROs. La inhibición de la NADH deshidrogenasas alternativas en la levadura (S. cerevisiae) dirigido a una disminución de la producción de EROs en el cultivo. La aparente contradicción bien podría ser debido a las diferentes respuestas de levaduras y hongos filamentosos con el estrés oxidante. (Li et al., 2009). 


\section{JUSTIFICACIÓN}

La fermentación en estado sólido presenta ventajas muy importantes con respecto a la fermentación tradicional en líquido, la más destacada son las mayores producciones que presenta de enzimas y metabolitos secundarios. Aunque la principal desventaja que presenta la fermentación sólida es que se conoce muy poco de la fisiología de este medio.

Es necesario comprender que estímulos son los que propician las sobreproducciones, para así poder aplicarlas y desarrollar sistemas de fermentación que aprovechen las particularidades de la fermentación sólida. Además de diferentes aplicaciones en otros campos, ya que los sistemas modernos en sólido tienen un récord de aplicaciones exitosas para la producción de enzimas microbianas y metabolitos secundarios.

La información que pueda obtenerse, además del aporte científico, servirá para poder diseñar mejores, más eficientes, novedosos y oportunos sistemas de producción de lovastatina y otros metabolitos secundarios.

Sin embargo, ha sido tan poco estudiado este sistema de fermentación que hay muy poca información de los estímulos que inducen una fisiología diferente, es decir la fisiología del medio sólido, la cual se manifiesta a menudo en una mayor producción del metabolito secundario y enzimas.

En el 2013, Miranda et al., al estudiar la señalización de la fisiología del medio sólido, se encontró un vínculo de las EROs con el metabolismo secundario, en 2014 demostraron que las EROs regulaban a nivel transcripcional la biosíntesis de lovastatina. Además, se sabe que la acumulación de EROs inicia al iniciar la idiofase; y que en FS hay una menor acumulación de EROs, aunque en concentraciones muy estables con respecto a la $\mathrm{FL}$, lo cual al parecer está relacionado con la mayor producción de lovastatina.

Dentro de los avances más importantes es que las EROs se pueden inhibir al usar antioxidantes, e incluso inducir por el uso de oxidantes como peróxido de hidrogeno; esto es de gran importancia para poder desarrollas sistemas para el estudio de las EROs, además del interés industrial para poder aplicar y determinar el funcionamiento de este estímulo de la FS en la FL.

Por el transcendental papel de las EROs en la producción de lovastatina, se volvió imprescindible saber el papel que juegan las EROs en la fisiología de los organismos como segundos mensajeros en las vías de transducción de señales, el presente proyecto estudio el rol que las EROs juegan en la biosíntesis de lovastatina. Para ello se realizó un análisis y manipulación de las EROs, además se realizó el uso de la cepa con el silenciamiento de yap1 en Aspergillus terreus para poder analizar el papel de las EROs en el metabolismo secundario. 
Parte importarte de comprender la fisiología del medio sólido es analizar los parámetros que controlan este tipo de fermentación, uno de los principales es la aireación. Se encontró que en la FS de lovastatina, a mayor aireación hay una menor acumulación de EROs y que esto provocó una menor producción de lovastatina (Ailed Pérez, Manuscrito en preparación).

Sin embargo, no se sabe por qué sin aireación, donde hay un menor contacto con el $\mathrm{O}_{2}$, la acumulación de EROs es mayor; y con mayor aireación, es lo contrario, es decir, los niveles de EROs son menores; entonces surgieron las siguientes preguntas, ¿qué relación tiene el contacto del aire con la formación de EROs?, ¿cómo influye éste en la producción de metabolitos secundarios en hongos?, ¿cómo se regulan estas EROs? y ¿cómo están señalizando las EROs la biosíntesis de lovastatina?. Sin duda, lograr resolver estas preguntas sería de gran importancia básica, además de un aporte para el diseño, innovación y el mejoramiento en la productividad y eficiencia de sistemas de FL y FS.

Con estos resultados se alcanzará una visión más amplia, integrada y profunda de la fisiología del medio sólido. Este conocimiento aclarará e integrará el nexo entre los estímulos del medio sólido con los cambios fisiológicos y genéticos que llevan a la fisiología del medio sólido, y por ende a una mayor producción de lovastatina.

Muy probablemente estos principios regirán también la producción de otros metabolitos secundarios por este y otros sistemas de fermentación sólida. Aunque es más complicado trabajar con microorganismos productores de uso industrial y no organismos modelo, así como directamente en sistemas de producción real, la gran ventaja es que todo el conocimiento es exacto sobre este binomio y los descubrimientos son rápida y directamente aplicables.

Así, estos conocimientos podrán aplicarse rápidamente al diseño de sistemas novedosos más efectivos de metabolitos secundarios. También se podrá desarrollar nuevas estrategias de mejoramiento genético para elaborar cepas más resistentes, rápidas, eficientes y sobreproductoras. 


\section{HIPÓTESIS}

- La lovastatina no es un antioxidante, por lo que no forma parte del mecanismo general de respuesta a estrés oxidante.

- Las EROs en la idiofase, están compuestas principalmente por $\mathrm{H}_{2} \mathrm{O}_{2}$ y $\mathrm{O}^{-}$, provienen de la mitocondria, NOX y Xantina oxidasa, estas actúan como señalizadores de la biosíntesis de lovastatina a lo largo de la toda la Idiofase; la actividad de Sod y Cat, estarán contendiendo las EROs en la trofofase, pero bajarán en la idiofase.

- El mecanismo por el que la fisiología del medio sólido impide el exceso de EROs, a pesar de que haya una gran cantidad de $\mathrm{O}_{2}$ disponible, es la respiración alternativa.

- El silenciamiento del gen Atyap1 provoca un aumento en la producción de EROs y debido a esto se debe la sobreproducción y adelanto de la biosíntesis de lovastatina; el adelanto de las EROs provoca la disminución de los niveles de AMPc y con ello la activación del metabolismo secundario. 


\section{OBJETIVOS}

\section{OBJETIVO GENERAL}

- Estudio de la producción y la regulación de las EROs sobre la biosíntesis de lovastatina por Aspergillus terreus.

\section{OBJETIVOS PARTICULARES}

- Demostrar que la lovastatina no es antioxidante y por lo tanto no forma parte de las defensas antioxidantes en la célula.

- Determinar el grado de importancia en la idiofase de las EROs en la señalización en la producción de lovastatina.

- Determinar cuáles son las moléculas señalizadora (EROs), la actividad de enzimas antioxidantes y la fuente de generación a través en trofofase e idiofase para FS y FL durante la biosíntesis de lovastatina.

- Establecer el papel que juega la respiración alternativa tanto en FS y FL, así como estudiar su papel en el control de la acumulación de EROs y la producción de lovastatina.

- Determinar el efecto del silenciamiento de atyap1 al normalizar los niveles de EROs (con antioxidante exógeno), evaluando el efecto en la producción de lovastatina.

- Estudiar el efecto del adelanto de las EROs en $\triangle a t y a p 1$ en la ruta de señalización vía PKA-cAMP durante la producción de lovastatina en Aspergillus terreus. 


\section{MATERIALES Y MÉTODOS.}

\subsection{EQUIPOS EMPLEADOS.}

- Balanza analítica OHAUS Explorer.

- Cámaras de electroforesis Electrophoretic Gel System E-C Minicell.

- Centrifuga 5415, Eppendorf.

- DTX 880 Multimode Detector (Beckman-Coulter, Inc, Brea, CA, USA)

- Sistema de oxıgeno 782 Warner-Strathkelvin Istruments

- Espectrofotometro UV-1201 Shimadzu.

- Eppendorf Biophotometer.

- Gel DOC 2000 BIO-RAD.

- Incubadora Environ-Shaker 3597.

- Horno de microondas SANYO.

- Microscopio Olympus CH30.

- Potenciómetro Orion mod.525 A.

- Termociclador Mastercycle Personal, Eppendorf.

- Transiluminador de luz UV, BIORAD.

- Ultracentrifuga AVANTI 30 BECKMAN.

- Ultracongelador $-20^{\circ} \mathrm{C}$ Revco.

- Ultracongelador $-70^{\circ} \mathrm{C}$ Forma Scientific.

\subsection{MICROORGANISMOS.}

\subsubsection{Aspergillus terreus TUB-F514.}

La cepa TUB F-514 de Aspergillus terreus utilizada para la producción de lovastatina fue aislada previamente del suelo en el desierto de Irak, por el Dr. György Szakács y pertenece a la colección de la Technical University of Budapest, Hungría. Esta cepa fue la mejor productora de lovastatina en FL. Esta cepa es considerada de alta producción (Szakács et al. 1998).

\subsubsection{Atyap1, cepa silenciada de yap1.}

La Atyap1 es una transformante que proviene de la cepa TUB F-514 de Aspergillus terreus, la cual se obtuvo del silenciamiento del gen yap1 por RNAi. El silenciamiento se llevó a cabo utilizando el vector pGdpPki-RNAi que contenía un sistema de interferencia por RNAi.Yap1p es un factor de respuesta antioxidante del tipo bzip, que parece ser regulado a nivel de localización nuclear y fosforilación (Ailed Pérez, Manuscrito en preparación). 


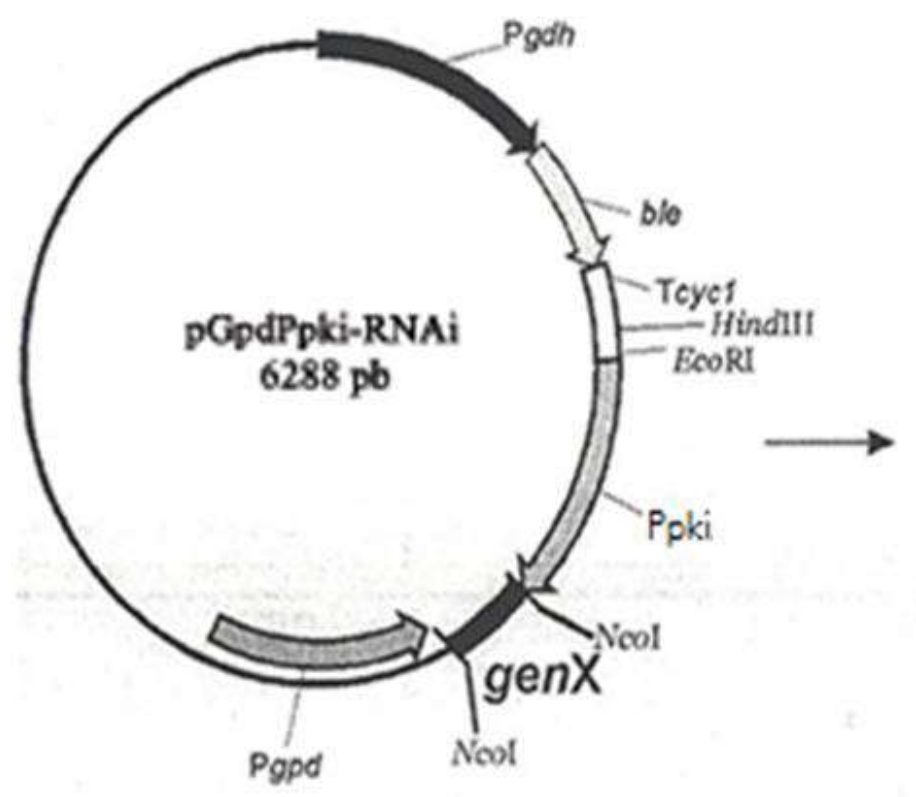

\section{${ }_{+\mathrm{X} \text { mRNA }}^{2+m}$}

3

-X MRNA

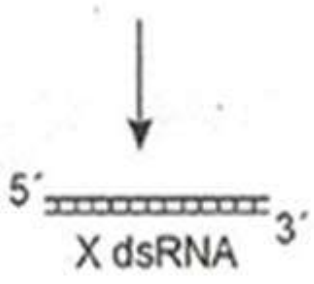

Figura 6.1 Vector pGdpPki-RNAi empleado para silenciar yap1 de A. terreus (Marcial et al. 2011).

La interferencia por RNA es una nueva y poderosa herramienta molecular para silenciar genes a nivel post-transcripcional, es utilizada como herramienta para reducir o bloquear la expresión de genes para la búsqueda de las funciones asociadas a estos. La interferencia por RNA proporciona una estrategia fácil y rápida para degradar los RNA mensajeros mediante la introducción de un RNA pequeño de doble cadena homólogo (siRNA) al RNA mensajero celular de interés.

La interferencia por RNA con la cual se puede reducir (knock-donw) o perder (knock-out) la expresión de un gen, se logra, mediante la introducción a nivel celular de un ARN de doble cadena pequeño (siRNA), el cual es reconocido a nivel celular por una maquinaria que media la degradación o supresión específica de los mRNA(s) que contiene la secuencia complementaria al siRNA formado, produciéndose principalmente una degradación del mRNA citoplasmático y una disminución de la traducción del mensaje.

La interferencia por RNA, es mediada por RNAs de doble cadena (siRNA), estos se pueden producir intracelularmente a través de pequeñas horquillas que son transcritas por una RNA polimerasa III a partir de un sistema de expresión plasmídico que son transformados a siRNA por DICER, y los siRNA producidos activan a RISC, un complejo multienzimático capaz de remover la hebra pasajera y dejar al complejo RISC activo con la hebra antisentido, listo para producir silenciamiento específico del RNA mensajero de secuencia complementaria al siRNA, produciendo la degradación específica del mRNA, por la enzima Ago2 capaz de degradar esta hibridación de la hebra pasajera y el RNA mensajero (Ullán, R.V. et al., 2008). 


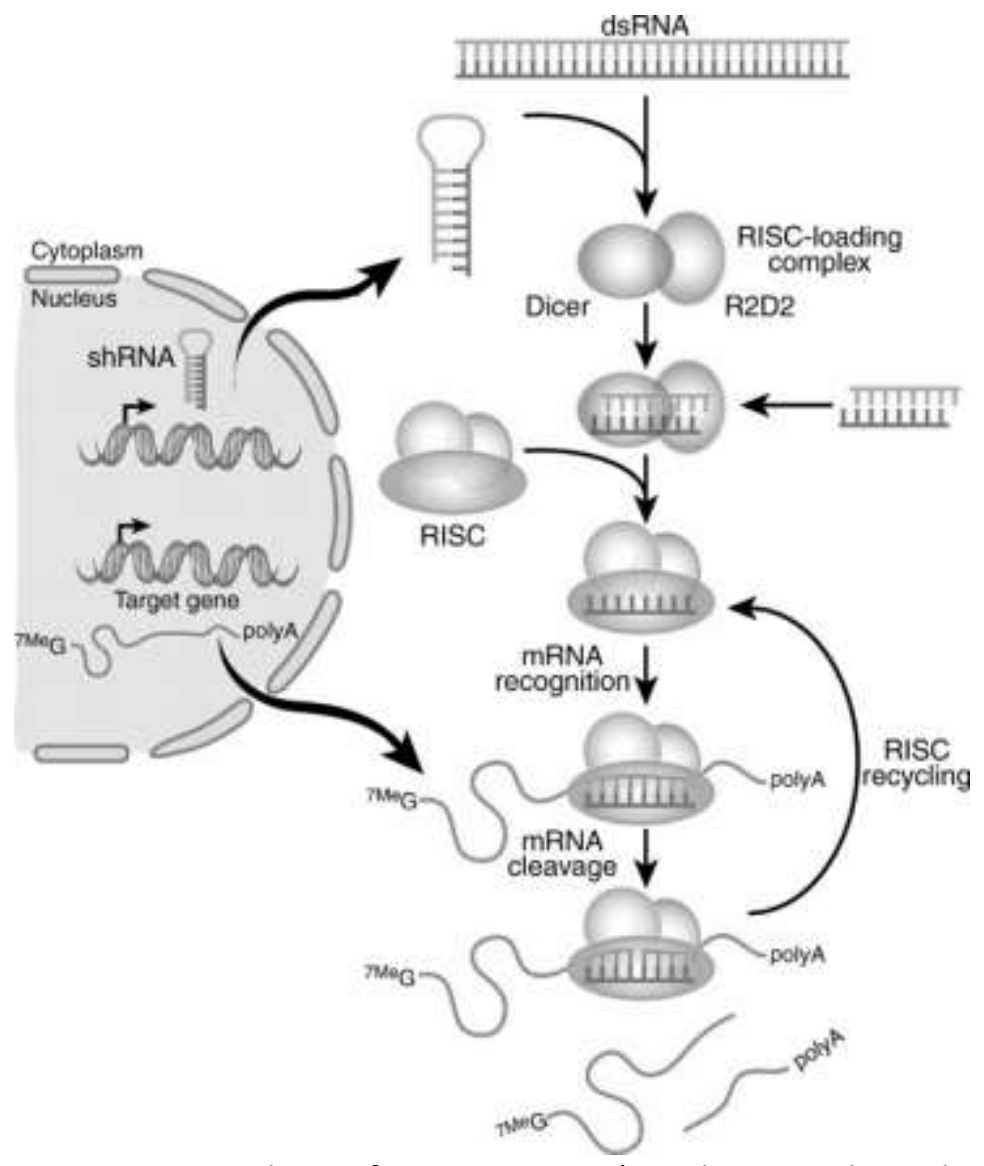

Figura 6.2 Mecanismo de interferencia por RNA (Monika Dominska et al. 2010)

\subsection{MEDIOS DE CULTIVO.}

Medios de cultivo para Aspergillus terreus.

\section{Medio PMI.}

$\begin{array}{ll} & \mathrm{g} / \mathrm{L} \\ \text { Balto peptona } & 5.0 \\ \text { Lactosa } & 5.0 \\ \mathrm{NaCl} & 4.0 \\ \text { Sólidos de maceración } & 1.0 \\ \mathrm{~K}_{2} \mathrm{HPO}_{4} & 0.060 \\ \mathrm{MgSO}_{4} \cdot 7 \mathrm{H}_{2} \mathrm{O} & 0.050 \\ \mathrm{FeCl}_{3} \cdot 6 \mathrm{H}_{2} \mathrm{O} & 0.003 \\ \mathrm{CuSO}_{4} \cdot 5 \mathrm{H}_{2} \mathrm{O} & 0.001\end{array}$

Medio de esporulación y mantenimiento (Aguirre et al. 2005). 
Medio CZAPEK.

$\begin{array}{ll} & \mathrm{g} / \mathrm{L} \\ \text { Sacarosa } & 30.0 \\ \mathrm{NaNO}_{3} & 2.0 \\ \mathrm{~K}_{2} \mathrm{HPO}_{4} & 0.5 \\ \mathrm{MgSO}_{4} \cdot 7 \mathrm{H}_{2} \mathrm{O} & 0.5 \\ \mathrm{FeSO}_{4} \cdot 7 \mathrm{H}_{2} \mathrm{O} & 0.01\end{array}$

De esporulación y mantenimiento (Aguirre et al. 2005).

Medio Power.

Medio PMI $\quad 50 \%$

Medio CZAPEK $\quad 50 \%$

Agar $2 \%$

De esporulación y mantenimiento (Aguirre et al. 2005).

Medio Completo.

SS20X $\quad 5 \mathrm{~mL}$

SET $\quad 100 \mu \mathrm{L}$

Glucosa $1 \mathrm{~g}$

Peptona $1 \mathrm{~g}$

Extracto de Levadura $0.05 \mathrm{~g}$

Se llevó a $100 \mathrm{~mL}$ de volumen y se ajustó el pH a 6.5 con $\mathrm{KOH}$ al 10\%.

Medio para obtención de micelio. En un matraz erlenmeyer de $125 \mathrm{~mL}$, se colocaron $35 \mathrm{~mL}$ de medio completo, se esterilizo $15 \mathrm{~min}$ a $120^{\circ} \mathrm{C}$. Se inoculo con una asada de esporas y se incubo a $30^{\circ} \mathrm{C}$ durante $18 \mathrm{~h}$ (Aguirre et al. 2005).

\section{Medio Papa Agar Dextrosa PDA (BD Bioxon®).}

Es un medio común de cultivo microbiológico, está hecho a partir de infusión de patata y dextrosa. Se utiliza como medio de esporulación y conservación. Se prepara a $39 \mathrm{~g} / \mathrm{L}$ y se esteriliza a $15 \mathrm{~min}$ a $120^{\circ} \mathrm{C}$. Se utilizó para la preparación en cajas de Petri con $40 \mathrm{ml} / \mathrm{caja}$. 


\section{Medio de producción de lovastatina.}

La cepa Aspergillus terreus TUB F-514, fue crecida sobre medio Power durante 4 días a $30^{\circ} \mathrm{C}$ para esporulación. Las esporas fueron colectadas con una solución de tween80 al $0.02 \%$ y usadas para inocular en condiciones estériles las fermentaciones de lovastatina $2 \times 10^{6}$ esporas/ml.

\begin{tabular}{ll}
$1 \mathrm{X}$ & $\%$ \\
Glucosa & 0.6 \\
Lactosa & 3.4 \\
Harina de soya & 0.3 \\
$\mathrm{KNO}_{3}$ & 0.2 \\
$\mathrm{KH}_{2} \mathrm{PO}_{4}$ & 0.3 \\
$\mathrm{NaCl}_{\mathrm{MgSO}} 7 \mathrm{H}_{2} \mathrm{O}$ & 0.05 \\
Elementos traza & 0.05 \\
\hline
\end{tabular}

pH 6.5 se ajusta con $\mathrm{NaOH} 0.1 \mathrm{M}$, este medio se utiliza en dos concentraciones $1 \mathrm{X}(\mathrm{FL})$ y 2.5X (FS) (Baños et al., 2005).

Solución de elementos traza para la producción de lovastatina.

$\begin{array}{ll}\text { Elemento } & \mathrm{g} / \mathrm{L} \\ \mathrm{MnSO}_{4} & 1.6 \\ \mathrm{ZnSO}_{4} 7 \mathrm{H}_{2} \mathrm{O} & 3.4 \\ \mathrm{CaCl}_{2} 6 \mathrm{H}_{2} \mathrm{O} & 2 \\ \mathrm{FeSO}_{4} 7 \mathrm{H}_{2} \mathrm{O} & 5\end{array}$

Se fueron adicionando los sólidos en orden, disolviendo cada uno completamente antes del siguiente. Se calentó a ebullición, se dejó enfriar y se ajustó el volumen el volumen (Baños et al. 2005).

\subsection{FERMENTACIONES}

\section{Fermentación liquida.}

En Matraz de $250 \mathrm{~mL}$ con gorro de algodón, el volumen utilizado fue de $50 \mathrm{~mL}$ de medio de cultivo de producción de $1 \mathrm{X}$, se incuban a $30^{\circ} \mathrm{C}$ con una agitación de $250 \mathrm{rpm}$. Se inocula con la concentración de $2 \times 10^{6} \mathrm{esp} / \mathrm{ml}$. Para todos los tipos de fermentación, cada punto de muestreo se realizó por triplicado (Baños et al. 2005). 


\section{Fermentación Solida.}

\section{Matraz.}

Se utilizó una concentración de 2.5 veces del medio de producción de lovastatina (2.5X). El soporte utilizado fue poliuretano (PUF) en cubos de $1 \mathrm{~cm}^{3}, 0.21 \mathrm{~g}$ de soporte por matraz Erlenmeyer de $250 \mathrm{~mL}$, estos fueron impregnados con $6 \mathrm{~mL}$ del medio inoculado (humedad del $85 \%$ ), los cuales fueron cubiertos con papel aluminio y parafilm (Pechiney Plastic Pacaging, Menasha, Wi, USA), fueron incubadas a $30^{\circ} \mathrm{C}$ a una humedad controlada del $80 \%$ usando la Incubadora RH520 ExTech ${ }^{\circledR}$ (Baños et al. 2009).

El soporte utilizado lleva un pretratamiento, el poliuretano (PUF) $\left(\delta: 20 \mathrm{~kg} / \mathrm{m}^{3}\right)$ se cortó en cubos de $1 \mathrm{~cm} \times 1 \mathrm{~cm} \times 1 \mathrm{~cm}$, posteriormente se lavaron con agua destilada, se exprimieron y se remojaron durante $10 \mathrm{~min}$ en una solución de $\mathrm{HCl}$ al $10 \% \mathrm{v} / \mathrm{v}$, se enjuagaron con agua destilada hasta neutralizar; se exprimieron y se remojaron durante 10 minutos más en una solución de $\mathrm{NaOH}$ al $4 \% \mathrm{p} / \mathrm{v}$, se enjuagaron con agua destilada hasta neutralizar. Se secaron a $60^{\circ} \mathrm{C}$ durante 24 horas y se almacenaron en bolsas negras hasta que se utilizaron. Se esterilizó a $15 \mathrm{lb} / \mathrm{in}^{2}$, durante 15 min (Baños et al. 2009).

\section{Columna.}

Para la preparación de las columnas, se adiciona previamente en un matraz el soporte PUF en donde se le impregna del medio inoculado en condiciones estériles, se colocó en el fondo de la columna una base de $1 \mathrm{~cm}$ de algodón estéril seguido por un filtro de $0.20 \mathrm{~mm}$, posteriormente se empaca $6 \mathrm{gr}$ de soporte húmedo inoculado con cuidado de evitar su compactación, y finalmente se colocó un filtro y una base de algodón de $1 \mathrm{~cm}$.

La columnas que se utilizaron fueron de $150 \mathrm{~mm}$ de largo x $21 \mathrm{~mm}$ de DI, con un volumen de $52 \mathrm{~cm}^{3}$ y se empacaron a una densidad de $0.144 \mathrm{~g} / \mathrm{cm}^{3}$, considerando que el volumen para el empaquetamiento fue de $41.5 \mathrm{~cm}^{3}$. A las columnas empacadas, se les adaptó un burbujeador de vidrio con agua destilada estéril, por donde se hizo pasar aire húmedo a un flujo de $0.05 \mathrm{~L} / \mathrm{gh}$ (Litro de aire por gramo de soporte húmedo por hora). Las columnas con los burbujeadores se colocaron en un baño de agua a $30^{\circ} \mathrm{C}$.

\subsection{PRUEBA DE ANTIOXIDANTE}

El desarrollo de esta metodología fue en base al artículo: Aplicación de diversos métodos químicos para determinar actividad antioxidante en pulpa de frutos de E. Marta Kuskoski et al. 2005. Usando el fundamento químico propuesto aquí usando el radical ABTS, se propone el uso de la misma metodología, pero usando DFC. 


\section{Prueba In Silico}

En una placa de Eliza (Costar 3603, 96 Well Assay Plate, Black plate, bottom whit Lid, tissue culture treated, polystyrene) se llenaron los pocillos con peróxido de hidrógeno (Sigma Aldrich, H1009) para llegar a una concentración final de 50mM. Posteriormente se adicionaron los uL necesarios para llegar a la concentración de $10 \mathrm{mM}$ del antioxidante NAC (Sigma Aldrich, A7250) y el metabolito a probar la lovastatina (Fermic S.A. de C.V.), se adiciono finalmente agua para llegar a un volumen de $200 \mathrm{uL}$ por pocillo.

El stock de lovastatina se preparó: disolviendo en $\mathrm{NaOH} 0.1 \mathrm{~N}-\mathrm{EtOH}$, se mantuvo a $50^{\circ} \mathrm{C}$ durante $20 \mathrm{~min}$, después se neutralizo con $\mathrm{HCl} 0.1 \mathrm{~N}$, para finalmente aforar con $\mathrm{H}_{2} \mathrm{O}$, se midió el volumen final y se calculó la concentración ajustada, las alícuotas se guardaron a $20^{\circ} \mathrm{C}$. El stock de NAC se preparó disolviendo en agua y ajustado a pH 6.5 con $\mathrm{NaOH} 1 \mathrm{M}$, se midió el volumen final y se calculó la concentración ajustada, se guarda a $4^{\circ} \mathrm{C}$.

\section{Prueba In vitro}

De cultivos de 48 horas de Aspergillus terreus de FL, se filtró y lavo la biomasa, se pesó 1gr que se disolvió en $10 \mathrm{~mL}$ de PBS y así se creó un stock de biomasa. En una placa de Eliza, se adiciono del stock de biomasa 150uL, después se adiciono peróxido de hidrógeno para llegar a una concentración final de $50 \mathrm{mM}$. Posteriormente se adicionaron NAC y lovastatina, para llegar a una concentración de 10uM, adicionando finalmente PBS para llegar a un volumen de $200 u \mathrm{~L}$ por pocillo.

Finalmente, para ambas pruebas, se adiciono 10uL de DFC (diacetato 2'7'diclorofluoresceína DCFH-DA) (D6883 Sigma Aldrich ${ }^{\circledR}$ ) para llegar a una concentración final de $10 \mathrm{uM}$, se agito durante 15 minutos en la oscuridad a $4^{\circ} \mathrm{C}$. Se leyó en DTX 880 multimodo detector de múltiples pocillos de fluorescencia lector de placas (Beckman-Coulter), con elfiltro de excitación en $485 \mathrm{~nm}$, el filtro de emisión en 530nm y tiempo de integración $0.4 \mathrm{~s}$ El fondo de florescencia se consideró como los pocillos vacíos de la placa. Para hacer los cálculos se resta el promedio del fondo de fluorescencia se realizó por triplicado.

${ }^{1}$ PBS: NaCl $137 \mathrm{mmol} / \mathrm{L}, \mathrm{KCl} 2.7 \mathrm{mmol} / \mathrm{L}, \mathrm{Na}_{2} \mathrm{HPO}_{4} .2 \mathrm{H}_{2} \mathrm{O} 10 \mathrm{mmol} / \mathrm{L}, \mathrm{KH}_{2} \mathrm{PO}_{4} 2 \mathrm{mmol} / \mathrm{L}, \mathrm{pH} 7.4$ se esteriliza y se guarda en refrigeración

\subsection{ADICIÓN DE NAC EN DIFERENTES TIEMPOS.}

Se adiciono NAC a la FL en distintos tiempos de la trofofase y la idiofase, muestreando a diferentes tiempos por triplicado. Se tomó muestra para comparar las EROs, la producción de lovastatina, biomasa, $\mathrm{pH}$. La adición se realiza en condiciones estériles y a partir de un stock de NAC (previamente descrito) (Miranda et al, 2015). 


\subsection{ORIGEN DE LAS EROs EN LA CELULA.}

Para esta prueba se usaron diferentes inhibidores: cianuro de potasio (KCN) (CAS 151-50-8 Reasol $^{\circledR}$ ) 30uM para inhibir la cadena respiratoria, difeniliodonio (DPI) (D2926 Sigma Aldrich $^{\circledR}$ ) 10uM para inhibir a las NADPH oxidasa (NOX) y alopurinol (ALO) (A8003 Sigma Aldrich ${ }^{\circledR}$ ) 10uM para inhibir a la Xantina Oxidasa basándonos en la metodología propuesta por Camile P. Semighini et al. 2008. Estos se adicionaron a la fermentación en el medio de cultivo a partir de un stock en condiciones estériles a las $0 \mathrm{~h}$. Se tomó muestra a lo largo del tiempo para comparar las EROs, la producción de lovastatina, biomasa, $\mathrm{pH}$.

Las concentraciones de los inhibidores usadas se determinaron previamente, esto se muestra en el Anexo A. El cálculo de los resultados fue el siguiente para cada uno de los inhibidores utilizados:

$\frac{\frac{R F U \text { sin inhibidor }}{\text { biomasa }}-\frac{R F U \text { con inhibidor }}{\text { biomasa }}}{\frac{R F T \text { sin } \text { inhibidor }}{\text { biomasa }}}=\%$ ROS de sistema inhibido

\subsection{PERÓXIDO DE HIDROGENO Y ANIÓN SUPEROXIDO}

\section{Determinación de peróxido de hidrogeno}

Para la cuantificación de especies reactivas como peróxido de hidrogeno y sus derivados se utilizó el 2,7diclorodihidrofluorosceina diacetato (DHFC Sigma-Aldrich). Las membranas celulares son permeables a la forma esterificada de DHFC, por lo que este compuesto entra libremente a la célula y una vez dentro, es desacetilado por esterasas y, por tanto, permanecen en el interior de la célula. Cuando este compuesto es oxidado, especialmente por peróxidos (Gómez-Quiroz et al., 2008), se forma un producto verde fluorescente el cual puede ser cuantificado por flourimetria.

Es importante establecer que, de acuerdo con lo publicado por Owusu-Ansah et al. 2008, este compuesto, no debería considerarse como una prueba específica del incremento en la producción de EROs, si no como un indicador del grado general del estrés oxidante de la célula. Para el cálculo de peróxido se consideró el restarle lo obtenido de otras especies reactivas de oxígeno a lo obtenido con DFC.

\section{Determinación de anión superóxido}

El dihidroetidio (DHE, Invitrogen D-1168) es un compuesto usado con frecuencia, debido a su capacidad para permear libremente por la membrana celular. Se caracteriza por reportar la producción del anión superóxido. Una vez que este compuesto reacciona con $\mathrm{O}^{2-}$; conforma un producto rojo fluorescente que se intercala con el ADN. Se considera que el DHE es quizá el producto más específico y menos problemático en la detección de $\mathrm{O}^{2-}$ (Owusu-Ansah et al., 2008). 
Se utilizó el mismo protocolo para la determinación de EROs, con la diferencia de remplazar la molécula de reacción en este caso la DFC y la DHE. El ensayo se realiza por triplicado con la normalización por biomasa determinada por ácidos nucleicos.

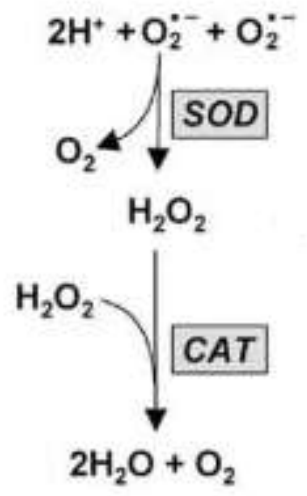

Figura 6.3 Reacciones catalíticas de las enzimas antioxidantes Sod y Cat con sus respectivos reactivos y productos.

\subsection{ACTIVIDAD ENZIMÁTICA DE LA CATALASA Y SÚPER OXIDO DISMUTASA}

Para determinar la actividad enzimática, primero se llevó a cabo un muestreo de las fermentaciones donde se tomó una muestra de biomasa que se congelo con $\mathrm{N}_{2}$ líquido, se guardado en un empaque de aluminio previamente etiquetado. Posteriormente se molió con mortero en $\mathrm{N}_{2}$ con precaución de no dejar que se descongele y se tomó una alícuota de $100 \mathrm{mg}$ aprox. de biomasa molida. Para después ser tratadas respecto a las instrucciones del kit: SOD Biovision Superoxide Dismutase Activity Assay Kit (Catalog \#K335-100) y CAT Blovision Catalase Activity Colorimetric/Fluorometric Assay Kit (Catalog \#K773-100).

\subsubsection{Cuantificación de actividad súper oxido dismutasa (SOD)}

En el ensayo SOD, los aniones superóxido, generados por la conversión de la xantina a ácido úrico y peróxido de hidrógeno debido a la actividad de la xantina oxidasa (XOD), reducen el WST-1 (4-[3-(4-iodophenyl)-2-(4-nitrophenyl)-2H-5-tetrazolio]-1,3-benzene disulfonate sodium salt) a cristales de formazán solubles en agua, los cuales pueden medirse mediante absorbancia a 438nm. Las SODs disminuyen el ratio de reducción de la reacción reduciendo las concentraciones del anión superóxido. Además, el porcentaje de inhibición de la reacción de reducción puede determinarse como una medida de la actividad SOD. 


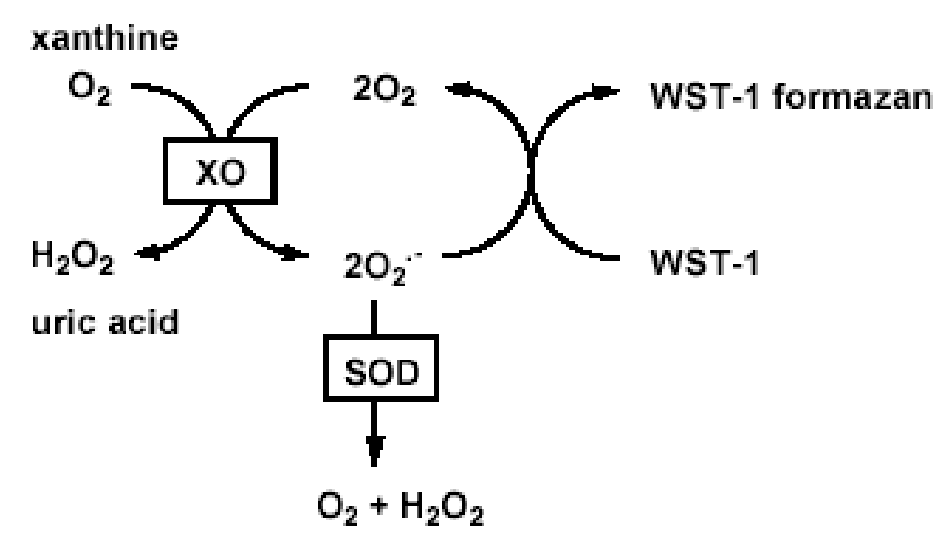

Figura 6.4 Fundamento de la cuantificación de la actividad de SOD (Kit Biovision SOD).

\subsubsection{Cuantificación de actividad catalasa (CAT)}

La catalasa es una enzima antioxidante que está presente en casi todos los organismos vivos. Funciona para catalizar la descomposición del peróxido de hidrógeno en agua y oxígeno. BioVision Catalasa Kit de ensayo proporciona un ensayo altamente sensible, simple, directo y filiforme para medir la actividad de catalasa en muestras biológicas. En el ensayo, la catalasa primero reacciona con $\mathrm{H}_{2} \mathrm{O}_{2}$ para producir agua y el oxígeno, el $\mathrm{H}_{2} \mathrm{O}_{2}$ no convertido reacciona con sonda OxiRed ${ }^{\mathrm{TM}}$ para producir un producto, que puede medirse a $570 \mathrm{~nm}$ (método colorimétrico). La actividad de catalasa es inversamente proporcional a la señal. El kit puede detectar $1 \mathrm{mU}$ o menos de la actividad de catalasa en muestras.

\subsection{MEDICIÓN DE LA RESPIRACIÓN}

Primero se montó y adaptó el sistema para medir la respiración; tanto en micelio proveniente de FL como de micelio de FS en MC y en C como se muestra en el Anexo B.

La velocidad de consumo de oxıgeno se midió en un Oxímetro modelo 782 con un electrodo de tipo Clark en una cámara con camisa de agua de $0.1 \mathrm{ml} \mathrm{a} 30^{\circ} \mathrm{C}$ y se analizaron los datos usando el sistema de oxıgeno 782 (warner/Strathkelvin Istruments) (Guerrero-Castillo et al., 2009). La muestra para FS fue de $0.2 \mathrm{~cm}^{3}$ de soporte con biomasa y en para FL aproximadamente $50 \mathrm{mg}$ que se diluyó en $1 \mathrm{~mL}$ buffer PBS. Posteriormente a la medición se determinó biomasa por glucosamina y Bradford (Miranda et al., 2015).

Se utilizó cianuro de potasio KCN para inhibir el citocromo C oxidasa 60 uM y 100 uM para FS y FL respectivamente. Debido a que el cianuro inhibe la vía del citocromo, los electrones se desvían hacia AOX. Se utilizó SHAM (Ácido Salicilhidroxamico) (S607 Sigma Aldrich ${ }^{\circledR}$ ) para inhibir a la oxidasa alternativa (AOX) 6 uM. 
Para medir la actividad de las NADH alternativas se utilizó el inhibidor Flavonona (Flavone F-2003 Sigma Aldrich ${ }^{\circledR}$ ), adicionando 50 mM en FL y 30 mM en FS; usando como control positivo de la respiración la rotenona (R8875 Sigma Aldrich ${ }^{\circledR}$ ) que inhibe al complejo I.

Para medir el efecto de los inhibidores de la respiración en la fermentación en sólido y líquido se adiciono a la fermentación cianuro de potasio 6 uM y 5 uM respectivamente. También se le adiciono propilgalato $1 \mathrm{mM}$ para FS y FL para inhibir a la oxidasa alternativa; a estos cultivos se determinó la respiración, acumulación de EROs y producción de lovastatina a las 48 horas usando como control fermentaciones sin inhibidores.

Para probar el efecto de EROs exógenos se adiciono $30 \mu \mathrm{M}$ de $\mathrm{H}_{2} \mathrm{O}_{2}$ a la FS y $\mathrm{FL}$ a las 0 horas de la fermentación; de igual manera se midieron todos los parámetros a las 48 horas.

Para realizar los cálculos se utilizaron las siguientes formulas:

Respiracion total $=$ Respiracion Citocromica + Respiracion Alternativa + Respiracion Residual

Al usar KCN se inhibió la Respiración Citocrómica por lo tanto la pendiente de consumo será: Inibicion con $C N=$ Respiracion alternativa + Respiracion Residual

Al inhibir con SHAM o PG, se quitó de la ecuación la AOX o respiración alternativa, por lo tanto:

$$
\text { Inhibicion con SHAM = Respiracion Total + Respracion Residual }
$$

Para analizar la primera parte de la cadena respiratoria se utilizó Flavonona con la cual se inhibió a las NADH alternativas y cuando se utilizó rotenona se inhibió al complejo I por lo tanto se obtiene:

Respiracion total $=$ Complejo $I+$ Nadh alternativas
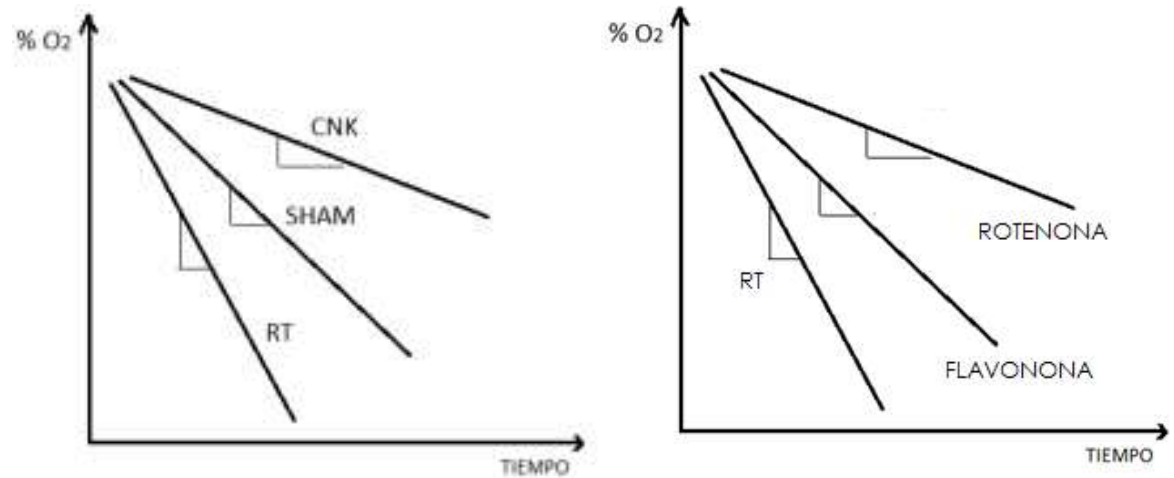

Figura 6.5 Ejemplificación de cómo se percibe el cambio de consumo de oxígeno al usar los inhibidores. 


\subsection{TÉCNICAS ANALÍTICAS.}

\subsubsection{Lovastatina.}

\section{EXTRACCIÓN DE FS.}

Se pesó $1 \mathrm{~g}$ de soporte húmedo, al cual se le adiciono $10 \mathrm{~mL}$ de acetonitrilo al $50 \%$ con agua, con agitación durante 30 min a 250 rpm y después 30 min en el sonicador (Branson 120), la muestra se pasó a través de una membrana de $0.40 \mathrm{~mm}$ de poro (Millipore). Las muestras se guardaron en microtubos de $1.5 \mathrm{~mL}$ a $4^{\circ} \mathrm{C}$ hasta su cuantificación.

\section{EXTRACCIÓN DE FL.}

Se tomaron dos tipos de muestra, una proveniente del caldo de fermentación, del cual se tomaron $2 \mathrm{~mL}$ de caldo, al cual se le adicionaron $2 \mathrm{~mL}$ de acetonitrilo al $50 \%$; la otra proveniente del micelio, se pesó $1 \mathrm{~g}$ de micelio húmedo el cual se pasó a un tubo con $5 \mathrm{~g}$ de perlas de vidrio y $10 \mathrm{~mL}$ de acetonitrilo al $50 \%$, seguida de una agitación en el vórtex durante $2 \mathrm{~min}$. Los tubos se colocaron en el sonicador durante $30 \mathrm{~min}$, la muestra se pasó a través de una membrana Millipore de $0.40 \mathrm{~mm}$ de poro. Todas las muestras fueron guardadas en microtubos de $1.5 \mathrm{~mL}$ a $4^{\circ} \mathrm{C}$ hasta su cuantificación.

\section{CUANTIFICACIÓN.}

Se realizó por Cromatografía de Líquidos de Alta Resolución (HPLC), utilizando una columna Novapack C-18 (150 x $3.9 \mathrm{~mm}, 4 \mathrm{~mm})$, con una fase móvil de acetonitrilo: ácido fosfórico $0.1 \%(50 \% \mathrm{v} / \mathrm{v})$, la velocidad de flujo fue de $1.5 \mathrm{~mL} / \mathrm{min}$, y la forma b-hidroxiácida se determinó a 238.

CURVA PATRÓN.

Se utilizó el procedimiento que se describe en Miranda et al. 2013, con las siguientes modificaciones, se realizó una conversión de la lovastatina de su forma Lactona a su forma $\beta$ - hidroxiácida, se usó lovastatina (Fermic S.A. de C.V.), se disolvieron en $50 \mathrm{~mL}$ de $\mathrm{NaOH}$ $0.1: 25 \% \mathrm{ACN}$, se incubó a $45^{\circ} \mathrm{C}$ durante $1 \mathrm{~h}$ y después se ajustó a pH 7.7 con $\mathrm{HCl} 0.1 \mathrm{~N}: \mathrm{ACN}$, finalmente se guardó en alícuotas a $-20^{\circ} \mathrm{C}$. Este proceso asegura un $98 \%$ de conversión de la forma lactona a la forma $\beta$-hidroxiácida (Yang \& Hwang 2006), sin embargo, hubo que confirmarlo mediante HPLC, para obtener una curva patrón con las concentraciones reales de la forma $\beta$ - hidroxiácida.

\subsubsection{Determinación de Biomasa y humedad.}

En FL, la biomasa y la humedad se determinó por peso seco, filtrando todo el contenido de un matraz a través de un papel filtro de peso conocido, y secando a $80^{\circ} \mathrm{C}$ durante $48 \mathrm{~h}$, hasta peso constante. En el caso de FS, se determinó indirectamente usando el contenido de glucosamina. Se tomaron unos cubos de soporte húmedo y se secaron al horno a $60{ }^{\circ} \mathrm{C}$ durante 48 h; por diferencia de peso se conoció la humedad. La biomasa se determinó por el método de Glucosamina (Marcial et al. 2011). 


\subsubsection{Cuantificación de pH.}

FS: Se tomó $1 \mathrm{~g}$ de soporte húmedo en $10 \mathrm{~mL}$ de agua. La mezcla fue sometida al vórtex durante $2 \mathrm{~min}$, el $\mathrm{pH}$ fue medido directamente en el líquido resultante.

FL: Se tomó directamente del caldo de fermentación después de haber filtrado el micelio. En las fermentaciones hibridas se toma el $\mathrm{pH}$ del caldo.

\subsubsection{Cuantificación de PKA.}

El análisis se realizó usando el kit: PKA kinase activity kit Catalog Number: ADI-EKS-390A $\mathrm{ENZO}^{\circledR}$. El ensayo de la actividad quinasa de PKA se basa en un ensayo inmunoabsorbente ligado a enzima en fase sólida (ELISA) que utiliza un péptido sintético específico como un sustrato para PKA y un anticuerpo policlonal que reconoce la forma fosforilada del sustrato.

Se tomó una muestra de biomasa que se congelo y molió con $\mathrm{N}_{2}$ en mortero, se llenaron tubos con 500 uL para y 200 uL para FL. Se homogenizo con $1 \mathrm{~mL}$ de Tris-B $20 \mathrm{mM} \mathrm{NaCl}$ $20 \mathrm{mM} \mathrm{pH} 7.4$, después se centrifugo a $3000 \mathrm{rpm}$ por $10 \mathrm{~min}$ a $4^{\circ} \mathrm{C}$. Se tomó del sobrenadante para su análisis siguiendo el protocolo del kit.

El ensayo está diseñado para el análisis de la actividad PKA en la fase de solución. En el ensayo, el sustrato, que es fosforilado fácilmente por PKA, es pre-recubierto en los pocillos de la placa proporcionado PKA sustrato de microtitulación. Las muestras al ser ensayadas se añaden a los pocillos apropiados, seguido por la adición de ATP para iniciar la reacción. La reacción de la quinasa se termina y un Substrato fosfoespecífico anticuerpo se añade a los pocillos que se une específicamente al sustrato péptido fosforilado.

El anticuerpo fosfoespecífico posteriormente es ligado por un anticuerpo secundario conjugado con peroxidasa. El ensayo se desarrolló con sustrato de tetrametilbenzidina (TMB) y se desarrolla un color en proporción a la actividad fosfotransferasa de PKA. EI desarrollo del color se detiene con una solución ácida de parada y la intensidad del color se mide en un lector de microplacas a $450 \mathrm{~nm}$. 


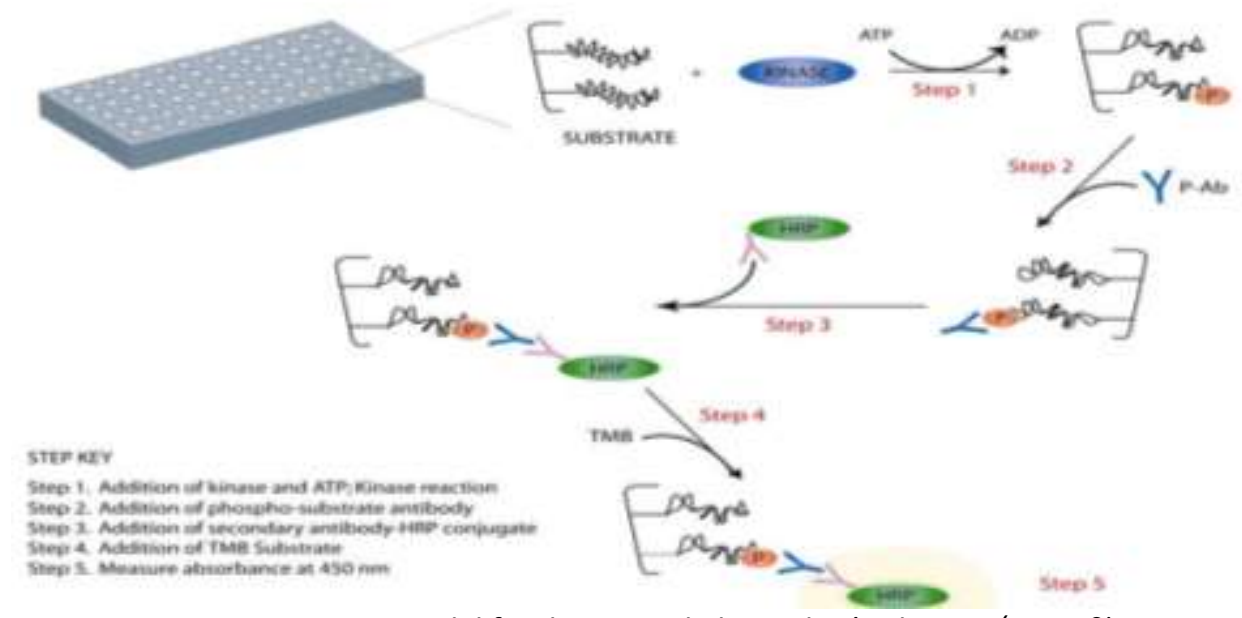

Figura 6.6 Esquema del fundamento de la medición de PKA $\left(\mathrm{ENZO}^{\circledR}\right)$.

\subsubsection{Cuantificación de cAMP.}

El análisis se realizó usando el kit: Direct cAMP ELISA kit Catalog \# ADI-900-066 96 Well Enzyme-linked Immunosorbent Assay Kit ENZO ${ }^{\circledR}$.

Se tomó una muestra de biomasa la cual es congela con $\mathrm{N}_{2}$ para después ser molida en mortero con $\mathrm{N}_{2}$. Se llenaron tubos eppendorf de biomasa molida para FS 500ul y FL con 200 ul. Se homogenizo con $1 \mathrm{~mL}$ de $0.1 \mathrm{M}$ de $\mathrm{HCl}$. El tratamiento de células y tejidos con $\mathrm{HCl}$ detendrá la actividad de la fosfodiesterasa endógena y permitirá la medición directa de estas muestras en el ensayo sin evaporación o procesamiento posterior. Después se centrifugo a $3000 \mathrm{rpm}$ por $10 \mathrm{~min}$ a $4^{\circ} \mathrm{C}$. Se tomó del sobrenadante para su análisis como marca el protocolo del kit.

El ensayo de inmunoabsorción ligado a enzimas AMP (ELISA) kit cíclico Direct es un inmunoensayo competitivo para la determinación cuantitativa de AMP cíclico en células, tejidos, y sobrenadantes de cultivos tratados con $\mathrm{HCl}$. Los patrones y las muestras se añaden a los pocillos recubiertos con un anticuerpo IgG GXR. A continuación, se añadió una solución de azul de cAMP conjugado con fosfatasa alcalina, seguido por una solución de color amarillo de anticuerpo policlonal de conejo a cAMP. Durante una incubación simultánea a temperatura ambiente se une el anticuerpo, de una manera competitiva, el cAMP en la muestra o conjugado.

La placa se lava, dejando sólo cAMP unido. Se añade solución de sustrato PNPP. El sustrato genera un color amarillo cuando catalizada por la fosfatasa alcalina en el conjugado de cAMP. Se añade la solución de Paro. El color amarillo se lee a 405nm. La cantidad de señal es indirectamente proporcional a la cantidad de AMPc en la muestra. 


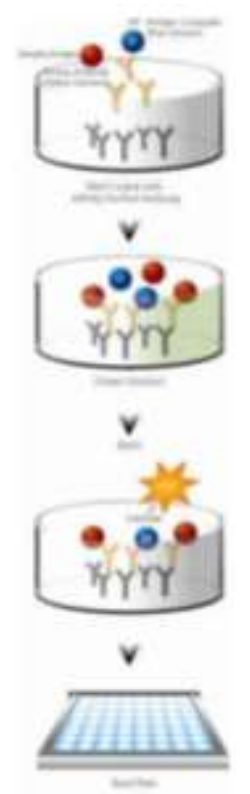

Figura 6.7 Esquema del fundamento de la medición de $\operatorname{AMPc}\left(E{ }^{\circledR}{ }^{\circledR}\right)$.

\subsubsection{Cuantificación de azúcares.}

Se tomó una muestra de caldo de cultivo previamente filtrado la cual se guardó a $-20^{\circ} \mathrm{C}$ para su posterior análisis. El análisis se realizó por HPLC, empleando una columna YMC-Pack $\mathrm{NH}_{2}$ S-5 um de 120 A (4.6 × 250 mm, $12 \mathrm{~nm})$ No .425006124, con una fase móvil de acetonitrilo: $\mathrm{H}_{2} \mathrm{O}$ (75:25), la velocidad de flujo fue de $1 \mathrm{~mL} / \mathrm{min}$. Presión $5.88 \mathrm{Mpa}$. Temperatura de $25^{\circ} \mathrm{C}$. Detección 64x106 RIU/F. La lactosa y la glucosa serán detectadas a los 8 y 5 min con un detector de refracción de lodos. Las curvas de patrón de los azucares de realizaron con los mismos reactivos usados para elaborar el medio de cultivo. Todas las muestras se filtraron con membranas Millipore de 0.40 mm de poro, antes de su lectura (Hugo León, 2010).

\subsubsection{Cuantificación de EROs.}

Se utilizó el procedimiento que se describe en Miranda et al. 2013, con las siguientes modificaciones. Los derivados de fluoresceína como el dichlorofluoreseina, (DCFH), no son fluorescentes después de ser oxidada por varios oxidantes, se convierten en DCF y emiten fluorescencia. La producción de EROs intracelular se detecta utilizando una sonda fluorogénica, no fluorescente que es permeable para las células, diacetato 2'7'diclorofluoresceína (DCFH-DA). DCFH-DA es hidrolizado por esterasas intracelulares y luego oxidada por los EROs a un compuesto fluorescente 2'-7'-DCF. Las placas negras reducen el ruido de fondo la contaminación cruzada lumínica entre pocillos en ensayos de fluorescencia. 


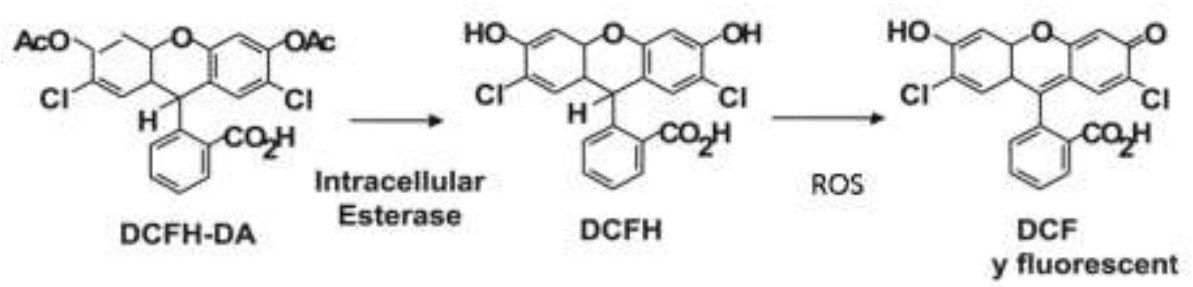

Figura 6.8 Mecanismo de reacción de la DCF (Sigma-Aldrich).

La oxidación de la sonda $\mathrm{H}_{2}$ DCF-DA (Sigma-Aldrich) por las EROs, se midió a través de una cinética. A $10 \mathrm{~mL}$ de $\mathrm{PBS}^{1}$ con una concentración de $20 \mathrm{mM} \mathrm{H2DCF-DA}$, se le adicionaron 50 $\mathrm{mg}$ de micelio de $\mathrm{FL}$ o en su caso, $0.5 \mathrm{~g}$ de cultivo sólido de FS. La reacción se incubó en condiciones de oscuridad y en hielo durante $40 \mathrm{~min}$. Transcurrido el tiempo, cada muestra se filtró, se lavó con $100 \mathrm{~mL}$ de $\mathrm{PBS}^{1}$, se congeló y se molió con $\mathrm{N}_{2}$ líquido (con ayuda de mortero y pistilo) todo en condiciones de obscuridad.

Aproximadamente $500 \mathrm{mg}$ del polvo (micelio molido y congelado), se adicionaron a un microtubo de $1.5 \mathrm{~mL}$ negro (o ámbar) previamente pesado, y a éste se le adicionó $1 \mathrm{~mL}$ de PBS $^{1}$ frío todo en condiciones de obscuridad. El tubo fue vortexeado durante 20 seg y centrifugado a $12,000 \mathrm{xg}$ a $4^{\circ} \mathrm{C}$ por $15 \mathrm{~min}$, se guardan a $4^{\circ} \mathrm{C}$. A las $48 \mathrm{~h}$ se tomaron $200 \mu \mathrm{L}$ del sobrenadante y se colocaron sobre una placa de 96 pozos para fluorescencia, la cual se leyó en el lector multimodal DTX 880 Multimode Detector (Beckman-Coulter, Inc, Brea, CA, USA), empleando $485 \mathrm{~nm}$ de excitación y $530 \mathrm{~nm}$ de emisión todo en condiciones de obscuridad.

Se realizó el mismo procedimiento, pero sin emplear la sonda $\mathrm{H}_{2}$ DCF-DA (control negativo), al final a la fluorescencia emitida en las muestras tratadas con la sonda, se les restó la fluorescencia del control negativo. La normalización de la Fluorescencia (dado en Unidades Relativas de Fluorescencia o URF) se obtuvo al dividir este resultado entre el contenido de biomasa, en FL por peso seco y en FS por glucosamina. Todo se realizó por triplicado.

\subsubsection{Muestreo para expresión de genes.}

FS: En una bolsa de aluminio de $5 \times 5 \mathrm{~cm}$ etiquetado, se colocaron de 5 cubos de soporte húmedo, los cuales se congelaron con $\mathrm{N}_{2}$ líquido. Las muestras se guardaron a $-70^{\circ} \mathrm{C}$ hasta su procesamiento.

FL: Una vez separado por filtración el caldo del micelio, se tomó el micelio se colocó dentro de una bolsa de aluminio de $5 \times 5 \mathrm{~cm}$ etiquetada y se congelo con $\mathrm{N}_{2}$ líquido. Las muestras se guardaron a $-70^{\circ} \mathrm{C}$ hasta su procesamiento. 


\subsection{TÉCNICAS MOLECULARES.}

\subsubsection{Extracción de ADN genómico de Aspergillus terreus.}

Se pusieron a germinar esporas frescas de $A$. terreus sobre medio completo. Se incubaron a $30^{\circ} \mathrm{C}$ durante $20 \mathrm{~h}$. El micelio producido se recogió y se colocó en una caja de Petri para luego ser congelado con $\mathrm{N}_{2}$ líquido. El micelio se guardó a $-70^{\circ} \mathrm{C}$ hasta su procesamiento. El micelio congelado se molió y se hicieron alícuotas de $0.5 \mathrm{~mL}$ del volumen del tubo eppendorf. A cada tubo, se le adicionaron $800 \mu \mathrm{L}$ de $\mathrm{BE}^{2}$, se incubo a $68^{\circ} \mathrm{C}$ durante $30 \mathrm{~min}$. Se centrifugo $5 \mathrm{~min}$ a temperatura ambiente. Al sobrenadante se le agrego $50 \mu \mathrm{L}$ de acetato

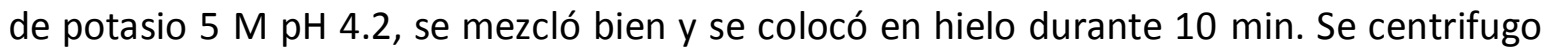
$5 \mathrm{~min}$. Del sobrenadante se tomaron $700 \mu \mathrm{L}$ y se le adicionaron $700 \mu \mathrm{L}$ de isopropanol. Se centrifugo $5 \mathrm{~min}$, se resuspendió en $400 \mu \mathrm{L}$ de $\mathrm{TE}^{3}$, y se le adicionaron $40 \mathrm{uL}$ de acetato de sodio $3 \mathrm{M} \mathrm{pH}$ 7.0. La mezcla se calentó $68^{\circ} \mathrm{C}$ durante $1 \mathrm{~h}$. Para solubilizar, se mezcló por agitación en vórtex. Se le adiciono $1 \mathrm{~mL}$ de etanol al 95\% y se centrifugo durante $5 \mathrm{~min}$. La mezcla se lavó 2 veces con $800 \mu \mathrm{L}$ de etanol al 70\%. El ADN se resuspendió en $100 \mu \mathrm{L}$ de TE con $100 \mathrm{mg} / \mathrm{mL}$ de RNAsa. La mezcla se incubo a $37^{\circ} \mathrm{C}$ durante $1.5 \mathrm{~h}$. Después, se le adicionaron $300 \mathrm{uL}$ de $\mathrm{TE}^{3}$. Se extrajo con 1 volumen de $\mathrm{CIA}^{4}$. Se centrifugo durante $5 \mathrm{~min}$. Se le agrego $1 \mu \mathrm{l}$ por cada $10 \mu \mathrm{l}$ de acetato de sodio $3 \mathrm{M} \mathrm{pH} 5.2$, más $700 \mu \mathrm{L}$ de etanol frio (2.5 vol.). Se centrifugo durante $20 \mathrm{~min}$ a $14000 \mathrm{rpm}$ a $4^{\circ} \mathrm{C}$. La pastilla se lavó con etanol al $70 \%$. Se secó y resuspendió en $30 \mu \mathrm{L}$ de $\mathrm{H}_{2} \mathrm{O}$ desionizada (Miranda et al. 2008).

\subsubsection{Electroforesis y cuantificación de ADN.}

Para la cuantificación se empleó el Nanodrop2000 (Thermo Scientific ${ }^{\circledR}$ ) se empleó el programa de ADN usando a 260, 230 y $280 \mathrm{~nm}$ de absorbancia. La electroforesis de ADN se realizó en geles de agarosa al $0.8 \%$ con gel Red y Tampón de carga $6 \mathrm{X}^{8}$, en TAE $1 \mathrm{X}^{9}$ a $80 \mathrm{~V}$. Como marcador de tamaño utilizado fue el de $1 \mathrm{kB}$ de Fermentas ${ }^{\circledR}$. Para revelar se utilizó el Gel DOC EZ Imagen BioRad $®$ para tomar las imágenes.

5Solucion I: 50 mM glucosa, 25 mM TRIS pH 8.0 y 10 mM EDTA pH 8.0.

${ }^{6}$ Solucion II. $400 \mathrm{ml} \mathrm{H} \mathrm{O}_{2}$; $50 \mathrm{ml}$ SDS $10 \%$ y $50 \mathrm{ml} \mathrm{NaOH} 2 \mathrm{~N}$.

${ }^{7}$ Solucion III: $5 \mathrm{M}$ Acetato de Potasio, ácido acético glacial.

${ }^{8}$ Tampón de carga 6X: Azul de bromofenol al $0.25 \%$, Sacarosa al $40 \%$ y xileno cianol al $0.25 \%$. Se esteriliza por 20 min a presión. Se guarda a $4^{\circ} \mathrm{C}$.

9TAE50X: $57.1 \mathrm{ml}$ Ácido acético glacial, $100 \mathrm{ml}$ de EDTA $0.5 \mathrm{M} \mathrm{pH} \mathrm{8,} 0.242 \mathrm{~g}$ Tris-base y agua destilada hasta completar $1 \mathrm{~L}$, se guarda en la obscuridad. 


\subsubsection{PCR}

Para el diseño de los oligos, se localizaron los genes en las bases de datos NCBI del microorganismo Aspergillus niger. Se realizó un análisis tipo BLASTn dentro del genoma de Aspergillus terreus y se encontró resultados con posibles proteínas para cada gen, a partir de ésta se diseñaron los primeros, usando la zona del exón más grande. Se realizó un PCR con gradiente de temperatura para determinar la Tm óptima, después se realizó una amplificación del gen con PCR. Las condiciones del PCR fueron las siguientes:

\begin{tabular}{lll}
$\begin{array}{l}\mathrm{H}_{2} \mathrm{O} \text { grado Biología Molecular } \\
\text { (MoBio Laboratorios) }\end{array}$ & $80.0 \mu \mathrm{L}$ & \multicolumn{1}{c}{ Programa en el termociclador } \\
Buffer 10X & $10.0 \mu \mathrm{L}$ & $1.94^{\circ} \mathrm{C} @ 3$ min Desnaturalización \\
$\mathrm{MgSO}_{4} 100 \mathrm{uM}$ & $2 \mu \mathrm{L}$ & $2.94^{\circ} \mathrm{C} @ 30$ seg Desnaturalización \\
dNTPs 10uM & $2 \mu \mathrm{L}$ & $3.63-70{ }^{\circ} \mathrm{C} @ 50$ seg Hibridación \\
$10 \mathrm{mM}$ Fower & $2.5 \mu \mathrm{L}$ & $4.72{ }^{\circ} \mathrm{C} @ 1.30$ minutos Elongación \\
$10 \mathrm{mM}$ Reversa & $2.5 \mu \mathrm{L}$ & $5 . \mathrm{GOTO} 2-4$ Repetición 30 veces \\
ADN genómico (1ug/ul) & $1.0 \mu \mathrm{L}$ & $6.72^{\circ} \mathrm{C} @ 5$ minutos Elongación Final \\
ADN polimerasa Taq (Promega) & $0.5 \mu \mathrm{L}$ & $7 . \mathrm{HOLD} @ 4.0^{\circ} \mathrm{C}$ \\
Total & $100 \mu \mathrm{L}$ &
\end{tabular}

El producto de este se purifico con el Kit Wizard ${ }^{\circledR}$ SV Gel and PCR Clean-Up System, posteriormente se corrió en un gel de electroforesis y se determinó la concentración usando el Nanodrop2000 Thermo Scientific ${ }^{\circledR}$. El producto obtenido se mandó secuenciar al Laboratorio Divisional de Biología Molecular UAM Iztapalapa. 
Tabla 6.1 Diseño de los primeros de los genes analizados por Northen Blot.

\begin{tabular}{|c|c|c|c|c|c|c|c|}
\hline Gen & Gene ID & Producto & $\begin{array}{l}\text { Fower } \\
5^{\prime} a 3^{\prime}\end{array}$ & $\begin{array}{l}\text { Reverse } \\
5^{\prime} a 3^{\prime}\end{array}$ & $\begin{array}{c}\text { Tm } \\
\text { Optima }\end{array}$ & $\begin{array}{l}\text { Tamaño del } \\
\text { fragmento }\end{array}$ & $\begin{array}{l}\text { \% Identidad de } \\
\text { la secuenciación }\end{array}$ \\
\hline nadh1 & 4355148 & $\begin{array}{l}\text { hypothetical } \\
\text { protein }\end{array}$ & $\begin{array}{l}\text { CTTGCTT } \\
\text { CCTGAAG } \\
\text { GAGGTCG }\end{array}$ & $\begin{array}{l}\text { CCGTTG } \\
\text { ACGACCA } \\
\text { GGTATTCG }\end{array}$ & 66 & 425 & $99 \%$ \\
\hline$a o x$ & 4321367 & $\begin{array}{l}\text { alternative } \\
\text { oxidase, } \\
\text { mitochondrial } \\
\text { precursor }\end{array}$ & $\begin{array}{l}\text { CTGAAAC } \\
\text { TGGCCGA } \\
\text { ACCAGG }\end{array}$ & $\begin{array}{l}\text { GCTTCAG } \\
\text { ATCTCC } \\
\text { ATGCCC }\end{array}$ & 62 & 549 & $99 \%$ \\
\hline ras1 & 4323026 & protein ras-1 & $\begin{array}{l}\text { TCGCGT } \\
\text { TGTGGGA } \\
\text { TGTCC }\end{array}$ & $\begin{array}{l}\text { CTGCTCG } \\
\text { GTAACCA } \\
\text { CCC }\end{array}$ & 59 & 239 & $98 \%$ \\
\hline ras2 & 4319312 & protein ras-2 & $\begin{array}{l}\text { CCATCG } \\
\text { AAGACT } \\
\text { CGTACC }\end{array}$ & $\begin{array}{l}\text { GCAGACC } \\
\text { ACTGCG } \\
\text { ATGG }\end{array}$ & 60 & 600 & $97 \%$ \\
\hline
\end{tabular}
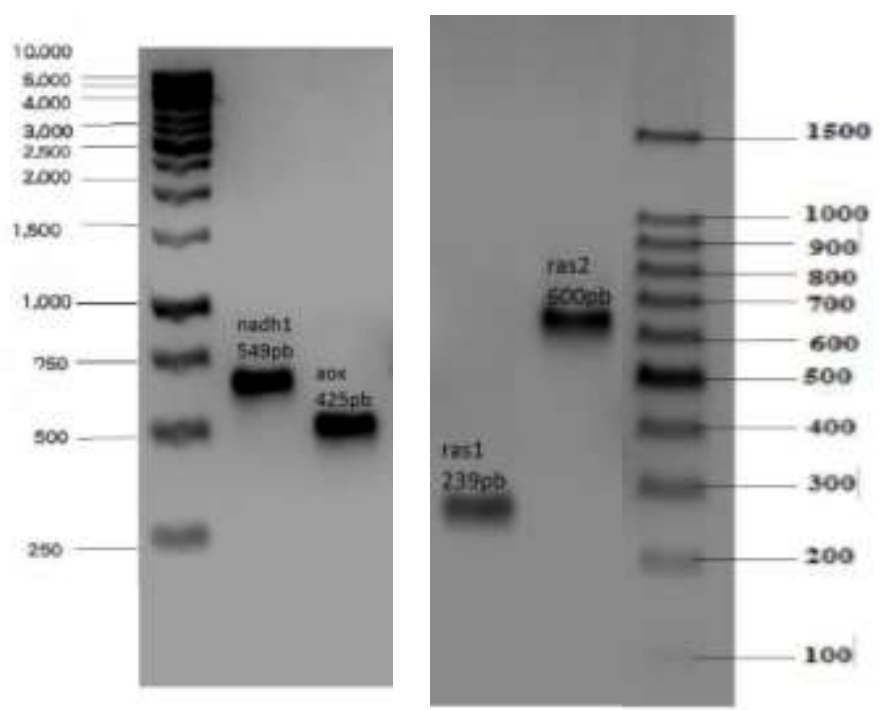

Figura 6.9 Sondas de los genes: nadh1, aox, ras1 y ras2. 


\subsubsection{Northern-blot.}

Se utilizó el procedimiento que se describe en Miranda et al. 2013, con las siguientes modificaciones.

\section{Extracción de RNA.}

Reactivo TRIZOL es un reactivo listo para el uso, diseñado para aislar el ARN de alta calidad total (así como el ADN y las proteínas) a partir de muestras de células y tejidos de origen humano, animal, vegetal, de levadura, o de origen bacteriano, dentro de una hora. EI TRIZOL es una solución monofásica de fenol, isotiocianato de guanidina, y otros componentes que facilitan el aislamiento de una variedad de especies de ARN de tamaño molecular grande o pequeño, este reactivo mantiene la integridad del ARN debido a la inhibición altamente eficaz de la actividad de RNAsa, mientras que interrumpe las células y disuelve los componentes celulares durante la homogeneización de la muestra.

Cada muestra de micelio o soporte previamente congelada se trituró con $\mathrm{N}_{2}$ líquido. Se llenaron los tubos a un volumen, para muestras de FL de $200 \mu \mathrm{L}$, y para el caso de muestras de $\mathrm{FS}$ de $400 \mu \mathrm{L}$, los cuales se pusieron en $\mathrm{N}_{2}$ líquido. A cada uno de estos tubos, se le adicionó $1 \mathrm{ml}$ de TRIZOL (Invitrogen $($ )), se mezcló por agitación con vórtex hasta su descongelación e incorporación total del reactivo. Para muestras de FS, se centrifugó a $14000 \mathrm{rpm}$ por 5 min a temperatura ambiente (TA) y para muestras de $\mathrm{FL}$, se incubaron durante $5 \mathrm{~min}$ a TA. Los tubos se centrifugaron a $4^{\circ} \mathrm{C}$ a $14000 \mathrm{rpm}$ por $15 \mathrm{~min}$. La fase acuosa se colectó y se colocó en un nuevo tubo. La precipitación se realizó con $500 \mu \mathrm{L}$ de isopropanol y se almacenaron a $-20^{\circ} \mathrm{C}$ durante $48 \mathrm{~h}$. Se centrifugó a $4^{\circ} \mathrm{C}$ a $14000 \mathrm{rpm}$ por 30 min. El precipitado se lavó con $1 \mathrm{~mL}$ de etanol al 75\%, se mezcló por agitación en vórtex y se centrifugó a $4^{\circ} \mathrm{C}$ a 7500 rpm por 5 min. Finalmente, el ARN se resuspendió en $10 \mu \mathrm{L}$ de $\mathrm{H}_{2} \mathrm{O}$ tratada con DEPC por cada tubo y se recolecto en un solo tubo.

\section{Electroforesis en geles con Formaldehído.}

Por cada $100 \mathrm{~mL}$ de solución de agarosa se necesitaron de $1.2 \mathrm{~g}$ de agarosa $+87 \mathrm{~mL}$ de agua (destilada estéril), la mezcla se fundió al microondas. Entre $50-55^{\circ} \mathrm{C}$, se le agregaron $10 \mathrm{~mL}$ de MAE10X ${ }^{13}$. En la campana de extracción, se le agregaron $3 \mathrm{~mL}$ de formaldehído al frasco. Tras gelificación, se colocaron dentro del tanque de electroforesis tampón MAE1X. Las muestras se colocaron dentro del pocillo del gel con Tampón de carga RNA $1.25^{14}$ y se aplicó 80 volts durante $50 \mathrm{~min}$. Las bandas se visualizaron con la luz ultravioleta, se tomó la foto y se procedió a la transferencia a membrana. 
Cuantificación y Normalización del RNA.

Se cuantifico empleando el Nanodrop (Thermo Scientific) usando el programa para RNA a 260, 230 y $280 \mathrm{~nm}$ de absorbancia. La normalización se lleva a cabo utilizando el programa de Imagen J (versión 1.43u) se calculan los pixeles de cada banda y se fija cual es la intensidad deseada a alcanzar, sabiendo cuantos $\mu \mathrm{L} / \mathrm{ml}$ por muestra.

Transferencia del RNA a Membrana Hybond-N+.

La transferencia se realizó por capilaridad como se describe a continuación: La cámara de transferencia se limpió con SDS $1 \%$ y se enjuagó con $\mathrm{H}_{2} \mathrm{O}$-depc. Se colocó buffer SSC10X ${ }^{15}$ en la cámara hasta los 2 bordes sin rebasarlos. Se colocó 1 tira larga de papel filtro $3 \mathrm{MM}^{16}$ (Whatman) y se verificó que los extremos colgaran y fueran mojados por el buffer, enseguida se colocaron la 2 da. y la 3er. tira. Con cuidado, se colocó el gel boca abajo (de manera que la transferencia se haga de la parte más plana), después se colocó la membrana de nylon Hybond-N+ (Amersham, GE Healthcare), y después se colocaron los 3 cuadros de filtro $3 \mathrm{MM}^{16}$ (al tamaño del gel), seguido de una torre de papel absorbente y/o papel periódico (altura aproximada de $15 \mathrm{~cm}$ ). Se colocó un vidrio cuadrado (centrado) y un libro de aproximadamente $250 \mathrm{~g}$. Se dejó O.N. Después la transferencia fue desmontada, quitando todo el peso hasta llegar a la membrana.

\section{Fijación del RNA a la membrana.}

La membrana fue colocada sobre una placa o un soporte limpio con SDS al $1 \%$. El RNA fue fijado mediante UV (UVC Crosslinker, Amersham Bioscience) empleando 70,000 $\mu / \mathrm{cm}^{2}$ de energía. La membrana se colocó dentro de $\mathrm{SSC}_{10 \mathrm{X}}{ }^{15}$ y con ayuda de una lámpara de UV, se marcaron los ribosomales y carriles con lápiz.

Marcaje de Sondas.

"Oligomarcaje" fue desarrollado como un método para etiquetar fragmentos de restricción de ADN a alta actividad específica para el uso como sondas de hibridación. El ADN para ser marcado es primero desnaturalizado y luego se mezcla con oligodesoxirribonucleótidos de secuencia aleatoria. Estos " oligómeros aleatorios " reconocen sitios al azar en el ADN y luego sirven como cebadores para la síntesis de ADN por una ADN polimerasa. Con el nucleótido dCTP marcado con $\alpha^{-32} \mathrm{P}$ y presente durante esta síntesis, se genera ADN altamente marcado. 
Las sondas fueron obtenidas por PCR, se calentó el tubo de la sonda ( $1 \mathrm{ng} / \mu \mathrm{L}$ ) por 10 minutos, a $95^{\circ} \mathrm{C}$ (ebullición), después en hielo 5 minutos y se juntó todo el líquido en la parte inferior del tubo con un pulso en centrifuga. Se adicionaron $45 \mu \mathrm{L}$ de la sonda (1 $\mathrm{ng} / \mu \mathrm{L}$ ) al tubo de marcaje kit Ready-To-GoTM DNA Labelling Beads (-dCTP) (Amersham, GE Healthcare). Después se adiciono $5 u l$ de marca radioactiva $\left[{ }^{32} \mathrm{P}\right]-\mathrm{dCTP}(10 \mu \mathrm{Ci} / \mu \mathrm{l})$, al tubo de marcaje y mezclar suavemente. Se incubo a $37^{\circ} \mathrm{C}$ por 30 minutos. Finalmente se adiciono $175 \mu \mathrm{L}$ de $\mathrm{NaOH} 0.1 \mathrm{M}$ para parar la reacción.

Hibridación.

Las membranas se pre-hibridaron junto con los controles correspondientes con $10 \mathrm{~mL}$ de buffer PSE ${ }^{17}$, en el horno de hibridación a $65^{\circ} \mathrm{C}$ durante $2-3$ horas. EI PSE ${ }^{17}$ de pre-hibridación se desechó y se le agregó $10 \mathrm{~mL}$ de PSE $^{17}$ nuevo al tubo de hibridación más $225 \mu \mathrm{l}$ de la sonda marcada ( $50 \mu \mathrm{L}$ sonda $+175 \mu \mathrm{L}$ de $\mathrm{NaOH} 0.1 \mathrm{M}$ ), para posteriormente meterlos en el horno de hibridación a $65^{\circ} \mathrm{CO}$.N.

Lavados.

Se etiquetaron tubos falcón de $15 \mathrm{~mL}$ con el nombre de la sonda. Cada tubo de hibridación se sacó del horno y se vació el líquido dentro del tubo falcón correspondiente, y posteriormente se guardó a $-20^{\circ} \mathrm{C}$. Por otra parte, al tubo de hibridación se le adicionaron $100 \mathrm{~mL}$ de SL ${ }^{18}$, el cual fue llevado nuevamente al horno de hibridación a $65^{\circ} \mathrm{C}$ durante 20 min, esta acción se realizó dos veces.

\section{Autorradiografía.}

Las membranas se colocaron entre dos películas de acetato y fueron envueltos en egapack y puestos dentro de un cassette de exposición (Hypercassette de Amersham GE Healtcare), el cual contenía pantallas intensificadoras de la misma marca. La exposición se llevó a cabo sobre películas Kodak Scientific Imaging ${ }^{\circledR}$ Film, X-Omat Blue XB-1, de $18 \times 24 \mathrm{~cm}$, a $-70^{\circ} \mathrm{C}$. El tiempo de exposición fue directamente proporcional a la señal proporcionada por el contador Geiger-Müller.

$\underline{\text { Revelado. }}$

Las películas Kodak Scientific Imaging ${ }^{\circledR}$ Film antes de ser expuestas contienen cristales de haluro de plata que tienen un color lechoso. Después del tiempo de exposición recibe pequeñas cantidades de radiación durante la exposición, son tan pocos los átomos convertidos en plata metálica negra, que no se percibe ningún cambio de tono, pero la imagen ya está impresionada, es la imagen latente. 
Para amplificar el tamaño de estos puntos negros, se recurre a un baño químico conocido como revelador (Kodak Scientific Imaging®) que actúa transformando en plata metálica negra todos los cristales de haluro que poseen algún átomo de plata, estos pequeños puntos iniciales se denominan núcleos de revelado. Por lo tanto, hay dos procesos: uno fotoquímico que transforma los haluros de plata en plata metálica al recibir un fotón, y otro químico mediante el que las sales de plata con núcleos de revelado pierden su átomo de bromo, cloro o yodo y se reducen a plata metálica. Se establece una etapa entre el revelador y el fijador consistente en un baño que actúa como amortiguador del pH, es el llamado baño de paro.

En la emulsión existen todavía cristales de haluro de plata que no han sido transformados en plata metálica y que, si no se eliminan ahora, cuando se obtengas el negativo se oscurecerá con la luz y se estropearán los resultados. Estos cristales sin reducir se disuelven en un medio ácido como el que llevan los fijadores (Kodak Scientific Imaging ${ }^{\circledR}$ ). Al finalizar el proceso, la película sigue siendo ácida y se encuentra empapada productos y residuos químicos que conviene eliminar para conseguir una imagen estable, pare ello se lleva a cabo una etapa de lavado.

\section{Densitometría.}

Se utilizó el programa ImageJ (versión 1.43u) para normalizar las señales emitidas en la película, las cuales eran proporcionales a la cantidad de transcritos del gen de estudio. Se empleó como base de cálculo el RNA ribosomal en cada carril.

\footnotetext{
${ }^{13}$ MAE10X: 0.2 M MOPS, $50 \mathrm{mM}$ acetato sódico y $10 \mathrm{mM}$ EDTA, ajustado a pH 7.0 con $\mathrm{NaOH}$.

${ }^{14}$ Tampón de carga RNA x 1.25: 2.2mL formamida, $0.8 \mathrm{ml}$ formaldehido, $0.5 \mathrm{~mL}$ de MAEx10, $0.4 \mathrm{ml}$ de $80 \%$ glicerol, $0.1 \mathrm{~mL}$ de $2 \%$ azul de bromofenol, $20 \mu \mathrm{L}$ de gel red $(10 \mathrm{mg} / \mathrm{ml})$ guardar a $-20^{\circ} \mathrm{C}$.

${ }^{15}$ SSC10X: $\mathrm{NaCl} 1.5 \mathrm{M}+$ Citrato de sodio $0.15 \mathrm{M}$, ajustado a $\mathrm{pH} 7 \mathrm{con} \mathrm{HCl} 0.1 \mathrm{~N}$.

${ }^{16}$ Papel para cromatografía 3MM: velocidad de flujo $130 \mathrm{~mm} / 30 \mathrm{~min}$.

${ }^{17}$ PSE: $3 \mathrm{ml}$ de Fosfato sódico 1M, pH 7.2, 7mL de SDS 10\%, y $20 \mu \mathrm{L}$ de EDTA 0.5M.

${ }^{18}$ SL: Solución de Lavado: Por cada $1050 \mathrm{~mL}$ : Fosfato de sodio $1 \mathrm{M} \mathrm{pH} 7.2$ (105 mL), SDA al $10 \%$ (70 mL) y 875 $\mathrm{mL} \mathrm{H}_{2} \mathrm{Od}$.
} 


\section{RESULTADOS}

\subsection{PRUEBA ANTIOXIDATE PARA LOVASTATINA.}

Con el fin de ver si la lovastatina podía ser parte de la respuesta antioxidante global, se evaluó un posible efecto antioxidante de la lovastatina en la célula. Se realizó el siguiente experimento que consistió en comparar el efecto de la lovastatina con el de la $\mathrm{N}$-acetil cisteína (NAC) (un antioxidante ya comprobado), en una prueba química y en una in vivo.

Se comparó directamente el efecto de NAC y la lovastatina; sobre la molécula diclorofluoresceína (DFC), la cual se vuelve fluorescente cuando es oxidada. Se adicionaron EROS exógenos (peróxido de hidrógeno) y después el antioxidante; con el antioxidante se evita que las EROs reaccionen con la DFC reduciendo así la cantidad de fluorescencia observada.

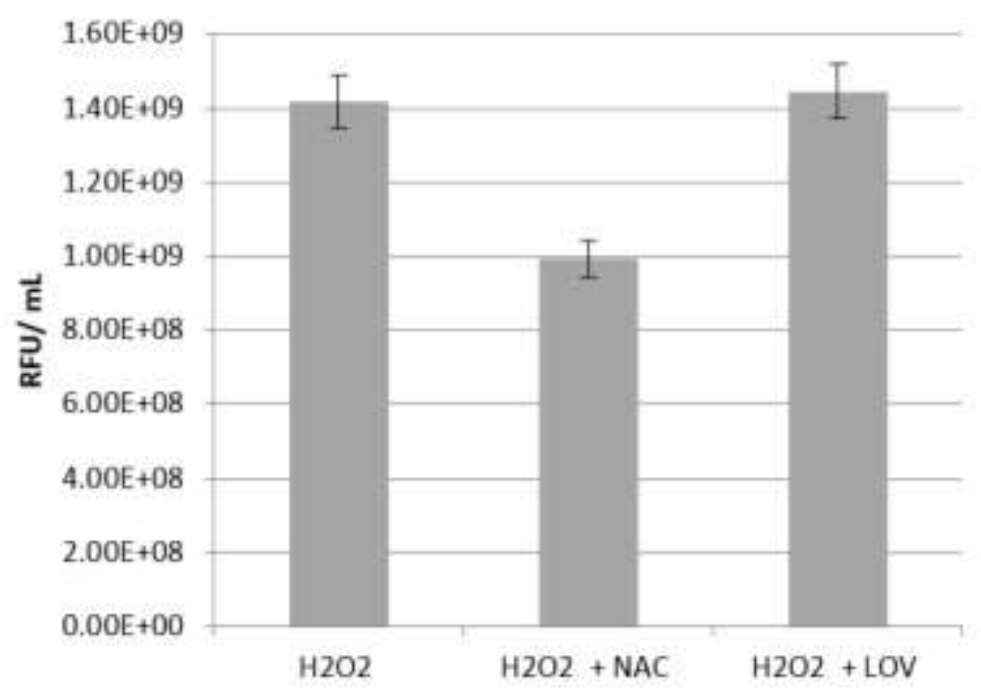

Figura 7.1 Comparación química de diversos tratamientos con DCF (10mM): en peróxido de hidrógeno $(50 \mathrm{mM})\left(\mathrm{H}_{2} \mathrm{O}_{2}\right)$, peróxido de hidrógeno más antioxidante $\mathrm{NAC}(10 \mathrm{mM})$ ( $\mathrm{N}$ acetil cisteína) $\left(\mathrm{H}_{2} \mathrm{O}_{2}+\mathrm{NAC}\right)$ y peróxido de hidrógeno con lovastatina $(10 \mathrm{mM})\left(\mathrm{H}_{2} \mathrm{O}_{2}+\mathrm{LOV}\right)$ en una reacción de 10 minutos. Se lee la fluorescencia de la DCF a excitación en $485 \mathrm{~nm}$ y emisión en $530 \mathrm{~nm}$.

En la primera prueba, en la comparación química — sin material biológico (figura 7.1) —, se observó que con el tratamiento de NAC hay una disminución 
de las EROs y con lovastatina no hay diferencia significativa con respecto a el control que es el tratamiento sin antioxidante.

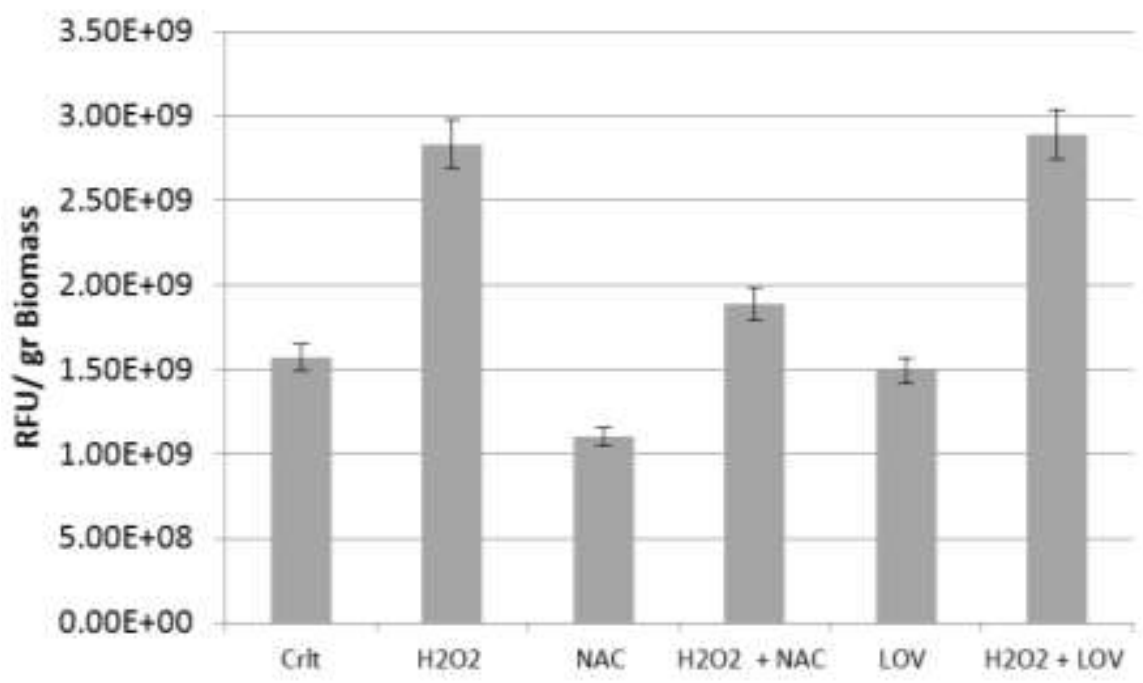

Figura 7.2 Prueba in vivo de diversos tratamientos con DCF (10mM) y micelio de $A$. terreus de la FL a las $48 \mathrm{~h}$ con la adición de los reactivos a las Oh: peróxido de hidrógeno $(50 \mu \mathrm{M})\left(\mathrm{H}_{2} \mathrm{O}_{2}\right)$, antioxidante NAC $(10 \mathrm{mM})(\mathrm{N}$ acetil cisteína) $\left(\mathrm{H}_{2} \mathrm{O}_{2}+\mathrm{NAC}\right)$, lovastatina (LOV) $(10 \mathrm{mM})$ y la combinación de estos. Se lee la fluorescencia de la DCF a excitación en $485 \mathrm{~nm}$ y emisión en $530 \mathrm{~nm}$.

En la prueba in vivo (figura 7.2), se utilizó micelio de Aspergillus terreus, y se observó cómo los tratamientos con NAC reducen los niveles de EROs, mientras que los tratamientos de lovastatina no tuvieron ningún efecto reduciendo los niveles de EROs.

\subsection{IMPORTANCIA DE LA SEÑALIZACIÓN DE LAS EROs EN DIFERENTES MOMENTOS DE LA IDIOFASE}

Para determinar la importancia y el impacto de las EROs, en diferentes tiempos de la idiofase, sobre la biosíntesis de lovastatina, se adicionó el antioxidante de NAC $15 \mathrm{mM}$ a la fermentación líquida en diferentes tiempos. Esto, para reducir los niveles de EROs y ver el efecto que tenían en la acumulación de las EROs y la producción de lovastatina a lo largo del tiempo. En los resultados, no se observaron diferencias significativas, en la concentración de biomasa y el $\mathrm{pH}$, como se muestra en la figura 7.3. 

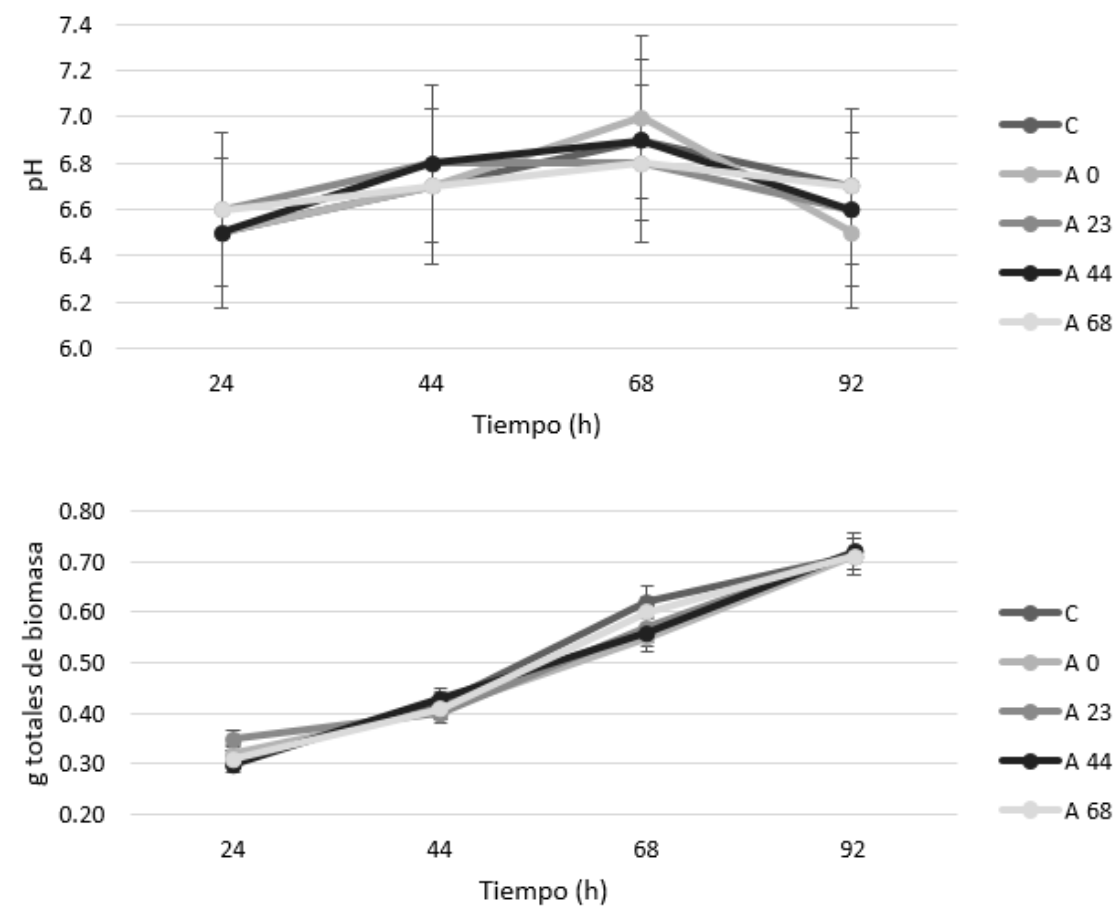

Figura 7.3 Efecto en el pH y la biomasa de la adición de NAC (n-acetil cisteína $15 \mathrm{mM}$ ) a la FL a diferentes tiempos: $\mathrm{A} 0$ adición a las 0 h, A23 adición a las 23 horas, A44 adición a las 44 horas, a lo largo del tiempo de las 24 a las $68 \mathrm{~h}$.

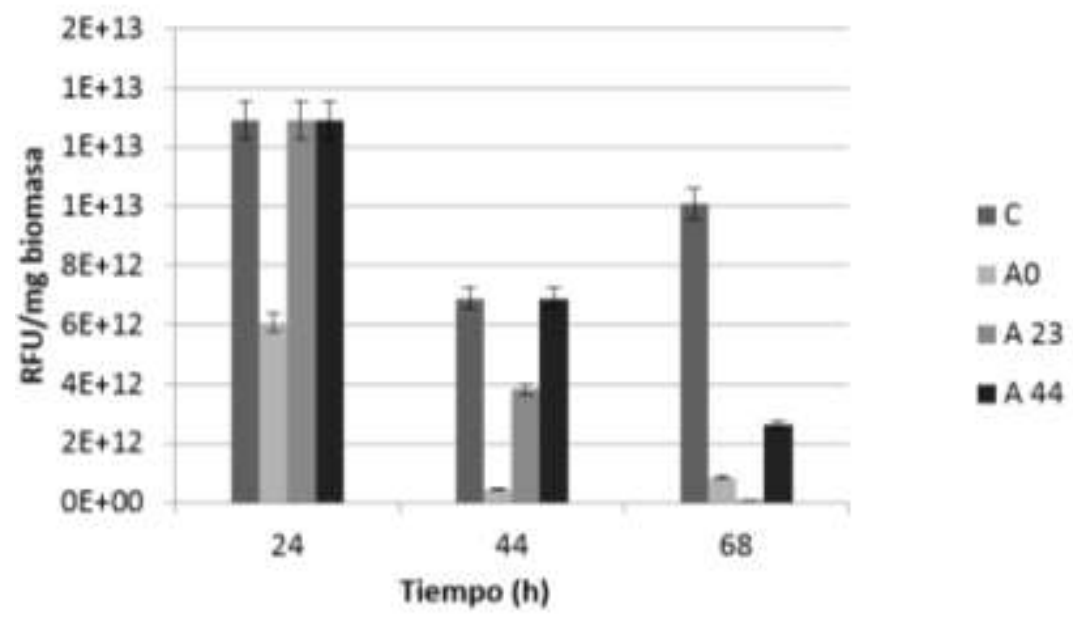

Figura 7.4 Efecto en las EROs de la adición de NAC (n-acetil cisteína $15 \mathrm{mM}$ ) a la FL a diferentes tiempos: A0 adición a las 0 h, A23 adición a las 23 horas, A44 adición a las 44 horas, a lo largo del tiempo de las 24 a las $68 \mathrm{~h}$. 


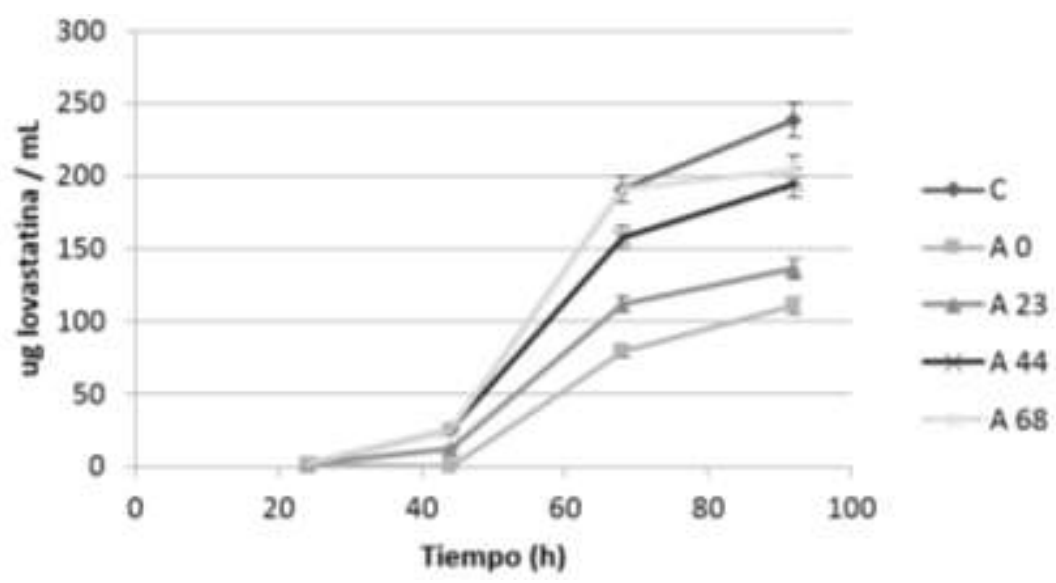

Figura 7.5 Efecto en la producción de lovastatina de la adición de NAC (n-acetil cisteína $15 \mathrm{mM}$ ) a la FL a diferentes tiempos: A0 adición a las 0 h, A23 adición a las 23 horas, A44 adición a las 44 horas, a lo largo del tiempo de las 24 a las $92 \mathrm{~h}$.

Tabla 7.1 Disminución de la producción de lovastatina con la adición de NAC a diferentes tiempos a lo largo de la fermentación.

\begin{tabular}{|c|c|c|c|c|}
\hline \multirow{2}{*}{ Tiempo (h) } & \multicolumn{4}{|c|}{ \% Disminución } \\
\cline { 2 - 5 } & A 0 & A 23 & A 44 & A 68 \\
\hline 44 & 99 & 51 & 0 & 0 \\
\hline 68 & 58 & 41 & 17 & 0 \\
\hline 92 & 53 & 43 & 18 & 14 \\
\hline
\end{tabular}

En la figura 7.3, se muestra la acumulación de EROs a lo largo del tiempo. Se notó que, al adicionar NAC a diferentes tiempos, se redujo la acumulación de las EROs a partir de ese momento las EROs van bajando. Se determinó una disminución mayor en las primeras horas de adición. Se observó que, con la adición de NAC a diferentes tiempos, va disminuyendo la producción de lovastatina a lo largo de la idiofase (figura 7.5); con un mayor impacto en las primeras horas de adición.

En la tabla 7.1, se determinó el porcentaje de disminución de la producción de lovastatina en diferentes tiempos de la idiofase. La adición a las 0 horas mostró el mayor impacto en la disminución con un $53 \%$ de la producción final (considerando a las $92 \mathrm{~h}$ como producción final. De este modo, el efecto va disminuyendo conforme se añade el antioxidante en tiempos más tardíos. La adición de las $23 \mathrm{~h}$ se disminuye un $43 \%$ de la producción final. La adición a las $44 \mathrm{~h}$ disminuye un $18 \%$ y la adición a las $68 \mathrm{~h}$ disminuye un $14 \%$ de la producción final. 


\subsection{ORIGEN DE LAS EROS EN LA CÉLULA.}

En la célula existen diferentes fuentes de EROs, y usando inhibidores se determinó el origen de éstas en las células de cultivos líquidos y de cultivos sólidos de Aspergillus terreus a lo largo del tiempo. Se utilizó cianuro de potasio (KCN) para inhibir la cadena respiratoria, difeniliodonio (DPI) para inhibir a las NADPH oxidasa (NOX) y alopurinol (ALO) para inhibir a la Xantina Oxidasa.

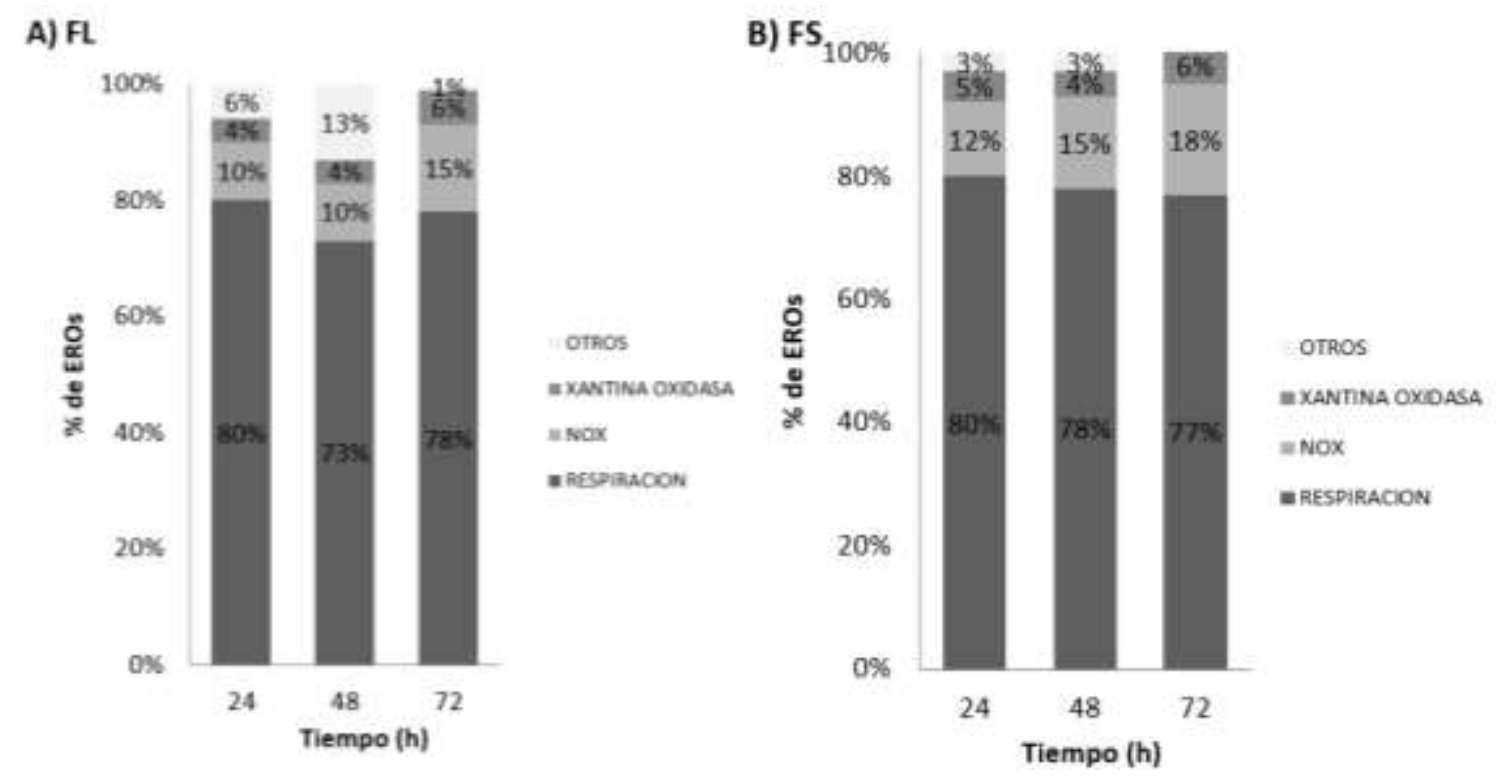

Figura 7.6 Origen de las EROs en A) FL y B) FS: \% de la producción de EROs en: mitocondria, NOX, xantina oxidasa y otros.

Se determinó el porcentaje que las diferentes fuentes de las EROs aportan en la célula (figura 7.6). Se encontró que, en promedio, la principal fuente de EROs es la mitocondria con una participación de un $75-80 \%$ de las EROs del micelio en idiofase. Después, en grado de aporte, se encontraron las de NOX con un $13-17 \%$ y, finalmente, las provenientes de xantina oxidasa con un 2-6\%. Esto sucede en ambas fermentaciones: sólida y líquida. 


\subsection{COMPOSICIÓN DE EROS: PERÓXIDO DE HIDRÓGENO Y ANIÓN SUPERÓXIDO}

Se determinó la composición de las EROs en la célula utilizando diferentes moléculas fluorescentes sensibles específicas para diferentes especies reactivas de oxígeno.

En la trofofase, se encontró que los niveles de EROs de las moléculas de peróxido de hidrogeno y anión súper oxido, estaban en bajos niveles para ambas fermentaciones (figura 7.7). Sin embargo, en la idiofase, la cual inicio a las (24h), el anión superóxido mostró un alza al inicio y después los niveles volvieron a bajar los niveles incluso más bajos que en la trofofase. Es decir, un pico a las $24 \mathrm{~h}$, el cual baja a niveles relativamente bajos a las $48 \mathrm{~h}$.

En el caso del peróxido de hidrógeno, éste se acumula en la idiofase manteniéndo la concentración desde las $24 \mathrm{~h}$ hasta las $96 \mathrm{~h}$. Esto para ambas fermentaciones, sin embargo, es importante notar que los niveles son notoriamente más altos en FL que en FS y se mantienen más estables en FS.

A) Fl
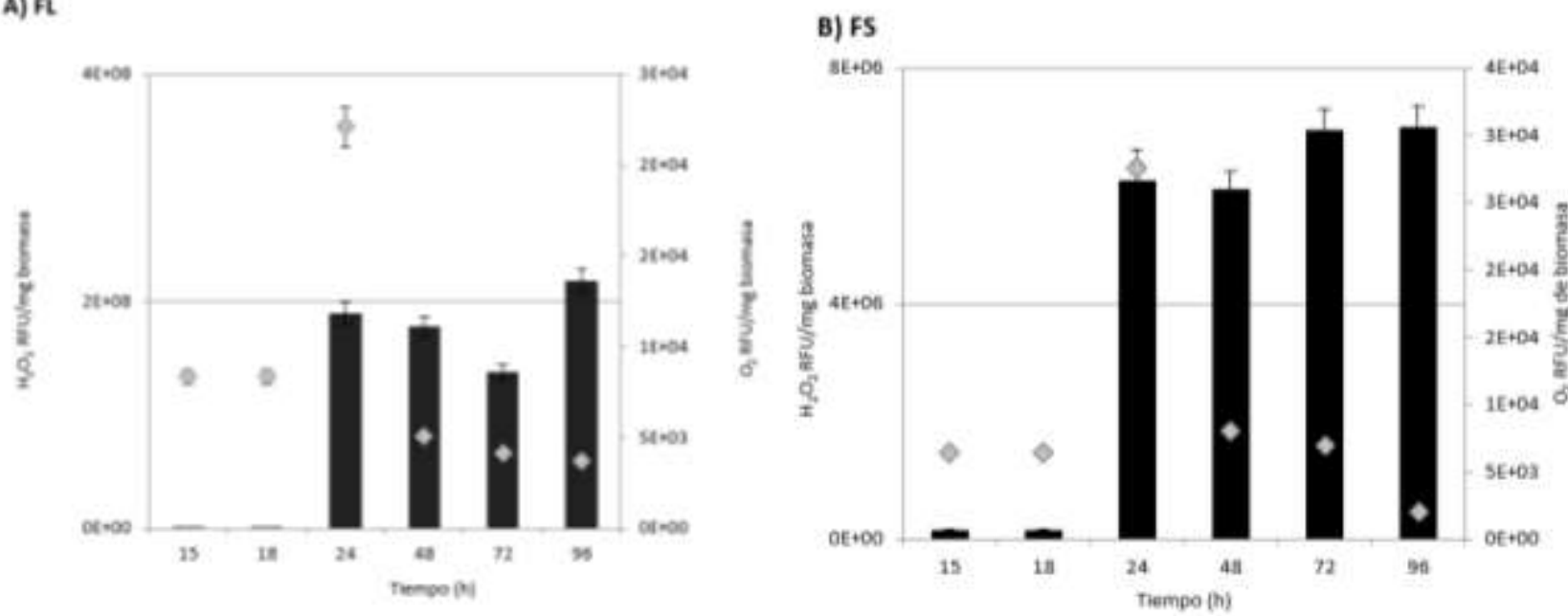

Figura 7.7 Producción de anión superóxido (rombos) y peróxido de hidrógeno (barras) en A) FL y B) FS a lo largo del tiempo. 


\subsection{ENZIMAS ANTIOXIDANTES:}

\section{SUPERÓXIDO DISMUTASA (SOD) Y CATALASA (CAT)}

Se analizaron las actividades enzimáticas de las principales defensas antioxidantes de la célula: la superóxido dismutasa (SOD) y la catalasa (CAT). Los resultados se muestran en la figura 7.8 y 7.9 de CAT y SOD respectivamente.

A)

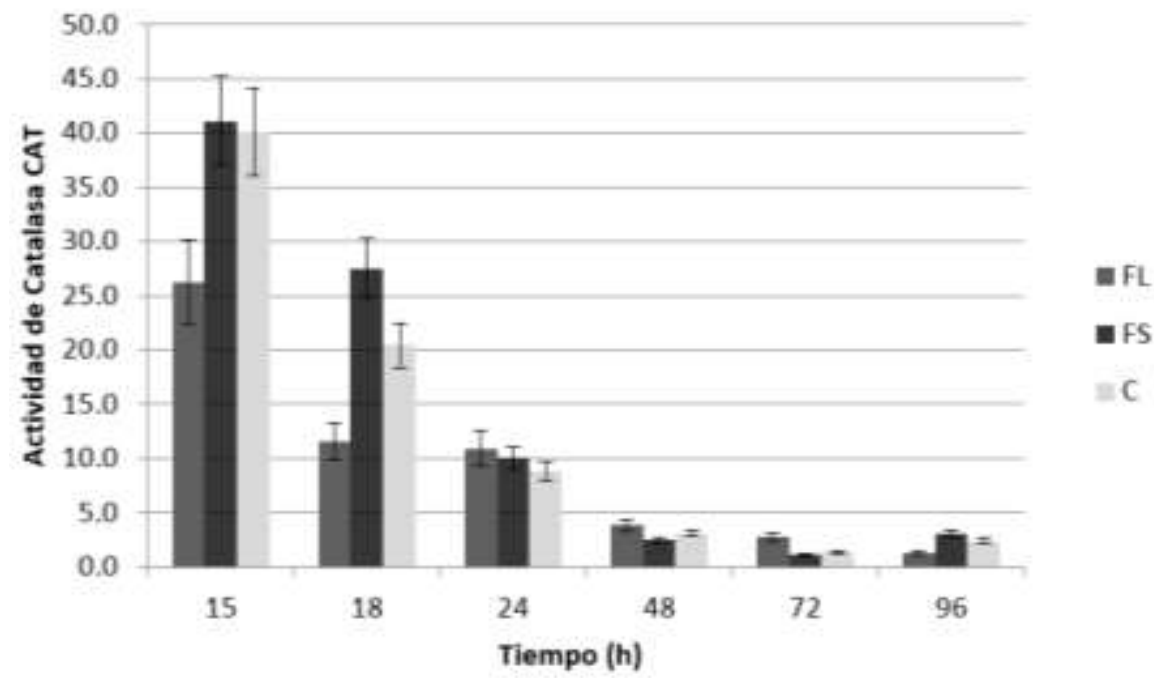

B)

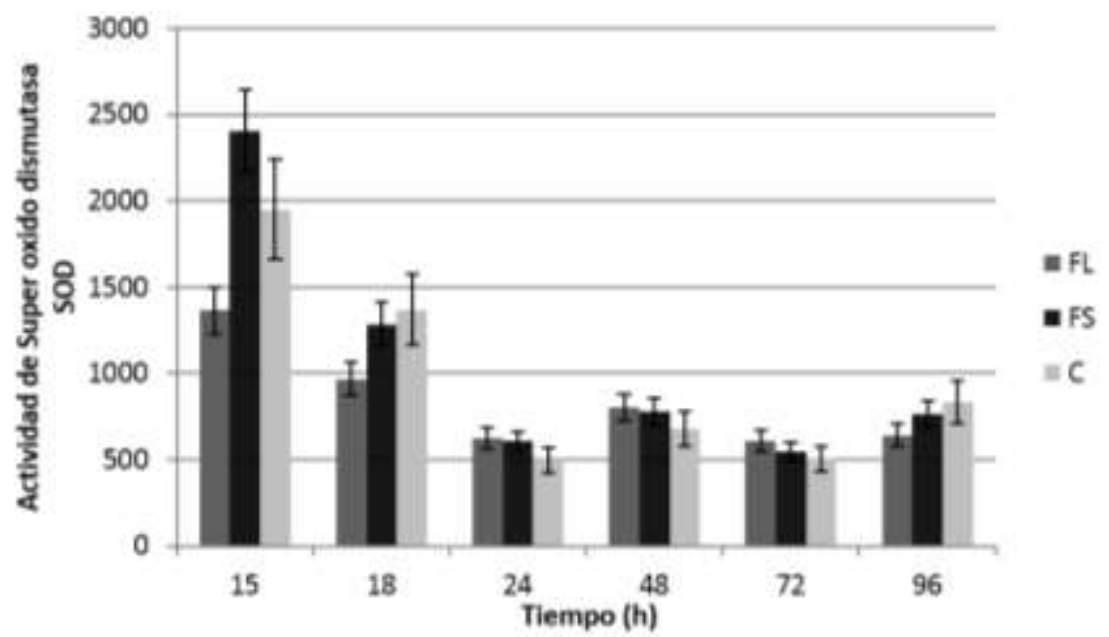

Figura 7.8 Actividad enzimática de A) catalasa (CAT) y B) superóxido dismutasa (SOD) a lo largo del tiempo (horas) en fermentación líquida (FL), fermentación sólida (FS) y columnas de aireación (C). 
En la trofofase, se observó que la actividad de estas enzimas está fuertemente activa. Presentando diferencias en FL y FS, con un $43 \%$ menos actividad de SOD y un $70 \%$ menos actividad de CAT en FL con respecto FS. En el caso de (FS en columna C y FS no hay diferencias significativas ni en trofofase ni en idiofase.

Después de esto, la actividad de SOD y CAT decrece fuertemente al entrar en la idiofase. La actividad de estas enzimas no presenta diferencias significativas entre FS, C y FL.

\subsection{RESPIRACIÓN ALTENATIVA: REGULACIÓN DE LAS EROS}

\subsubsection{RESPIRACION ALTERNATIVA EN FS CON DIFERENTES GRADOS DE AIREACION}

La producción de lovastatina alcanzó $25 \mathrm{mg} / \mathrm{g}$ de cultivo en la FS sin aireación (CF), mientras que el cultivo aireado solo alcanzó $13 \mathrm{mg} / \mathrm{g}$ de cultivo seco. Curiosamente, la acumulación de EROs también fue menor en el cultivo aireado. Este efecto parece contradictorio, ya que en presencia de mayor disponibilidad de $\mathrm{O}_{2}$ se esperaría una mayor producción de EROs.

Para explorar el mecanismo por el cual se reduce la acumulación de EROs en el cultivo aireado, se realizaron experimentos sobre la función mitocondrial en donde se comparó el perfil de respiración en fermentaciones sólidas con distintos grados de aireación; se compararon entonces el sistema de FS en Matraz cerrado (MC) con aireación nula y una columna aireada con una tasa de aireación de $0.05 \mathrm{l} / \mathrm{g} / \mathrm{h}$ (C).

Las actividades respiratorias se midieron por el método clásico de electrodo de oxígeno. La proporción de respiración del citocromo (normal o total), respiración alternativa (resistente al cianuro) y respiración residual (cianuro + SHAM resistente) en la actividad respiratoria se determinaron mediante inhibidores específicos. 
Como se esperaba, los resultados mostraron que la respiración del citocromo o total (RT) era más activa en la FS aireada, particularmente después de $22 \mathrm{~h}$, y aumentaba con el tiempo hasta el final del cultivo (figura 7.9). En contraste, el cultivo de aireación limitada en el MC mostró una alta actividad de la respiración del citocromo en la trofofase, pero disminuyó bruscamente a un nivel inferior en la Idiofase. Curiosamente, la respiración alternativa (RA) se detectó sólo en idiofase, es decir desde 24 h en adelante.

Además, la RA fue más alta en el cultivo aireado, aproximadamente 2 veces más alta que en los $\mathrm{MC}$ a las 24 y $38 \mathrm{~h}$, siendo la diferencia más pequeña en los últimos tiempos. Por otro lado, el consumo de oxígeno residual, que se llamó respiración residual (RR), fue comparativamente más pequeña en ambos cultivos, pero también fue activa sólo durante idiofase (figura 7.9).

Además del hecho de que la RA se activa en idiofase, la RA fue más alta en el cultivo aireado que en el MC. A las $24 \mathrm{~h}$, la RA fue 2 veces mayor en C, con 16 $\mathrm{mmolO}_{2} / \mathrm{h}$.mg de biomasa, mientras que en CF solo alcanzó $8 \mathrm{mmolO} 2 / \mathrm{h} / \mathrm{mg}$ de biomasa (figura 7.9). 

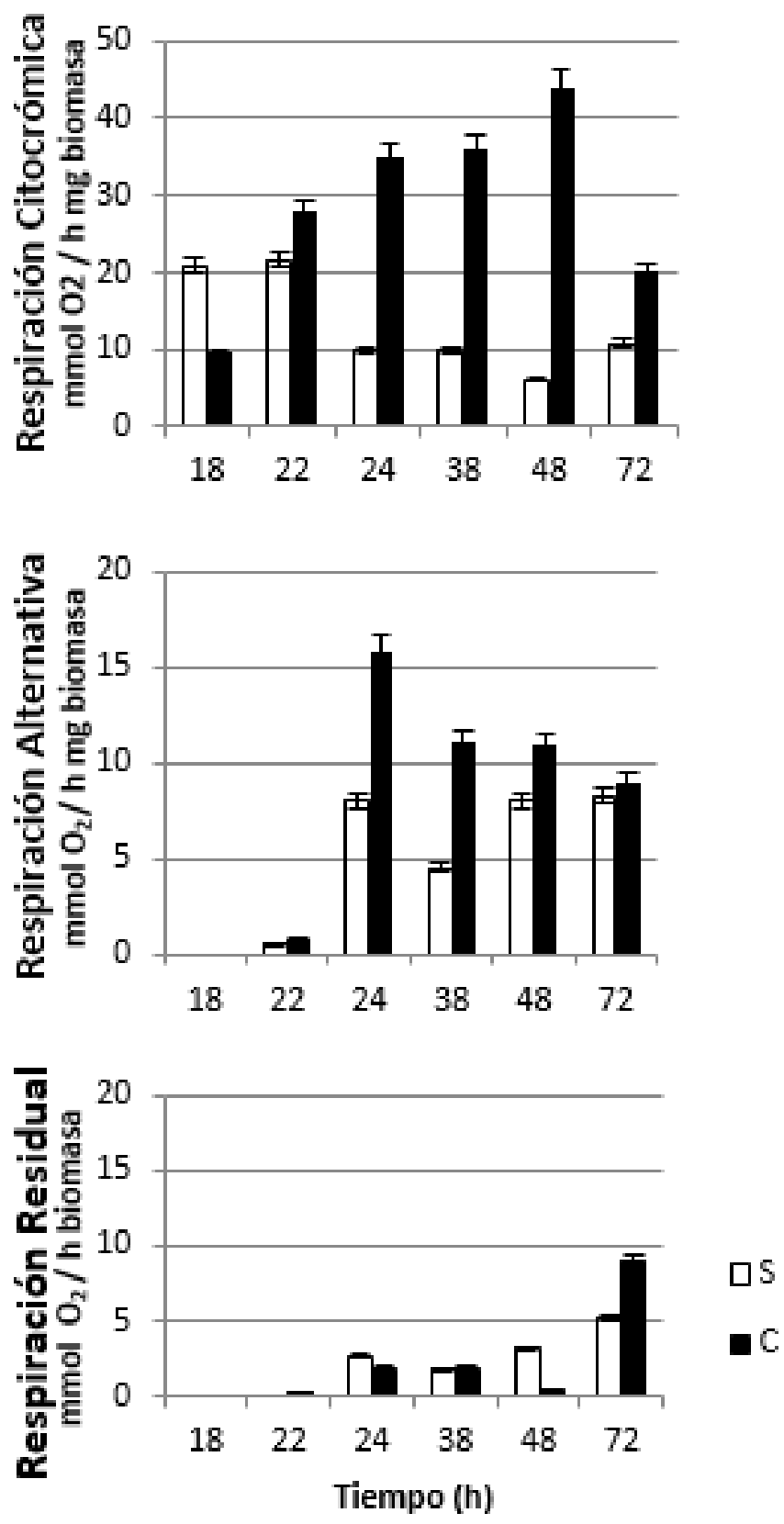

Figura 7.9 Comparación de la capacidad respiratoria a lo largo del tiempo (h) en S (Matraz Cerrado) y C (Columna aireada) $\mathbf{\square}$; compuesta por respiración citocrómica, panel A); respiración alternativa, panel B); y respiración residual, panel C) en $\mathrm{mmol}_{2} / \mathrm{h} \mathrm{mg}$ de biomasa. 


\subsubsection{RESPIRACION ALTERNATIVA: FS VS FL}

Para investigar si la RA en idiofase era sólo una característica de FS, se realizó un experimento donde se compararon los perfiles respiratorios de las FS y FL de lovastatina. Los resultados mostraron una respiración citocrómica (RC) mucho más alta en el micelio de la FS, donde era muy activa en la trofofase y menor en la idiofase (figura 7.10).

La RC de la FS mostró una actividad 7 veces mayor en la trofofase, alrededor de $20 \mathrm{mmol}$ de $\mathrm{O}_{2} / \mathrm{h} / \mathrm{mg}$ de biomasa y se redujo a $5 \mathrm{mmol}$ de $\mathrm{O}_{2} / \mathrm{h} / \mathrm{mg}$ de biomasa en idiofase. En FL, la RC también disminuye ligeramente en la idiofase de 3 a $2 \mathrm{mmol}$ de $\mathrm{O}_{2} / \mathrm{h} / \mathrm{mg}$ de biomasa, aunque vuelve a aumentar en los últimos tiempos.

En relación con la respiración alternativa (figura 7.10), como en el experimento anterior, solo se detectó durante la idiofase de la FS. Sorprendentemente, no se detectó RA, en ningún momento, en el micelio de FL. Aparentemente, esta es una característica fisiológica exclusiva de FS.

Con respecto a la respiración residual (RR); se encontró actividad para ambos sistemas FL y FS ambos se activan en idiofase y permanece así durante toda esta fase 

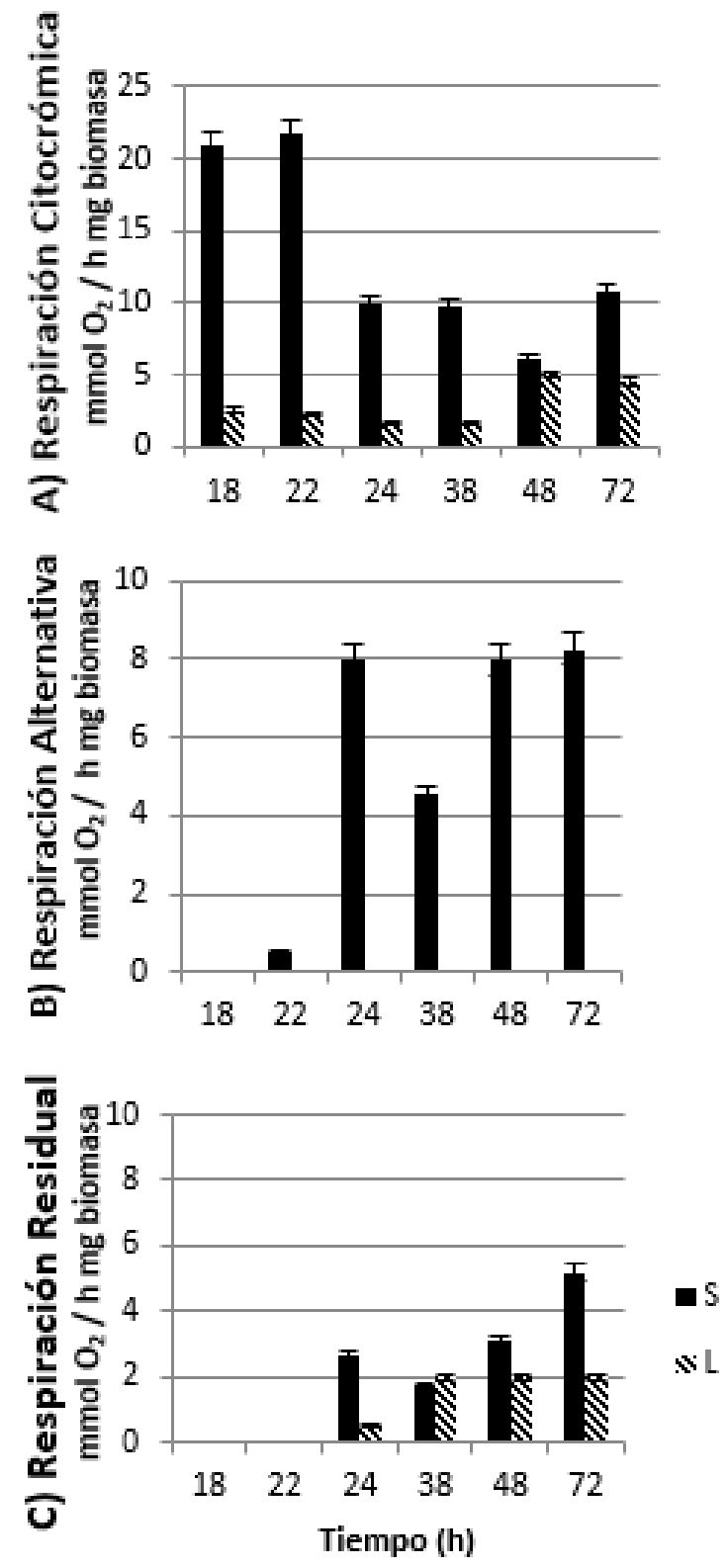

Figura 7.10 Capacidad respiratoria a lo largo del tiempo $(\mathrm{h})$ en diferentes sistemas de fermentación FS (S) $\mathbf{D}$ yL (L) $\$$; compuesta por respiración citocrómica, panel A); respiración alternativa, panel $B)$; y respiración residual, panel $\mathrm{C}$ ) en $\mathrm{mmol}_{2} / \mathrm{h} \mathrm{mg}$ de biomasa. 


\subsubsection{EFECTO DE LA ADICION DE EROS EN LA RESPIRACION ALTERNATIVA}

Para apoyar aún más el vínculo entre EROs y RA, se llevó a cabo un experimento donde fueron agregados EROs exógenos $\left(\mathrm{H}_{2} \mathrm{O}_{2}\right)$ a la fermentación de lovastatina de FS y FL.

En la FS, la adición de $\mathrm{H}_{2} \mathrm{O}_{2}$ (figura 7.11) indujo un aumento en RA de 3.01 a 3.9 $\pm 0.1 \mathrm{mmol} \mathrm{O} / \mathrm{h} / \mathrm{mg}$ de biomasa en idiofase $(48 \mathrm{~h})(\mathrm{p}<0.05)$, mientras que el valor de RR disminuyó en estas condiciones. La adición exógena de EROs también provocó un aumento en la acumulación interna de las EROs, y por lo tanto un aumento en lovastatina producción: de 7.10 a $8.04 \mathrm{mg} / \mathrm{gdc} \pm 0.45, \mathrm{p}$ $<0.05$.

En relación con la $\mathrm{FL}$, se logró inducir la $\mathrm{RA}$ en esta cultura líquida. Es decir, la RA fue detectada por primera vez tiempo en este sistema de cultivo. Como en el caso anterior, la adición de $\mathrm{H}_{2} \mathrm{O}_{2}$ causó un aumento en la acumulación interna de EROs durante idiofase (48 h), causando solamente un ligero (no significativo) aumento en la producción de lovastatina. 


\section{A) FS}
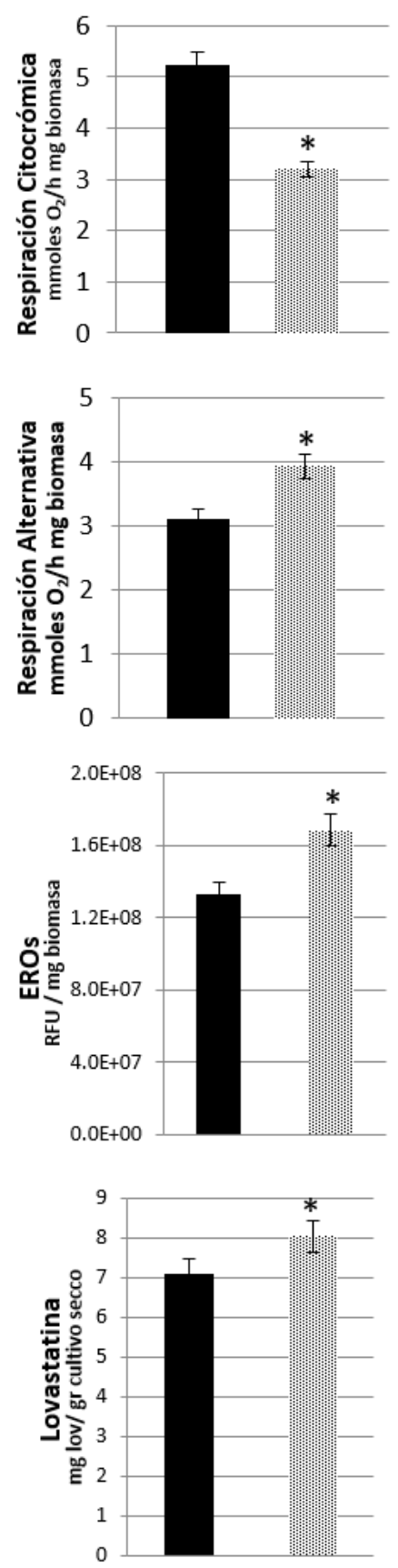

B) FL
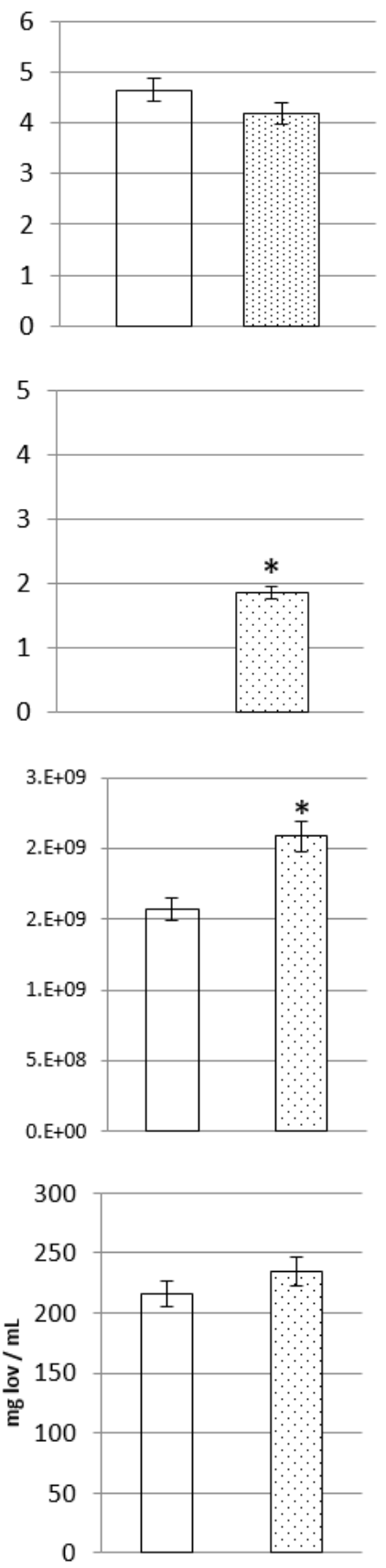

Figura 7.11 Efecto de la adición de peróxido de hidrógeno; $\mathrm{FS}$ control $\square$, FS con $\mathrm{H}_{2} \mathrm{O}_{2} \square$, FL control $\square$ y $\mathrm{FL}$ con $\mathrm{H}_{2} \mathrm{O}_{2}$ 圆; evaluando los parámetros de: respiración citocrómica y alternativa, acumulación de EROs y biosíntesis de lovastatina a las $48 \mathrm{~h}$. 


\subsubsection{EFECTO DE LA ADICION DE INHIBIDORES EN LA RESPIRACION}

ALTERNATIVA

Para estudiar más a fondo el papel de la RA en la acumulación de EROs en la idiofase, se adicionaron a la FS y FL inhibidores de los complejos de respiración. En experimentos preliminares se determinaron las concentraciones de los inhibidores, para no afectar negativamente el crecimiento.

El inhibidor de AOX (RA), SHAM, al adicionarlo directo en la fermentación causó un efecto opuesto, estimulando este componente. Por lo tanto, se usó propilgalato para inhibir la RA en estos experimentos.

En FS, la inhibición de la RC (mediante la adición de cianuro) causó un aumento fuerte y significativo del $60 \%(p<0,01)$ de la RA, mientras que las EROs disminuyeron drásticamente y la producción de lovastatina cayó casi el 52\% (figura 7.12).

En el caso de la FL (figura 7.12), la inhibición de la RC también indujo la RA, aunque a un valor relativamente menor, junto con una reducción drástica de las EROs. En consecuencia, la producción de lovastatina se redujo a sólo el $25 \%$ del valor de control.

Como se puede ver en la figura 7.12, en la FS la inhibición de RA con propilgalato provocó un ligero aumento en la RC. La reducción en RA también provocó un aumento en la concentración de EROs. En FL, donde no hay RA, el uso de propilgalato no causó ninguna diferencia significativa en la concentración de EROs o lovastatina. 


\section{A) FS}
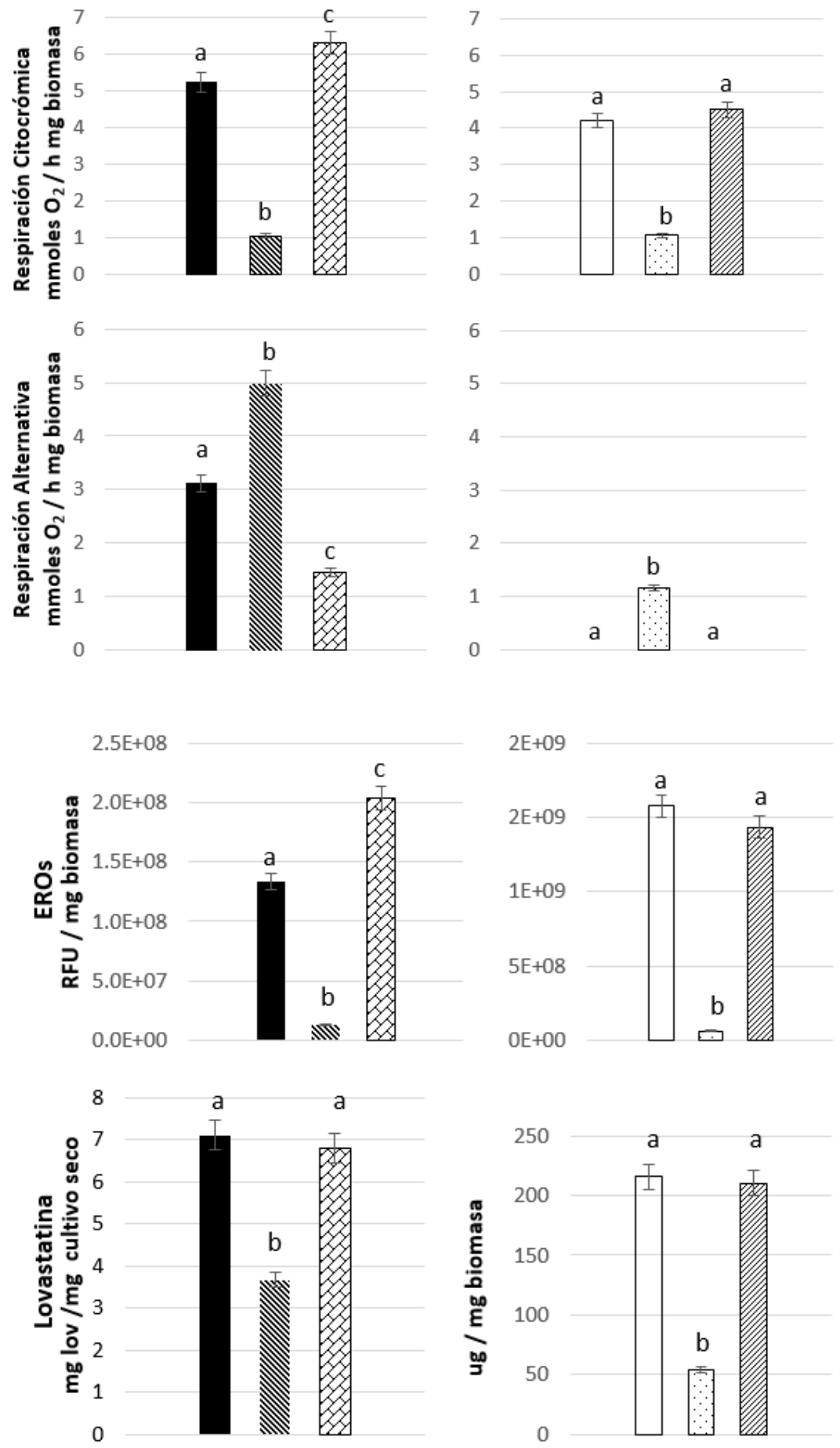

$2 \mathrm{E}+09$

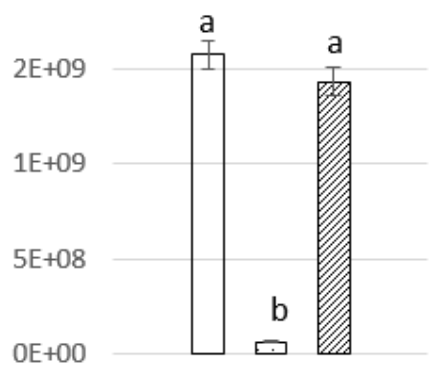

Figura 7.12 Efecto de los inhibidores de la respiración: En FS $\square$, FS con CN 와, FS con PG 因, FL $\square$, FL con $\mathrm{CN}$, FL con PG , evaluando la respiración citocrómica y alternativa, acumulación de EROs y la producción de lovastatina a las $48 \mathrm{~h}$. 


\subsubsection{ESTUDIO DE LAS PRICIPALES ENZIMAS DE LA RESPIRACION}

ALTERNATIVA: AOX Y NADH alternativa
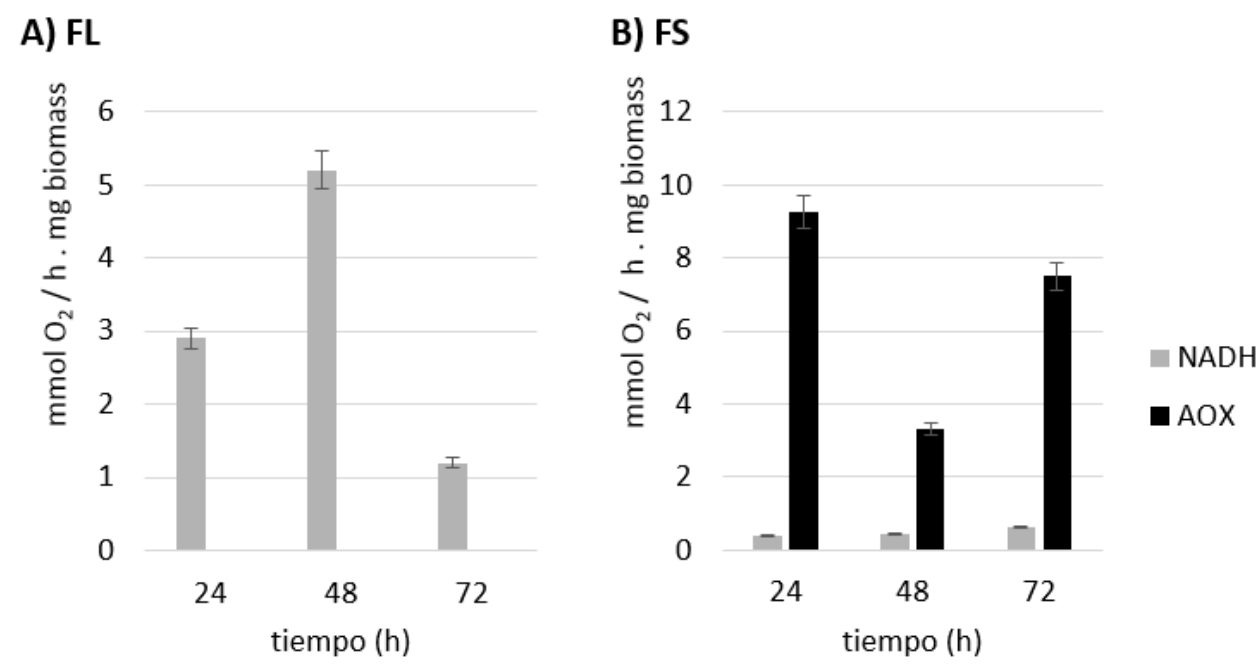

Figura 7.13 Actividad de la NADHa y AOX durante la idiofase (h) en diferentes sistemas de fermentación A) FS y B) FL.

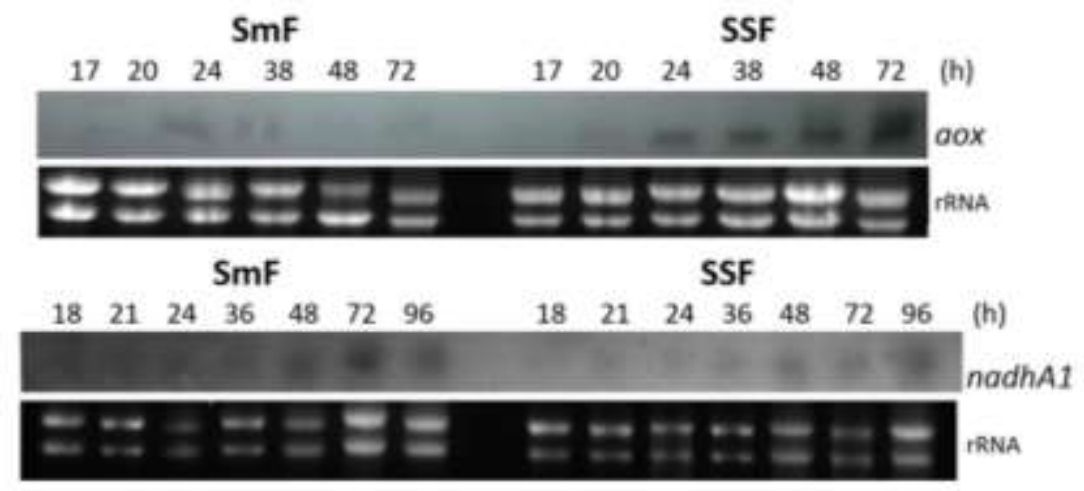

Figura 7.14 Expresión genética de aox y nadh1 enzimas de la respiración alternativa y residual, a lo largo (horas) de la fermentación en FS y FL obtenida por Northen Blot. 
Las pruebas de funcionalidad anteriores indicaron la existencia de una oxidasa alternativa (AOX) responsable de la RA en $A$. terreus. Se encontró una ORF, que muestra una alta identidad del $79 \%$ con el gen aox de Aspergillus fumigatus. Con esta información, fue posible obtener un perfil de expresión de este gen durante la fermentación de lovastatina FS y FL.

El Northern blot reveló que en FS la expresión del gen oxidasa alternativa era casi inexistente en la trofofase (figura 7.14), pero intensamente expresada en idiofase, es decir, hubo una inducción de AOX a las $24 \mathrm{~h}$, y la expresión continuó a lo largo de la fase de producción. Por el contrario, AOX solo se expresó débilmente en FL a las 24 y $38 \mathrm{~h}$.

Debido a la actividad de la NADH alternativa encontrada anteriormente en idiofase, y que no se había descrito previamente en $A$. terreus. Se realizó una búsqueda del gen encontrando una posible proteína hipotética de la NADH alternativa.

Se obtuvo un perfil de expresión de este gen en FS y FL (figura 7.14), y se encontró que la NADH alternativa está presente en ambas fermentaciones, pero es más intensa en la idiofase. Es importante notar que es más activa en $\mathrm{FL}$, lo que coincide con la actividad encontrada en la figura en 7.13.

\subsection{VÍA DE TRANSDUCCIÓN DE SEÑALES DE LAS EROS EN EL METABOLISMO SECUNDARIO}

\subsubsection{ADICION DE NAC A LA FERMENTACION EN $\triangle$ siyap1.}

Las cepas silenciadas para el gen yap1 (o AtyapA) en la tesis de maestría produjeron más lovastatina, pero también un incremento en la concentración de EROs acumuladas en idiofase. Con el fin de poder dilucidar qué fue lo que causó el cambio en la biosíntesis de lovastatina en la cepa silenciada de yap1, se realizó la adición de un antioxidante para poder reducir las EROs y poder evaluar únicamente el efecto del silenciamiento del gen yap1 sin el efecto secundario de la mayor acumulación de las EROs. 


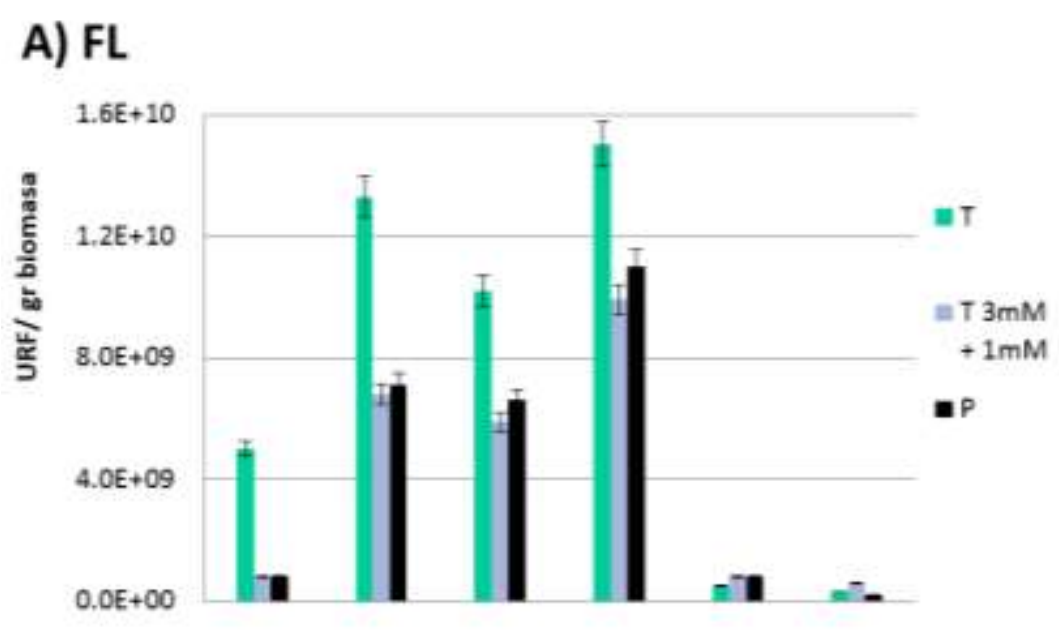

B) FS

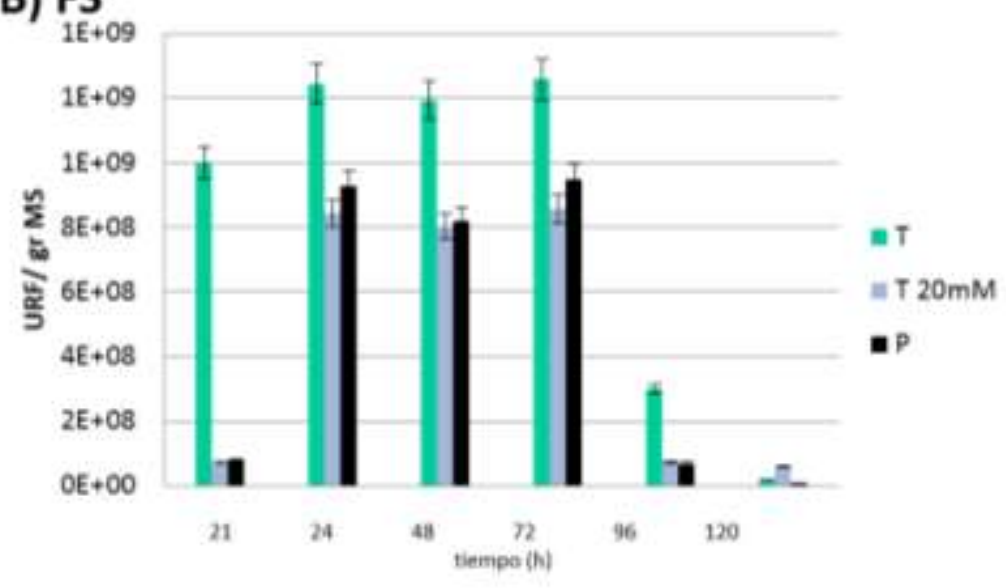

Figura 7.15 EROs en A) FL y B) FS a lo largo del tiempo. Para la cepa parental (P), para la transformante del silenciamiento de yap1 $(\mathrm{T})$, y la transformante con silenciamiento y tratamiento de antioxidantes (T3mM $+1 \mathrm{mM}$ y T20mM) se adicionó en $\mathrm{FL}$ a las Oh una concentración de $3 \mathrm{mM}$ para después a las $25 \mathrm{~h}$ adicionar NAC y llegar a una concentración final de $1 \mathrm{mM}$. En el caso de la FS, se adicionó NAC a las Oh para llegar a una concentración final de $20 \mathrm{mM}$. 


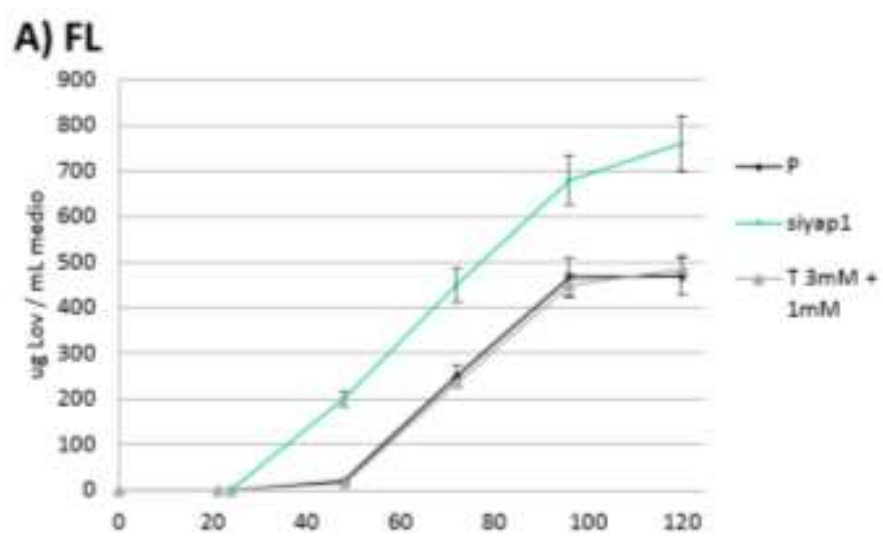

\section{B) FS}

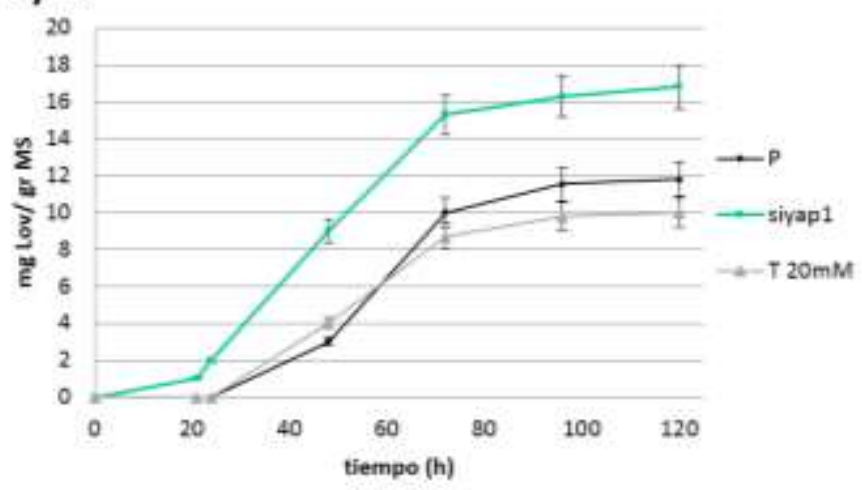

Figura 7.16 Producción de lovastatina en A) FL y B) FS a lo largo del tiempo. Para la cepa parental $(\mathrm{P})$, para la transformante del silenciamiento de yap1 $(\mathrm{T})$, y la transformante del silenciamiento yap1 con tratamiento de antioxidantes $(\mathrm{T} 3 \mathrm{mM}+1 \mathrm{mM}$ y $\mathrm{T} 20 \mathrm{mM})$ se adicionó en $\mathrm{FL}$ alas $\mathrm{Oh}$ una concentración de $3 \mathrm{mM}$ para después a las $25 \mathrm{~h}$ adicionar NAC y llegar a una concentración final de $1 \mathrm{mM}$. En el caso de la FS se adicionó NAC a las Oh para llegar a una concentración final de $20 \mathrm{mM}$.

Como se muestra en la figura 7.15, se logró igualar las EROs de la cepa parental con la transformante siyap1, a través del uso de un antioxidante exógeno NAC ( $\mathrm{N}$-acetil cisteína) en FL y FS.

En la figura 7.16 se muestran los resultados en cuanto a la biosíntesis de lovastatina. Se encontró que, cuando a siyap1 se le adicionan antioxidantes y se resta el efecto de las EROs, la biosíntesis de lovastatina también se redujo al mismo rango de la cepa silvestre, mientras que siyap1 sin antioxidantes muestra mayores niveles característicos del silenciamiento y con un adelanto. 


\subsubsection{AMPC - PKA}

Se determinó en los sistemas de FS y FL los niveles intracelulares de AMPc, así como también la actividad enzimática de las PKA, las concentraciones de las fuentes de carbono, la acumulación de EROs y biosíntesis de lovastatina.

Los resultados se muestran en la figura 7.17; la cinética presenta un perfil y niveles esperados de lovastatina, EROs, glucosa, lactosa, AMPc y PKA, para ambos sistemas de FS y FL, y coinciden con los reportados anteriormente para Aspergillus terreus en la cepa silvestre.

Los niveles observados de AMPc-PKA son mayores en trofofase y van decreciendo conforme inicia la idiofase. La observación más importante que se determinó comparando la cepa parental y la silenciada de yap1 fue a las $21 \mathrm{~h}$ en FL y $19 \mathrm{~h} F \mathrm{~F}$. En esos tiempos, se observó un adelanto en la acumulación de EROs en la cepa silenciada. Este adelanto coincide con un adelanto en la baja de los niveles de AMPc y un adelanto en la baja de la actividad de PKA, así como un adelanto de la biosíntesis de lovastatina. Sin embargo, se conservan los mismos niveles de fuente de carbono: glucosa y lactosa en esos tiempos. 
A) $\mathrm{FL}$
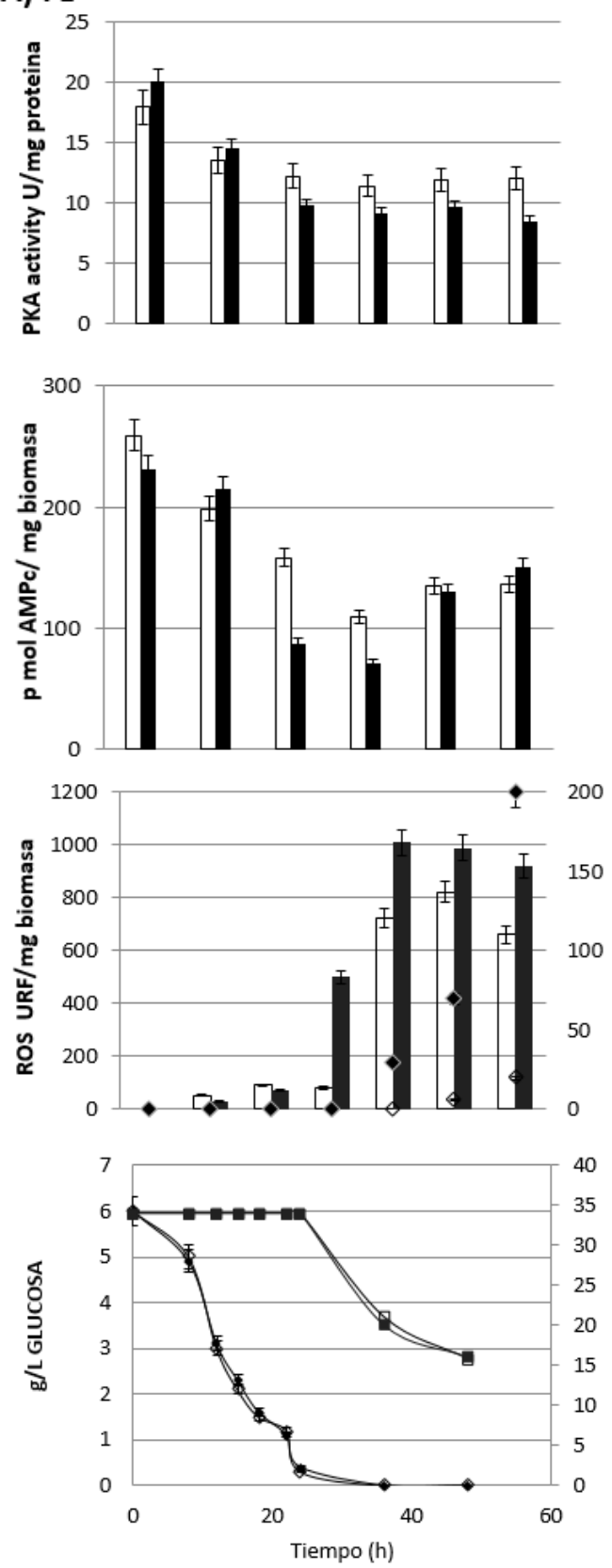

B) FS
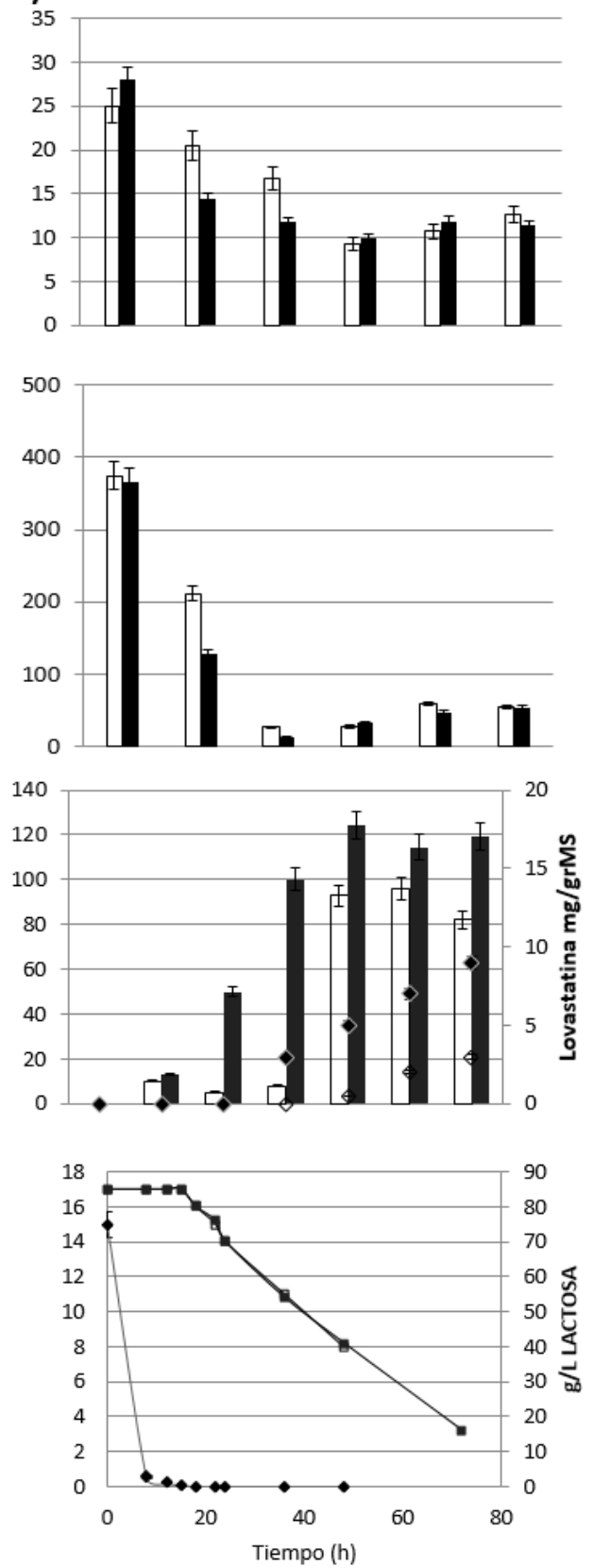

Figura 7.17 Cinética de concentración de AMPc, actividad de PKA y concentraciones de EROs, lovastatina, glucosa y lactosa en FL (panel A) y en la FS (panel B), de la cepa parental $\square$ (WT) y la transformante con el silenciamiento de yap1 $\mathbf{\square}$ (siyap1). 


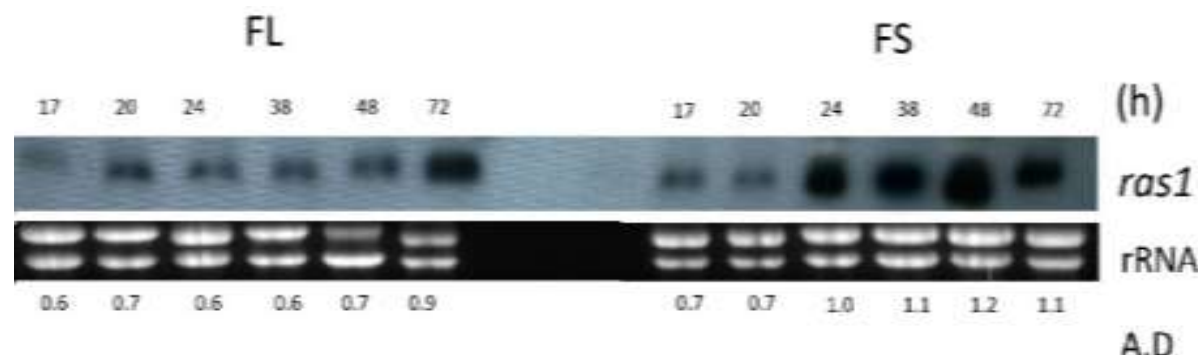

FL $\quad$ FS

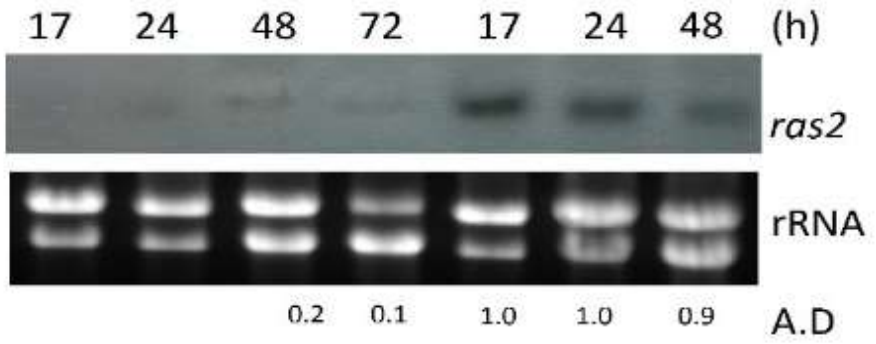

Figura 7.18 Expresión genética de Ras 1 y 2, a lo largo de la fermentación (horas) en FS y FL obtenida por Northen Blot.

Las proteínas RAS están unidas a la membrana y activan varias rutas de transducción de señales, incluyendo la vía de AMPc-PKA. Por ello, se realizó un análisis de expresión de RAS. En el caso de RAS1 la expresión es constitutiva en $\mathrm{FL}$, y en FS con un incremento en la expresión en idiofase. En el caso de RAS2 sólo se encontró expresión en la FS (figura 7.18) en ambas fases. 


\section{DISCUSION DE RESULTADOS}

Es evidente que las EROs juegan un rol muy importante como moléculas señalizadoras y que interactúan con las vías de transducción de señales, para dar una respuesta a ciertas condiciones ambientales. Existe una interacción entre cada una de las diferentes vías de regulación en la célula y que mientras el combatir a las EROs es una necesidad común para el hongo (Folch\&Mallol et al. 2004), en diferentes casos hace uso de diferentes mecanismos no sólo para detoxificarse y asegurar supervivencia, sino que también las EROs actúan como moléculas señalizadores en esta compleja maquinaria de regulación.

Este proyecto se dedicó al estudio de la acumulación de las EROs con el fin de profundizar en la investigación de los mecanismos que pueden regular el metabolismo secundario en la producción de lovastatina por $A$. terreus.

Los resultados obtenidos en este proyecto han aclarado la función de las EROs en la biosíntesis de lovastatina y se describe cómo se ha avanzado pasó a paso para entender el mecanismo del papel de estas moléculas en el metabolismo secundario.

\section{PRUEBA ANTIOXIDATE PARA LOVASTATINA.}

En plantas se ha encontrado que las EROs actúan como segundos mensajeros y son requeridas en diferentes procesos fisiológicos están involucrados en procesos de desarrollo y producción de metabolitos secundarios (Apel y Hirt 2004, Jones et al. 1994).

Efectos parecidos se han observado en mamíferos, han revelado que ciertas rutas de señalización son reguladas por el estado intracelular redox de la célula (Kamata y Hirata 1999), estudios recientes encontraron que los niveles apropiados de las EROs estimulan la modulación del sistema inmune y la regulación de la proliferación celular (Bokoch y Knaus 2003).

Estudios similares en hongos, encontraron en Aspergillus parasiticus, que hay un estado oxidante en la producción de aflatoxinas, que coincide con la 
transición entre trofofase e idiofase; esto lo relacionan con que las aflatoxinas participan como antioxidante en el hongo (Jayashree y Subramanyam 2000).

En A. terreus, Miranda et al. 2013 encontraron un efecto parecido al de $A$. parasiticus, ya que la acumulación de EROs coincidió con el inicio de la producción de lovastatina, y además demostraron que las EROs contribuyen en la señalización de la biosíntesis del metabolismo secundario.

Por esto una de las hipótesis que surgió, era que la lovastatina era un sistema antioxidante que le servía a la célula a combatir el exceso de las EROs y por ello se regulaban con estas moléculas oxidativas, como pasaba con el caso de la producción de las aflatoxinas. Y debido a la importante relación que está marcándose entre las EROs y el metabolismo secundario, es importante saber ¿por qué las EROs están regulando la biosíntesis de lovastatina?, acaso este era un mecanismo general o se debe a una respuesta antioxidante.

Para refutar el efecto antioxidante de la lovastatina en la célula se comparó con el efecto antioxidante con $\mathrm{N}$-acetil cisteína (NAC), un antioxidante ya probado. El análisis consistió en comparar directamente las propiedades antioxidantes sobre la molécula diclorofluoresceína (DFC) que es sensible a las EROs y emite florescencia al oxidarse. Se adicionó una fuente de EROs a través de peróxido de hidrógeno y después se adicionó el antioxidante en este caso NAC y la lovastatina. El DFC es oxidado por las EROs y esto provoca que la molécula sea fluorescente y así se puede determinar cuánto DFC es oxidado, con el antioxidante se evita que las EROs reaccionen con la DFC reduciendo así la cantidad de fluorescencia observada.

El efecto encontrado en ambas pruebas, química e in vivo, mostro que la lovastatina no tiene efecto antioxidante; ya que, mientras los tratamientos con NAC reducen la oxidación de la DFC, la lovastatina no tiene ningún efecto. Por lo tanto, la lovastatina no juega ningún papel en el control de las EROs dentro de la célula. Por lo que el papel de las EROs regulando la biosíntesis de lovastatina no está relacionado con la respuesta global al estrés oxidante. Entonces las EROs están regulando el metabolismo secundario de Aspergillus terreus, como un mecanismo independiente del estado redox de la célula. 
IMPORTANCIA EN LA ACUMULACION DE EROS DURANTE TODA LA IDIOFASE

Miranda et al. 2014, encontró que las EROs están señalizando la biosíntesis de lovastatina; estas inician a las 24 horas justo cuando arranca la idiofase y el metabolismo secundario, además de que estas EROs parece que no sólo regular un punto de la fermentación, ya que la acumulación de las EROs se mantienen a la alta en un nivel toda la idiofase.

Esto contrasta con los estudios realizados con el hongo Neurospora crassa que indican que hay un breve y transitorio periodo de incremento de las EROs al comienzo de cada etapa morfogénica (Toledo et al. 1995). Es decir, al parecer la conidiación y otras transiciones morfogénicas suceden después de un período oxidante, mientras que el metabolismo secundario en $A$. terreus se lleva a cabo durante todo el período oxidante de la idiofase.

Así surgieron preguntas importantes acerca la biosíntesis de lovastatina y la regulación de las EROs: ¿Cuando las EROs estaban señalizando, durante la idiofase?, y ¿son igual de importantes al inicio que al final? Buscando resolver estas preguntas se adicionó el antioxidante NAC a la fermentación líquida en diferentes tiempos para reducir los niveles de EROs y ver qué efecto tenían en la producción de lovastatina.

Se observó que con la adición de NAC, se va disminuyendo la producción de lovastatina, como era de esperarse. Esto significa que, al reducir las EROs con NAC, se frena la producción de lovastatina. Lo más relevante de esto fue que se determinó que el tiempo de adición es proporcional al impacto en la disminución de la producción, esto es que a menor tiempo de adición del antioxidante mayor el impacto de biosíntesis.

En otras palabras, se encontró que las EROs de las primeras horas de la biosíntesis de lovastatina son cruciales para la señalización, sin embargo las EROs están señalizando durante toda la idiofase, aunque las primeras horas son las más importantes para que la acumulación de las EROs señalice la biosíntesis de lovastatina. 


\section{EL ORIGEN DE LAS EROs EN LA CÉLULA.}

Otra de las cuestiones más importantes fue, ¿dónde se estaban originando las EROs dentro de la célula? Esto nos ayudó a comprender dónde se estaba llevando a cabo la producción de las EROs y poder determinar los puntos críticos de esta acumulación.

Se sabe que existen varios orígenes de los radicales libres en la célula, pero los principales cuatro son: Mitocondria, NOX, Citocromo P450 y Xantina Oxidasa (Luis E Gómez-Quiroz, 2017), por ello se decidió estudiar qué proporción de la acumulación de las EROs en la idiofase de la producción de lovastatina, provenía de estas fuentes.

Usando diferentes inhibidores se determinó la disminución de las EROs en ambos sistemas de fermentación líquida y sólida a lo largo del tiempo. Se puede observar como el aporte más importante de las EROs durante la idiofase para ambas fermentaciones es el de la respiración originada en la mitocondria con un $75-80 \%$, esto coincidió de la bibliografía ya que se ha reportado que la mitocondria es el principal organelo donde se producen las EROs, en este se genera el $90 \%$ de anión súper oxido en la célula y tiene dos orígenes en el complejo I y el complejo III (Luis E Gómez-Quiroz, 2017).

Las NOX a diferencia de la mitocondria, son enzimas diseñadas para formar el anión súper oxido coincidiendo con lo reportado para otros microrganismo (Luis E Gómez-Quiroz, 2017), se encontró que para A. terreus el aporte de las NOX es de $13-17 \%$ de las EROs en la idiofase de FS y FL.

Finalmente se observó que la Xantina oxidasa aporta del 2 al 6\%; esto para ambas fermentaciones, esta enzima participa en la vía metabólica de la degradación de las purinas, lo que hace esta vía es pegar tres grupos cetos para polarizar y de esta forma es soluble en agua y se elimina, la formación de anión súper oxido es como subproducto (Angélica Coyoy et al. 2012). 
Quedó claro que, el sitio donde más EROs se produce a lo largo de la fermentación en ambos cultivos es en la mitocondria durante la respiración, esto es un impórtate indicio sobre en dónde se está llevando a cabo una importante regulación de las EROs.

La mitocondria suele ser considerada como la generadora de EROs por excelencia. Existe la concepción, poco precisa, de que la producción de EROs por el organelo es consecuencia "accidental" de la fuga de electrones que son captados por el oxígeno molecular. Existe evidencia de que la mitocondria presenta algunos mecanismos bien regulados que permiten la producción de EROS con la finalidad de conducir procesos celulares bien definidos (Zorov, D. B et al. 2014).

Se ha visto que las NADPH oxidasas en la mitocondria son capaces de producir EROs con el único objetivo de señalizar con umbrales que permiten este proceso y no el daño celular (Luis E Gómez-Quiroz, 2017), por ello es fundamental conocer como la producción de las EROs se lleva a cabo en la mitocondria y la relación con en la producción de lovastatina en $A$. terreus.

\section{COMPOSICIÓN DE EROS: PERÓXIDO DE HIDRÓGENO Y ANIÓN SUPERÓXIDO}

Las EROs son moléculas muy reactivas entre las que se encuentran los iones de oxígeno, los radicales libres y los peróxidos. Su gran reactividad se debe a que poseen electrones desapareados que les hace reaccionar con otras moléculas orgánicas en procesos de óxido-reducción (Bedard y Krause, 2007).

Cuando se miden, se determina un conjunto y una mezcla de todas las que están presentes en la célula. Así surgieron las preguntas, ¿cuál es la composición de esta mezcla de moléculas?, y ¿qué molécula estaría jugando un papel fundamental en la señalización? Ya que existe evidencia que sugiere que las especies reactivas de oxigeno (EROs), tales como los aniones superóxido y el peróxido de hidrogeno, funcionan como segundos mensajeros intracelulares. 
Por ello, con el fin de tener una visión más amplia de la composición de las EROs en la célula, se determinaron las EROs más relevantes: el anión superóxido y el peróxido de hidrógeno. Hay que recordar que, el anión superóxido es muy inestable y se trasforma inmediatamente en peróxido de hidrógeno por las superóxido dismutasas, para que después el peróxido de hidrógeno sea neutralizado por las catalasas formando agua y oxígeno (Finkel, 1998).

Los resultados obtenidos, muestran que existe un patrón para ambas fermentaciones, al inicio de la idiofase solo a las $24 \mathrm{~h}$ hay una acumulación del anión superóxido, esto indica que podría estar participando en el arranque del inicio de la idiofase y la biosíntesis del metabolismo secundario; sería interesante realizar un análisis más profundo de la función de esta ya que en algunos casos ha encontrado que el anión superóxido tiene una función muy importante, ya que participa en la descarga respiratoria de las células fagocíticas activadas por contacto con partículas extrañas en los eventos inmunológicos. (Bedard y Krause, 2007).

En el caso del peróxido de hidrógeno se encontró que está acumulándose durante toda la idiofase; aunque no es un radical libre, tiene una gran afinidad que le permite atravesar las membranas celulares y reaccionar con el anión superóxido en presencia de metales de transición, para generar el radical hidroxilo, por esta razón se le considera un oxidante importante en las células de los organismos aerobios (Bedard y Krause, 2007).

El encontrar al peróxido de hidrógeno acumularse durante toda la idiofase y en niveles tan estables; indica que la molécula con mayor grado de importancia y aportación para la señalización del metabolismo secundario es el peróxido de hidrógeno. 


\section{ENZIMAS DE DEFENSA ANTIOXIDANTE:}

\section{SUPERÓXIDO DISMUTASA (SOD) Y CATALASA (CAT)}

Está comprobado que las EROs están relacionadas a nivel transcripcional con la biosíntesis de lovastatina. Saber cómo éstas son reguladas para señalizar el metabolismo secundario durante la idiofase es primordial para poder entender cómo funciona esta vía de transducción de señales y así poder controlar la producción de metabolitos secundarios.

Así, surge la pregunta de cómo los niveles de EROs son regulados durante la idiofase, ¿cuál es el sistema que se encarga de mantener el nivel necesario para la señalización de la lovastatina? El primer candidato para responder esta pregunta fue el sistema enzimático de defensa antioxidante, que se encarga de contener y mantener los niveles saludables y necesarios para la señalización de las EROs.

Para este análisis se estudiaron las actividades enzimáticas de las principales defensas antioxidantes de la célula: la superóxido dismutasa (SOD) y la catalasa (CAT). Hay que recordar que, al inicio de la fermentación en la trofofase las EROs mantienen niveles muy bajos, para después en la idiofase, fase donde se lleva a cabo la producción de metabolitos secundarios, se dé el aumento en la acumulación de estos a niveles que desencadenan la cascada de señalización.

Lo que se observó, fue que en la trofofase la actividad de estas enzimas, tanto de SOD como de CAT, está fuertemente activa y va decreciendo conforme arranca la idiofase. Este comportamiento aparece en ambos sistemas de fermentación.

Cuando se compara la FS vs la FL, las principales diferencias se presentan en la trofofase, en cuanto a la $\mathrm{FL}$ son mucho menos activas las enzimas antioxidantes que en el sistema de FS. Sin embargo, al entrar la idiofase, no presentan diferencias significativas, por lo que estas enzimas en idiofase no son las responsables de las diferencias en la acumulación de las EROs presentes en estos sistemas de fermentación. 
Esto coincide con Kreiner et al. 2000, que estudiaron el efecto de la tensión de oxígeno disuelto y la concentración de oxígeno en la tasa de crecimiento del hongo $A$. niger B1-D, encontraron que existía una mayor actividad de las enzimas Sod y Cat al final de la fase estacionaria y al inicio de la fase de decaimiento (Bai $Z$ et al. 2003b).

Al estudiar la FS un parámetro importante de estudio es la aireación por eso se realizó el estudio de la acumulación de las EROs con diferentes grados de aireación, fue inesperado encontrar concentraciones más bajas de EROs con mayor aireación, a pesar de que en FS el micelio está en contacto directo con el aire, es decir, hay más $\mathrm{O}_{2}$ disponible y nuestra predicción era que habría más actividad respiratoria y por lo tanto EROs más altos.

Sin embargo, en FS se encontró una particular relación con la aireación y las EROs, esto coincidió con un estudio previo realizado por Baños et al. (2009) donde demostraron que la producción máxima de lovastatina se obtiene en condiciones de aireación limitada, es decir, en matraces cubiertos con parafilm y papel de aluminio (matraces cerrados).

En un estudio posterior, se encontró que la producción específica de lovastatina disminuía con la aireación, aunque estas condiciones tenían un fuerte efecto positivo sobre el crecimiento (concentración de biomasa) y que esto también ocurría en FS más convencionales como FS en salvado de trigo o bagazo de caña de azúcar (Pérez -Sánchez et al., Manuscrito en preparación).

Así surge otra de las grades preguntas al estudiar la FS , ¿cómo la acumulación de las EROs es menor cuando se aumenta la aireación?, ya que es contradictorio puesto que, al estar en mayor contacto con el oxígeno, se esperaba mayor cantidad de EROs. Se supuso que este comportamiento se debía a una diferencia en la actividad enzimática antioxidante, por ello se analizó la actividad de Cat y Sod en sistemas con diferente nivel de aireación. 
En los resultados se encontró que durante la idiofase, el matraz y la columna no presentaron ninguna diferencia significativa, por lo que el nivel de aireación no causa ninguna diferencia en la actividad enzimática antioxidante. Por lo tanto los niveles de EROs son contenidos o nivelados por otro sistema al entrar la idiofase. Mientras que en la trofofase la acumulación de las EROs es contrarrestada por Sod y Cat.

Mientras que combatir las EROs es una necesidad común para el hongo, en diferentes organismos se hace uso de diversos mecanismos para detoxificarse de las EROs y asegurar la supervivencia (Folch-Mallol et al., 2004); se encontró que en $A$. terreus el sistema de detoxificación en trofofase es Cat y Sod. Sin embargo, debe existir otro sistema que ayude a regular la acumulación de las EROs en idiofase.

Aún continuaba entonces la pregunta de ¿cómo los niveles de EROs son controlados para la correcta señalización de la lovastatina durante la idiofase?; ahora que ya se sabe que no son Sod ni Cat el sistema de defensa antioxidante en regularlas había que explorar otras opciones.

\section{RESPIRACIÓN ALTENATIVA: REGULACIÓN DE LAS EROs}

En el presente trabajo, se confirmó que una mayor aireación provoca una menor producción de lovastatina. Además, se demostró que el efecto negativo de la aireación en la producción de lovastatina está mediado por las EROs, es decir, una aireación más alta reduce la concentración de las EROs en la idiofase.

Esto significa que la razón subyacente para la reducción en la producción del metabolito es la disminución de la concentración de las EROs. Esto parecía contradictorio ya que se sabe que las EROs generalmente son un subproducto de la respiración aeróbica y, por lo tanto, las fugas de electrones deberían ser más intensas en las culturas más aireadas. Esto no podría ser el trabajo de las enzimas defensivas, como la superóxido dismutasa o la catalasa, ya que se había demostrado que sus genes estaban regulados negativamente en idiofase 
(Miranda et al., 2013) y su actividad también es menor en esta etapa (PérezSánchez et al. manuscrito en preparación).

El presente estudio estableció que en la FS de lovastatina, la respiración alternativa (RA) se activa precisamente al comienzo de idiofase manteniendo una actividad bastante constante durante toda la fase de producción. Los resultados mostraron que en la FS aireada, la RA era aproximadamente 2 veces mayor que en la FS con aireación limitada. Esto indicó que esta mayor actividad de la RA fue responsable de las concentraciones más bajas de EROs encontradas en el cultivo aireado.

Además, en cada experimento donde se estimuló RA, la concentración de EROs presentaron una fuerte disminución. Esto muestra que RA funciona como el mecanismo por el cual los niveles de EROs se reducen, y se mantienen en niveles saludables, en FS. Además, estos niveles de EROs comparativamente más bajos y más estables son posiblemente la razón por la cual los genes biosintéticos se expresan más intensamente en FS (Barrios-González et al., 2008).

Esta es la primera vez que se demuestra la participación de AOX en la intrincada regulación del metabolismo secundario y por otro lado, el hecho de que RA se inicie precisamente en el inicio de la idiofase, que es el momento de la acumulación de EROs y la biosíntesis de lovastatina, sugirió que las EROs estaban induciendo la RA. De hecho, se identificó el gen aox en el genoma de A. terreus y se demostró que en $\mathrm{FS}$ se induce durante la idiofase. Esto indicó que, en $A$. terreus, las EROs regulan positivamente la RA a nivel transcripcional.

La producción convencional de lovastatina y muchos metabolitos secundarios se lleva a cabo en FL, sin embargo, en años recientes, la investigación ha despertado un interés por la FS como una alternativa industrial a la FL. Esto se debe a las ventajas que presenta la FS, principalmente las altas productividades y rendimientos. 
No sólo esto, sino que existen metabolitos que sólo se pueden producir en FS Por ello, la FS es un método de cultivo alternativo que se ha vuelto cada vez más atractivo para la investigación y para la industria (Barrios- González, 2011).

Debido a estas ventajas que la FS presenta ante la FL; es importante encontrar y comprender los estímulos de la fisiología de la FS para poder aplicar y desarrollar sistemas de fermentación que aprovechen las particularidades de la FS, por ello en una siguiente etapa del estudio de la RA se comparó la FS con FL.

Curiosamente se encontró que la RA no existe en la FL de lovastatina, por lo que esta es una característica exclusiva de FS es decir, que es parte de la fisiología del medio sólido y en particular del metabolismo secundario en FS.

Se ha estudiado el efecto de la oxigenación excesiva de birreactores en FL para la producción de proteínas recombinantes en Aspergillus niger, sin embargo, el estrés oxidante inducido por estas condiciones tuvo efectos perjudiciales en la producción (Wongwicharn et al., 1999; Bai et al., 2004).

Como en el presente estudio, los autores razonaron que estos cultivos de FL experimentan condiciones oxidativamente estresantes, por lo que se esperaría que los niveles de las EROs aumentaran, sin embargo, Bai et al. (2003a, 2003b) describieron una generación de $\mathrm{O}_{2}{ }^{\bullet}$ significativamente disminuida en cultivos de $A$. niger aireados con aire enriquecido en $\mathrm{O}_{2}$. Propusieron que esto podría deberse a una mayor actividad de una enzima NADH deshidrogenasa alternativa, que podría actuar en lugar del complejo I (Bai et al., 2004).

En otros experimentos, se añadieron directamente a las fermentaciones de lovastatina inhibidores de la cadena respiratoria, lo que encontró fue la inhibición de la respiración citocrómica $(\mathrm{RC})$ con $\mathrm{CN}$ como se esperaba y lo más notable es que se logró inducir la RA. Esto sugiere fuertemente que la RC y la RA están regulados coordinadamente, de tal forma que uno puede respaldar el mal funcionamiento del otro. Por otro lado, cuando la RA se inhibió, las EROs 
aumentaron fuertemente en FS, apoyando aún más la idea de que la función de que la RA es controlar la producción de EROs para mantenerlos en un nivel saludable, a expensas de la producción de ATP, y que esto es una característica clave de la fisiología del medio sólido que podría explicar, al menos en parte, la producción de metabolitos secundarios más altos en este sistema de cultivo.

En FS debido a que la RA se activa al inicio y durante la idiofase, y es en esta fase cuando se acumulan las EROs, consideramos que las EROs estaban induciendo la RA. En la siguiente parte del estudio se adicionó peróxido de hidrógeno a la FS y FL de lovastatina. Se encontró entonces que las EROs inducían la RA en $\mathrm{FL}$ y la aumentaban en FS. En resumen la adición de $\mathrm{H}_{2} \mathrm{O}_{2}$ indujo la RA en FS y sorprendentemente también en FL. Esto significa que concentraciones suficientemente altas de EROs pueden inducir esta actividad también en un cultivo líquido.

Los resultados también sugieren que, en FL, la concentración instantánea de EROs es menor, por lo que no echa a andar este mecanismo. Todavía no se sabe el papel y las funciones fisiológicas de las enzimas respiratorias alternativas que se encuentran en muchos hongos y plantas. En la mayoría de los sistemas estudiados, las AOX están sujetos a múltiples formas de regulación y generalmente operan solo en condiciones que inhiben el transporte de electrones estándar (Joseph-Horne et al., 2001).

Estudios en los hongos Hansenula anómala y Magnaporthe grisea han demostrado que las AOX fueron inducidas por las EROs, independientemente del estado funcional de la cadena respiratoria (Minagawa et al., 1992; Yukioka et al., 1998), coincidiendo con lo encontrado por nosotros en $A$. terreus.

De acuerdo con nuestros resultados, la respiración residual (RR) también se activa en idiofase en ambos sistemas de cultivo. Pero, lo que se llamó RR en este trabajo, muy probablemente incluye la actividad de NADH deshidrogenasas alternativas no mitocondriales y reacciones no específicas de consumo de $\mathrm{O}_{2}$ que podrían ser extra mitocondriales y llevarse a cabo en el citoplasma. 
En esta tesis, se propone que en FS, el contacto directo con el aire representa una gran disponibilidad de $\mathrm{O}_{2}$, que induce la respiración rápida, esto puede generar concentraciones de EROs peligrosas, entonces la RA se activa para disminuir la producción de EROs en idiofase.

Esto probablemente crea concentraciones de EROs adecuadas y relativamente estables en idiofase, que representan una mejor señalización para los genes biosintéticos de lovastatina. Por el contrario en FL, la menor disponibilidad de oxígeno induce una RC menor $\mathrm{y}$, por lo tanto, una generación de las EROs menos peligros, por lo que no se activa la RA. Sin embargo, esto redunda en niveles de EROs más altos que en FS y menos estables.

Dado que no se encontró actividad de AOX en FL, pero sí de las NADH alternativas es posible que estas oxidasas no mitocondriales alternativas sean el mecanismo de reducción de las EROs en este sistema de cultivo.

Este conocimiento se puede aplicar potencialmente para aumentar la producción de lovastatina y quizás otros metabolitos secundarios en la industria. El objetivo sería generar cepas que alcancen un nivel óptimo de EROs en la idiofase y en niveles relativamente constantes. Esta última característica parece estar asociada a la actividad de AOX, ya que esto se observa típicamente en las FS de lovastatina, mientras que en las EROs de FL los niveles son relativamente altos y muy variables. 


\section{VÍA DE TRANSDUCCIÓN DE SEÑALES DE LAS EROS EN EL METABOLISMO SECUNDARIO}

Hay que recordar que el objetivo de este proyecto es saber cómo funcionan las EROs dentro de la célula, debido a su papel en la fisiología de los organismos como segundos mensajeros en las vías de transducción de señales.

Así surge la pregunta, ¿cuál es el mecanismo por medio del cual las EROs regulan los genes de biosíntesis de lovastatina y probablemente otros metabolitos secundarios? ¿Y por qué vía es transducida esta señal? Nuestro grupo de trabajo propuso entonces que, la vía por la que las EROs inducen la biosíntesis de lovastatina a través de factores transcripcionales de respuesta estrés oxidante.

Por ello se consideró que el factor transcripcional Yap1p podría ser el nexo entre las EROs y los genes de lovastatina. Para evaluar esta hipótesis, se silenció el gen yap1, a través de un sistema de RNAi, que ha demostrado ser una herramienta rápida y efectiva para disminuir la expresión de un gen de interés (Ailed Pérez, manuscrito en preparación).

La cepa silenciada de yap1 se caracterizó en cuanto a crecimiento, termotolerancia, sensibilidad a estrés osmótico, y a estrés de pared, buscando diferencias que pudieran haber causado el silenciamiento del gen, sin embargo, no se encontraron diferencias significativas con la cepa parental.

Los principales efectos del silenciamiento del gen yap1 fueron el adelanto e incremento en la acumulación de EROs, así como también el adelanto e incremento en la biosíntesis de lovastatina. Hasta aquí parecía que Yap1p podría estar involucrado en la regulación de la ruta de biosíntesis de lovastatina.

Entonces se plantearon dos posibilidades: 1) el factor transcripcional yap1, además de modificar las EROs es un regulador negativo de los genes de lovastatina y, 2) el silenciamiento de yap1 sólo modificó la acumulación de las EROs y éstas fueron las responsables del cambio en la biosíntesis de lovastatina. 
Con el fin de poder dilucidar qué fue lo que causó el cambio en la biosíntesis de lovastatina en la cepa silenciada de yap1, se realizó la adición de un antioxidante para poder reducir las EROs, a niveles similares a los del control, y poder evaluar únicamente el efecto del silenciamiento del gen yap1 sin el efecto secundario de la acumulación de las EROs.

Se logró igualar las EROs de la transformante siyap1, a niveles similares a los de la cepa parental a través del uso de un antioxidante exógeno NAC ( $\mathrm{N}$-acetil cisteína). Así, se encontró que cuando a siyap1 se le resta el efecto del incremento de EROs, la biosíntesis de lovastatina también se redujo al mismo nivel de la cepa silvestre. Esto contrastando con siyap1 sin antioxidantes que muestra mayor producción de lovastatina y con un adelanto en la biosíntesis.

Con esto se verificó que el silenciamiento de yap1 bajó la concentración de las EROs y esto fue la causa del aumento y adelanto de la biosíntesis de lovastatina; y que el gen yap1 no es un regulador negativo de la biosíntesis de lovastatina.

Se comprobó entonces que el silenciamiento de yap1 provocó que se adelantaran y aumentaran las EROs, y que esto fue el causante de que la biosíntesis de lovastatina se adelantara, pero quedaba todavía la pregunta, ¿cómo las EROs están señalizando la producción de lovastatina?

El grupo de Linz ha propuesto que las EROs podrían está señalizando el metabolismo secundario a través de factores transcripcionales como yap1, (asociada a la vía de transducción de señales MAPKinasa SAPK también conocida como Hog. También proponen que que otra vía que podría estar participando es la AMPc-PKA (Hong et al. 2013). Debido a esto, se consideró que la mutante siyap1 sería un excelente sistema de estudio para ver la relación de las EROs y el AMPc, en relación con la biosíntesis de lovastatina. 
En el modelo de biosíntesis de aflatoxinas, la presencia de probables sitios de unión a AP-1 en el promotor de aflR (factor transcripcional específico del cluster), sugirió que el EOX puede regular la biosíntesis de aflatoxinas. Reverberi et al. (2007) construyeron mutantes $\triangle$ ApyapA (ortólogo de AP-1) de Aspergillus parasiticus, las cuales mostraron un incremento en el EOX, conidiogénesis y biosíntesis de aflatoxinas prematura, lo que coindice con nuestros estudios en Aspergillus terreus. Los autores concluyeron que ApyapA es un nexo entre EROS y los genes de biosíntesis.

En el silenciamiento de Atyap1, se observó que el aumento en la biosíntesis de lovastatina fue un efecto indirecto de la acumulación de ROS y que no tenía una relación directa con la regulación de genes de lovastatina, efectos que no se tenía considerado, pero debido a esto es posible, que otro factor transcripcional relacionado al estrés oxidante podría ser el que este regulando la biosíntesis de lovastatina y más aún jueguen un papel fundamental en la fisiología particular de la FS como msnA, srrA, atfA o atfB que se habían encontrado como yap1, tenían sitios putativos en el promotor de juegan un papel importante en la biosíntesis de lovastatina y más aún en la fisiología especial de la FS (Miranda et al. 2013)

En S. cerevisiae, una de las rutas principales de señalización que regulan el metabolismo y el crecimiento, en respuesta a la presencia de nutrientes y a las condiciones de estrés, la vía AMPc-PKA, involucra a la enzima PKA, la cual estimula tanto a las enzimas de la glucólisis y la fermentación como a aquellas involucradas en el desarrollo y en la proliferación celular, por otro lado, inhibe a las proteínas involucradas en la resistencia al estrés, en la gluconeogénesis y en la síntesis de la trealosa y del glucógeno (Thevelein JM et al., 1999).

En esta tesis se determinaron los niveles intracelulares de AMPc y la actividad enzimática de la PKA, que son las efectoras de la señalización del AMPc (RubioTexeira $M$ et al., 2010). La cinética presentó perfiles y niveles esperados de lovastatina, EROs, glucosa, lactosa, AMPc y PKA, en ambos sistemas (FS y FL), y coinciden con los reportados anteriormente para Aspergillus terreus en la cepa silvestre. 
En donde los niveles de AMPc y de PKA son mayores en trofofase y van decreciendo conforme inicia la idiofase, iniciando así el metabolismo secundario una vez que los niveles de AMPc han bajado. La diferencia más importante, entre a la cepa parental y la silenciada de yap1, fue a las $21 \mathrm{~h}$ en FL y 19 h FS. C

omo ya se había visto, en ese momento hay un adelanto en la acumulación de EROs, pero ahora se pudo comprobar que este adelanto en la acumulación de EROs coincide con un adelanto de la baja de los niveles de AMPc y un adelanto de la baja de la actividad de PKA.

Estos resultados demuestran que el incremento prematuro de EROS, en la cepa silenciada, provocó una baja prematura de AMPc y consecuentemente de PKA y que esto es lo que provocó un adelanto de la biosíntesis de lovastatina.

Un aspecto muy interesante de estos experimentos es que, en la cepa silvestre y la silenciada de yap1, muestran los mismos perfiles de consumo de fuente de carbono (particularmente de glucosa). Esto indica que la regulación por ROS anula o revoca la regulación por glucosa. Lo cual sugiere que la regulación de las EROs está cascada arriba de la represión catabólica y que es a través de la modificación de AMPc-PKA en la biosíntesis de lovastatina por Aspergillus terreus.

Las células proliferan cuando disponen de nutrientes y, por el contrario, crecen lentamente cuando éstos escasean o cuando las condiciones fisicoquímicas del medio les son adversas. Para modular su crecimiento la célula monitorea el ambiente circundante mediante estrategias diversas, integrando los estímulos o señales generadas y restructurando, incluso, el estado transcripcional del genoma (Folch-Mallol JL, 2004). 
En levadura se sabe que los azúcares extracelulares son inicialmente percibidos por la proteína receptora transmembranal Gpr1. El receptor, al percibir la glucosa, estimula el intercambio del GDP por el GTP de la proteína Gpa2 (proteína tipo Ga). Unido el GTP a Gpa2, la adenilato ciclasa (AC), Cyr1, es estimulada con el consecuente aumento en la actividad de la PKA en respuesta a la rápida elevación de los niveles del AMPc (Rubio-Texeira M et al., 2010). Además, la ruta de señalización de la PKA está altamente conservada en los hongos.

En esta tesis se comparó la cepa parental con la cepa silenciada en yap1, y se encontró que, durante la fermentación de lovastatina, los niveles de glucosa fueron iguales en ambas cepas, pero que las EROs se acumularan antes en SiyapA.

El hecho de que esto provocara la baja del AMPc y el arranque prematuro de la biosíntesis de lovastatina indica que la regulación por EROs, del metabolismo secundario, podría ser a través del AMPc; además, que ésta regulación tiene mayor jerarquía que la regulación por carbono.

Las proteínas Ras son miembros de una familia de pequeñas GTPasas monoméricas que se conserva notablemente en eucariotas. Ras sirve como un transductor de señal entre los estímulos extracelulares y las cascadas de señalización intracelular. El control de la actividad de Ras está mediado por la unión del guanosina nucleótido difosfato (GDP) / guanosina nucleótido trifosfato (GTP) de forma binaria En Aspergillus fumigatus, la vía de RasA se ha convertido en un importante regulador de la morfogénesis. (Tiffany $S$ et al. 2014).

Los factores que contribuyen a la regulación de RasA no se conocen tan bien, aunque se sabe que la adecuada activación temporal de RasA y la localización espacial de RasA en la membrana plasmática desempeñan papeles importantes en la regulación del metabolismo secundario (Fortwendel JR et al. 2004). 
En A. fumigatus se han identificado, dos homólogos Ras (RasA y RasB) y cada uno desempeña un papel importante en los procesos celulares incluida la morfogénesis de las hifas, el crecimiento polarizado y el desarrollo asexual (Fortwendel JR et al. 2004).

En Aspergillus terreus, se analizaron estos genes ras 1 y ras2 (RasA y Ras B respectivamente), se realizó un análisis de expresión de estas enzimas por Northen Blot y lo que se encontró fue muy interesante, ya que para el caso de ras1, la expresión es constitutiva, aunque se intensifica en la idiofase. Mientras que los homólogos de RasA están presente tanto en hongos filamentosos como en levaduras. Los homólogos RasB son exclusivos de los hongos que experimentan crecimiento filamentoso durante alguna fase de su ciclo de vida (Fortwendel JR et al. 2004); Sorprendentemente en A. terreus, sólo se encontró expresión de ras 2 en la FS. Esto podría ser clave para entender la diferente fisiología diferente que se observa en este tipo de fermentación, en relación con la FL. 


\section{CONCLUSIÓN.}

1) La lovastatina no es un antioxidante, por lo que no forma parte del mecanismo general de respuesta a estrés oxidante.

2) Las EROs que señalizan la biosíntesis de lovastatina, están señalizando durante toda la idiofase aunque las primeras horas son las más efectivas, se originan principalmente de la respiración en la mitocondria con un $75-80 \%$, NOX $13-17 \%$ y $2-6 \%$ de la xantina oxidasa; se componen de $\mathrm{H}_{2} \mathrm{O}_{2}$ y $\mathrm{O}$; las enzimas Sod y Cat tiene una fuerte actividad en la trofofase para de crecer en la idiofase y nos ser las responsables de contenderlas.

3) En FS la función de la respiración alternativa es controlar la producción de EROs para mantenerlos en un nivel saludable. El aumento en los niveles de EROs induce la RA en FS, e incluso en FL donde no hay actividad de la AOX. La inhibición de la RC induce la RA y con esto se redujo la acumulación de EROs. En contraste, la inhibición de la RA incrementó fuertemente las EROs. El gen aox en FS se induce durante la idiofase, lo cual sugiere que en $A$. terreus las EROs regulan la RA a nivel transcripcional. En FL no se encontró expresión del gen aox, pero sí de la NADHalternativa.

4) El silenciamiento de yap1 en $A$. terreus ocasionó una acumulación prematura de las EROs y fue esto lo que ocasionó el aumento y adelanto de la biosíntesis de lovastatina. Por consiguiente, el gen yap1 no es un regulador negativo de la biosíntesis de lovastatina.

5) En A. terreus los niveles de AMPc-PKA son mayores en trofofase y van decreciendo conforme inicia la idiofase, iniciando así el metabolismo secundario una vez que los niveles de AMPc han bajado coincide con el aumento en la acumulación de EROs.

6) Durante la fermentación sólida o líquida de lovastatina con A. terreus, la expresión del gen ras1 es contante en trofofase, aunque se intensifica en idiofase. En contraste, el gen ras 2 sólo se expresa en la FS. Debido a que las proteínas Ras activan varias vías de transducción de señales, esto podría ser clave para entender mejor la diferente fisiología en medio sólido. 


\section{PERSPECTIVAS}

Este proyecto abrió muchas e interesantes perspectivas sobre el papel de las EROs y como estas interactúan para la señalización y regulación de biosíntesis de metabolitos secundarios. Basado en los conocimientos obtenidos en este trabajo parece cercano el desarrollo de sistemas más eficientes y súper productores de metabolitos secundarios.

Los avances realizados en cómo, dónde y cuándo se producen las EROs así como el quién las controla, se podrá aplicar a la manipulación de los niveles de EROs y así optimizar el proceso de biosíntesis, adelantando y aumentado la producción, controlando la señalización del metabolismo secundario.

Esto se podría hacer de varias maneras, ya sea directamente alterando los niveles de EROs en la célula con la adición de oxidantes en momentos clave a lo largo de la fermentación, o también se podría manipular los niveles de las EROs controlando cómo se producen, esto último se puede realizar con inhibidores o inductores creando novedosos sistemas que aprovechen la señalización de las EROs, no solo para mejorar la producción en medio sólido si no para inducir la fisiología del medio solido en el líquido.

La manipulación de los niveles de EROS también se podrían realizar con modificaciones genéticas sobre los genes involucrados en la acumulación de las EROs, creando así cepas altamente eficientes en la producción de metabolitos secundarios, incluso para ambos sistemas.

También se realizaron importantes hallazgos en relación al papel de la respiración alternativa en la acumulación de EROs y la biosíntesis de metabolitos secundarios. Estos servirá en un futuro para diseñar cepas de interés industrial que a través de la respiración alternativa alcanzarían un nivel óptimo de EROs y así lograr mejorar y acelerar las producciones.

Una importante perspectiva sería el diseño de nuevos sistemas de producción donde se manipule la respiración y con ello los niveles de las EROs y así el metabolismo secundario logrando la optimización de la producción para ambos sistemas de fermentación.

El continuar con esta línea de investigación, revelará cómo está relacionada la respiración alternativa con el metabolismo secundario no sólo en $A$. terreus sino en otros microorganismos de interés industrial. Otro importante punto de interés es el estudio es el cómo se realiza la señalización de la AOX en FS y el estudio de un mecanismo equivalente en la fermentación liquida. 
Este proyecto incursionó en el estudio de la señalización de EROs al metabolismo secundario, usando una cepa modificada genéticamente a través del silenciamiento de genes mediante el mecanismo de RNAi. Esta metodología ayudará a futuros estudios del papel de otros factores transcripcionales y genes involucrados en la regulación de metabolismo secundario.

El determinar que atyap1 no es un regulador de la biosíntesis de lovastatina es un descubrimiento que nos ayudará en un futuro cercano a averiguar cuáles otros factores transcripcionales están regulando o cuales otras vías podrían estar involucradas en la regulación del metabolismo secundario.

Desde el punto de vista aplicado, esta metodología, junto con el conocimiento de las redes de regulación, podría emplearse como una estrategia para la creación de mejores cepas de interés biotecnológico y sistemas de producción. 


\section{REFERENCIAS}

- Aguirre, J. et al., (2005). Reactive oxygen species and development in microbial eukaryotes. Trends in microbiology, 13(3):111-118.

- Aguirre, J., Hansberg, W. \& Navarro, R., (2006). Fungal responses to reactive oxygen species. Medical Mycology, 44(s1):101-107.

- Aidoo, K. E., Hendry, R., \& J.B. Wood. (1982). Solid substrate fermentations. Advances in Applied Microbiology. 28: 201-237.

- Ailed Pérez, 2014. Efecto de los estímulos del medio sólido: contacto directo con el aire y estimulo del soporte, en la producción de lovastatina por Aspergillus terreus, Manuscrito en preparación.

- Alberts AW, Chen J, Kurov G, Hunt V, Huff J, Hoffman C, Rothrock J, Lopez M, Joshua H, Harris E, Patchett A, Monaghan R, Currie S, Stapley E, Albers-Schonberg G, Hensens O, Hirschfield J, Hoofsteen KJ, Liesch J, Springer J (1980) Mevinolin: a highly potent competitive inhibitor of hydroxymethylglutaryl-coenzyme A reductase and a cholesterol-lowering agent. Proc Natl Acad Sci USA 77:3957-3961.

- Angélica Coyoy Salgado y Julio Morán (2012), Papel de las ero producidas por la NOX en procesos fisiológicos, REB 31(3): 100-109.

- Angelova MB, Pashova SB, Spasova BK, Vassilev SV, Slokoska LS, (2005), Oxidative stress response of filamentous fungi induced by hydrogen peroxide and paraquat. Mycol Res 109: 150-158

- Apel, K. \& Hirt, H., (2004). REACTIVE OXYGEN SPECIES: Metabolism, Oxidative Stress, and Signal Transduction. Annual Review of Plant Biology, 55(1): 373-399.

- ArnaldoVideira and MargaridaDuarte, (2002). From NADH to ubiquinone in Neurospora mitocondria, Biochimica et Biophysica- Bioenergetics Vol. 1555, Issues 1-3, Pág. 187-191. https://doi.org/10.1016/S0005-2728(02)00276-1

- Ávila Cisneros Nayeli, (2009). "Efecto del contacto con el aire, el estrés osmótico y el estímulo de exploración del micelio sobre la producción de lovastatina en A. terreus" Dirección: Barrios-González Javier, Tesis Maestría, Universidad Autónoma Metropolitana, México, D.f.

- Bai Z, Harvey LM, McNeil B 2003a. Oxidative stress in submerged cultures of fungi Crit Rev Biotechnol 23:267-302.

- Bai Z, Harvey LM, McNeil B (2003b). Physiological responses of chemostat cultures of Aspergillus niger (B1-D) to simulated and actual oxidative stress. Biotechnol Bioeng 82:691701.

- Bai Z, Harvey LM, White S, McNeil B (2004). Effects of oxidative stress on production of heterologous and native protein, and culture morphology in batch and chemostat cultures of Aspergillus niger B1-D. Enzym Microb Technol 34:10-21.

- Baños JG, Mejía A, Garay A, Barrios-González J (2007b). Producción de lovastatina en fermentación sólida por mutantes resistentes a estrés oxidante. XII Congreso Nacional de Biotecnología y Bioingeniería 25 a 29 de junio. Morelia, Michoacán, México.

- Baños JG, Tomasini A, Szakács G, Barrios-González J (2009). High lovastatin production by Aspergillus terreus in solid-state fermentation on polyurethane foam: an artificial inert support. J Biosci Bioeng 108 105-110. 
- Baños Mejía Jesús Gabriel, (2010). “Producción de lovastatina en fermentación sólida sobre soporte inerte artificial, por una cepa silvestre de Aspergillus terreus (TUB F-514) y por sus mutantes resistentes a estrés osmótico y a estrés oxidante" Dirección: Barrios-González Javier, Tesis Doctoral, Universidad Autónoma Metropolitana, México, D.F.

- Barrios-González, (2012) "Solid-state fermentation: Physiology of solid medium, its molecular basis and applications" Review Journal Process Biochemistry, 47: 175-185.

- Barrios-González, J, Tomasini A., Viniegra-González G \& López J. (1988). Penicillin production by solid state fermentation. Biotechnology Letters, 10(11): 793-798.

- Barrios-González, J. (2008). Lovastatin biosynthetic genes of Aspergillus terreus are expressed differentially in solid-state and in liquid submerged fermentation. Applied Microbiology and Biotechnology, 79(2):179-186.

- Barrios-González, J. et al., (2005). Secondary metabolites production by solid state fermentation. Malaysian J Microbiol, 1:1-6.

- Barrios-González, J., \& Miranda, R. (2010). Biotechnological production and applications of statins. Applied Microbiology and Biotechnology, 85(4), 869-883.

- Barrios-González, J., Fernández, F.J. \& Tomasini, A., (2003). Microbial secondary metabolites production and strain improvement. Indian Journal of Biotechnology, 2(3):322-333.

- Bedard K, Krause KH, (2007), The NOX family of EROs gerating NADPH oxidases: physiologysiology. Physio Rev 87: 245-313.

- Bedard Karen, and Krause Karl-Heinz. (2007). The NOX Family of ROS-Generating NADPH Oxidases: Physiology and Pathophysiology. Physiological Reviews vol. 87, No. 1. https://doi.org/10.1152/physrev.00044.2005

- Belozerskaya, T.A. \& Gessler, N.N., (2007). Reactive oxygen species and the strategy of antioxidant defense in fungi: A review. Applied Biochemistry and Microbiology, 43(5):506515.

- Bigelis R, He H, Yang H, Chang LP, Greenstein M. (2006). Production of fungal antibiotics using polymeric solid supports in solid-state and liquid fermentation. Microbiol Biotechnol.; 33: 815-826.

- Bok, J. \& Keller, N., (2004). LaeA, a regulator of secondary metabolism in Aspergillus spp. 114 Eukaryotic Cell, 3(2):527.

- Bokoch, G.M. \& Knaus, U.G., (2003). NADPH oxidases: not just for leukocytes anymore, Trends in biochemical sciences, 28(9):502-508.

- Camile P. Semighini y Steven D. Harris, (2008), Regulación de la dominancia apical en Aspergillus nidulans Hyphae por especies reactivas de oxígeno, Genetica vol. 179 no. 4 19191932; https://doi.org/10.1534/genetics.108.089318

- Cannon J F, Tatchell K (1987) Characterization of Saccharomyces cerevisiae genes encoding subunits of cyclic AMP-dependent protein kinase. Mol Cell Biol 7: 2653-2663.

- Cano-Dominguez, N., (2008). NADPH Oxidases NOX-1 and NOX-2 Require the Regulatory Subunit NOR-1 to Control Cell Differentiation and Growth in Neurospora crassa. Eukaryotic Cell, 7(8):1352-1361.

- Chance, B., B. Schoener, R. Oshino, F. Itshak, and Y. Nakase. (1979). Oxidation-reduction ratio studies of mitochondria in freeze-trapped samples. NADH and flavoprotein fluorescence signals. J Biol Chem 254: 4764-71.

- Cristina Blan Sanmartin Curso (2012), La proteína AOX como terapia génica para enfermedades mitocondriales. Departamento de Bioquímica y Biología Molecular y Celular, Universidad de Zaragoza. 
- Delaunay, A., Isnard, A.D., \& M.B. Toledano. (2000). $\mathrm{H}_{2} \mathrm{O}_{2}$ sensing through oxidation of the Yap1 transcription factor. EMBO J. 19(19): 5157-66.

- E. Marta Kuskoski; Agustín G. Asuero; Ana M. Troncoso; Jorge Mancini-Filho; Roseane Fett, (2005), Aplicação de diversos métodos químicos para determinar atividade antioxidante em polpa de frutas, Ciênc. Tecnol. Aliment. vol.25 no.4 Campinas. http://dx.doi.org/10.1590/S0101-20612005000400016

- Fernández J., Hernandez M., Rios G. y Gutierrez C. (2003). Cholesterol biosynthetic pathway J. Antibiot. 16:234-246.

- Finkel, T. (1998). Oxygen radicals and signaling. Current Opinion in Cell Biology. 10:248- 253.

- Folch-Mallol JL, Martínez LM, Casas SJ, Yang R, Martínez-Anaya C, López L, Hernández A, Nieto-Sotelo J (2004) New roles for CDC25 in growth control, galactose regulation and cellular differentiation in Saccharomyces cerevisiae. Microbiology 150: 2865-2879.

- Folch-Mallol, J.L., Garay-Arroyo, A., Lledías, F., \& A.A. Covarrubias-Robles. (2004). La respuesta a estrés en la levadura Saccharomyces cerevisiae. Revista Latinoamericana de Microbiologia. 46(1-2):24-46.

- Fortwendel JR, Panepinto JC, Seitz AE, Askew DS, Rhodes JC. (2004). Aspergillus fumigatus $\operatorname{ras} A$ and $\operatorname{ras} B$ regulate the timing and morphology of asexual development. Fungal Genet Biol.; 41: 129-39.

- Furberg CD (1999) Natural statins and stroke risk. Circulation 99:185-188

- Garmendia-Torres C, Goldbeter A, Jacquet M (2007) Nucleocytoplasmic oscillations of the yeast transcription factor Msn2: evidence for periodic PKA activation. Curr Biol 17: 1044-1049.

- Garrido, E., \& C.M. Grant. (2002). Role of thioredoxins in the response of Saccharomyces cerevisiae to oxidative stress induced by hydroperoxides. Molecular Microbiology. 43(4):9931003.

- Gómez-Quiroz, Luis Enrique, Salas-Silva, Elsy Soraya, Simoni-Nieves Arturo, Miranda-Labra, Roxana U. (2017). Basics in redox signaling: Lessons from reactive oxygen species generating systems, Mens. Bioquim. 4:108-115.

- Guerrero-Castillo S, Vázquez - Acevedo M, González - Halphen D, Uribe-Carvajal S. (2009). In Yarrowia lipolytica mitochondria, the alternative NADH dehydrogenase interacts specifically with the cytochrome complexes of the classic respiratory pathway. Biochim Biophys Acta 1787:75-85

- Hahn JS, Thiele DJ. (2004). Activation of the Saccharomyces cerevisiae heat shock transcription factor under glucose starvation conditions by Snf1 protein kinase. J Biol Chem 279: 5169-5176.

- Hajjaj, H., P. Niederberger \& P. Duboc. (2001). Lovastatin biosynthesis by Aspergillus terreus in a chemically defined medium. Applied and Environmental Microbiology. 67 (6): 2596-2602.

- Halliwell, B. \& M.C. Gutteridge. (1999). Free Radicals in Biology and Medicine. London. Oxford University Press.

- Hata Y, Ishida H, Kojima Y, Ichikawa E, Kawato A, Suginami K, et al. (1997). Comparison of two glucoamylases produced by Aspergillus oryzae in solid-state culture (koji) and submerged culture. J Ferment Bioeng 84: 532-7.

- Héctor Hugo León Santiesteban. (2010). Inmovilización de Rhizopus oryzae ENHE, T Tesis para obtener el grado de: Maestro en Biotecnología. UAM.

- Hendrickson, L. (1999). Lovastatin biosynthesis in Aspergillus terreus: characterization of blocked mutants, enzyme activities and a multifunctional polyketide synthase gene. Chemistry \& biology, 6 (7): 429-439. 
- Hisada, H., Y. Hata, A. Kawato, Y. Abe \& O. Akita. (2005). Cloning and expression analysis of two catalase genes from Aspergillus oryzae. Journal of Bioscience and Bioengineering. 99 (6): 562-568.

- Hu Y, Liu E, Bai X, Zhang A. (2010). The localization and concentration of the PDE2-encoded high-affinity CAMP phosphodiesterase is regulated bycAMP-dependent protein kinase $A$ in the yeast Saccharomyces cerevisiae. FEMS Yeast Res 10: 177-187.

- Jaszek M, Grzywnowicz K, Malarczyk E, Leonowicz A. (2006). Enhanced extracellular laccase activity as a part of the response system of white rot fungi: Trametes versicolor and Abortiporus biennis to paraquat-caused oxidative stress conditions. Pestic Biochem Physiol 85: 147-154.

- Jayashree, T. \& Subramanyam, C. (2000). Oxidative stress as a prerequisite for aflatoxin production by Aspergillus parasiticus. Free Radical Biology and Medicine, 29 (10): 981-985.

- Joseph-Horne T, Babij J, Wood PM, Hollomon D, Sessions RB. (2000). New sequence data enable modelling of the fungal alternative oxidase and explain an absence of regulation by pyruvate. FEBS Lett 481: 141-146

- Juárez O, Guerra G, Velázquez I, Flores-Herrera O, Rivera- Perez RE, Pardo JP. (2006). The physiologic role of alternative oxidase in Ustilago maydis. FEBS J 273: 4603-4615

- Kamata, H. \& Hirata, H. (1999). Redox Regulation of Cellular Signalling. Cellular Signalling, 11(1): 1-14.

- Kannel W.B., Dawber T.R., Kaban A., Revotskie S.J.L. (1961). Factors of risk in the development of coronary heart disease six year follow up experience; the Farmingham study. Ann Intern Med. 40: 602-609.

- Kennedy EJ, Ghosh G, Pillus L. (2008). Identification of functionally distinct regions that mediate biological activity of the protein kinase A homolog Tpk2. J Biol Chem 283: 1084-1093.

- Kennedy J. (1999). Modulation of polyketide synthase activity by accessory proteins during lovastatin biosynthesis. Science, 284 (5418): 1368-1372.

- Kreiner, M., McNeil, B. \& Harvey, L. (2000). "Oxidative stress" response in submerged cultures of a recombinant Aspergillus niger (B1-D). Biotechnology and Bioengineering, 70 (6): 662-669.

- Li Q, Trush MA. (1998). Diphenyleneiodonium, an NADPH oxidase inhibitor, also potently inhibits mitochondrial reactive oxygen species production. Biochem Biophys Res Commun 253: 295-299.

- Li Q., Bai Z., O'Donnell A., Harvey L.M., Hoskisson P.A., McNeil B. (2011). Oxidative stress in fungal fermentation processes: the roles of alternative respiration. Biotechnol Lett 33: 457467.

- Li Q, Harvey LM, McNeil B. (2009). Oxidative stress in industrial fungi. Crit Rev Biotechnol 29: 199-213.

- Magnani Taisa, Frederico Marianetti Soriani, Vicente de Paulo Martins, Anna Carolina de Freitas Policarpo, Carlos Artério Sorgi, Lúcia Helena Faccioli, Carlos Curti, Sergio Akira Uyemura. (2007). El silenciamiento del gen de la oxidasa alternativa mitocondrial de Aspergillus fumigatus mejora la producción de especies reactivas de oxígeno y la muerte del hongo por macrófagos. Revista de Bioenergética y Biomembranas, 40: 631.

- Manzoni, M. \& M. Rollini. (2002). Biosynthesis and biotechnological production of statins by filamentous fungi and application of these cholesterol-lowering drugs. Applied Microbiology and Biotechnology. 58: 555-564. 
- Manzoni, M., Rollini, M., Bergomi, S., \& Cavazzoni, V. (1998). Production and purification of statins from Aspergillus terreus strains. Biotechnology Techniques, 12 (7): 529-532.

- Marcial J. (2011). Identificación de una aspartato proteasa producida por Amylomyces rouxii, silenciamiento del gen que la codifica y efecto sobre la actividad tirosinasa. Tesis (Doctorado en Biotecnología), México, D.F. Universidad Autónoma Metropolitana.

- Mazumdar-Shaw, K. \& S. Suryanarayan. (2003). Commercialization of a novel fermentation concept. Advances in Biochemical Engineering /Biotechnology. 85: 29-42.

- McDonald, A. E. (2009a). "Alternative oxidase: what information can protein sequence comparisons give us?" Physiologia plantarum 137 (4): 328-341.

- McDonald, A. E., G. C. Vanlerberghe. (2009b). "Alternative oxidase in animals: unique characteristics and taxonomic distribution." The Journal of experimental biology 212 (Pt 16): 2627-2634.

- Medentsev AG, Arinbasarova AY, Akimenko VK. (2004). Reactivation of the alternative oxidase of Yarrowia lipolytica by nucleoside monophosphates. FEMS Yeast Res 5:231-236.

- Milenkovic L, Scott MP. (2010). Self-Induced Patched Receptor Down-Regulation Modulates Cell Sensitivity to the Hedgehog Morphogen Gradient. Sci Signal 3 p. pe14. DOI: 10.1126/scisignal.3117pe14.

- Minagawa N, Koga S, Nakano M, Sakajo S, Yoshimoto A. (1992). Possible involvement of superoxide anion in the induction of cyanide-resistant respiration in Hansenula anomala. FEBS Lett 302:217-219.

- Minu Chaudhuri, Robert Daniel Ott, George C. Hill. (2006). Tripanosoma oxidasa alternativa: de molécula a función, Science Direct, 22 (10): 484-491. https://doi.org/10.1016/j.pt.2006.08.007.

- Miranda Labra Roxana. (2008). "Expresión del gen sod1 durante la trofofase e idiofase de Aspergillus terreus en fermentación sólida y líquida para la producción de lovastatina". Dirección: Barrios-González Javier, Tesis Maestría, Universidad Autónoma Metropolitana, México, D.F.

- Miranda U. Roxana, Gómez-Quiroz Luis E., Mendoza Mariel, Pérez-Sánchez Ailed, Fierro Francisco, Barrios-González Javier. (2014). Reactive oxygen species regulate lovastatin biosynthesis in Aspergillus terreus during submerged and solid-state fermentations; Fungal Biology DOI: 10.1016/j.funbio.2014.09.002.

- Miranda, Barrios-González, Gómez-Quiroz, Armando Mejía. (2013). Oxidative state in idiophase links reactive oxygen species (EROs) and lovastatin biosynthesis: Differences and similarities in submerged and solid state fermentations. Fungal Biology I -9 .

- Monika Dominska and Derek M. Dykxhoorn. (2010). Breaking down the barriers: siRNA delivery and endosome escape, Journal of Cell Science 123, 1183-1189. doi:10.1242/jcs.066399.

- Moye-Rowley, WS. (2003). Transcription factors regulating the response to oxidative stress in yeast. Antioxidant \& Redox Signaling. 4 (1): 123-40.

- Narasaiah, K., Sashidhar, R. \& Subramanyam, C. (2006). Biochemical analysis of oxidative stress in the production of aflatoxin and its precursor intermediates. Mycopathologia, 162 (3): 179-189.

- Nian-Qing Shi, Jose Cruz, Fred Sherman and Thomas W. Jeffries. (2002). SHAM-sensitive alternative respiration in the xylose-metabolizing yeast Pichia stipites, Yeast, 19: 1203-1220. DOI: 10.1002/yea.915. 
- O'Donnell A, Bai Z, McNeil B, Harvey LM. (2007). Introduction to bioreactors of shake-flask inocula leads to development of oxidative stress in Aspergillus niger. Biotechnol Lett 29: 895900.

- Ooijkaas, L.P., Weber, F.J., Buitelaar, R.M., Tramper, J. \& A. Rinzema. (2000). Defined media and inert supports: their potential as solid-state fermentation production systems. Trends in Biotechnology. 18: 356-360.

- Owusu-Ansah \& Utpal Banerjee. (2008). Reactive oxygen species prime Drosophila haematopoietic progenitors for differentiation. Nature 461: 537-54. doi: 10.1038/nature08313.

- Pandey, A., Soccol, C. R., Rodriguez-Leon, J. A., \& P. Nigam. (2001). Solid-State Fermentation in Biotechnology-Fundamentals and Applications. Asia Tech Publishers, Inc. New Delhi: 100-221.

- Popov VN, Simonian RA, Skulachev VP, Starkov AA. (1997). La inhibición de la oxidasa alternativa estimula $\mathrm{H}_{2} \mathrm{O}_{2}$ de producción en las mitocondrias de plantas. DOI: http://dx.doi.org/10.1016/S0014-5793(97) 01099-5.

- Reverberi M., Zjalic S., Ricelli A.a, Punelli F., Camera E., Fabbri C., Picardo, Fanelli C., and A. Fabbri A. (2007). Modulation of Antioxidant Defense in Aspergillus parasiticus Is Involved in Aflatoxin Biosynthesis: a Role for the ApyapA Gene Eukaryotic Cell, 7 (6): 988-1000.

- Rollini, M. (2002). Biosynthesis and biotechnological production of statins by filamentous fungi and application of these cholesterol-lowering drugs. Applied Microbiology and Biotechnology, 58 (5): 555-564. doi: 10.1007/s00253-002-0932-9

- Roze, L.V., (2011). Stress-related transcription factor AtfB integrates secondary metabolism with oxidative stress response in Aspergilli. Journal of Biological Chemistry, 286 (40): 3513735148.

- Rubio-Texeira M, Van Zeebroeck G, Voordeckers K, Thevelein JM. (2010). Saccharomyces cerevisiae plasma membrane nutrient sensors and their role in PKA signaling. FEMS Yeast Res 10: 134-149.

- Ruíz-Leza H. A., R. M. Rodríguez-Jasso, R. Rodríguez-Herrera, J. C. Contreras-Esquivel y C. N. Aguilar. (2007). "Bio-reactors desing for solid state fermentation" Revista Mexicana de Ingeniería Química, 6 (1): 33-40.

- Skroblin P, Grossmann S, Schäfer G, Rosenthal W, Klussmann E. (2010). Mechanisms of protein kinase A anchoring. Int Rev Cell Mol Biol 283: 235-330.

- Storz, G., Christman, M.F., Sies, H. \& B.N. Ames. (1987). Spontaneous mutagenesis and oxidative damage to DNA in Salmonella typhimurium. Proceedings of the National Academic of Sciencies. 84: 8917-8921.

- Sung-Ypng Hong, ludmila V. Roze and john E. Linz. (2013). Oxidative Stress-Related Trascription Factors in the Regulation of Secondary Metabolism. Toxins Jounal 5: 683-702.

- Szakács, G., G. Morovján Y R.P. Tengerdy. (1998). Production of lovastatin by a wild strain of Aspergillus terreus. Biotechnology Letters. 20 (4): 411-415.

- Tanton LL, Nargang CE, Kessler KE, Li QH, Nargang FE. (2003). Alternative oxidase expression in Neurospora crassa. Fungal Gen Biol 39: 176-190

- Thevelein JM, de Winde JH. (1999). Novel sensing mechanisms and targets for the CAMPprotein kinase A pathway in the yeast Saccharomyces cerevisiae. Mol Microbiol 33: 904-918.

- Toledo, I., Rangel, P., \& W. Hansberg. (1995). Redox imbalance at the start of each morphogenetic step of Neurospora crassa conidiation. Archives of Biochemistry and Biophysics. 319 (2): 519-524. 
- Turrens, J.F. (2003). Mitochondrial formation of reactive oxygen species. J Physiol 552: 33544.

- Ullán R.V. (2008). RNA-silencing in Penicillium chrysogenum and Acremonium chrysogenum: Validation studies using $\beta$-lactam genes expression. Journal of microbiological methods, 75 (2): 209-218.

- Umbach AL, Siedow JN. (2000). The cyanide-resistant alternative oxidases from the fungi Pichia stipitis and Neurospora are monomeric and lack regulatory features of the plant enzyme. 15; 378 (2): 234-45.

- Valera, H.R, J. Gomes, S. Lakshmi, R. Gururaja, S. Suryanarayan \& D. Kumar. (2005). Lovastatin production by solid state fermentation using Aspergillus flavipes. Enzyme and Microbial Technology. 37: 521-526.

- Wongwicharn A, McNeil B, Harvey LM. (1999). Effect of oxygen enrichment on morphology, growth, and heterologous protein production in chemostat cultures of Aspergillus niger B1D. Biotechnol Bioeng 65: 416-424.

- Yoshizawa, Y. (1994). Revision of the biosynthetic origin of oxygens in mevinolin (lovastatin), a hypocholesterolemic drug from Aspergillus terreus MF 4845. Journal of the American Chemical Society, 116 (6): 2693-2694.

- Yukioka H, Inagaki S, Tanaka R, Katoh K, Miki N, Mizutani A, Masuko M. (1998). Transcriptional activation of the alternative oxidase gene of the fungus Magnaporthe grisea by a respiratoryinhibiting fungicide and hydrogen peroxide. Biochim Biophys Acta 1442: 161-169.

- Zorov, D. B., Juhaszova, M., and Sollott, S. J. (2014). Mitochondrial Reactive Oxygen Species (ROS) and ROS-Induced ROS. Release Physiol Rev 9: 909-950. https://doi.org/10.1152/physrev.00026.2013. 


\section{ANEXO A}

\section{ORIGEN DE LAS ROS}

Para esta prueba se usaron diferentes inhibidores: cianuro de potasio (KCN) (CAS 151-50-8 Reasol ${ }^{\circledR}$ ), difeniliodonio (DPI) (D2926 Sigma Aldrich ${ }^{\circledR}$ ) y alopurinol (ALO) (A8003 Sigma Aldrich ${ }^{\circledR}$ ) basándonos en la metodología propuesta por Camile P. Semighini et al. 2008. Estos se adicionaron en diferentes concentraciones (UM) a la fermentación en el medio de cultivo de FS y FL a partir de un stock en condiciones estériles a las $0 \mathrm{~h}$. Se tomó muestra a las $48 \mathrm{~h}$ y se comparó la biomasa y $\mathrm{pH}$.
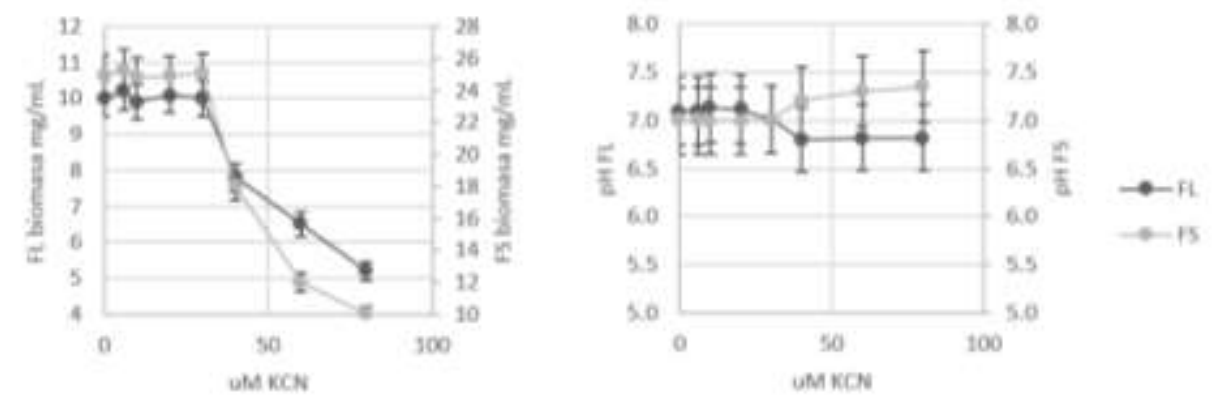

Figura A1. Adición en diferentes concentraciones de KCN: pH y biomasa en la fermentación de FS y FL a las 48h.
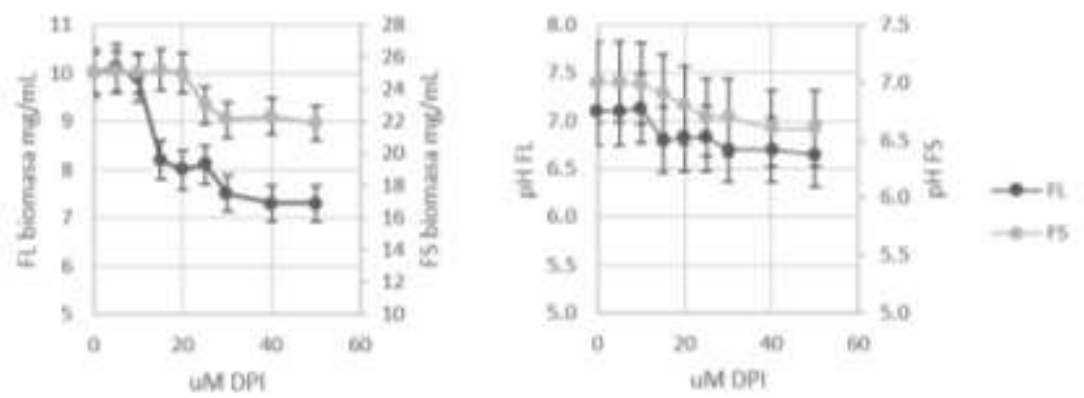

Figura A2. Adición en diferentes concentraciones de DPI: $\mathrm{pH}$ y biomasa en la fermentación de FS y FL a las $48 \mathrm{~h}$. 

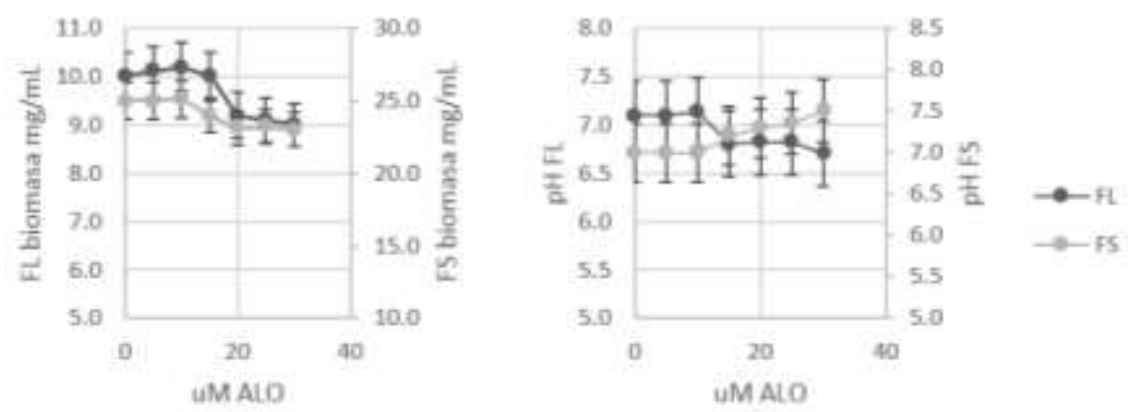

Figura A3. Adición en diferentes concentraciones de ALO: $\mathrm{pH}$ y biomasa en la fermentación de FS y FL a las $48 \mathrm{~h}$.

Las concentraciones de los inhibidores que fueron usadas se determinaron a partir del análisis de $\mathrm{pH}$ y biomasa, buscando no afectar el crecimiento ni las condiciones de cultivo. Se seleccionó la concentración en la que no se encontraron cambio o diferencias significativas en el pH y la biomasa. En el caso de cianuro de potasio (KCN) 30uM para inhibir la cadena respiratoria, difeniliodonio (DPI) 10uM para inhibir a las NADPHoxidasa (NOX) y alopurinol (ALO) 10uM para inhibir a la Xantina Oxidasa. 


\section{ANEXO B}

\section{METODO MEDICÍON DE LA RESPIRACIÓN ALTERNATIVAS}

Se montó y adaptó el sistema para medir la respiración; tanto en micelio proveniente de FL como de micelio de FS. La velocidad de consumo de oxígeno se midió en un Oxímetro modelo 782 con un electrodo de tipo Clark en una cámara con camisa de agua de $0.1 \mathrm{ml} \mathrm{a} 30^{\circ} \mathrm{C}$ y se analizaron los datos usando el sistema de oxígeno 782 (warner/Strathkelvin Istruments) (Guerrero-Castillo et al., 2009). En $1 \mathrm{~mL}$ buffer PBS, posteriormente a la medición se determinó biomasa por glucosamina (Miranda et al., 2015).
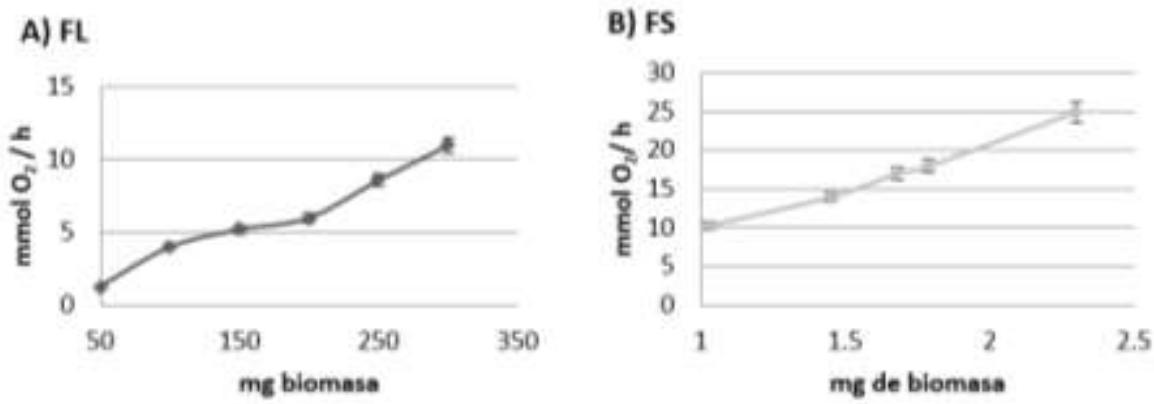

Figura B1. Estandarización de la biomasa para la medición de la respiración en FS y FL, usando cultivos de $48 \mathrm{~h}$, de la fermentación de lovastatina en $A$. terreus.

Se realizó un control negativo con PUF donde no se registró consumo de oxígeno. A mayor biomasa mayor respiración (figura B1). Determino usar aproximadamente $50 \mathrm{mg}$ de biomasa lo que corresponde a la cuarta parte un cuadrito de PUF y 200uL de un stock de biomasa de FL de $100 \mathrm{mg}$ en $1000 \mathrm{uL}$ aproximadamente. Se determina exactamente la cantidad de biomasa posteriormente por el método de glucosamina (Miranda et al., 2015).

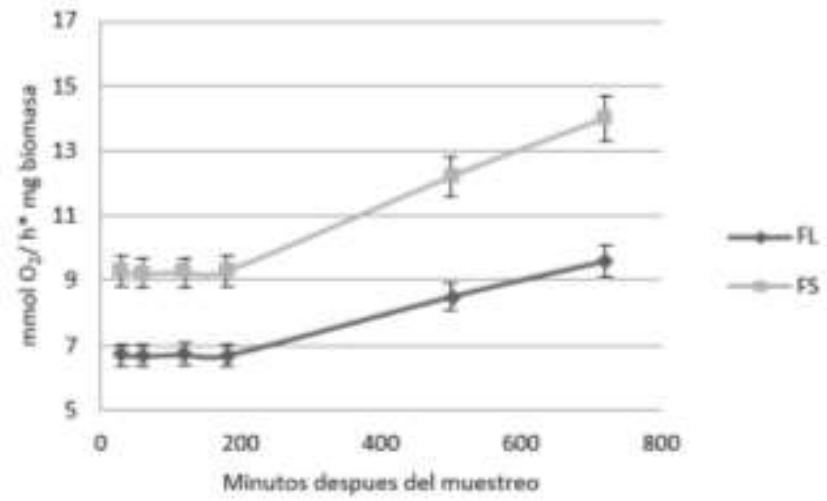

Figura B2. Estandarización del tiempo de ayuno y determinación de la viabilidad para la medición de la respiración en FS y FL, usando cultivos de 48h, de la fermentación de lovastatina en $A$. terreus. 
La muestra de biomasa proveniente de FS y FL no muere, ni sufre perdida de viabilidad figura B2. Conforme pasa el tiempo, la biomasa entra en ayuno que hace que se vuelva más activa, es decir se respira más rápido, dentro de las $5 \mathrm{~h}$ posteriores del muestreo la muestra estable y no presenta cambios. Para efectos prácticos y más reales cercanos de lo que pasa a la hora de muestreo no se dejó ayuno en las determinaciones.
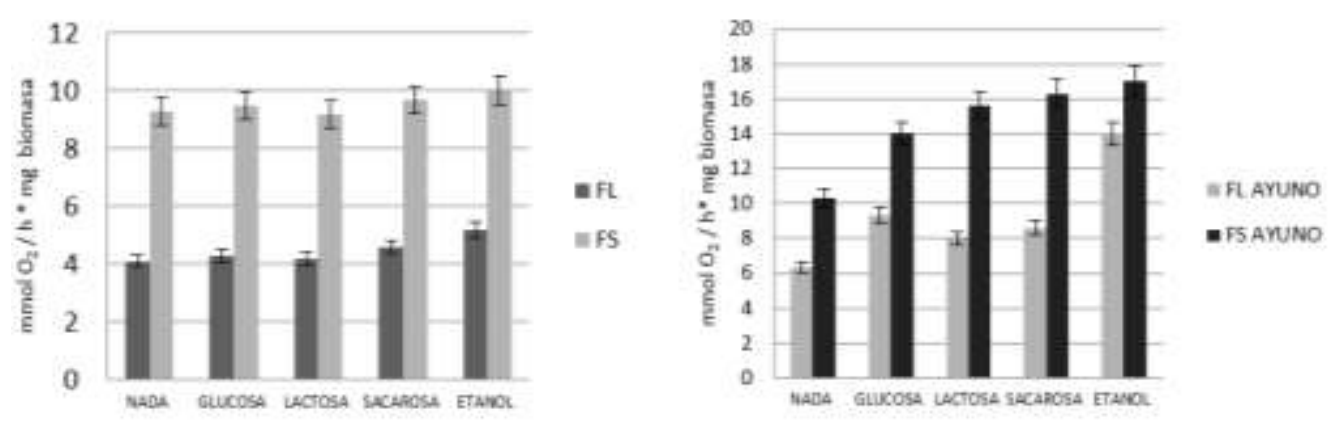

Figura B3. Estandarización de la fuente de energía para la medición de la respiración en FS y FL, usando cultivos de $48 \mathrm{~h}$, de la fermentación de lovastatina en $A$. terreus.

Se probaron diferentes fuentes de energía figura B3, es decir sustratos que proporcionen energía para poder respirar, esto es muy frecuente para las mitocondrias, pero en este caso, no se requiere, además de que no se quiere modificar las condiciones del muestreo. La mejor fuente fue el etanol, posiblemente porque no requiere trasportadores de membrana. El ayuno aumenta el consumo del azúcar y la respiración. Con esto también se verifico que no hay problemas de difusión.

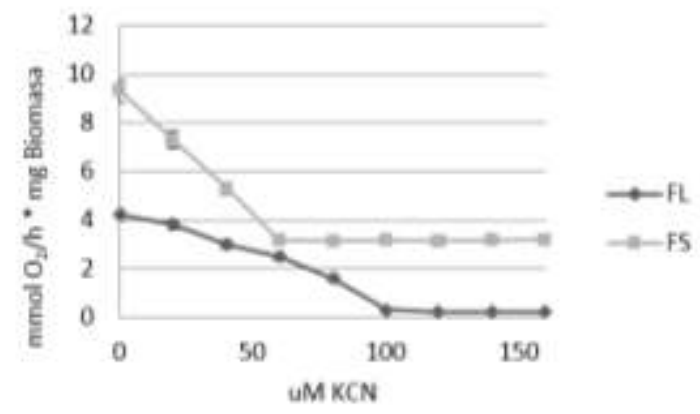

Figura B4. Estandarización para la medición de la respiración, determinación de la cantidad de KCN en FS y $\mathrm{FL}$, usando cultivos de $48 \mathrm{~h}$, de la fermentación de lovastatina en $A$. terreus.

Se determinó la concentración mínima a la que se inhibía la cadena respiratoria, se usó para las posteriores pruebas 60 uM y 100 uM de KCN para FS y FL respectivamente (figura B4). 


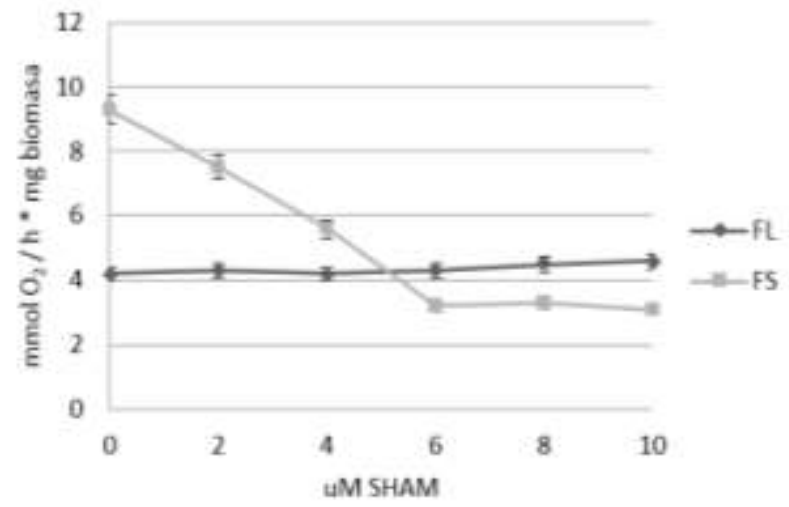

Figura B5. Estandarización para la medición de la respiración, determinación de la cantidad de SHAM en FS y $\mathrm{FL}$, usando cultivos de $48 \mathrm{~h}$, de la fermentación de lovastatina en $A$. terreus.

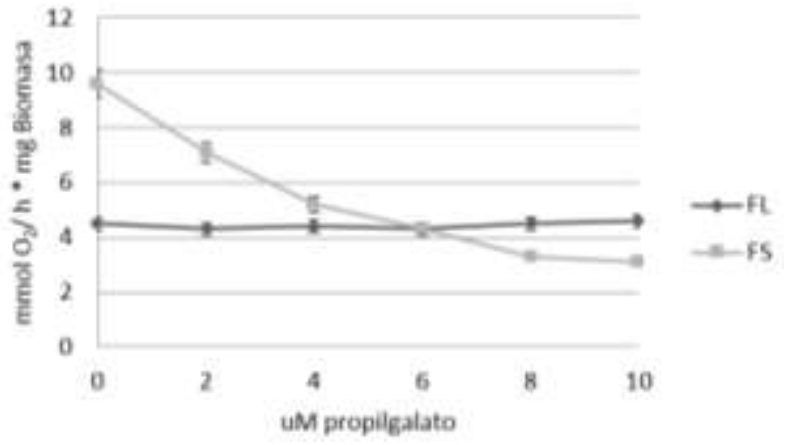

Figura B6. Estandarización para la medición de la respiración, determinación de la cantidad de Propilgalato en FS y FL, usando cultivos de $48 \mathrm{~h}$, de la fermentación de lovastatina en $A$. terreus.

Para inhibir a las AOX existen dos compuestos el SHAM y el propilgalato, se determinó la concentración mínima de ambas para verificar el efecto inhibitorio de la enzima AOX figura B6 y B7. Se determinó a usar 6uM de SHAM y 8uM de propilgalato para ambas fermentaciones FS y FL. 


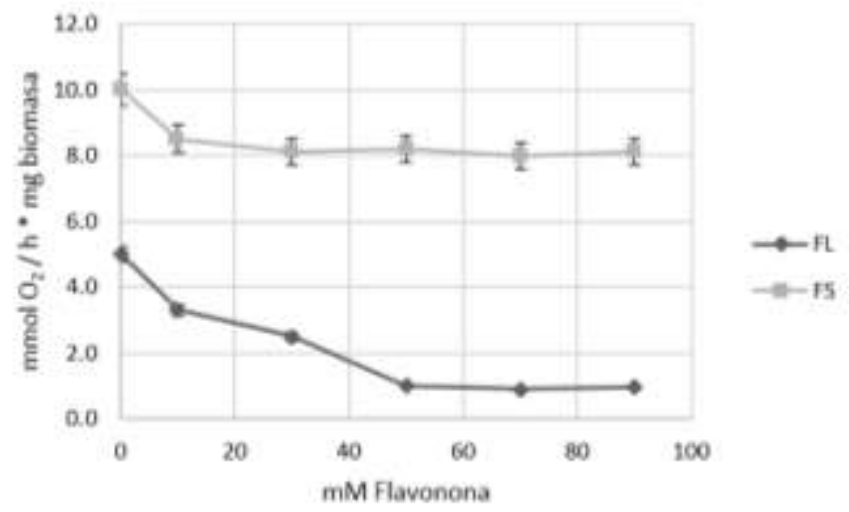

Figura B7. Estandarización para la medición de la respiración, determinación de la cantidad de Flavonona en FS y FL, usando cultivos de $48 \mathrm{~h}$, de la fermentación de lovastatina en $A$. terreus.

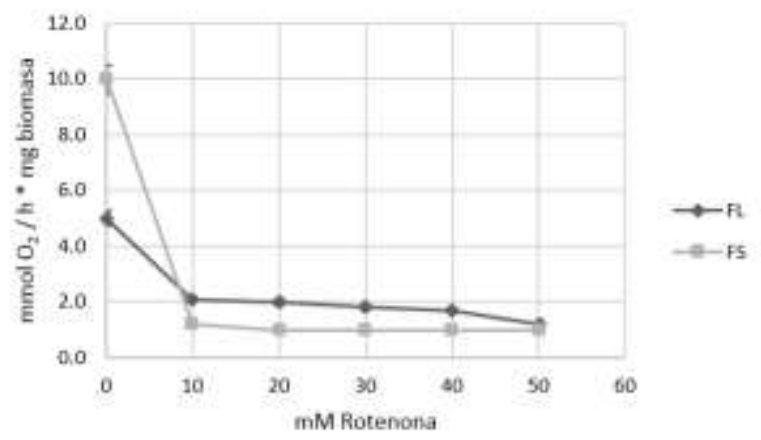

Figura B8. Estandarización para la medición de la respiración, determinación de la cantidad de Rotenona en FS y FL, usando cultivos de $48 \mathrm{~h}$, de la fermentación de lovastatina en $A$. terreus.

Para medir la actividad de las NADH alternativas entonces se determinó a usar el inhibidor flavonona adicionando $50 \mathrm{mM}$ en $\mathrm{FL}$ y $30 \mathrm{mM}$ en FS; usando como control positivo de la respiración la rotenona que inhibe al complejo I, adicionando $10 \mathrm{mM}$ para ambas fermentaciones.

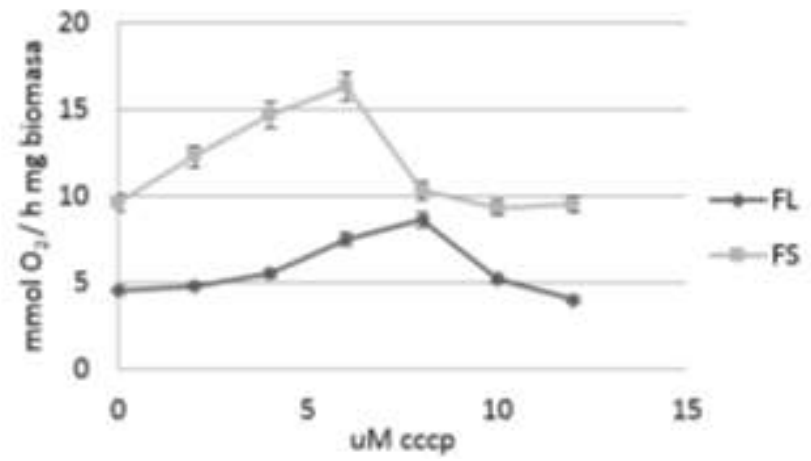

Figura B9. Estandarización para la medición de la respiración, determinación de la cantidad de cccp en FS y $\mathrm{FL}$, usando cultivos de $48 \mathrm{~h}$, de la fermentación de lovastatina en $A$. terreus. 
Se determinó la concentración de este desacoplador de membranas que ayuda a determinar la respiración máxima que tiene una muestra. Se determinó a usar 6 uM y 8 uM para FS y FL respectivamente.
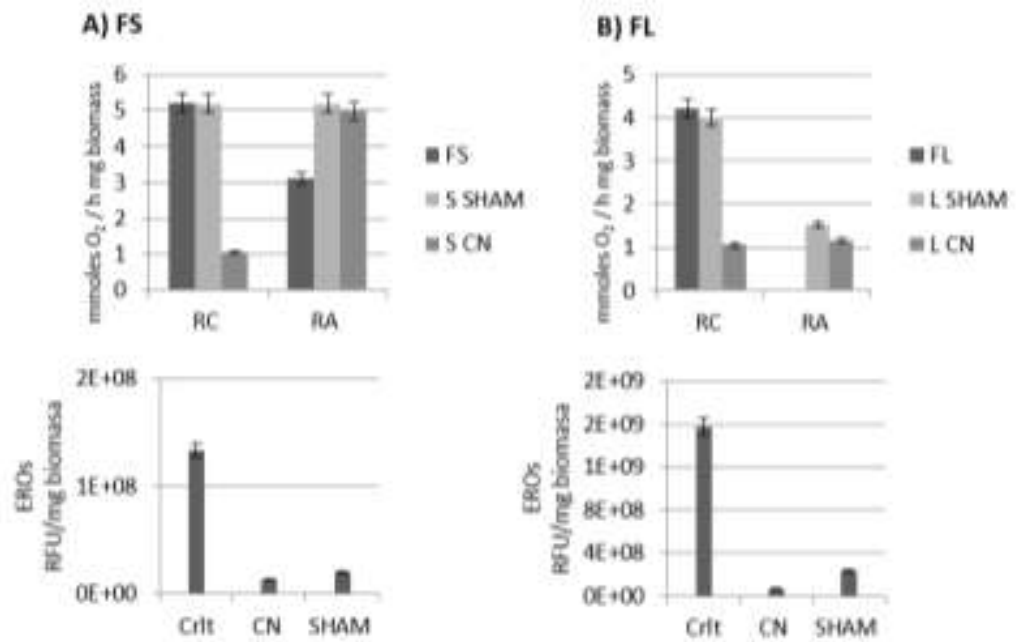

Figura B10.Adicion de CN y SHAM a la A) FS y B) FL a las $48 \mathrm{~h}$ de $A$. terreus, determinando la RC (respiración total o Citocrómica) y RA (respiración alternativa), así como la determinación de la acumulación de EROs.

Se verifico la relación de la RA con la disminución de las ROS figura B10: el CN inhibe la RC e induce la RA incluso en FL, con lo que bajan las ROS. El SHAM, aunque es inhibidor también puede actuar como un activador dentro de un cultivo, y se puede ver que a estas concentraciones activa la RA y bajan las ROS; actúa como el CN por eso se determinó usar propilgalato en el cultivo de lovastatina para encontrar el efecto de la inhibición de la respiración alternativa. 


\section{ANEXO C}

\section{CARACTERIZACIÓN DE LA CEPA Siyap1.}

Se llevó a cabo la caracterización del silenciamiento de yap1 en cuanto estrés osmótico, estrés de pared y termo-tolerancia en esporas a continuación se muestran los resultados.

\section{GERMINACIÓN EN ESTRÉS OSMÓTICO}

Los conidios pueden afrontar una condición de hiperosmolaridad tanto en el campo donde es asperjado como una vez dentro del insecto, donde existe una alta presión osmótica en la hemolinfa. Para esta prueba, se consideraron los valores de actividad de agua Aw reportados por Hallsworth y Magan 1999, para el crecimiento optimo es de 0.99-0.97. Se utilizó medio PDA y se adiciono cloruro de sodio para disminuir el Aw de $0.975 \mathrm{n} 0.5 \mathrm{M} \mathrm{NaCl}$ y $0.9990 .2 \mathrm{M} \mathrm{NaCl}$. En todos los casos Aw se determinó con ayuda de un equipo de medición de agua AQUALAB CX-2. No se encontraron diferencias en la resistencia o sensibilidad al estrés osmótico para la cepa siyap1 figura C1.

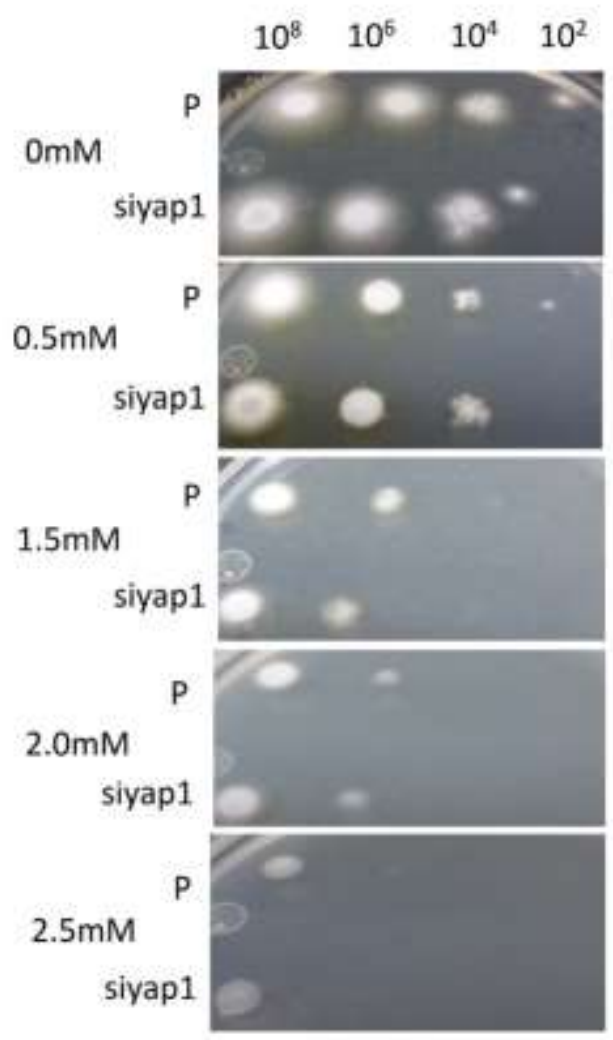

Figura C1. Estrés osmótico en la cepa siyap1 utilizando diferentes concentraciones de $\mathrm{NaCl}$ en cultivos de PDA, a las $72 \mathrm{~h}$. 


\section{GERMINACIÓN EN ESTRÉS DE PARED}

Se utilizó en el medio de cultivo PDA con Calcofluor White (Sigma $\left.{ }^{\circledR} 18909-F\right)$ y SDS (J.T Baker 409504) y Rojo Congo (Sigma ${ }^{\circledR}$ C6767), que generan estrés de pared en las células a las 72 h. No se encontraron diferencias en la resistencia o sensibilidad al estrés de pared para la cepa siyap1 figura C1.

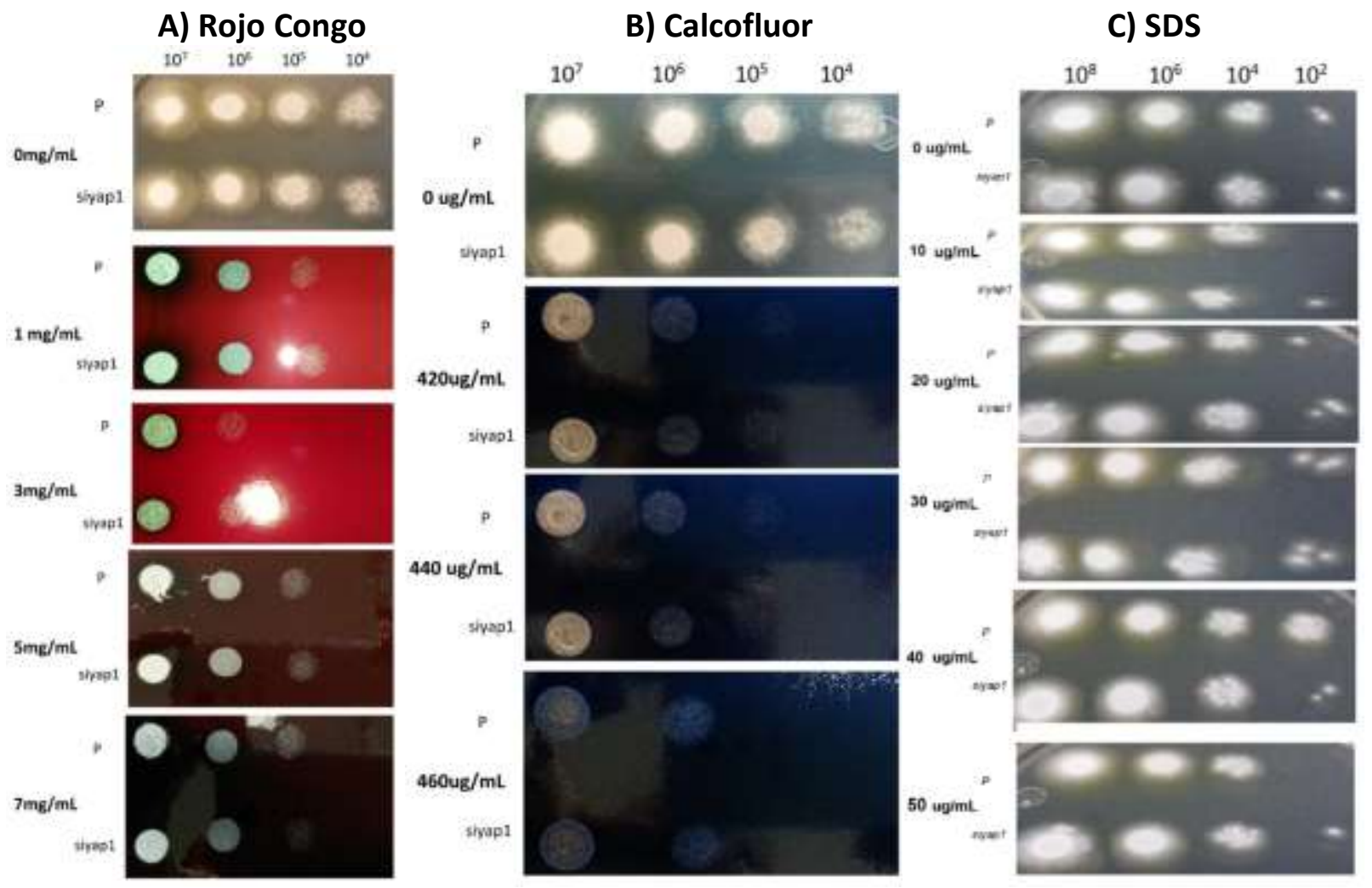

Figura C2. Estrés de pared en la cepa siyap1 utilizando diferentes concentraciones de A) Rojo Congo, B) Calcofluor, C) SDS en cultivos de PDA a las $72 \mathrm{~h}$. 


\section{TERMOTOLERANCIA}

Este factor está directamente relacionado con la persistencia y desarrollo de los conidios en campo (Magan, 1997). Esta prueba se realizará en base a la metodología reportada por Rangel et al., 2005, con algunas modificaciones.

Trascurridas $120 \mathrm{~h}$ se cosecharon los conidios con tween $800.02 \% \mathrm{NaCl} 0.9 \%$, la suspensión obtenida se estandarizo a una concentración final de $1 \times 10^{4} \mathrm{con} / \mathrm{ml}$. Un $\mathrm{ml}$ de esta suspensión se agregó a tubos de vidrio $8 \mathrm{ml}$ con tapa de rosca. Los tubos se colocarán en un baño de agua. Las temperaturas para evaluar serán 38 y $40^{\circ} \mathrm{C}$. Los tiempos de exposición fueron $0,2,4$,6 y 8 horas.

En cada tiempo, se tomó dos tubos de manera aleatoria a cada tratamiento, 30ul (Aprox. 300 conidios) se colocó en cajas Petri $90 \times 15 \mathrm{~mm}$ con $20 \mathrm{ml}$ de medio PDA que sirve para compactar las colonias y facilitar el conteo, las cajas se incubaron a $30^{\circ} \mathrm{C}$.

La viabilidad de los conidios se evaluó considerando las unidades formadoras de colonias (UFC). Los porcentajes de viabilidad se calcularon comparando las UFC de cada tratamiento respecto a lo encontrado en el control (el control se consideró como el tiempo de exposición Oh) es decir:

$$
\% \text { Viabilidad }=\frac{\text { Numero UFC tratamiento }}{\text { Numero de UFC control }} \times 100
$$

Los datos experimentales se ajustaron al modelo de decaimiento exponencial (Miranda-Hernández et al., 2014):

Dónde:

$$
S=S_{o} e^{-(k t)}
$$

S: Viabilidad de los conidios a un tiempo $t$

So: Viabilidad Inicial (\%)

$\mathrm{K}$ : tasa específica del decaimiento en la viabilidad $\left(\mathrm{h}^{-1}\right)$

$\mathrm{t}$ : tiempo (h)

Usando este modelo, se puedo estimar el tiempo en el que la viabilidad de los conidios ha disminuido a $50 \%$ en una temperatura dada, lo que se representa con el parámetro $\mathrm{TS}_{50}(\mathrm{~h})$. Este experimento se realizará dos veces en diferentes ocasiones con replicas en cada uno de ellos figura C1 y no se encontraron las diferencias significativas entre la cepa parental y la siyap1.

Tabla C1. Parámetros de termotolerancia "K y TS ${ }_{50}$ "en las cepas siyap1 y parental.

\begin{tabular}{|c|c|c|c|c|c|c|}
\hline & Parental & & & siyap 1 & & \\
\hline Horas & $k$ & TS 50 (h) & D.E & $k$ & TS 50 (h) & D.E \\
\hline 35 & 0.4571 & $\mathbf{1 . 5 2}$ & 0.60 & 0.4806 & $\mathbf{1 . 4 4}$ & 0.41 \\
\hline 45 & 0.4630 & $\mathbf{1 . 5 0}$ & 0.87 & 0.2752 & $\mathbf{2 . 5 2}$ & 1.08 \\
\hline 50 & 0.4115 & $\mathbf{1 . 6 8}$ & 2.17 & 0.2595 & $\mathbf{2 . 6 7}$ & 0.72 \\
\hline
\end{tabular}



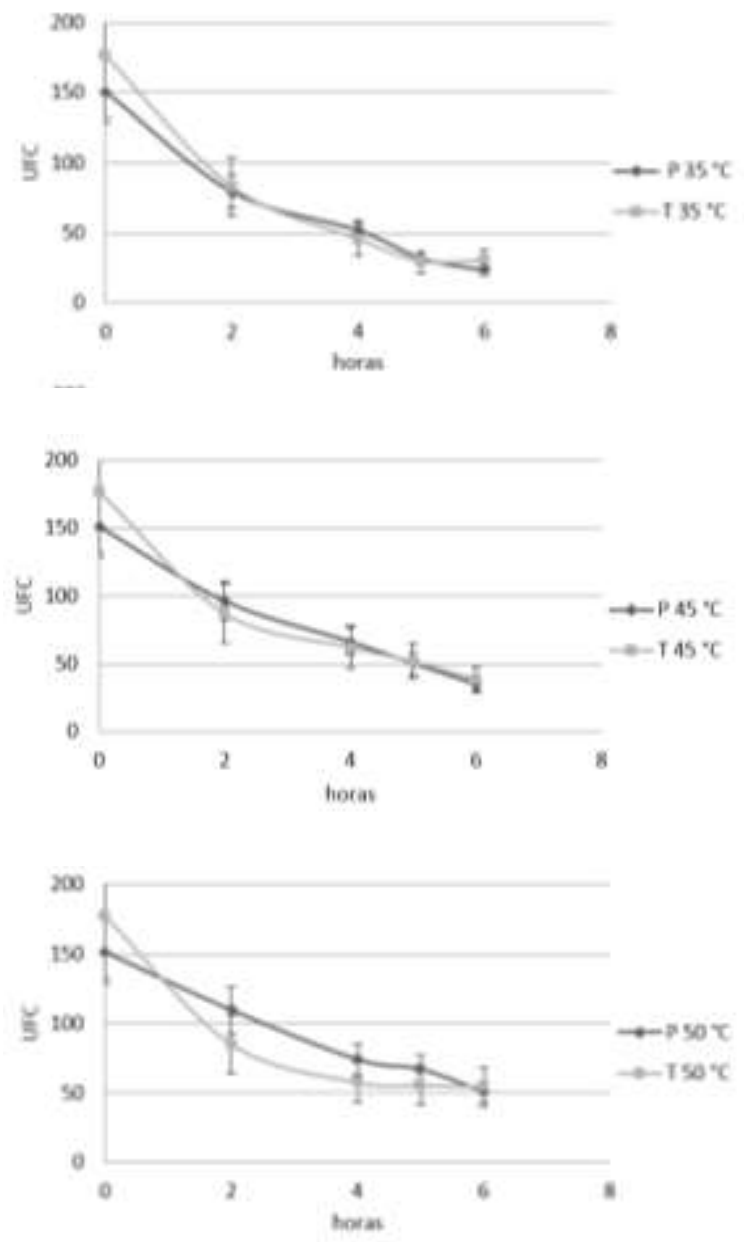

Figura C3. Termotolerancia en la cepa siyap1 $(\mathrm{T})$ y la parental $(\mathrm{P})$ a $35^{\circ} \mathrm{C}, 45^{\circ} \mathrm{C}$ y $50^{\circ} \mathrm{C}$, a $0,2,4,5$ y 6 horas. 


\section{ADICION DE NAC A LA CEPA siyap1}

Se realizó el estudio del efecto de la adición de antioxidantes en la producción de lovastatina y acumulación de EROS con las transformantes siyap1 de A. terreus, con el fin de poder evaluar el silenciamiento sin el efecto secundario de las EROs. Se adiciono NAC en condiciones estériles a partir de un stock a la FL y FS, muestreando a diferentes tiempos por triplicado. Se tomó muestra para comparar las EROs, hasta lograr obtener los mismos niveles que la cepa parental (Miranda et al, 2015).

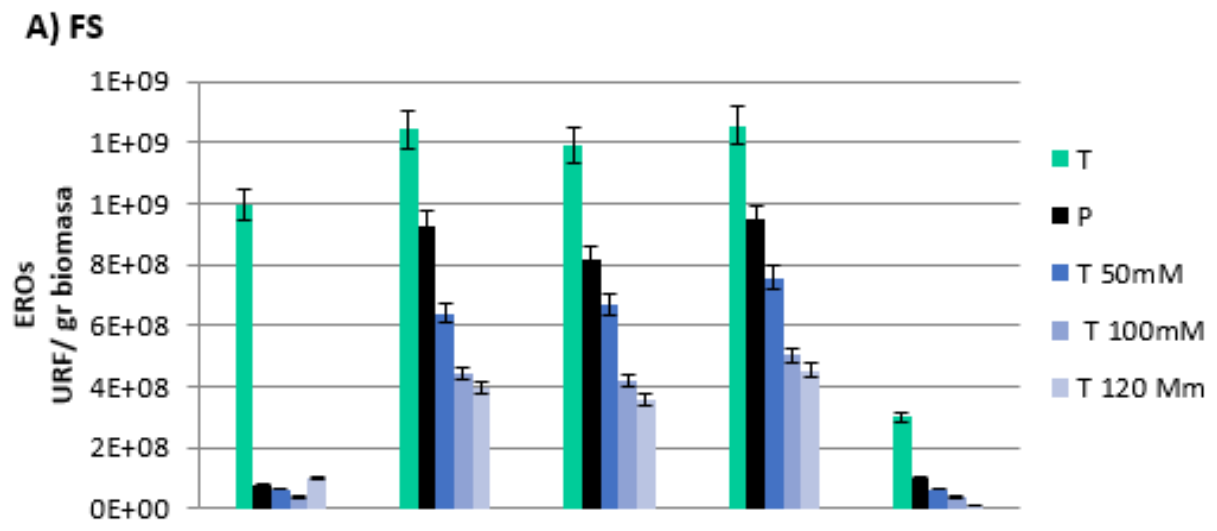

\section{B) FL}

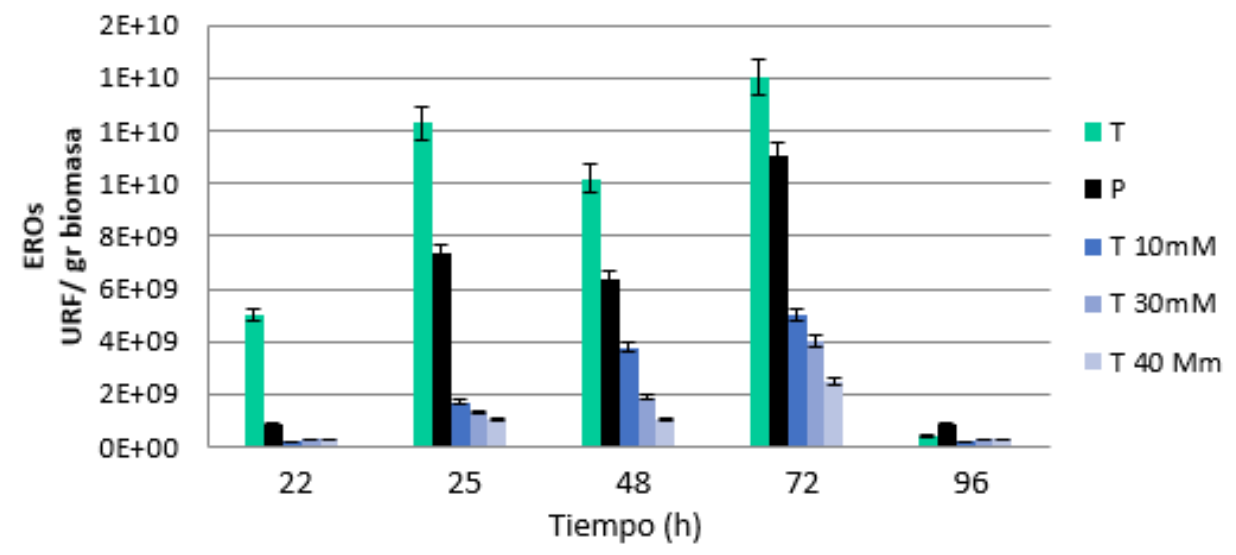

Figura C4. Adición del antioxidante NAC en la cepa siyap1 (T) a la A) FS y B) FL primer intento acumulación de las EROs.

En el primer intento de la adición de antioxidante figura C4 se adiciono demasiado NAC, lo que provocó una disminución abrupta de ROS. Se propuso entonces probar concentraciones más bajas. 
A) FS

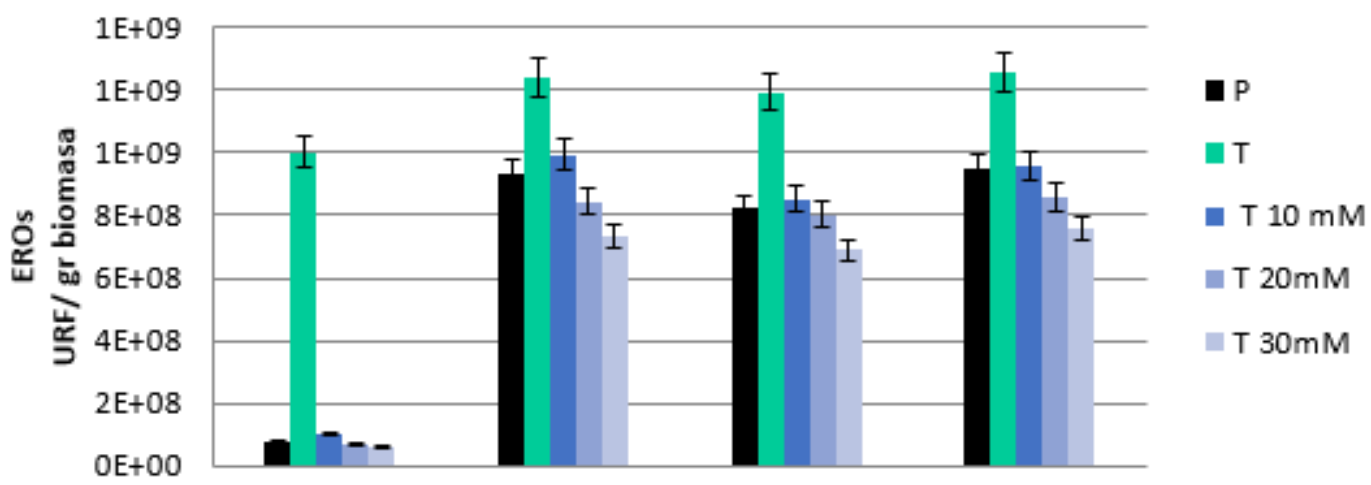

\section{B) FL}

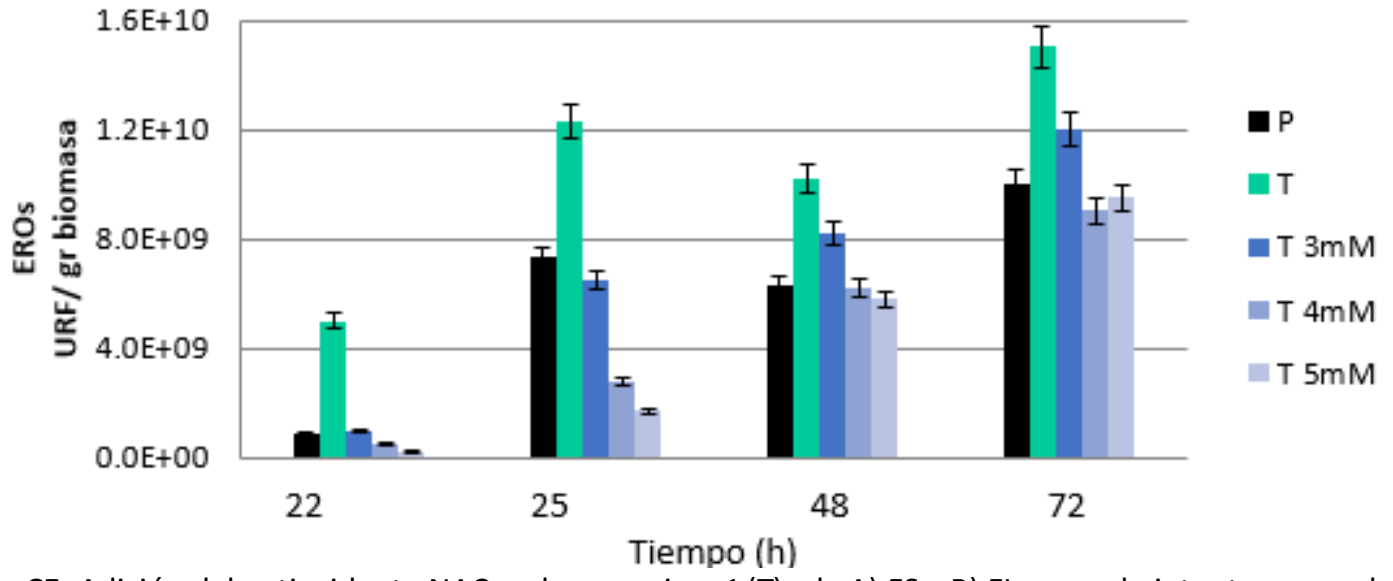

Figura C5. Adición del antioxidante NAC en la cepa siyap1 (T) a la A) FS y B) FL segundo intento, acumulación de las EROs.

En el caso de la FS con 10 y 20 mM de NAC (figura C5), se logró disminuir las EROs de la cepa de siyap1 a los mismos niveles de la cepa parental sin presentar diferencias significativas. Se escogió trabajar a 20 mM de NAC en FL por acercarse más al promedio de la parental a las 22 y $25 \mathrm{~h}$.

En el caso de la FL con 3mM de NAC (figura C5), se logró disminuir las EROs de la siyap1 a los mismos niveles de la cepa parental en las primeras horas, pero no fue suficiente el efecto en las últimas horas. Se propone agregar más antioxidante a las $25 \mathrm{~h}$ para prolongar el efecto de contención de las EROs en las siguientes horas de la fermentación. 


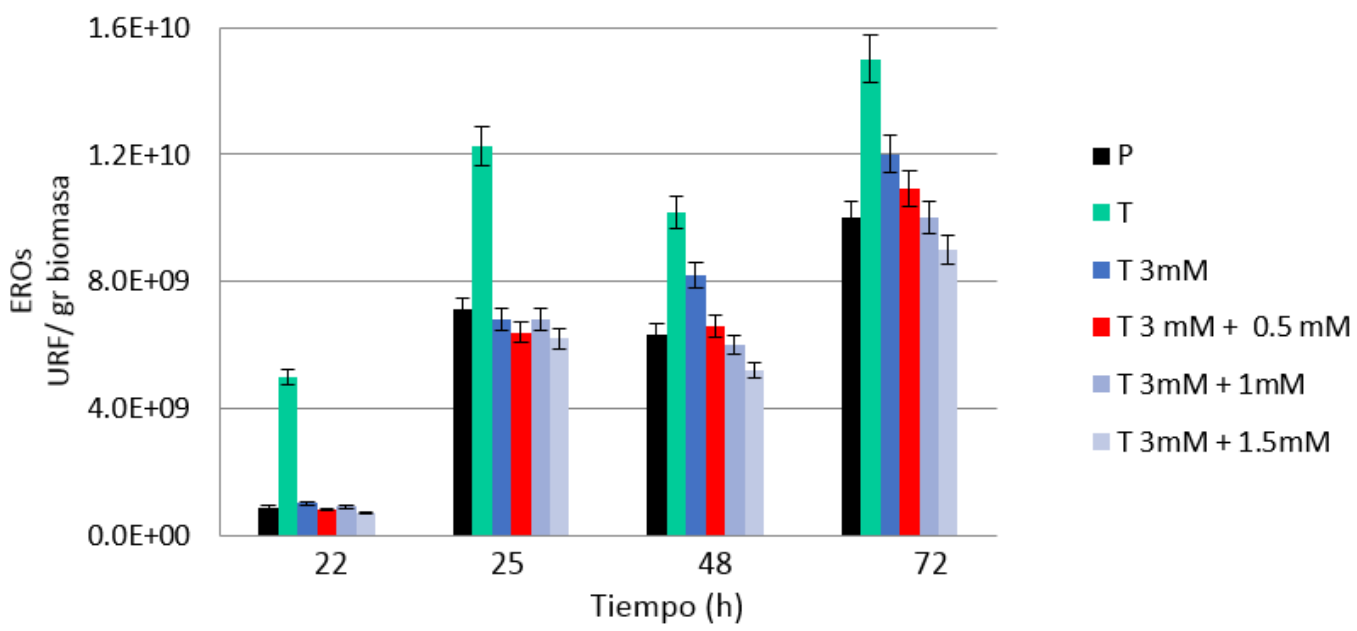

Figura C6. Adición del antioxidante NAC en la cepa siyap1 (T) a la FL tercer intento, acumulación de las EROs.

En FL adicionando a las 0 h $3 \mathrm{mM}$ se controlan las EROs hasta las 25 h, a partir de ahí se agregó diferentes concentraciones más de NAC (figura C6). Con el tratamiento de $3 \mathrm{mM}+1 \mathrm{mM}$ (Adicionado a las 25 h) NAC se logró mantener las EROs de la siyap1 sin diferencias significativas a lo largo del tiempo con la cepa parental. 
Requlación y producción de las EROs en F'S y FL de

lovastatina por Aspergiliue

terreus.
En la ciudad de Mexico, se presentaron a las 12:00 horas del dia 3 del mes de diciembre del ano 2018 en la Unidad Irtapalapa de la Dniversidad Autonoma Metropolitana, los suscritos miembros del jurado:

OR LUTS EMRTOUE GOMEZ QUIROZ

DRA. ROXAMA URI MIRANDA LABRA

DRA. GABRIELA RODRIGUEZ SERRANO

DR. ARMANDO MEJIA ALVAREZ
Bajo la Presidencia del primero y con caracter de Secretarlo el diltimo, se reunieron a la presentación de la Disertacion pablica cuya denominacion aparece ol margen, para la obtención del grado de:

DOCTORA EN BIOTECNOLOGIA

DE: AILED PEREZ SANCHEZ

$y$ de acuerdo con el articulo 78 fracción IV del Reglamento de Estudios Superiores de la Unfversidad Autonoma Metropolitana, 108 mienbros del furado resolvieron:

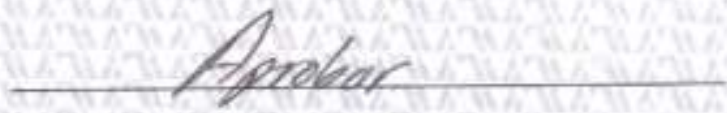

Acto continuo, el presidente del jurado comunico a la interesada el resultado de la evaluación $y$, en caso aprobatorio. le fue toroada la protesta. DR JOSE ANRENIOOGG OS REYES HEREDIA
SECRETQRIO GENERAL
AILED PEREZ SANCHEZ ALUMNA

\section{REWSO}

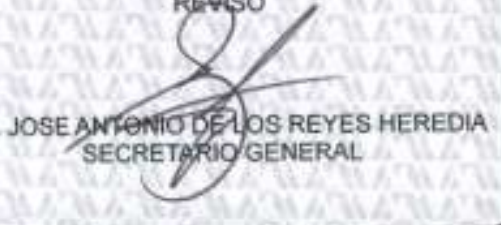

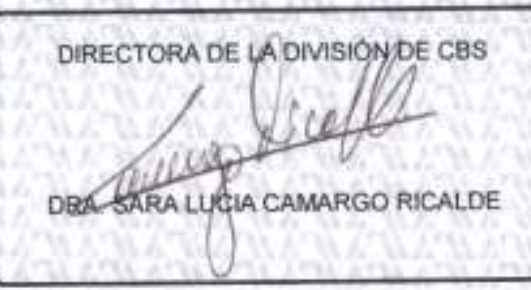
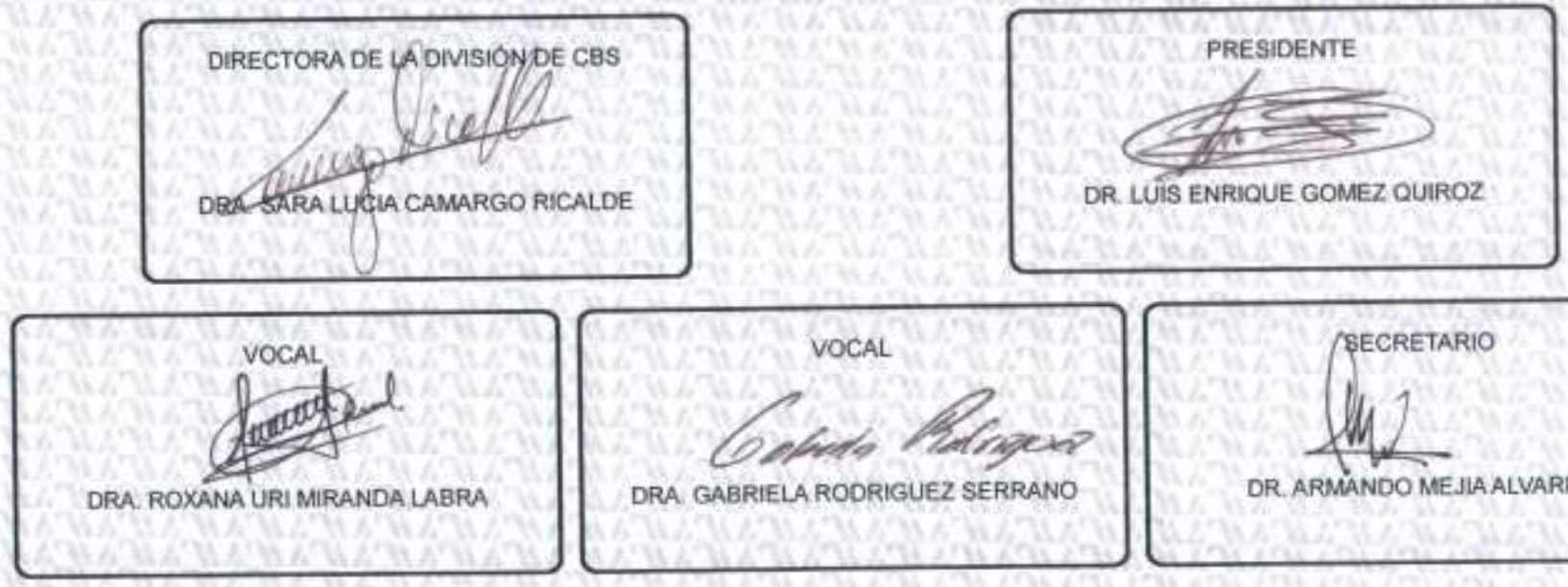

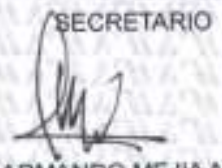

DR. ARMANDO MEJIAALVAREZ 